\title{
Initial Stress State and Stress History Effects on Liquefaction Susceptibility of Sands
}

\author{
Submitted By
}

\section{Manmatharajan Vipulanantham}

B. Sc. Eng, University of Peradeniya, Sri Lanka (2007)

\begin{abstract}
A research thesis submitted to the Faculty of Graduate and Postdoctoral Affairs in partial fulfillment of the requirements for the degree of Master of Applied Science in Engineering
\end{abstract}

Department of Civil and Environmental Engineering

Carleton University

Ottawa, Ontario

Canada

(C) 2011 Manmatharajan, V.

The Master of Applied Science in Civil Engineering Program is a joint program with University of Ottawa, administrated by the Ottawa-Carleton Institute of Civil Engineering 


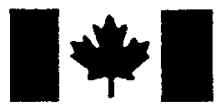

Library and Archives
Canada

Published Heritage

Branch

395 Wellington Street

Ottawa ON K1A ON4

Canada
Bibliothèque et

Archives Canada

Direction du

Patrimoine de l'édition

395 , rue Wellington

Ottawa ON K1A ON4

Canada
Your file Votre référence

ISBN: 978-0-494-81665-3

Our file Notre référence

ISBN: 978-0-494-81665-3

\section{NOTICE:}

The author has granted a nonexclusive license allowing Library and Archives Canada to reproduce, publish, archive, preserve, conserve, communicate to the public by telecommunication or on the Internet, loan, distribute and sell theses worldwide, for commercial or noncommercial purposes, in microform, paper, electronic and/or any other formats.

The author retains copyright ownership and moral rights in this thesis. Neither the thesis nor substantial extracts from it may be printed or otherwise reproduced without the author's permission.
AVIS:

L'auteur a accordé une licence non exclusive permettant à la Bibliothèque et Archives Canada de reproduire, publier, archiver, sauvegarder, conserver, transmettre au public par télécommunication ou par l'Internet, prêter, distribuer et vendre des thèses partout dans le monde, à des fins commerciales ou autres, sur support microforme, papier, électronique et/ou autres formats.

L'auteur conserve la propriété du droit d'auteur et des droits moraux qui protège cette thèse. $\mathrm{Ni}$ la thèse ni des extraits substantiels de celle-ci ne doivent être imprimés ou autrement reproduits sans son autorisation.
In compliance with the Canadian Privacy Act some supporting forms may have been removed from this thesis.

While these forms may be included in the document page count, their removal does not represent any loss of content from the thesis.
Conformément à la loi canadienne sur la protection de la vie privée, quelques formulaires secondaires ont été enlevés de cette thèse.

Bien que ces formulaires aient inclus dans la pagination, il n'y aura aucun contenu manquant. 


\begin{abstract}
An experimental study of the effects of stress state and history on the cyclic liquefaction potential of sands under undrained loading is presented. The primary objective was to determine the dependency of the widely used correction factors $K_{\sigma}$ and $K_{\alpha}$ on state variables and particle shape, especially OCR. Cyclic resistance of semi-angular Fraser River sand and sub-rounded Silica sand were evaluated at various stress/density states and at several OCR values

Cyclic resistance increases significantly with increasing OCR in both sands under most conditions. At a given initial state, the correction factor $\mathrm{K}_{\sigma}$ is not dependent on the type of the sand, but the $K_{\alpha}$ correction factor is highly dependent on the sand. The effect of over consolidation on $\mathrm{K}_{\sigma}$ and $\mathrm{K}_{\alpha}$ factors under simple shear stress condition was assessed for both sands. While the $\mathrm{K}_{\sigma}$ correction that is applied to account for the overburden stress does not show significant differences between normally and over consolidated states, the $K_{\alpha}$ is critically influenced by over consolidation. These results indicate that the current practice of accounting for the effects of stress level and density without regard to the particle shape, or OCR may lead to unsafe designs.

Rotation of principal stresses profoundly influence liquefaction resistance, and the lowest resistance is observed when the major principal stress was inclined at (rotated between) about $45^{\circ}$ to $60^{\circ}$ to vertical, and not when the inclination is $90^{\circ}$. The alignment of the plane of maximum shear stress along the weak bedding plane is primarily responsible for this response. This suggests that simple shear test can be a useful tool not only when characterizing liquefaction susceptibility due to vertically propagating s-waves, but also in cases involving surface waves that have both dilatational and shear components.
\end{abstract}




\section{TABLE OF CONTENTS}

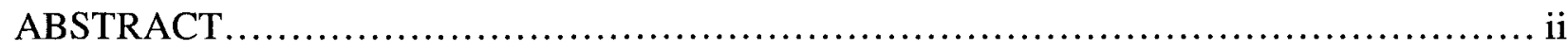

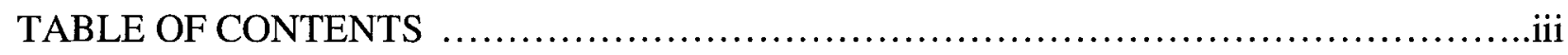

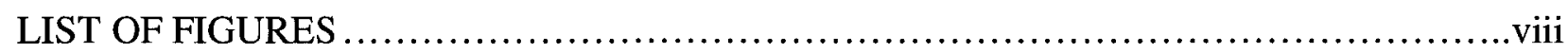

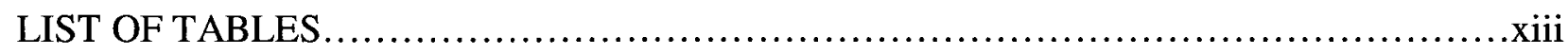

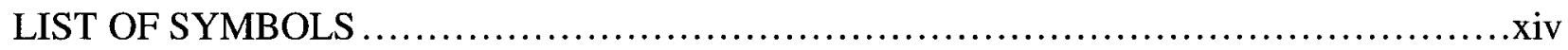

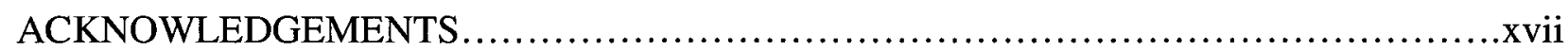

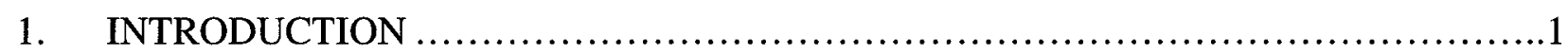

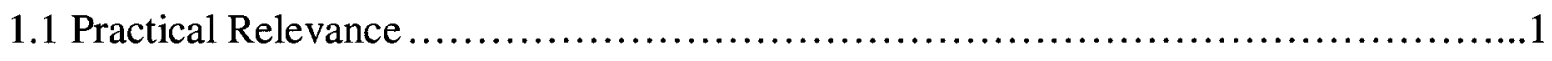

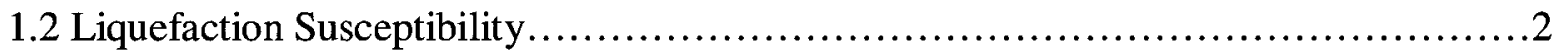

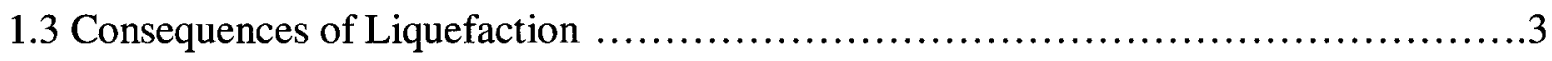

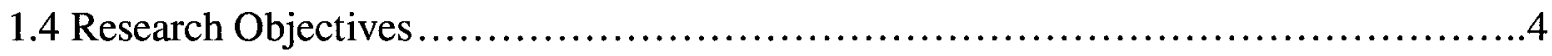

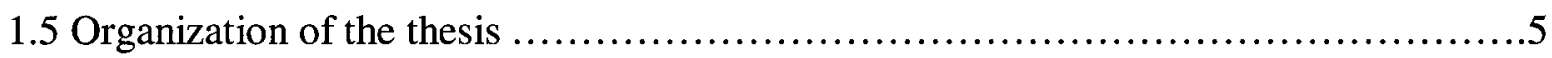

2. LITERATURE REVIEW ....................................................

2.1 Introduction.............................................................

2.2 Undrained Monotonic Behaviour.......................................... 8

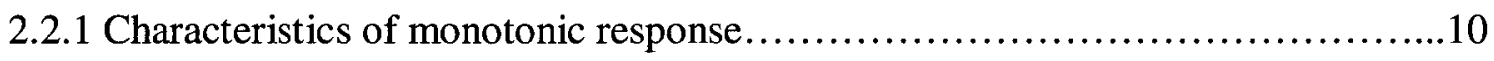

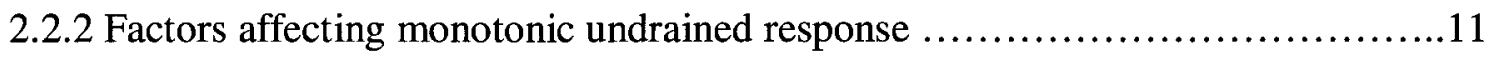

2.2.3 Effect of over consolidation .............................................

2.2.4 OCR and Shear Modulus............................................. 14

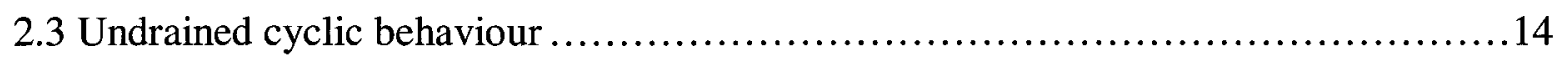

2.3.1 Loading mode effects on cyclic resistance............................19 
2.3.2 Effect of over consolidation ................................................20

2.3.3 Effect of confining stress level..............................................

2.3.4 Effect of initial static shear................................................ 21

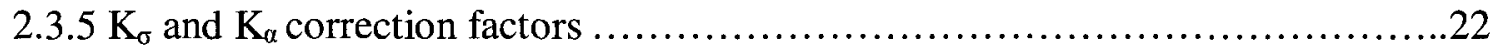

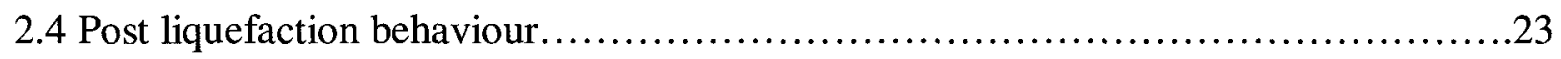

3. LABORATORY TESTS FOR LIQUEFACTION CHARACTERIZATION ..............27

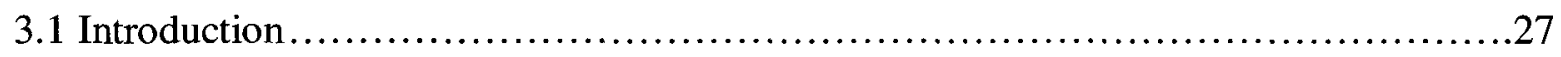

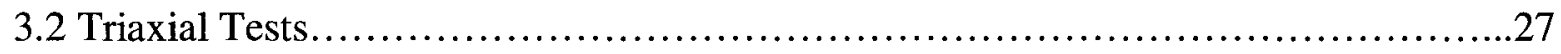

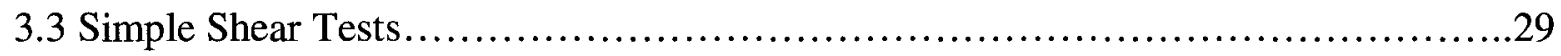

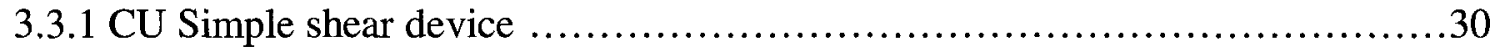

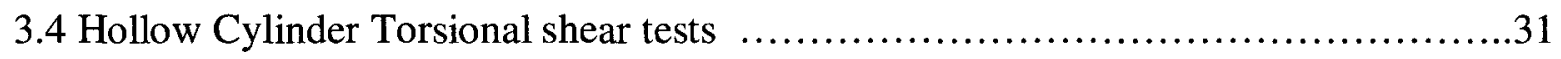

3.4.1 Stress and Strain in a Hollow cylindrical specimen ..........................33

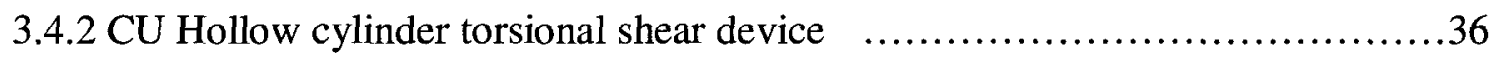

3.4.3 Measurement and control of stresses and strains ............................37

3.4.3.1 Measurement resolutions.............................................40

3.4.3.2 Stress/Strain controlled loading systems ............................41

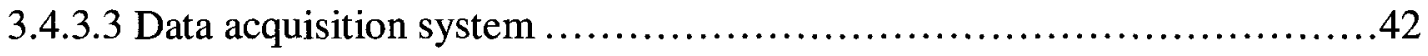

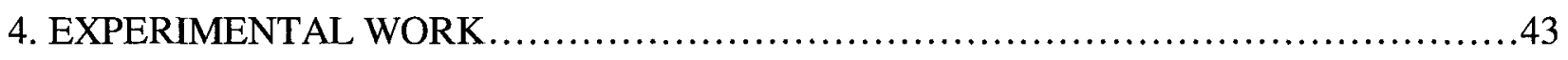

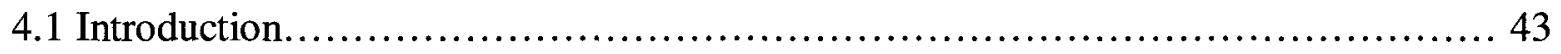

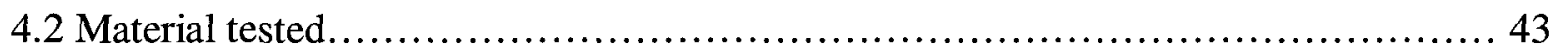

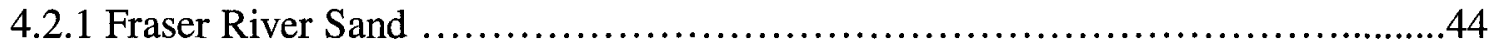

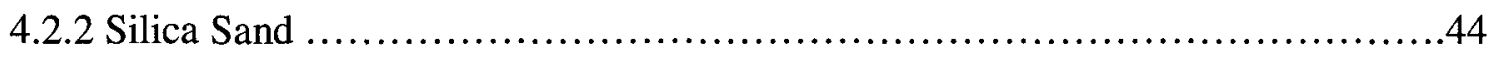

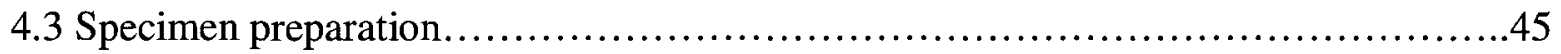




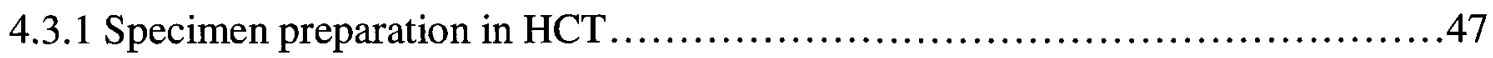

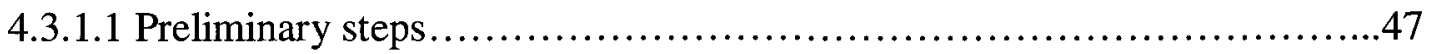

4.3.1.2 Specimen preparation steps.........................................48

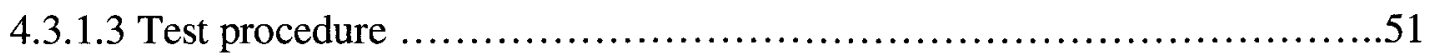

4.3.2 Specimen preparation in simple shear test................................52

4.3.2.1 Specimen preparation steps..........................................51

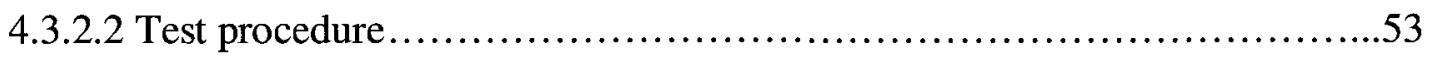

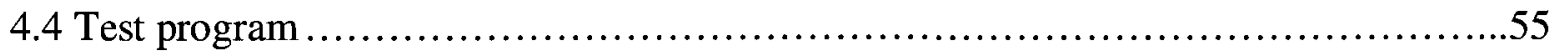

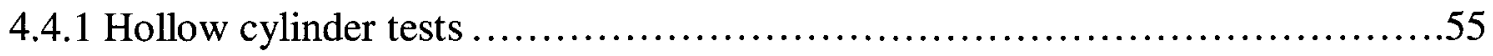

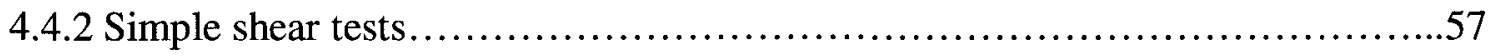

4.4.2.1 Simple shear tests of Fraser River Sand ..............................58

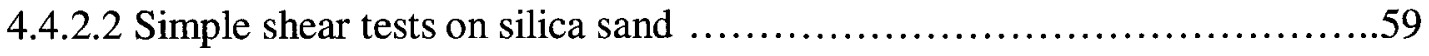

5. EFFECT OF PRINCIPAL STRESS ROTATION ON CYCLIC RESISTANCE ..........60

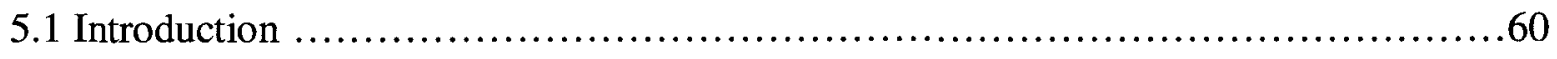

5.2 Cyclic loading in Hollow Cylinder Test........................................6 61

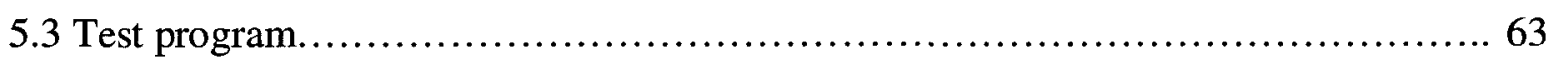

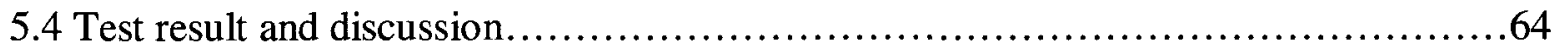

5.4.1 Smooth rotation of principal stresses.....................................65

5.4.2 Jump rotation of principal stresses........................................69

5.4.3 Stress rotation and liquefaction susceptibility: Discussion....................71

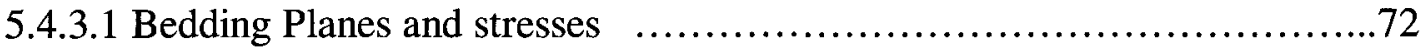

5.4.3.2 Maximum shear stress $\tau_{\max }$ vs the shear stress on the horizontal plane $\tau_{\mathrm{z} \theta} \ldots 73$

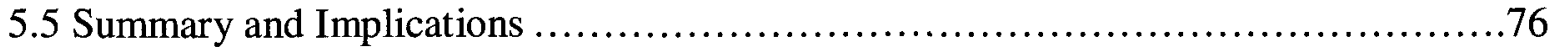


6. EFFECT OF OVERCONSOLIDATION ON LIQUEFACTION POTENTIAL ............78

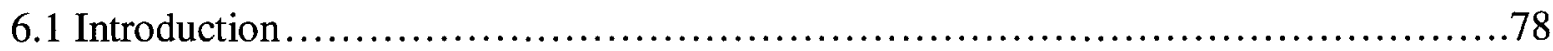

6.2 Undrained Monotonic response............................................... 79

6.2.1 Response at the loosest state ...............................................

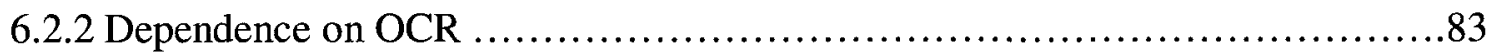

6.3 Cyclic liquefaction potential ..................................................... 87

6.3.1 Cyclic response and overconsolidation ..................................... 88

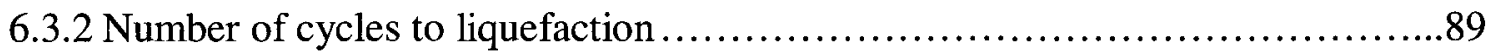

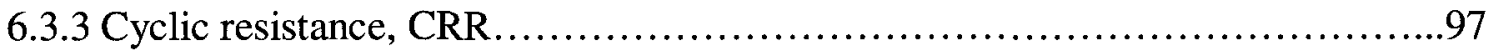

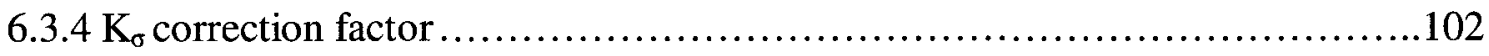

6.3.5 Behaviour of sand subjected to initial static shear ...........................106

6.3.5.1 Effect of static shear on cyclic resistance ratio ........................107

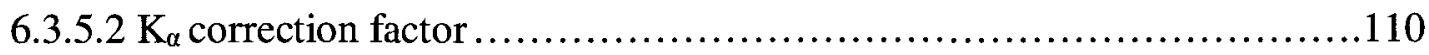

6.4 Post liquefaction behaviour..................................................... 115

6.4.1 Post liquefaction stress-strain response..................................115

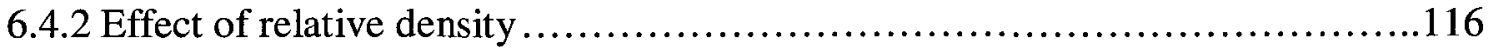

6.4.3 Effect of overconsolidation ratio.........................................117

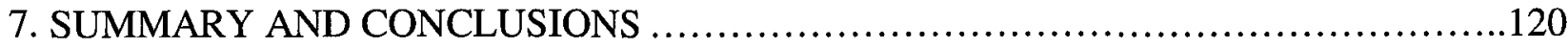

7.1 Hollow cylinder torsional shear tests ........................................120

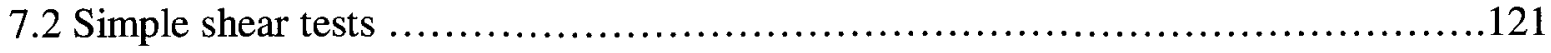

7.2.1 Monotonic simple shear tests ........................................122

7.2.2 Cyclic behaviour ...........................................................

7.2.3 Post-liquefaction behaviour ...........................................125 


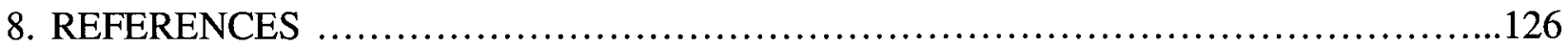

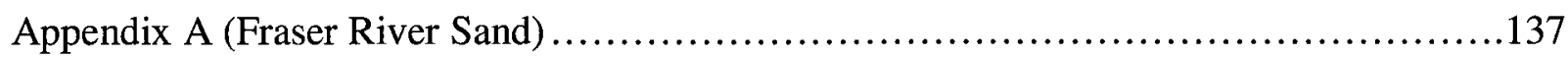

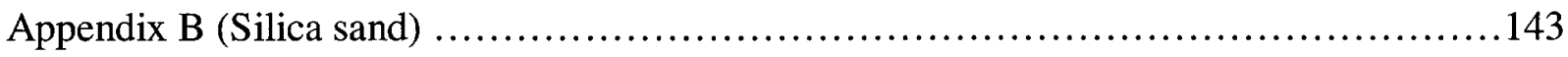

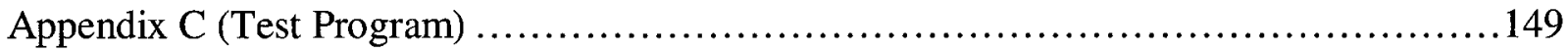




\section{LIST OF FIGURES}

Fig. 2.1 Characteristic response of sand under undrained static loading (After Chern 1985) ...9

Fig. 2.2 Behaviour of water pluviated sand under compression and extension mode

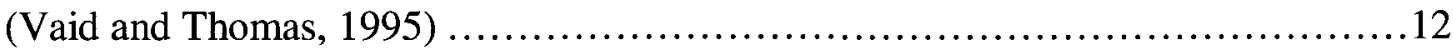

Fig. 2.3 Stress paths under triaxial compression (a) and extension (b) test .................13

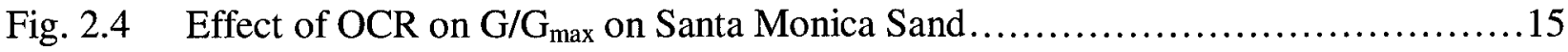

Fig. 2.5 Effect of OCR on G/G $\mathrm{G}_{\max }$ on Santa Monica and Antelope Valley Sand ...........15

Fig. 2.6 Cyclic loading behaviour of contractive sand (After Vaid and Chern 1985) ........17

Fig. 2.7 Cyclic mobility with (X) without (Y) transient state of zero effective stress

(After Vaid and Chern 1985)................................................. 18

Fig. 2.8 Effect of over consolidation during cyclic loading (after Ishihara et al., 1978)...... 20

Fig. 2.9 Comparison of $\mathrm{K}_{\boldsymbol{\sigma}}$ values with several sands (After Youd et al., 2001) .............24

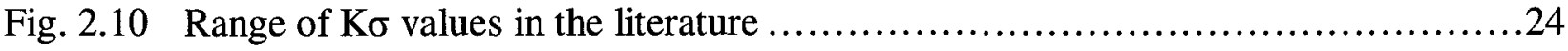

Fig. 2.11 Range of Ko relationship for sands at different density states

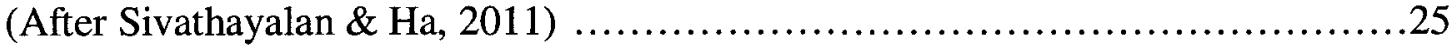

Fig. 2.12 Pre and Post Liquefaction of sand (After Kuerbis 1989) . ....................25

Fig. 2.13 Characterization of post-cyclic behaviour (After Vaid and Thomas, 1995).........26

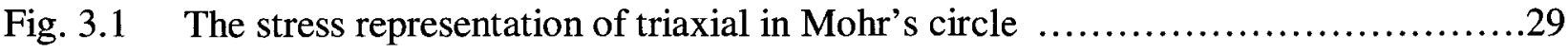

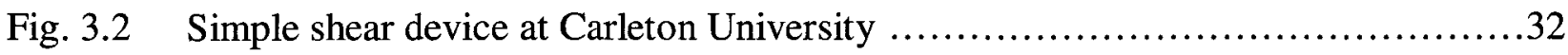

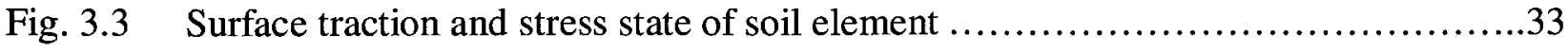

Fig. 3.4a Schematic layout of HCT device at Carleton University (After Logeswaran, 2010) ..38

Fig. 3.4b Hollow cylinder torsional device at Carleton University $\ldots \ldots \ldots \ldots \ldots \ldots \ldots \ldots \ldots \ldots \ldots \ldots$

Fig. 3.5 Porous stones embedded into end platen with radial ribs .........................39 
Fig. 3.6 Vertical and Torsional load applying system (After Logeswaran, 2010)..........40

Fig. 4.1 Grain size distribution of Fraser River sand and Silica sand $\ldots \ldots \ldots \ldots \ldots \ldots \ldots \ldots . . \ldots 5$

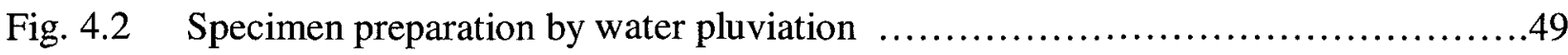

Fig. 4.3 Sample preparation during (a) siphoning and (b) with top cap in place .............54

Fig. 4.4 Compressibility characteristics of FRS at different initial state ..................58

Fig. 5.1 Cyclic shear stress and direction of principal stresses .........................63

Fig. 5.2 Stress path of Fraser River sand during cyclic loading of $\sigma_{d} /\left(2 \sigma_{m c}^{\prime}\right)=0.15$

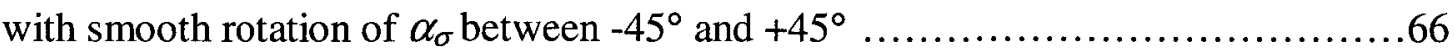

Fig. 5.3 Stress path of Fraser River sand during cyclic loading of $\sigma_{d} /\left(2 \sigma_{m c}^{\prime}\right)=0.25$

with smooth rotation of $\alpha_{\sigma}$ between $-30^{\circ}$ and $+30^{\circ}$

Fig. 5.4 The Number of cycles to liquefaction at different CSR values ...................68

Fig. 5.5 Variation of number of cycles at $\sigma_{d} /\left(2 \sigma_{m c}^{\prime}\right)=0.15$ in smooth rotation .............68

Fig. 5.6 Comparison of number of cycles required for liquefaction during smooth and jump

Rotation of principal direction (After Logeswaran, 2010)

Fig. 5.7 Stress path of Fraser River sand during cyclic loading of $\sigma_{d} /\left(2 \sigma_{m c}^{\prime}\right)=0.20$

with smooth rotation of $\alpha_{\sigma}$ between $-75^{\circ}$ and $+75^{\circ}$

Fig. 5.8 Excess pore pressure of Fraser River sand during cyclic loading

principal stress direction at 5 cycles

Fig. 5.9 The planes of maximum shear stress for different principal stress rotations $\ldots . \ldots . .75$

Fig. 5.10 Imposed torsional shear stress during Smooth rotation of principal stress direction ..76

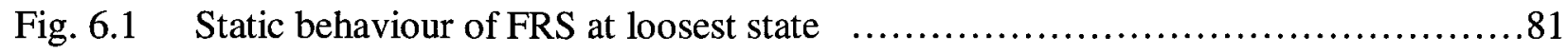

Fig. 6.2 Normalized shear stress and excess pore pressure at loosest state ................82

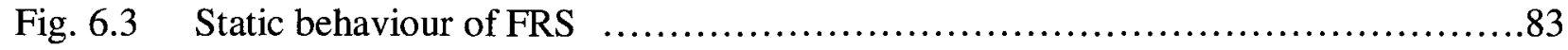


Fig. 6.4 Static behaviour at a given overconsolidation ratio $\ldots \ldots \ldots \ldots \ldots \ldots \ldots \ldots \ldots \ldots \ldots \ldots$

Fig. 6.5 Effect of OCR on static behaviour at a given confining stress level.................85

Fig. 6.6 Initial shear modulus changes with OCR (a) and confining stress level (b)..........86

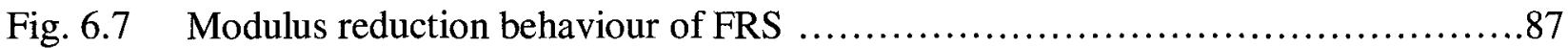

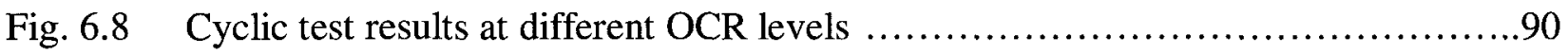

Fig. 6.9 Stress-Strain and stress path responses at different OCR levels ...................91

Fig. 6.10 Dependence of cyclic simple shear resistance at different OCR values $\quad$...........93

Fig. 6.11 Variation of number of cycles to liquefaction at a given CSR and OCR level ......93

Fig. 6.12 Variation of number of cycles with confining stress at a given relative density $\quad$....94

Fig. 6.13 Variation of number of cycles to liquefaction with $\mathrm{OCR}$ at a given $\mathrm{D}_{\mathrm{r}}$ of $41 \% \ldots \ldots . .94$

Fig. 6.14 The variation of $K_{O C N}$ with OCR at several CSR levels........................96

Fig. 6.15 The variation of $K_{O C N}$ with OCR at stress levels for selected CSR levels ...........96

Fig. 6.16a The variation of the cyclic resistance ratio, CRR of the sand at $100 \mathrm{kPa} \ldots \ldots \ldots \ldots . .97$

Fig. 6.16 The variation of CRR of the sand at $200 \mathrm{kPa}$ (b) and $400 \mathrm{kPa}$ (c) $\ldots \ldots \ldots \ldots \ldots \ldots \ldots . . . .98$

Fig. $6.17 \mathrm{a}$ Variation of $\mathrm{K}_{\text {ocr }}$ over the range of OCR at $40 \%$ relative density $\ldots \ldots \ldots \ldots \ldots \ldots \ldots . \ldots 100$

Fig. 6.17 Variation of Kocr over the range of OCR at $50 \%$ (b), $60 \%$ (C) and $70 \%$ (d)

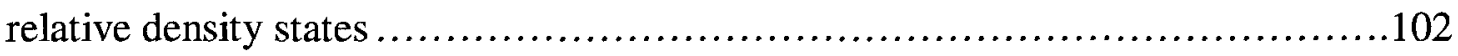

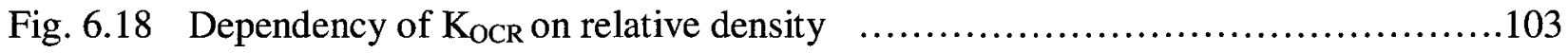

Fig. 6.19 The variation of $K_{\sigma}$ with confining stress level at $40 \%$ (a) and $70 \%$ (b) of FRS ......105

Fig. 6.20 The variation of $K_{\sigma}$ with confining stress level at $40 \%$ of Silica Sand ..............105

Fig. 6.21 The variation of $K_{\sigma}$ with confining stress level at $70 \%$ of Silica Sand ...............106

Fig. 6.22 Cyclic tests with initial static shear stress.....................................108

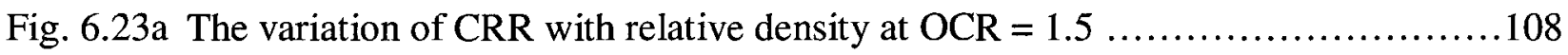


Fig. 6.23b The variation of CRR with relative density at $\mathrm{OCR}=2 \ldots \ldots \ldots \ldots \ldots \ldots \ldots \ldots \ldots$

Fig. 6.24 The variation of CRR with relative density at $\mathrm{OCR}=1(\mathrm{After} \mathrm{Da} \mathrm{Ha}, 2004) \ldots \ldots .110$

Fig. 6.25 Comparison of $K_{\alpha}$ values at a given alpha over range of densities............... 112

Fig. 6.26 Variation of $K_{\alpha}$ with alpha at different OCR levels at a given relative density .....112

Fig. 6.27 Variation of $K_{\alpha}$ with alpha at different OCR levels over range of relative density...113

Fig. 6.28 Variation of $K_{\alpha}$ with alpha at different OCR and relative density states..........114

Fig. 6.29 Post Liquefaction response of Silica sand................................ 117

Fig. 6.30 Effect of relative density on post liquefaction for silica sand ...................118

Fig. 6.31 Effect of OCR on post liquefaction for silica sand ..........................119

Fig. 6.32 Effect of OCR on post liquefaction for Fraser sand ............................119

Fig. A1 Variation of number of cycles to liquefaction at $100 \mathrm{kPa}$ and $\mathrm{OCR}=1 \ldots \ldots \ldots \ldots 138$

Fig. A2 Variation of number of cycles to liquefaction at $200 \mathrm{kPa}$ and $\mathrm{OCR}=1 \ldots \ldots \ldots \ldots 138$

Fig. A3 Variation of number of cycles to liquefaction at $400 \mathrm{kPa}$ and $\mathrm{OCR}=1 \ldots \ldots \ldots \ldots 139$

Fig. A4 Variation of number of cycles to liquefaction at $100 \mathrm{kPa}$ and $\mathrm{OCR}=1.5 \ldots \ldots \ldots 139$

Fig. A5 Variation of number of cycles to liquefaction at $200 \mathrm{kPa}$ and $\mathrm{OCR}=1.5 \ldots \ldots \ldots .140$

Fig. A6 Variation of number of cycles to liquefaction at $400 \mathrm{kPa}$ and $\mathrm{OCR}=1.5 \ldots \ldots \ldots .140$

Fig. A7 Variation of number of cycles to liquefaction at $100 \mathrm{kPa}$ and $\mathrm{OCR}=2.0 \ldots \ldots \ldots 141$

Fig. A8 Variation of number of cycles to liquefaction at $200 \mathrm{kPa}$ and $\mathrm{OCR}=2.0 \ldots \ldots \ldots 141$

Fig. A9 Variation of number of cycles to liquefaction at $400 \mathrm{kPa}$ and $\mathrm{OCR}=2.0 \ldots \ldots \ldots .142$

Fig. A10 The variation of $K_{\sigma}$ with confining stress level at 50\% of FRS ..................142

Fig. B1 Variation of number of cycles to liquefaction at $100 \mathrm{kPa}$ and $\mathrm{OCR}=1 \ldots \ldots \ldots \ldots 144$

Fig. B2 Variation of number of cycles to liquefaction at $200 \mathrm{kPa}$ and $\mathrm{OCR}=1 \ldots \ldots \ldots \ldots 14$

Fig. B3 Variation of number of cycles to liquefaction at $400 \mathrm{kPa}$ and $\mathrm{OCR}=1 \ldots \ldots \ldots \ldots 145$ 
Fig. B4 Variation of number of cycles to liquefaction at $100 \mathrm{kPa}$ and $\mathrm{OCR}=1.5 \ldots \ldots \ldots \ldots .145$

Fig. B5 Variation of number of cycles to liquefaction at $200 \mathrm{kPa}$ and $\mathrm{OCR}=1.5 \ldots \ldots \ldots \ldots .146$

Fig. B6 Variation of number of cycles to liquefaction at $400 \mathrm{kPa}$ and $\mathrm{OCR}=1.5 \ldots \ldots \ldots \ldots 146$

Fig. B7 Variation of number of cycles to liquefaction at $100 \mathrm{kPa}$ and $\mathrm{OCR}=2.0 \ldots \ldots \ldots \ldots .147$

Fig. B8 Variation of number of cycles to liquefaction at $200 \mathrm{kPa}$ and $\mathrm{OCR}=2.0 \ldots \ldots \ldots \ldots 147$

Fig. B9 Variation of number of cycles to liquefaction at $400 \mathrm{kPa}$ and $\mathrm{OCR}=2.0 \ldots \ldots \ldots . .148$

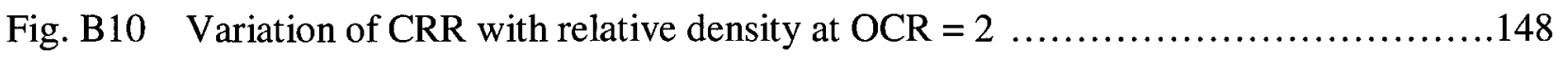




\section{LIST OF TABLES}

Table $4.1 \quad$ Cyclic hollow cylinder torsional shear tests ................................57

Table C.1 Monotonic Simple shear tests on Fraser River sand ........................150

Table C.2 Cyclic Simple shear tests on Fraser River sand............................. 151

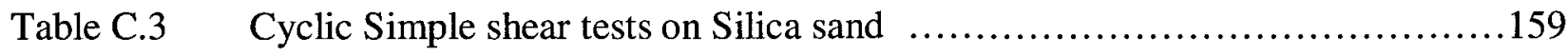




\section{LIST OF SYMBOLS}

$\begin{array}{ll}A / D & \text { Analog to Digital } \\ a & \text { Pore pressure parameter } \\ C_{c} & \text { Coefficient of curvature } \\ C_{u} & \text { Uniformity coefficient } \\ C S R & \text { Critical Stress Ratio } \\ D / A & \text { Digital to Analog } \\ D P T & \text { Differential Pressure Transducer } \\ D P V C & \text { Digital Pressure/Volume Controller } \\ D_{50} & \text { Average particle size, mm } \\ D_{r} & \text { Relative density } \\ D_{r c} & \text { Relative density at end of consolidation } \\ F_{z} & \text { Vertical load } \\ F R S & \text { Fraser River Sand } \\ H & \text { Height of specimen } \\ H C T & \text { Hollow Cylinder Torsional device } \\ K_{\mathfrak{c}} & =\sigma_{l d}^{\prime} \sigma_{3 c}^{\prime}, \text { Effective stress ratio at the end of consolidation } \\ K_{0} & =\sigma_{l}^{\prime} / \sigma_{3}^{\prime}, \text { Effective stress ratio } \\ L V D T & \text { Linear Variable Displacement Transducer } \\ M S C & \text { Multi-channel Signal Conditioner } \\ N & \text { Number of cycles } \\ P_{e} & \text { Outer chamber pressure } \\ P_{i} & \text { Inner chamber pressure } \\ P T & \text { Phase Transformation } \\ Q S S & \text { Quasi Steady State } \\ R & \text { Radius } \\ R_{a v} & \text { Average stress ratio } \\ R_{e} & \text { Outer radius of specimen } \\ R_{i} & \text { Inner radius of specimen } \\ R_{m a x} & \text { Maximum stress ratio } \\ & \end{array}$




\begin{tabular}{|c|c|}
\hline$R_{\min }$ & Minimum stress ratio \\
\hline$S S$ & Steady State \\
\hline$T_{h}$ & Torque \\
\hline$b_{\sigma}$ & $=\left(\sigma_{2}-\sigma_{3}\right) /\left(\sigma_{1}-\sigma_{3}\right)$, Intermediate principal stress parameter \\
\hline$b_{\Delta \sigma}$ & $=\left(\Delta \sigma_{2}-\Delta \sigma_{3}\right) /\left(\Delta \sigma_{l}-\Delta \sigma_{3}\right)$, Intermediate principal stress parameter \\
\hline$b_{\sigma c}$ & Intermediate principal stress parameter at the end of consolidation \\
\hline$d r$ & Change of radius \\
\hline$d \varepsilon_{v}$ & Change of volumetric strain \\
\hline$e_{\max }$ & Maximum void ratio \\
\hline$e_{\min }$ & Minimum void ratio \\
\hline$\alpha_{\sigma, \max }$ & Maximum inclination of principal stress with vertical axis \\
\hline$\alpha_{\sigma}$ & Inclination of major principal stress to the vertical axis \\
\hline$\alpha_{\sigma c}$ & Inclination of major principal stress to vertical axis at the end of consolidation \\
\hline$\phi^{\prime}$ & Effective internal friction angle \\
\hline$\phi_{P T}$ & Friction angle mobilized at PT \\
\hline$\sigma_{l}$ & Major principal stress \\
\hline$\sigma_{2}$ & Intermediate principal stress \\
\hline$\sigma_{3}$ & Minor principal stress \\
\hline$\sigma_{c}$ & Confining stress \\
\hline$\sigma_{d}$ & $=\sigma_{1}-\sigma_{3}$, deviatoric stress \\
\hline$\sigma_{h}$ & Horizontal stress \\
\hline$\sigma_{m}$ & Total mean normal stress \\
\hline$\sigma_{r}$ & Radial stress \\
\hline$\sigma_{v}$ & Vertical stress \\
\hline$\sigma_{x}$ & Stress along the $x$ - axis \\
\hline$\sigma_{y}$ & Stress along the $y$-axis \\
\hline$\sigma_{z}$ & Vertical stress \\
\hline$\sigma_{\theta}$ & Tangential stress \\
\hline$\sigma_{1}^{\prime}$ & Effective major principal stress \\
\hline$\sigma_{2}^{\prime}$ & Effective intermediate principal stress \\
\hline
\end{tabular}




\begin{tabular}{|c|c|}
\hline$\sigma_{3}^{\prime}$ & Effective minor principal stress \\
\hline$\sigma_{d, c y c}$ & Cyclic deviatoric stress \\
\hline$\sigma_{m}^{\prime}$ & $=\left(\sigma_{1}^{\prime}+\sigma_{2}+\sigma_{3}^{\prime}\right) / 3$, Effective mean normal stress \\
\hline$\sigma_{m c}^{\prime}$ & $=\left(\sigma_{1 c}+\sigma_{2 c}^{\prime}+\sigma_{3 c}\right) / 3$, Effective mean normal stress at the end of consolidation \\
\hline$\Delta H$ & Change of height of specimen \\
\hline$\Delta R_{e}$ & Change of outer radius of specimen \\
\hline$\Delta R_{i}$ & Change of inner radius of specimen \\
\hline$\Delta U$ & Excess pore pressure \\
\hline$\Delta \theta$ & Increment of angular rotation \\
\hline$\Delta \sigma_{1}$ & Major component of stress increments \\
\hline$\Delta \sigma_{2}$ & Intermediate component of stress increments \\
\hline$\Delta \sigma_{3}$ & Minor component of stress increments \\
\hline$\Delta \sigma_{m}$ & Increment of total mean normal stress \\
\hline$\Delta \gamma_{\max }$ & Change of maximum shear strain \\
\hline$\Delta \varepsilon_{V}$ & Change of volumetric strain \\
\hline$\varepsilon_{l}$ & Major principal strain \\
\hline$\varepsilon_{2}$ & Intermediate principal strain \\
\hline$\varepsilon_{3}$ & Minor principal strain \\
\hline$\varepsilon_{a}$ & Axial strain \\
\hline$\varepsilon_{r}$ & Radial strain \\
\hline $\mathcal{E}_{v}$ & Volumetric strain \\
\hline$\varepsilon_{x}$ & Strain along $x$ - axis \\
\hline$\varepsilon_{y}$ & Strain along $y$-axis \\
\hline$\varepsilon_{z}$ & Axial strain \\
\hline$\varepsilon_{\theta}$ & Tangential strain \\
\hline$\tau_{z \theta}$ & Shear stress \\
\hline$\tau_{z x}$ & Shear stress along $\mathrm{z}$ direction in $\mathrm{x}$ plane \\
\hline$\tau_{z x}$ & Shear stress along $\mathrm{x}$ direction in $\mathrm{z}$ plane \\
\hline$\gamma_{\max }$ & Maximum shear strain \\
\hline$\gamma_{z \theta}$ & Torsional shear strain \\
\hline
\end{tabular}




\section{ACKNOWLEDGEMENTS}

I am greatly indebted to my supervisor Professor Siva Sivathayalan for his continuous support, guidance, and encouragement throughout this research. Without his patient direction and understanding, this research would never have been possible. It has been a great honor and pleasure to work under him.

I would like to express my sincere thanks to Dr. Logeswaran, who provided his continuous assistance and encouragement throughout my studies. I take this opportunity to thank all my friends and colleagues.

I gained a lot of knowledge and experience during the course of my master's study in the advanced geotechnical research laboratory at Carleton University. I would like to acknowledge the laboratory technicians Stanly, Pierre, and Jason for their great support to do my lab experiments.

Lastly and most importantly I would like to express my deepest gratitude to my parents whose continued support, patience and love encouraged me throughout my study and life. 


\section{INTRODUCTION}

\subsection{Practical Relevance}

Liquefaction induced ground failures have caused extensive damage over the years in various parts of the world. Liquefaction, in current practice, is generally understood in terms of excessive deformation, and could be triggered during rapid dynamic loading, such as an earthquake or due to static loading. Development of excess pore water pressure under undrained loading is responsible for this phenomenon, and as a result saturated soils are generally more prone to liquefaction.

Ground shaking induced by earthquakes has been the cause of liquefaction in many instances. Liquefaction failures induced by the 1891 Mino-Owari, 1906 San Francisco, 1940 Fukai, 1964 Alaska, 1964 Niigata, 1979 Imperial Valley, 1989 Loma Prieta, 1994 Northridge, 1995 Kobe, 1999 Kocaeli (Turkey), 1999 Chi-Chi (Taiwan) and the 2011 Christchurch earthquakes point to the catastrophic consequences and broader vulnerability across the globe. The consequences of the 1964 earthquakes in Alaska, and Niigata were responsible for the initial research on the liquefaction phenomena.

Even though cyclic loading associated with earthquakes are the commonly feared trigger mechanisms, several liquefaction failures have also occurred due to static loading. Failure under static loading generally occurs due to flow or limited flow deformation of slopes and embankments. Several such failures have been reported in the literature, including the failures of the Calaveras Dam (Hazen, 1918), Nerlerk underwater berms (Sladen et al. 1985), Fort Peck dam 
(Casagrande 1965), Merriespruit tailings dam (Fourie et al. 2001), and Wachusett Dam (Olson and Stark, 2003). The caisson failures at Barcelona \& Malaga harbours (Campo and Negro, 2011) highlight the potential risks to marine structures. These failures clearly indicate that liquefaction is a concern under both static and cyclic loading.

Even though the assessment of cyclic liquefaction potential is often based on empirical relationships in current practice, the basic understanding of this phenomenon, and the effects of various factors controlling it have been derived from controlled laboratory experiments. These experimental studies have provided several insights into this phenomenon by systematically assessing the effects of individual variables. A better understanding of the mechanisms leading to soil liquefaction, and factors affecting it are critical for confident designs.

\subsection{LIQUEFACTION SUSCEPTIBILITY}

Characterization of liquefaction susceptibility has been a challenging endeavour in geotechnical earthquake engineering practice and many simplifying assumptions are generally made in the analysis process. Site specific assessments are not always made in practice, and correction factors derived from the literature are often used to account for the effects of various state variables. Liquefaction potential of sands depend on various state parameters including relative density, effective stress level, soil fabric, stress/strain history, and loading path. The effects of density and stress level are better understood than that of the other variables. Research on the effects of soil fabric and prior stress history has been fairly limited, and significant challenges are faced by design engineers when dealing with these variables in practice. Current liquefaction resistant design practice does not pay attention to the potential effects of prior stress history, such as overconsolidation (OC). The implicit assumption that the soils are normally consolidated (NC) generally leads to a conservative design. Overconsolidation is known to 
increase the dilative tendencies of soils, and thus stronger response. However, the effect of overconsolidation on the correction factors used in cyclic liquefaction resistance has not been researched adequately to date, and further insights into the interactions of the initial state variables and these empirical correction factors are required for confident designs.

The most critical mode of seismic shaking generally occurs due to vertically propagating shear waves which are simulated well by cyclic simple shear tests. However, most of our understanding of liquefaction resistance has been derived from cyclic triaxial tests. Seismic wave in-situ generally leads to the oscillation of the principal stress directions, but the stress conditions in cyclic triaxial tests are not representative of the field conditions. Simple shear tests involve principal stress rotation, but do not permit a systematic study of the effects of stress rotation. A hollow cylinder torsional shear device permits fundamental studies on the effects of principal stress rotation, and can provide insights into the effects of principal stress rotation during earthquakes.

\subsection{CONSEQUences of LiQuefaction}

Liquefaction failures can manifest in a variety of forms depending on the geometry and the nature of stresses acting prior to and during the loading. Sand boils caused by the flow of pore water at higher piezometric pressures beneath ground towards the surface are often indicative of liquefaction in-situ. Deformations due to liquefaction are generally unidirectional in sloping ground (dams, embankments etc.) which are subjected to static shear stresses. Lateral spreading is common in relatively level ground.

The loss of shear strength during liquefaction may lead to scenarios that violate the required safety and/or serviceability limit states. Initial design attempts focussed on avoiding the occurrence of soil liquefaction, but recent studies that are aimed at assessing the response of the 
liquefied soil indicate that proper understanding of the post-liquefaction response can lead to the development of appropriate mitigation measures, even if the soils liquefy under the seismic loading. Significant volumetric deformation and much softer stress-strain behaviour have been noted in the limited research studies reported in the literature. Better understanding of the postliquefaction behaviour can significantly improve current design practices due to its potential ability to accept liquefaction as an eventuality, but ensure that the liquefied soil will not exceed the prescribed limit states.

\subsection{ReSEaRCh OBJectives}

The primary goal of the research program is to improve the current understanding of the effects of select initial state variables and stress path on liquefaction susceptibility both under static and dynamic loading. The dependence of monotonic undrained response on overconsolidation ratio was characterised at different initial stress and density states. Response of the liquefied sand was assessed under monotonic loading to obtain insights into the post-cyclic loading behaviour of the sand following seismic shaking. A comprehensive experimental research study was undertaken to systematically assess the role of overconsolidation on cyclic resistance in general, and the correction factors used in engineering design in particular. Two different sands, both fairly uniform, but with significantly different particle shapes were tested under cyclic loading to assess the potential effects of particle shape. The sub-angular Fraser River sand underlies the heavily populated Lower Mainland Region in British Columbia, and the sub-rounded Silica sand is similar to the widely used Ottawa sand in geotechnical research.

The effects of both the magnitude and nature of principal stress rotation on cyclic liquefaction were assessed using a series of hollow cylinder torsional shear device. A better understanding of the effects of the nature of principal stress rotation ('smooth' vs. 'jump') on 
cyclic resistance is required to assess the suitability of cyclic triaxial tests to characterise liquefaction potential under seismic loading. Stress-rotation tests indicate that the stress conditions in simple shear loading lead to cyclic resistance measurements that are closest to the weakest mode. In addition, simple shear closely simulates the in-situ stress conditions during earthquakes. Therefore, both the monotonic and cyclic tests to assess the effects of overconsolidation on liquefaction potential were conducted under the simple shear loading mode. This is expected to yield the most reliable estimate of the actual response in-situ.

\subsection{Organization OF The TheSIS}

A comprehensive review of the literature is presented in chapter two, which follows this introductory chapter that has highlighted the relevance and importance of the research to both fundamental understanding and engineering practice. The background presented in chapter 2 highlights the historical development, and the current state of the art relating to soil behaviour under monotonic and cyclic loading conditions, and current design practice. The stress and strain conditions associated with the testing devices used in previous studies are critically reviewed in chapter 3. This is required enable the use of appropriate experimental devices in this research, since the objective is to facilitate, and enable the extension of these laboratory results to in-situ soils. Detailed descriptions of the experimental devices used in this research together with the details of the data acquisition systems are provided in this chapter.

Chapter four presents a detailed description of experimental aspects, including a characterization of the materials tested, specimen reconstitution and test procedures etc. together with a review of the effects of different reconstitution techniques. Undrained cyclic behaviour under hollow cylindrical torsional loading is presented in chapter 5 to enable an assessment of the effects of principal stress rotation. Chapter six presents the test results and discusses the 
implications of the findings. Undrained behaviour of both Fraser River and Silica sands under monotonic, cyclic and post cyclic loading are presented to facilitate comparisons, and enhance the correction factors used in current design. Finally, Chapter 7 provides a summary and presents the conclusions drawn from this research. 


\section{LITERATURE REVIEW}

\subsection{INTRODUCTION}

A significant amount of research effort over the past four decades has focused on understanding the fundamental mechanisms leading to liquefaction in soils. The term liquefaction has evolved since the early reference to "spontaneous liquefaction" by Terzaghi and Peck (1948), and in current practice, it is understood to represent excessive deformation under undrained loading (NRC, 1985) regardless of the level of excess pore water pressure or the mechanism responsible for the strain development. Liquefaction induced failures in natural soil deposits, man-made fills, and mine tailing stacks have caused catastrophic damage. Such failures can be triggered by monotonic loading, earthquakes, vibration during pile driving, train traffic, geophysical exploration, and blasting. Several case histories of liquefaction failures have been reported in the literature (Seed et al., 1975; Jeyapalan et al., 1983; Isihara et al., 1990; Bardet and Davis, 1996; Boulanger et al., 1997; Whitman, 1987; Barends et al., 1992; Byrne at al., 1996; Finn et al., 1996; Ishihara et al., 1996).

An understanding of the liquefaction phenomena has been derived from controlled laboratory tests, both under static and cyclic loading conditions (Castro, 1969; Peacock and Seed, 1971; Finn et al 1971; Vaid \& Chern 1985; Ishihara 1993; Vaid et al. 1990a; Vaid and Sivathayalan, 1996). The generation of excess pore pressure, and the associated reduction in effective stress, is the most vital factor that controls the triggering of liquefaction. Thus a 
comprehensive understanding of the undrained response of soils, and factors affecting such response are critical in liquefaction studies.

\subsection{UNDRAINED MONOTONIC BEHAVIOR}

The static undrained behaviour of sands has been mostly studied under triaxial compression loading on reconstituted samples, and distinct deformation types, shown in Figure 2.1, have been identified (e.g. Castro, 1969; Lee and Seed, 1970; Castro et al., 1982; Vaid \& Chern, 1985; Vaid \& Thomas, 1992; Ishihara, 1993). The type of response is considered to be primarily dependent on the relative density. The undrained behavior at a given initial stress state changes from a type 1 to a type 3 with increasing relative density as shown in Figure 2.1. In type 1 response, the strength of soil increases to peak, and decreases thereafter to reach a steady state. Such post-peak flow deformation can lead to catastrophic failures in-situ. Castro (1969) followed by Casagrande (1975) and Seed (1979) called this strain softening type of response 'liquefaction', but Chern (1985) named it as true liquefaction to differentiate it from material that exhibits partial, or limited flow. Pore water pressure continually increases and reaches its peak value at steady state, and thus unlimited flow deformation occurs at a fixed point on the stress path plot (Fig 2.1c). This type of response is expected to be characteristic of loose sands.

Type 2 strain softening response (Fig. 2.1) is similar to type 1 in the early stages, but with limited flow deformation. Large deformations may occur at constant shear and normal stresses at quasi-steady state, and the material strain hardens upon reaching the minimum strength and peak pore pressure. The state at which the material behaviour changes from contractive to dilative has been termed the phase transformation (PT) state by Ishihara (1975). Negative pore pressures develop, and the strength of the material increases beyond the PT state. Castro (1969) and Vaid 
and Chern (1985) called this response limited liquefaction, while Lee and Seed (1970) termed it as partial liquefaction. This type 2 response is generally associated with medium dense sand. Type 3 stain hardening behaviour is associated with dense sands. This type of behaviour is generally called dilative, even though it is typical to have a small region with contractive volume change tendency, which reflects as the development of positive pore water pressure in an undrained test. Positive pore pressure development is limited to a small strain range, and subsequent negative pore pressure development might lead to very large strength values, possibly even larger than the drained strength.
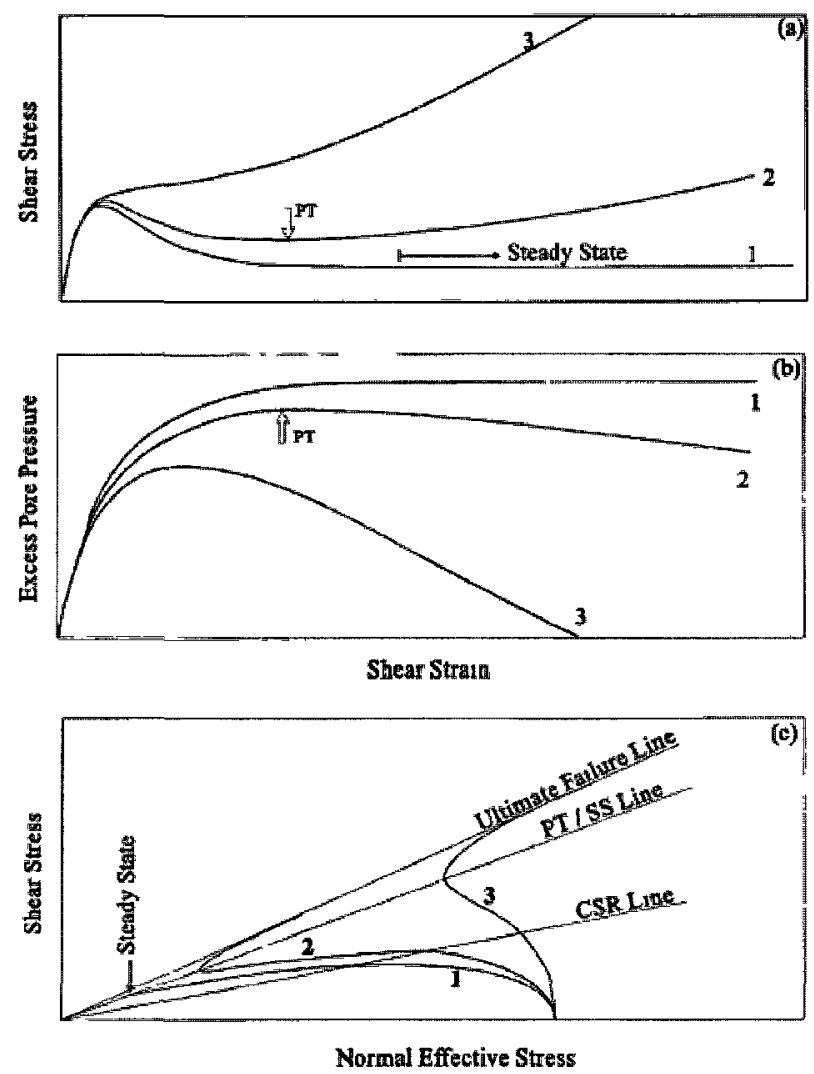

Fig 2.1: $\quad$ Characteristic response of sand under undrained static loading (After Chern 1985) 


\subsubsection{Characteristics of Monotonic Response}

Monotonic undrained response is generally characterized in terms of the undrained strength, and/or the friction angles mobilized at different states. Both, a peak strength $\left(S_{\text {peak }}\right)$ and minimum strength ( $S_{S S}$ or $S_{Q S S}$ ) can be defined in strain softening materials. No such states are available in type 2 strain hardening material, and it is typical in this case to assess the strength at phase transformation which corresponds to the lowest effective stress state $\left(S_{P T}\right)$. There is strong consensus in the literature that the friction angle mobilised at steady quasi steady or phase transformation state $\left(\varphi_{S S}, \varphi_{Q S S}\right.$, or $\left.\varphi_{P T}\right)$ is a unique material property (Castro, 1969, Vaid \& Chern, 1985; Vaid \& Sivathayalan 2000). Castro (1969) indicated that the steady state strength $S_{S S}$ is uniquely related to the void ratio alone, and not dependent on the confining stress levels in moist tamped sands. The existence of such unique relationship has been disputed by many researchers (Vaid et al., 1990; Konrad 1990; Mesri \& Stark, 1992) who indicate that normalised undrained strength (with initial consolidation stresses) is an appropriate index.

The possibility of strain softening deformation is generally a key concern under monotonic loading, and the phase transformation state has received significant attention as it represents a significant conversion from softening to hardening type of behaviour. The minimum undrained shear strength in QSS type of response occurs either at PT state, or just prior to that (Sukumaran, 1996). The mobilized friction angle $\left(\varphi_{P T / S S}\right)$ at PT state was observed to be unique for a given sand regardless of void ratio, initial stress state, mode of loading (cyclic or monotonic), type of response (contractive or dilative), reconstitution method (water pluviated, air pluviated, moist tamping), intermediate principal stress level (b), and rotation of principal stress $\left(\alpha_{\sigma}\right)$ (Chern, 1985; Vaid and Thomas, 1995; Stedman, 1997; Uthayakumar and Vaid, 1998; Vaid et al., 1999). Neguessy et al., (1986) noted that this angle is equal to the constant volume friction angle under 
drained conditions, and is dependent on soil mineralogy. These findings were further extended by Logeswaran (2005), who showed that mobilized friction angle at the maximum pore pressure state under partially drained conditions is also equal to $\varphi_{P T}$.

The stress path following the phase transformation state rapidly approaches the line of maximum obliquity. The friction angle corresponding to this failure state at large strains is often called ultimate friction angle $\left(\varphi_{u l t}\right.$ or $\left.\varphi_{f}\right)$, and was reported to be a unique property in water deposited sands by Vaid and Chern (1985), and Thomas (1994). In contrast, Miura and Toki, 1982 reported that this failure angle increases as relative density increases and depends on soil fabric. Generally, $\varphi_{u l t}$ is about $3^{\circ}$ to $5^{\circ}$ larger than $\varphi_{P T}$ (Vaid and Sivathayalan, 1996).

\subsubsection{Factors affecting the Monotonic Undrained Response}

Void ratio (or relative density) is clearly the most dominant factor affecting the undrained response. Contractive behaviour of sand gradually transforms into dilative with increasing relative density (or decreasing void ratio) at a constant initial stress state (Bishop, 1971; Been et al., 1991; Vaid and Thomas, 1995; Vaid and Sivathayalan, 1996; Vaid and Uthayakumar, 1998). Increasing confining stress level at a constant relative density tends to promote more contractive response. This occurs since the increased normal stresses suppress the dilation potential in the material (Vaid and Thomas, 1995; Vaid and Sivathayalan, 1996).

Most natural soils are anisotropic and thus their behaviour is direction dependent. Gravity deposited materials often have a horizontal bedding plane, and thus yield stronger response under triaxial compression loading compared to extension (Vaid et al., 1990a; Thomas, 1994). Many researchers have demonstrated that some water deposited sands strain harden under triaxial compression loading even at the loosest density state, but strain soften under extension loading over a range of density states (Figure 2.2). Systematic changes in undrained response depending 
on the direction of principal stresses can be noted in the research reported by Symes et al. (1985), Shibuya and Height (1987), Uthayakumar (1995) and Logeswaran (2010) among others. Vaid et al. (1999) clearly demonstrated that fabric plays a significant role on the undrained response, possibly as critical as that of void ratio. Different deposition processes in-situ, or reconstitution methods in the laboratory give rise to different fabric and these finding highlight the need to adopt appropriate reconstitution techniques in experimental studies.

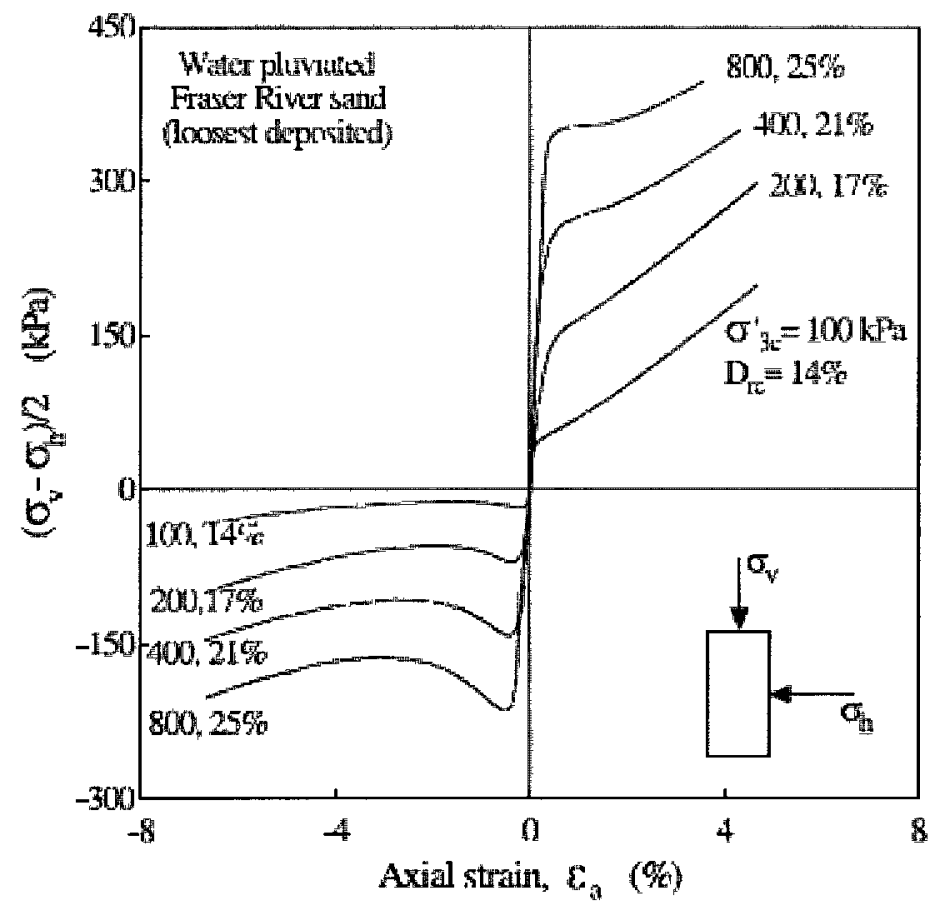

Fig. 2.2: $\quad$ Behaviour of water pluviated sand under compression and extension mode (Vaid and Thomas, 1995)

\subsubsection{Effects of Overconsolidation}

Effects of overconsolidation have been widely studied in clayey soils. Overconsolidated clay samples showed significant dilative behaviour compared to their normally consolidated counterparts in several studies (Murthy et al., 1981; Hattab \& Hiches, 2004). This effect of overconsolidation in clays has been noted to be similar to that of the effect of relative density in 
sands. Ishihara and Odaka (1978) researched the monotonic response of overconsolidated sands under triaxial compression and extension loading, and noted a systematic reduction in pore pressure generation with increasing OCR (Figure 2.3). It was discovered that even small levels of over consolidation can cause a significant change in the response at a given relative density (Yamashita, 1974; Ishihara et al., 1978).
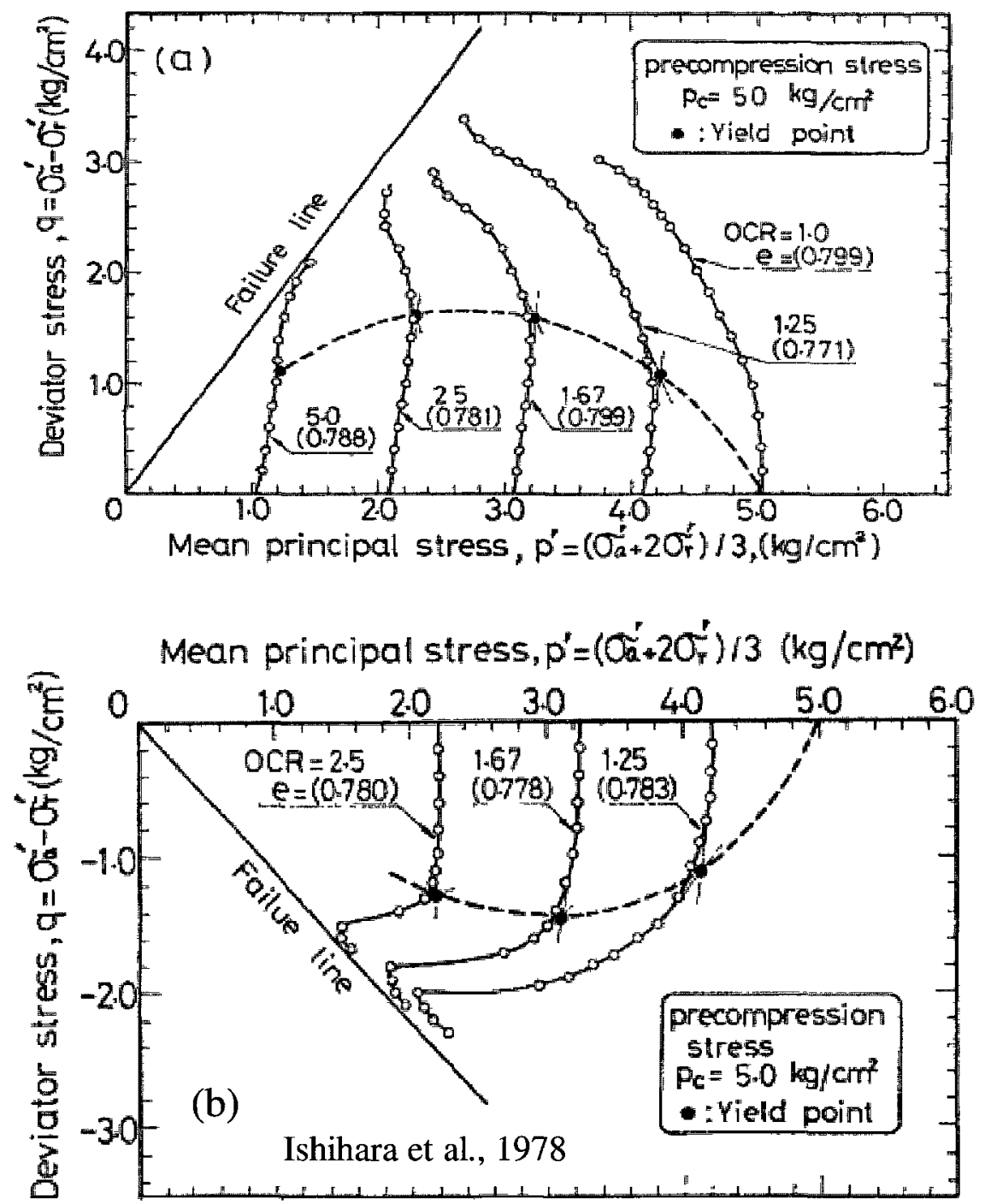

Fig.2.3: $\quad$ Stress paths under triaxial compression (a) and extension (b) test 


\subsubsection{OCR and Shear Modulus}

Shear modulus of soil, and its degradation with strain are key input parameters in ground response analysis. Elastic stiffness of soils, generally called $G_{\max }$ can be determined from wave velocity measurements, or resonant column tests. Improved measurement resolution would enable a direct measurement of $G_{\max }$ from laboratory shear testing devices such as triaxial or simple shear. $G_{\max }$ is noted to be influenced by relative density, confining stress level, plasticity index (in clays), and overconsolidation ratio (Seed at al., 1970; Iwasaki et al., 1978; Kokusho et al., 1982; Vucetic et al., 1998; Stokoe et al., 1999). Soil behaviour is nonlinear, and modulus degradation with strain is generally characterized through modulus reduction curves in practice. Modulus reduction curves are normally presented in a normalized form $G / G_{\max }$. Data presented by Seed and Idriss (1970) from tests on Santa-Monica sand suggest that modulus reduction curves are affected by overconsolidation, but only minimally (Figure 2.4). Vucetic and Dobry (1991) presented data that shows somewhat larger dependency of $G / G_{\max } v s \gamma$ relationship on OCR as shown in Figure 2.5. The normalized shear modulus reduction curve shifted upwards slightly with increasing overconsolidation at given confining stress level.

\subsection{UndRaINED CyCLIC BeHAVIOUR}

Development of large strains, generally due to the generation of significantly large levels of excess pore water pressure, is the most common concern under cyclic loading. Deformation mechanisms under cyclic loading have been found to reflect the characteristics identified under monotonic loading. The type of response is dependent on many factors, including relative density (void ratio), confining stress level, and initial static shear stress levels. At a given initial stress state denser materials have higher cyclic resistance. A progressive increment of pore pressure and deformation was observed with increasing number of cycles. 

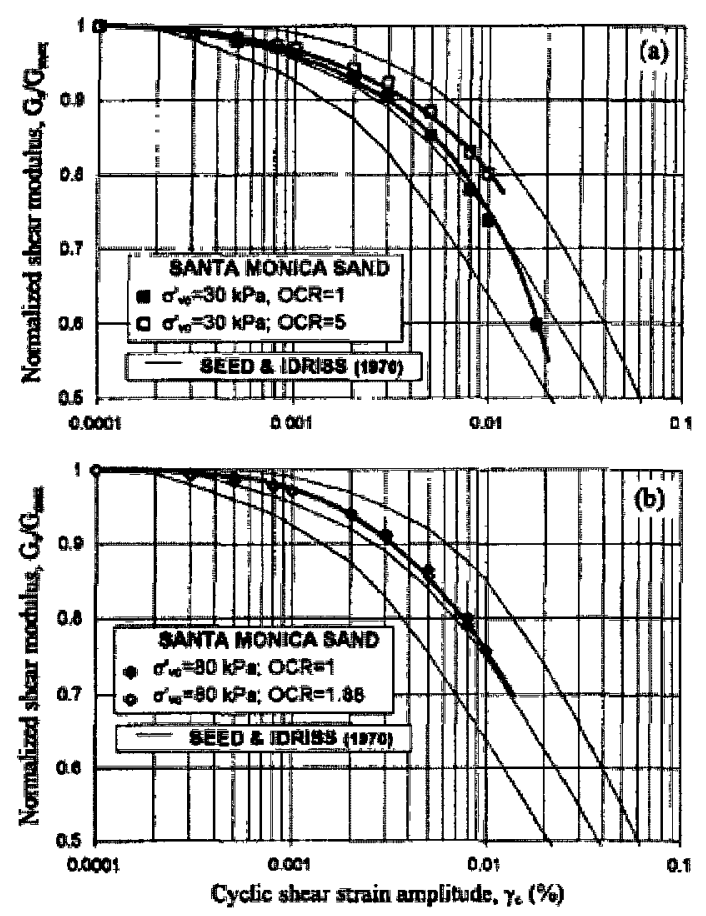

Fig. 2.4: $\quad$ Effect of OCR on $G / G_{\max }$ on Santa Monica Sand
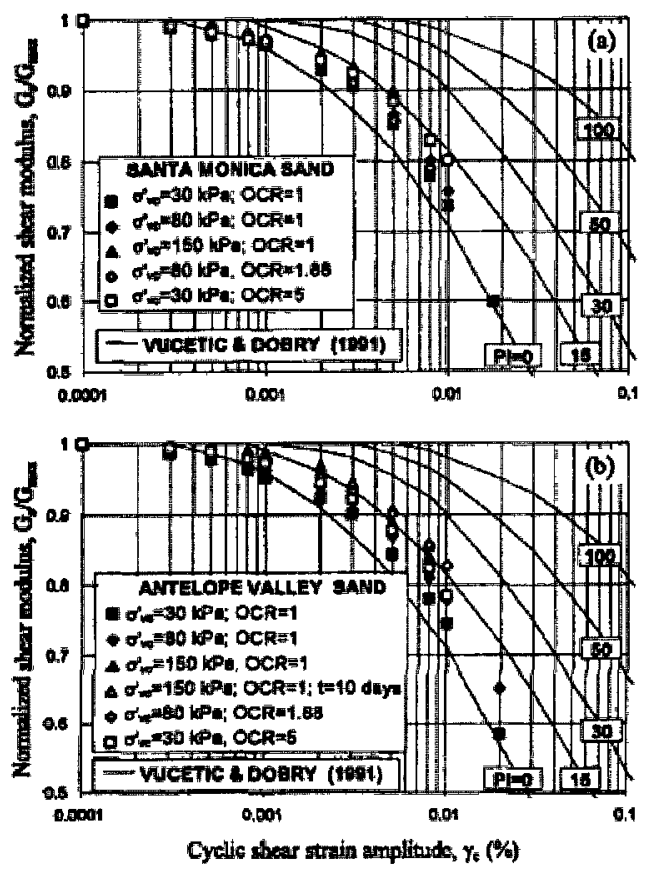

Fig. 2.5: $\quad$ Effect of OCR on $\mathrm{G} / \mathrm{G}_{\max }$ on Santa Monica and Antelope Valley Sand 
Figure 2.6 illustrates the stress-strain response, effective stress path, and strain development in contractive, strain-softening sands. Loosest sands that exhibit Type 1 response in monotonic loading can generate similar flow failure type of deformation under cyclic loading as shown in Figure 2.6(a). Limited liquefaction followed by cyclic mobility, illustrated in Figure 2.6(b) is characteristic of medium dense sands. The type of response in general has been found to be dependent on relative density (void ratio), confining stress level, and initial static shear stress level under cyclic loading. Deformation under cyclic loading in dilative (Type 3) sands generally occurs on account of cyclic mobility as illustrated in Figure 2.7. The unloading pulse upon reaching the phase transformation state PT state usually generates very large excess pore water pressure, and the effective stress state reaches zero soon thereafter. Subsequent oscillations of the effective stress state through transient zero states is generally responsible for the development of large strains. Shear strain development is small until the excess pore pressure ratio $\left(\Delta u / \sigma_{v c}^{\prime}\right)$ exceeds about $60 \%$ (Seed, 1979). A pore pressure ratio of $100 \%$ is normally pre requisite for large strain development due to cyclic mobility. If the amplitude of cyclic shear stress is smaller than that of the initial static shear stress then no shear stress reversal would occur, and as a result transient states of zero effective stress cannot be realized. Strain development due to cyclic mobility in such cases would be limited.

Liquefaction susceptibility under cyclic loading is normally characterized by the cyclic stress ratio, CSR that is required to exceed the specified level of strain in a number of cycles. Following the recommendations of the NRC (1985) committee, a shear strain criterion is commonly adopted to define the occurrence of liquefaction. Specimens exceeding $3.75 \%$ shear strain in simple shear (or the equivalent $2.5 \%$ axial strain in triaxial) are deemed to be liquefied in most experimental research studies. The number of load cycles expected is dependent on the 
magnitude of the earthquake, and it is typical to assess the CSR causing liquefaction in 10 cycles (corresponding to an earthquake magnitude of $M$ 6.75). The specific value of CSR that causes liquefaction in a given number of cycles represents the cyclic resistance, and is often called the cyclic resistance ratio, CRR.

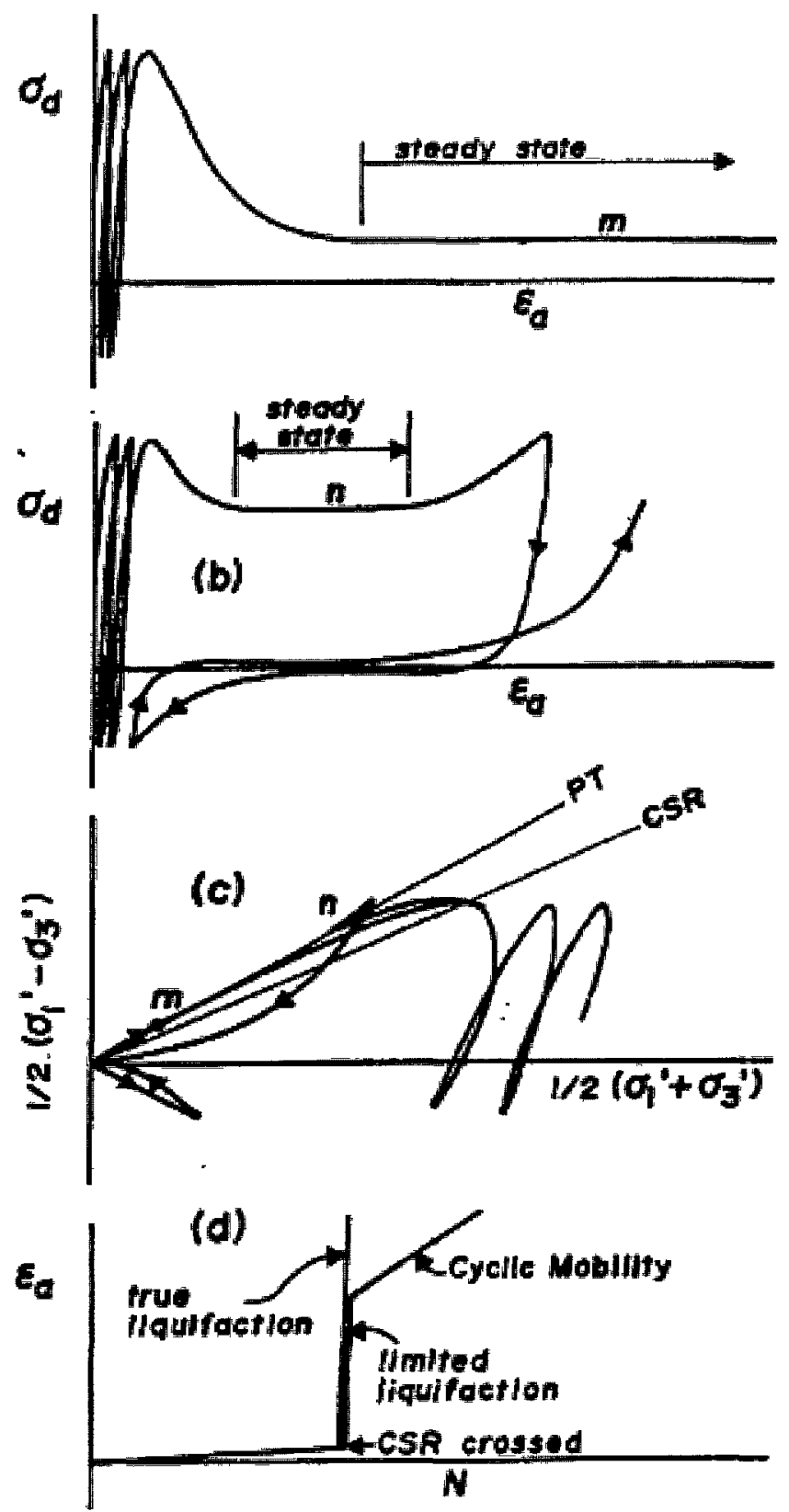

Fig. 2.6: $\quad$ Cyclic loading behaviour of contractive sand (After Vaid and Chern 1985) 

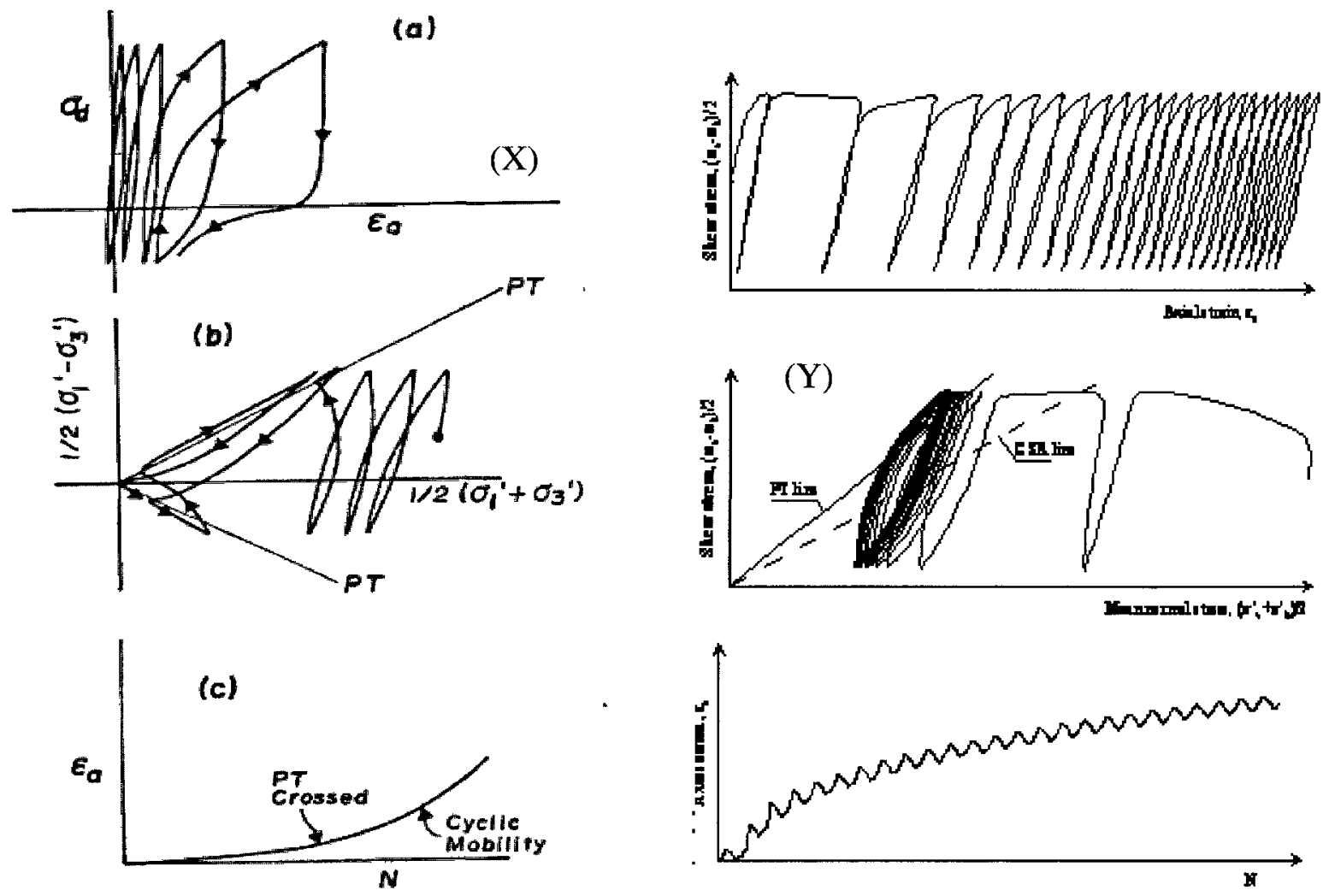

Fig. 2.7: $\quad$ Cyclic mobility with $(\mathrm{X})$ and without $(\mathrm{Y})$ transient state of zero effective stress (After Vaid and Chern 1985)

Cyclic resistance of sands, regardless of whether liquefaction is triggered due to strain softening or cyclic mobility, relative density confining pressure, pre-strain history, Ko (Finn et al., 1971; Castro and Poulos, 1977; Seed et al., 1977; Vaid and Cherrn, 1985; Vaid and Sivathayalan, 2000), and soil fabric (Mullilis et al. 1977; Vaid el al. 1999). Void ratio (or relative density) is one of the most important parameters that affect the liquefaction potential. Sand with relative density less than of $40 \%$ has been suggested to be highly susceptible to liquefaction, generally due to flow deformation, and that at denser than about $45 \%$ was expected to develop cyclic mobility (Chern, 1985). It was also noted that the cyclic resistance of sands with rounded particles increases at a faster rate with relative density compared to sands with angular particles. However, the influence of various other parameters, such as the loading mode, soils fabric and 
stress level indicates that such generalizations are very approximate, and cannot be expected to be valid in all cases.

\subsubsection{Loading Mode Effects on Cyclic Resistance}

As noted earlier, most soils have an anisotropic fabric, and thus their response is dependent on the direction of loading. Cyclic triaxial tests have provided the basis for most of the current understanding about liquefaction susceptibility. Most triaxial specimens are hydrostatically consolidated prior to cyclic loading (Lee \& Seed, 1970; Thomas, 1994), even though in-situ stress states are invariably anisotropic. Anisotropic consolidation states have been simulated in cyclic triaxial tests by some researchers (Vaid et al 1999). Depending on the initial stress consolidation stresses, a cyclic triaxial test may not involve any stress rotation, or involve jump rotation of principal stresses. Such, jump rotation alternatively invokes the strong compression mode and the weak extension mode during each half of the loading cycles, and is not at all expected during actual in-situ loading. A cyclic simple shear test simulates the stress conditions in-situ during vertically propagating shear waves very well, and is considered to be a more appropriate test to assess liquefaction susceptibility in the laboratory (Finn et al., 1977; Vaid \& Sivathayalan, 1996; Sivathayalan \& Ha, 2006). Even though simple shear test does not permit any control over principal stress rotation, principal stresses smoothly rotate during the loading between $\pm 45^{\circ}$. Such smooth and continuous rotation is typical of in-situ loading. Cyclic resistance measured in axi-symmetric triaxial loading is generally higher than that in simple

shear, and a correction factor $C_{r}$ has been proposed to account for the differences. (Peacock \& Seed (1971) suggested a $C_{r}$ value of 0.45 , but Vaid \& Sivathayalan (1996) indicate that $C_{r}$ value is dependent on relative density. Cyclic hollow cylinder torsional shear tests have been reported by a few researchers (Uthayakumar, 1995; Yoshimine \& Ishihara, 1998; Logeswaran, 2010) to 
provide better insights into the effects of stress rotation on cyclic resistance. However, these studies have been limited in scope, and additional studies are required to better understand the influence of stress rotation on liquefaction potential.

\subsubsection{Effect of Overconsolidation}

Research on the effects of overconsolidation on cyclic resistance of sands has been fairly limited in the literature. Ishihara et al (1978) reported that overconsolidation increases the cyclic resistance under cyclic triaxial loading. The number of cycles to liquefaction at a given CSR increased significantly at specimens at essentially similar initial states. No studies on the effects of overconsolidation on cyclic simple shear resistance were located in the literature.
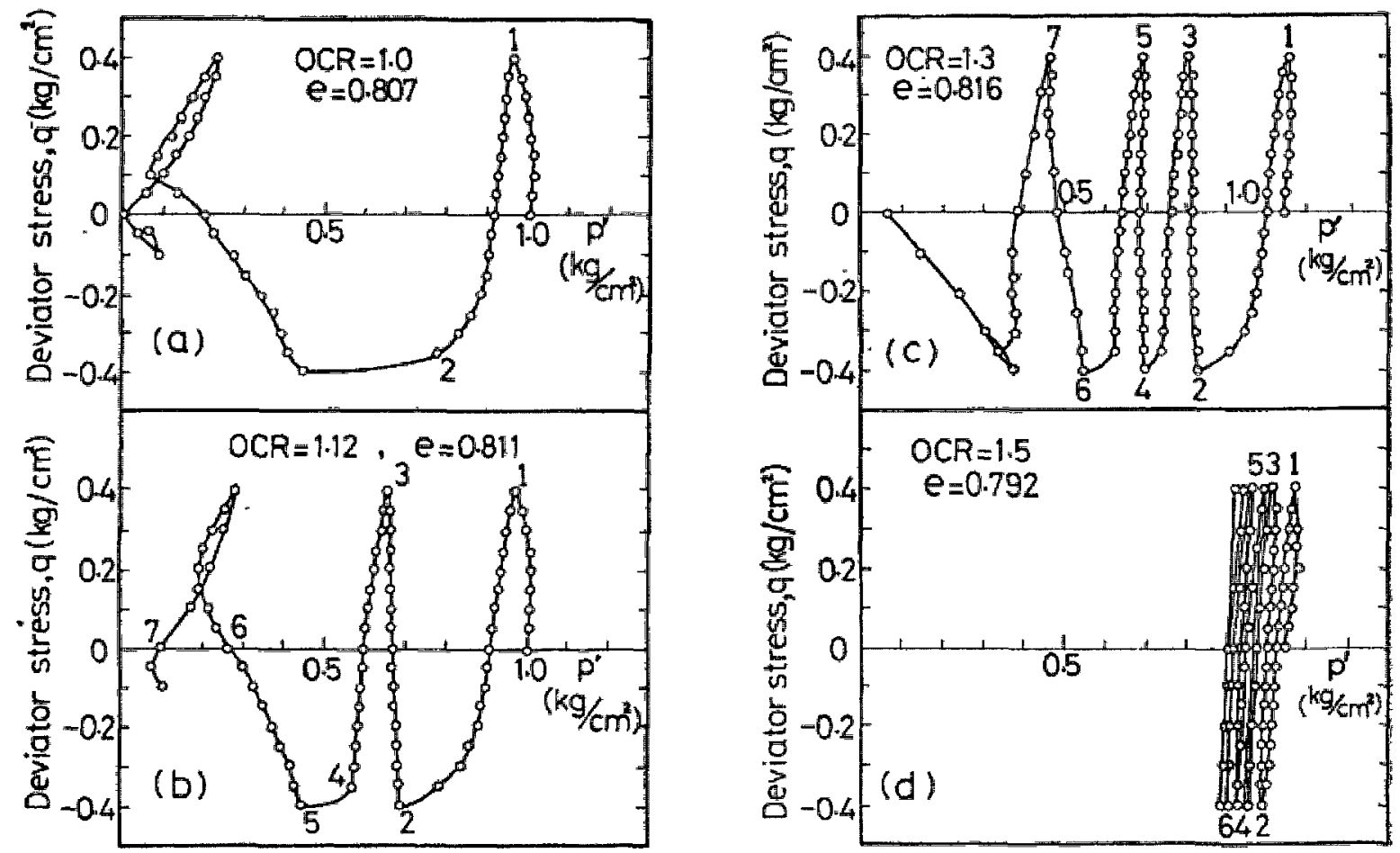

Fig.2.8: $\quad$ Effect of over consolidation during cyclic loading (After Ishihara et al., 1978) 


\subsubsection{Effect of Confining Stress Level}

Many studies have noted that cyclic resistance decreases with increasing confining stress level (Chern, 1985; Vaid and Thomas, 1994; Vaid et al. 2001). As noted earlier, increasing confining stress promotes more contractive behaviour under monotonic loading. This naturally leads to higher rates of excess pore pressure generation, and thus lower cyclic resistance. Confining stresses at a site vary with depth, and it is common practice to determine to the cyclic resistance ratio at a reference stress level, and appropriately correct it for required stress level. Seed (1983) proposed a correction factor $K_{\sigma}$ to account for the effects of stress level of cyclic resistance.

$$
K_{\sigma}=\frac{\frac{\tau_{c y}}{\sigma_{v}^{\prime}} \text { causing liquefaction at } \sigma_{v}^{\prime}}{\frac{\tau_{c y}}{\sigma_{v}^{\prime}} \text { causing liquefaction at } \sigma_{v}^{\prime}=1 \mathrm{~atm}}=\frac{C R R_{\sigma_{v}^{\prime}}}{C R R_{1}}
$$

\subsubsection{Effect of Initial Static Shear}

Unlike increasing confining stresses which decrease the cyclic resistance, increasing initial static shear stress levels may either increase or decrease the cyclic resistance (Seed \& Harder, 1990; Vaid et al., 2001; Sivathayalan \& Ha, 2006). The level of static shear is normally characterized by the static shear stress ratio, $\alpha$ defined as the ratio of shear stress on the horizontal plane to the vertical effective overburden stress in most scenarios, except in experimental research using cyclic triaxial tests. Thus, $\alpha=\tau_{s t} / \sigma_{v c}^{\prime}$ where $\tau_{s t}$ is the shear stress on the horizontal plane. There are no shear stresses on the horizontal plane in triaxial loading, and $\alpha$ in this case is defined by $\left(\sigma_{1 c}^{\prime}-\sigma_{3 c}^{\prime}\right) / 2 \sigma_{3 c}^{\prime}$. Vaid and Chern (1985) reported that the effect of initial static shear depends on the relative density, the magnitude of applied initial static shear, and defined liquefaction strain criterion. The effects of the initial static shear stress $\tau_{s t}$ on 
cyclic resistance is accounted for by a correction factor $K_{\alpha}$ which is defined as the ratio of CRR with static shear to that without as shown in equation (2.2)

$$
K_{\alpha}=\frac{\frac{\tau_{c y}}{\sigma_{v}^{\prime}} \text { causing liquefaction with } \tau_{s t}}{\frac{\tau_{c y}}{\sigma_{v}^{\prime}} \text { causing liquefaction with no static shear }}=\frac{C R R_{\alpha}}{C R R_{\alpha=0}}
$$

\subsection{5 $K_{\sigma}$ and $K_{\alpha}$ Correction Factors}

Liquefaction susceptibility assessment requires site specific evaluation of cyclic resistance CRR at the confining and static shear stress levels encountered in-situ. This is a fairly formidable task, regardless of whether in-situ correlations or actual laboratory tests are used to determine the CRR values. It is common practice to determine a reference cyclic resistance ratio, typically at $100 \mathrm{kPa}$ confining stress level with no static shear, and then modifying it to the required confining and static shear stress levels by using $K_{\sigma}$ and $K_{\alpha}$ factors as noted in equation 2.3 (Seed, 1983).

$$
C R R_{\sigma, \alpha}=C R R_{\sigma=1 \text { tsf }, \alpha=0} \times K_{\sigma} \times K_{\alpha}
$$

$K_{\sigma}$ values were initially considered to be dependent on confining stress level alone (Seed, 1983; Seed \& Harder, 1990). Subsequent experimental research (Vaid et al. 1985; Vaid \& Thomas, 1995; Vaid \& Sivathayalan, 1996; Haynes \& Olsen, 1998) has indicated that $K_{\sigma}$ is dependent on both confining stress levels, and relative density, and these findings have been incorporated in the consensus report of the NCEER workshop (Youd et al. 2001). The loading mode effects reported by Vaid \& Sivathayalan (1996) are not explicitly considered, but the values recommended by Youd et al. (2001), and commonly used in practice (Figure 2.9) are somewhat conservative than the lower bound of the reported $K_{\sigma}$ values that correspond to the weaker simple shear loading mode. Figure 2.9 and 2.10 show the range of values reported in 
recent literature. Relatively higher $K_{\sigma}$ values proposed by Boulanger \& Idriss (2004) based on relative state parameter index analysis imply that Haynes \& Olsen (1998), Youd et al. (2001) are somewhat conservative (Figure 2.9). Boulanger \& Idriss (2004) values are closest to the lower bound values reported by Vaid \& Sivathayalan (1996) and shown in Fig. 2.10. The largest deviations are noted at the loosest states $(\mathrm{Dr}=40 \%)$. Regardless of whether one adopts the values in the NCEER summary report, Vaid \& Sivathayalan, or Boulanger \& Idriss, these $K_{\sigma}$ values are considered fairly reliable, and have been widely adopted in design practice. However, these data correspond to normally consolidated soils only, and the applicability of the current $K_{\sigma}$ factors to over consolidated sands has not been properly addressed in the literature.

A range of $K_{\alpha}$ values have been proposed in the literature (Figure 2.11), generally as a function of $\alpha$ and relative density, but recent studies (Boulanger \& Idriss, 2003; Sivathayalan \& Ha, 2006) indicate that relative density may not be an appropriate parameter to quantify $K_{\alpha \text {. As a }}$ result of the uncertainties of the effects of loading mode, and material characteristics on $K_{\alpha}$, this correction is not as widely used in practice, especially when dealing with dense sands because of the expectation that ignoring this effect would lead to a conservative design. However, Sivathayalan \& $\mathrm{Ha}$ (2006) point out that ignoring the static shear correction might lead to unsafe designs, even in dense sands, if the sand at the denser state deforms contractively.

\subsection{POST LIQUEFACTION BEHAVIOUR}

The residual state following liquefaction generally corresponds to very small effective stress (or very large excess pore water pressures). This can lead to significant settlement in level ground, or shear deformation in sloping ground, with static shear stresses. Post liquefaction behaviour of sand is primarily dependent on the residual effective normal stress at the end of 
cyclic loading (Vaid \& Thomas, 1995). The stress-strain response of Brenda sand (Kuerbis, 1989) during cyclic loading provided one of the first insights into post liquefaction undrained response.

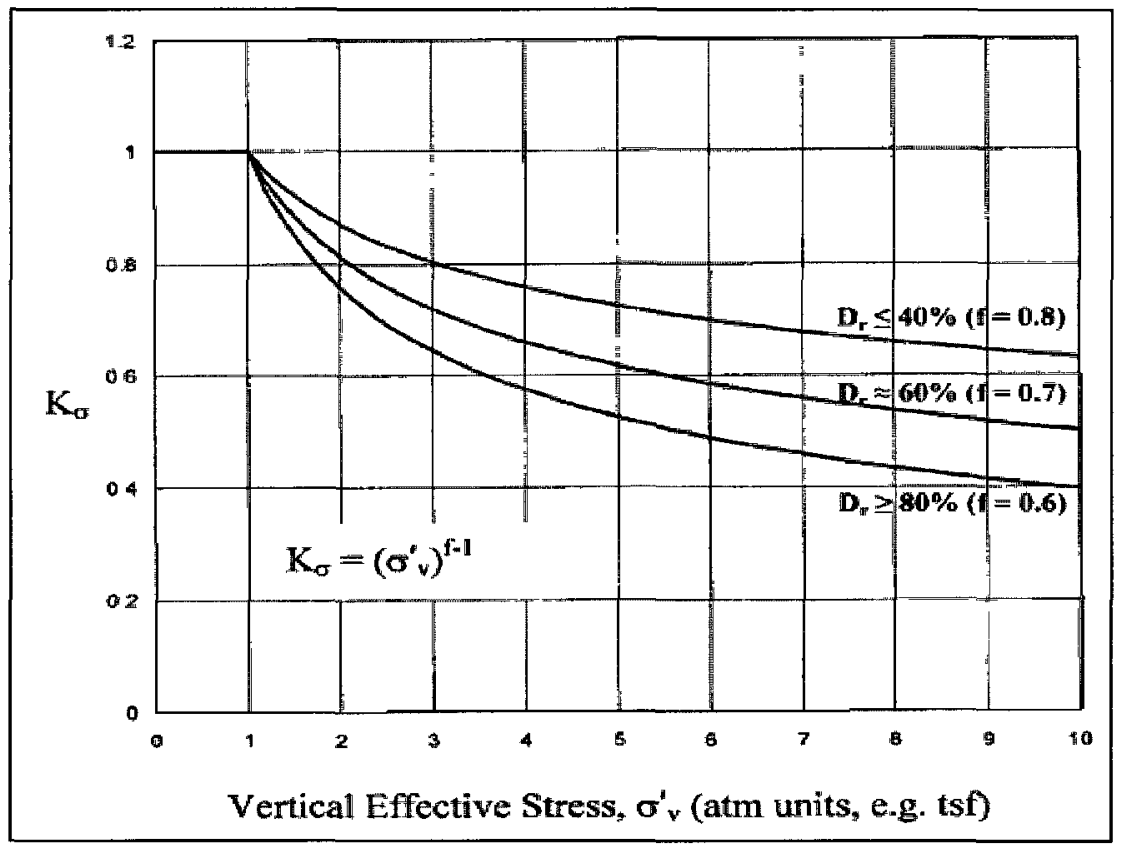

Fig. 2.9: $\quad$ Comparison of $K_{\sigma}$ values with several sands (After Youd et al., 2001)

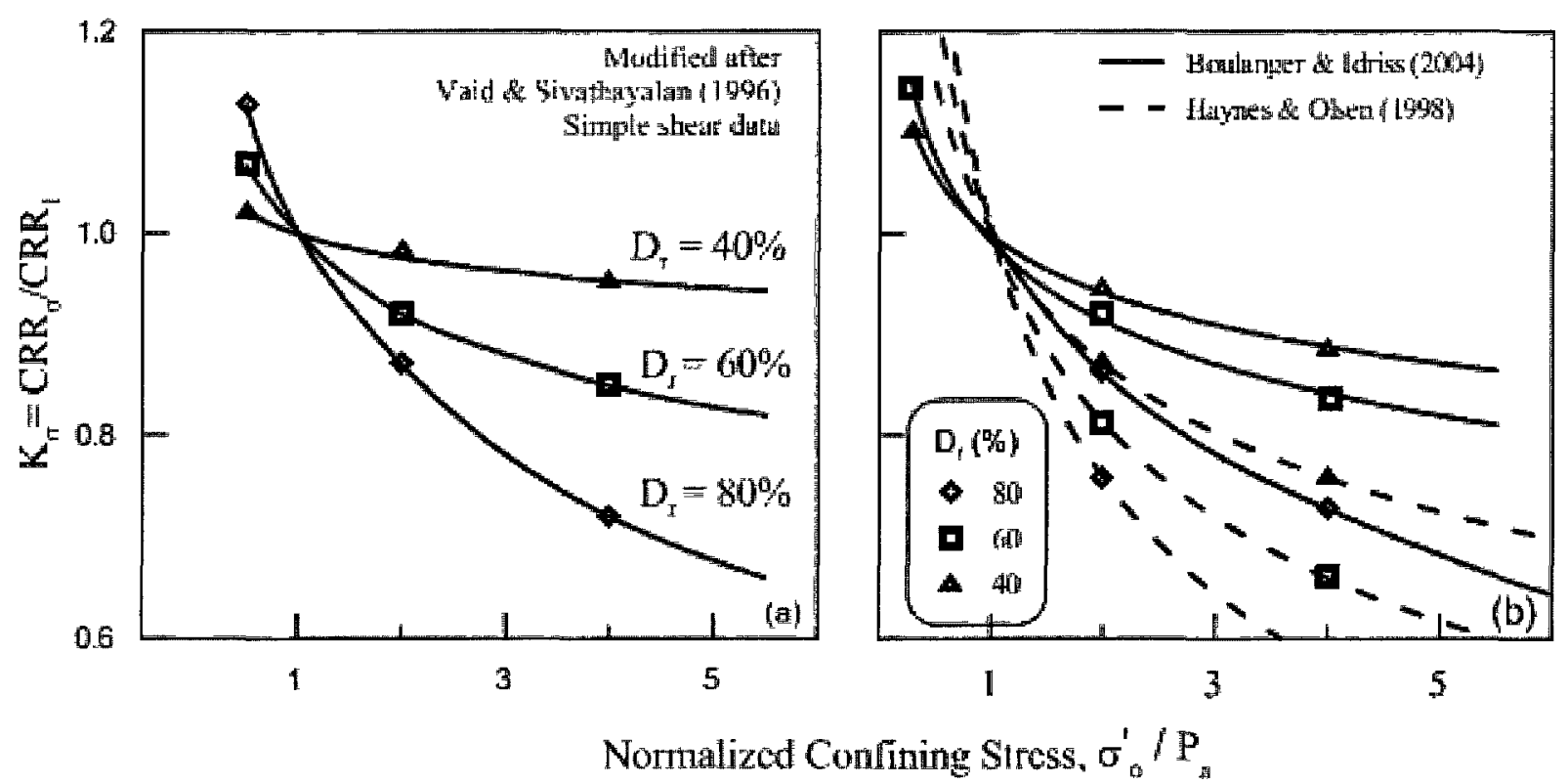

Fig. 2.10: $\quad$ Range of $\mathrm{K}_{\sigma}$ values in the literature 

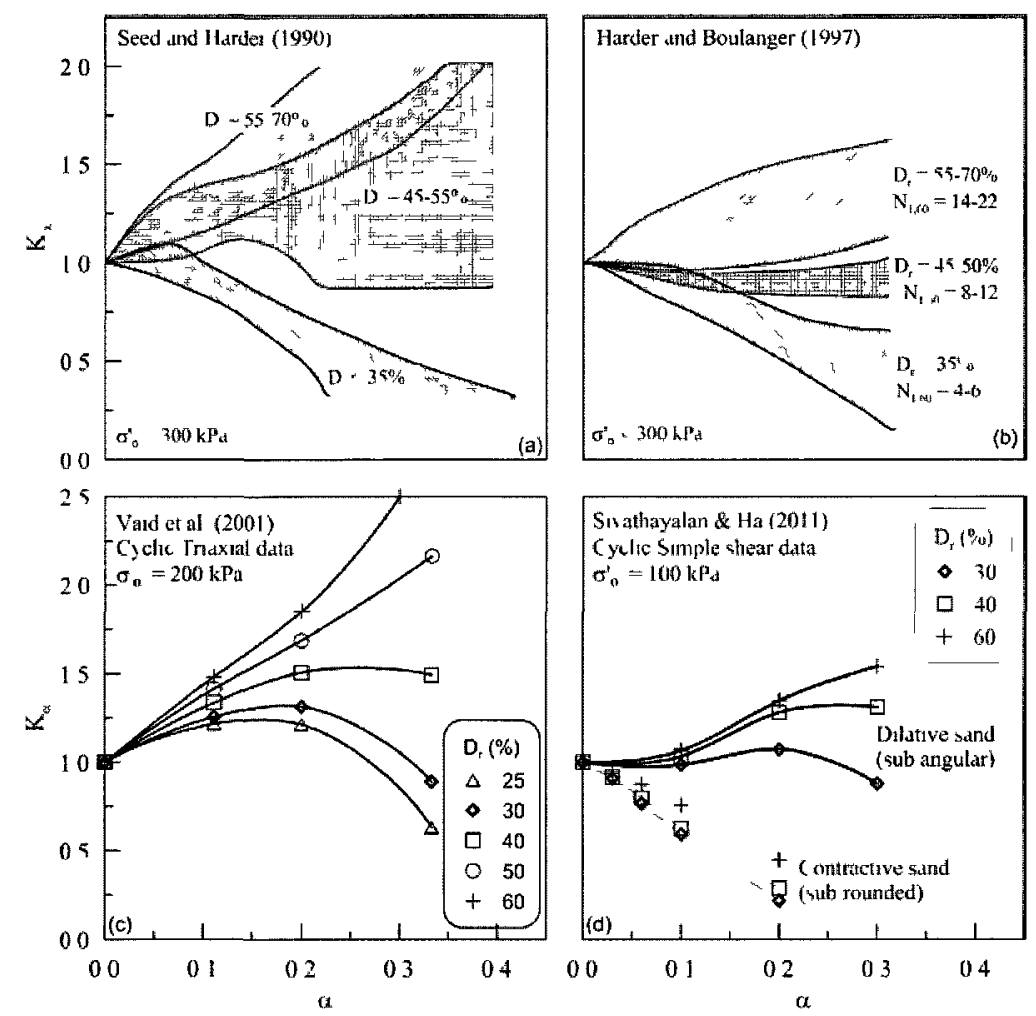

Fig. 2.11: Range of $\mathrm{K}_{a}$ versus $a$ relationship for sands at different density states (after Sivathayalan \& Ha, 2011)

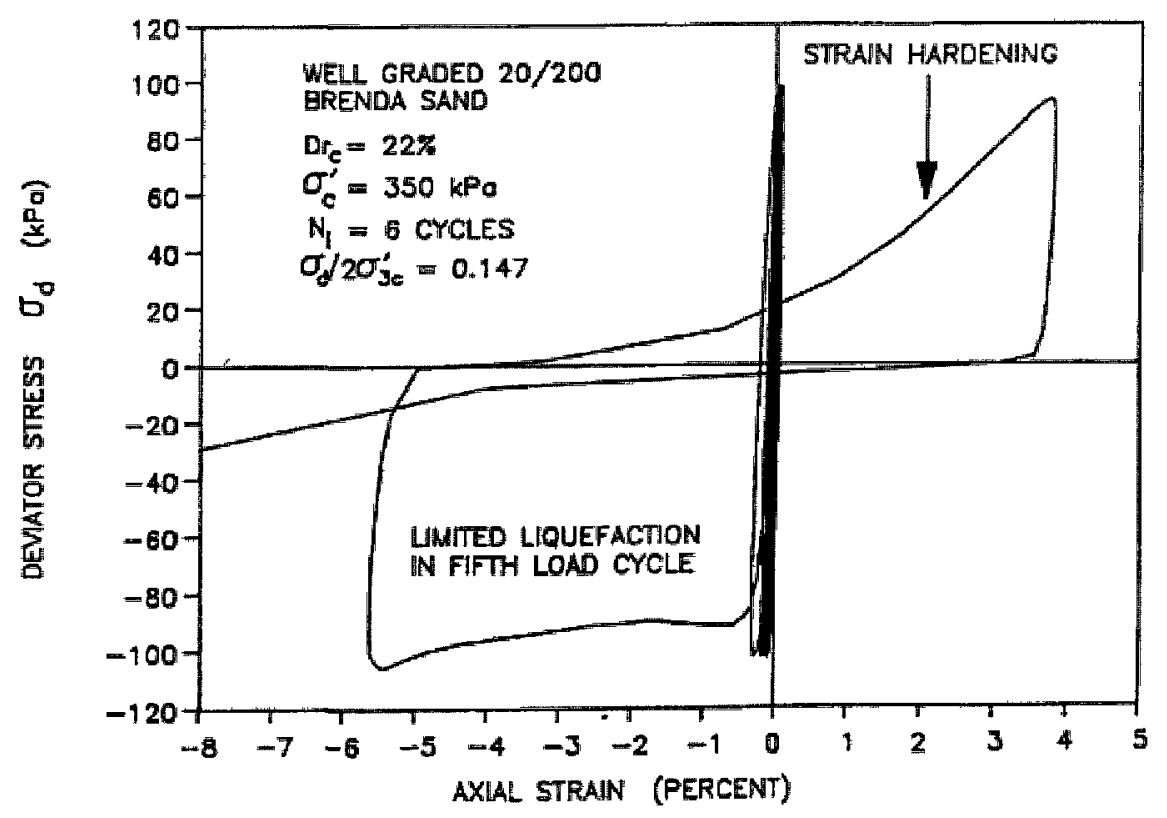

Fig.2.12: $\quad$ Pre and Post Liquefaction of sand (After Kuerbis 1989) 
Post liquefaction deformation is induced by redistribution of the void ratio (densification) in relatively permeable materials, and a change in stiffness and shear resistance. During an earthquake, the development of excess pore pressure brings the effective stress to zero (100\% pore pressure generation). The hydraulic gradient which is generated by remaining pore pressure after liquefaction drives the pore water out of void ratio (redistribution) and starts to decrease with water flows. This mechanism simply reduces the volume of soil mass (densification) and triggers the post liquefaction deformation.

Vaid \& Thomas (1995) identified three distinct regions in the post liquefaction stress-strain curve (Fig. 2.13). The first region represents deformation at essentially zero strength and stiffness. The second region characterizes a gradual increase in stiffness. A parabolic shape was noticed in the second region, in which shear stiffness increases with increasing strain. The shear stiffness remains at an essentially constant value at large strains the third region. Relative density, initial confining stress level, and loading mode have been reported to influence the deformation characteristics of liquefied soils (Vaid and Thomas, 1995; Vaid and Sivathayalan, 1997; Shamoto et al., 1997; Sivathayalan and Yazdi, 2004).

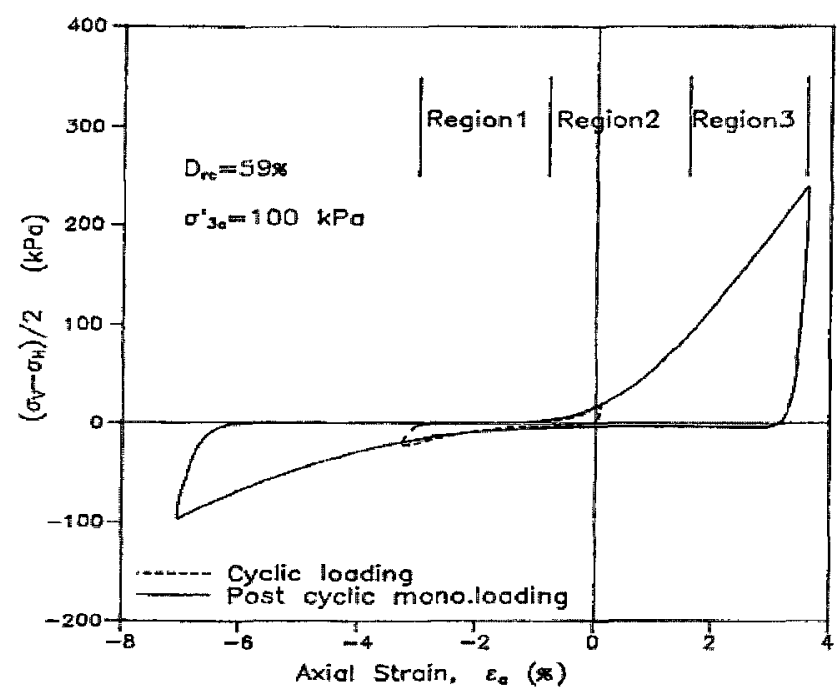

Fig. 2.13: Characterization of Post-Cyclic behaviour (After Vaid and Thomas, 1995) 


\section{LABORATORY TESTS FOR LIQUEFACTION CHARACTERIZATION}

\subsection{INTRODUCTION}

Liquefaction susceptibility of soils can be assessed using in-situ testing data with empirical correlations, or from laboratory tests. It is not uncommon to use a combination of both laboratory and in-situ methods in projects of significance. Laboratory assessment should preferably be conducted on undisturbed specimens consolidated to in-situ stress states, and subjected to anticipated field loading paths. However, geometry and configuration of laboratory testing devices limit the possible consolidation stress states, and stress paths. This chapter discusses the features of common shear testing devices used in liquefaction assessment. While other devices (e.g., resonant column) and techniques (e.g., wave velocity measurement) are employed in the laboratory to obtain specific parameters (e.g., $\mathrm{G}_{\max }$, damping), triaxial, simple shear and hollow cylindrical torsional tests provide the most common means of assessing liquefaction potential in the laboratory. This chapter presents a detailed description of each of these devices, and discusses their suitability and capability in liquefaction assessment. The research reported in this thesis is conducted using two of these devices (simple shear \& HCT).

\subsection{TRIAXial TESTS}

The triaxial test is the most commonly used geotechnical test to assess the mechanical behaviour of soils. Triaxial devices are widely available, and have become the choice for routine soil testing due to their simpler design, and non-complicated, straightforward testing procedures. 
A tall cylindrical soil sample, typically with a height to diameter ratio of two, is confined by all around pressure, and generally is axially loaded. Triaxial compression tests are the most common, but triaxial extension tests can also be conducted. The specimen, surrounded by a rubber membrane, is supported by top and bottom end platens that facilitate drainage (when required). The restraint caused by these end platens gives rise to some stress non-uniformity, but it can be minimized by increasing the aspect ratio of the specimen. Taylor (1948), Bishop and Green (1965) and Lade (1982) and many others have noted that the effect of end restraint is generally negligible in specimens with a height to diameter ratio of two or larger. Lubricated end platens have also been used to reduce the end restraint effects (Rowe and Barden, 1964; Barden and Khayatt, 1966), but this technique is known to introduce bedding errors (Sarsby et al., 1980).

The stress path in triaxial can be understood by using Mohr's circle as illustrated in Figure 3.1. Principal stresses act along the vertical and horizontal directions, and since this is an axisymmetric test, two of the three principal stresses are always equal. Major principal stress acts along the vertical direction in a compression test, and along the horizontal (radial) direction in an extension test. Even though hydrostatic initial conditions have been commonly used in triaxial testing, the device can apply non-hydrostatic initial conditions.

The triaxial device cannot independently control the intermediate principal stress $\left(\sigma_{2}\right) . \sigma_{2}$ equals $\sigma_{3}$ in triaxial compression mode, and it takes the value of $\sigma_{1}$ during extension mode of loading. The intermediate principal stress parameter $b=\left(\sigma_{2}-\sigma_{3}\right) /\left(\sigma_{1}-\sigma_{3}\right)$ is thus zero in compression tests, and one in extension tests. Major principal stress direction is either along the vertical deposition direction (in compression), or at $90^{\circ}$ to it (in extension). Principal stresses may not rotate at all, or rotate suddenly ("jump") during a cyclic triaxial test But rotation of principal stress direction in-situ is expected to be smooth and continuous. In addition, the 
axisymmetric lateral deformation that occurs in triaxial tests may not be suitable to represent many in-situ boundary conditions that lead to plane strain deformation.
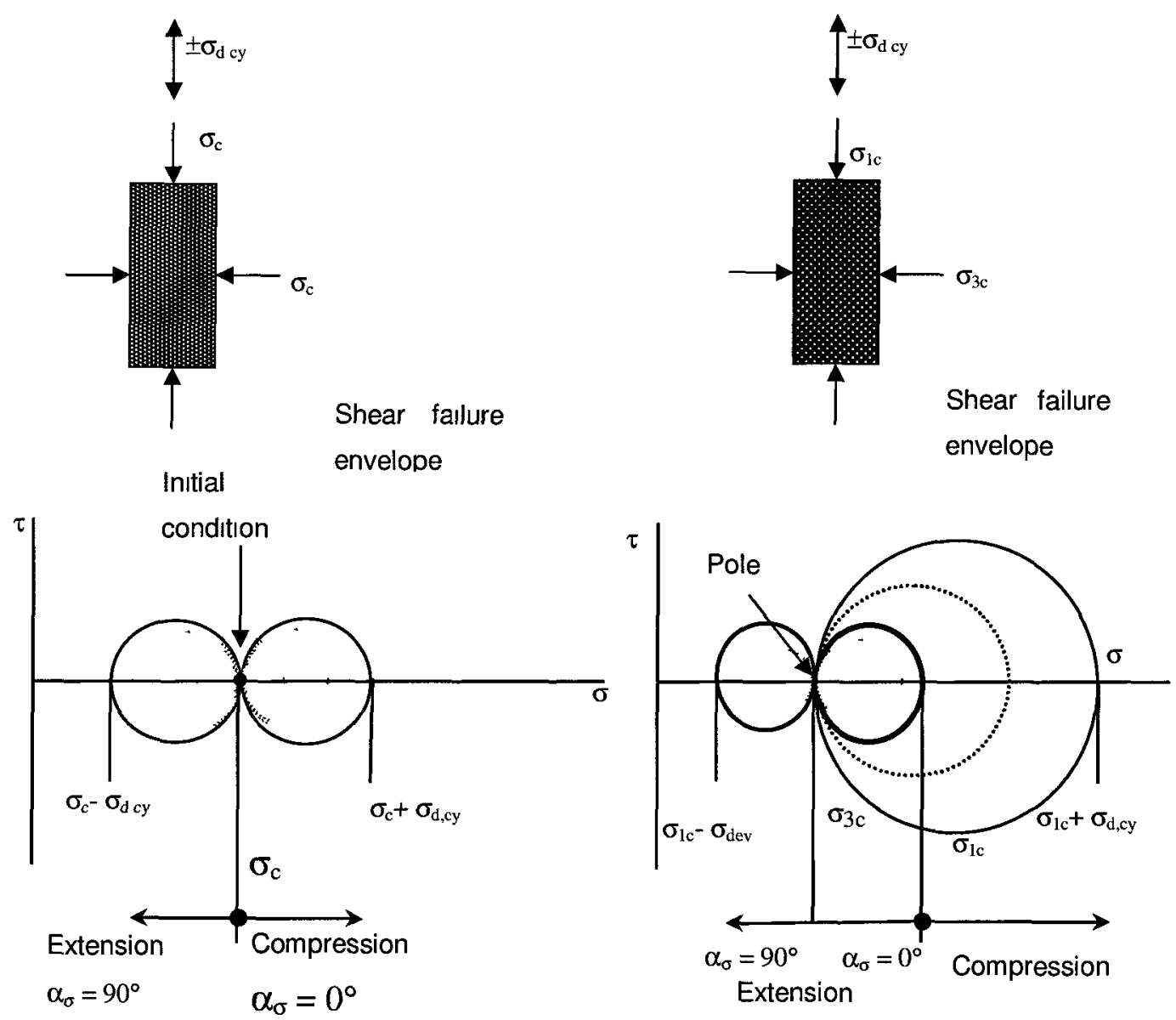

Fig. 3.1: The stress representation of triaxial in Mohr's circle.

\subsection{SIMPLE SHEAR TESTS}

A simple shear device simulates the in-situ stress conditions during earthquakes very well, and as a result is preferred in cyclic liquefaction studies. Typically, only the average vertical normal stress, and horizontal shear stress, and axial, shear strains are measured in a simple shear device. "NGI (Norwegian Geotechnical Institute) type" simple shear devices (Bjerrum \& Landva, 1966) that test short cylindrical specimens are widely used in practice. "Cambridge 
type" (Roscoe, 1971) simple shear device, which takes cubical specimens, and permits extensive instrumentation has provided much of the fundamental understanding required to interpret simple shear tests. Both NGI type and Cambridge type simple shear devices enforce plane strain conditions, and principal stresses rotate smoothly during loading, even though the rotation cannot be controlled.

Simple shear devices enable appropriate simulation of in-situ stress states during consolidation. Level ground conditions are represented by $K_{o}$ consolidation, and stress states on sloping ground (embankments, dams etc.) can be simulated by adding shear stresses on the horizontal plane during consolidation. Simple shear is recognized to simulate the stress conditions in-situ due to vertically propagating shear waves well, since the cyclic shear stress is applied on the horizontal plane. However, it limits principal stress rotation to within $\pm 45^{\circ}$, and does not direct the major principal stress along the weakest (horizontal) plane. This might raise concerns whether loading modes weaker than simple shear could be encountered in-situ, and in such cases whether designs based on simple shear characterizations could be unsafe.

\subsubsection{CU Simple Shear Device}

The simple shear device available at Carleton's geotechnical research laboratory is of the NGI type, and uses a steel reinforced rubber membrane to confine the sample and limit lateral deformations. The commercial device from Seiken Inc. (Model ASK DTC 148) has been rebuilt in-house to permit both stress and strain controlled loading during monotonic and cyclic tests.

A photograph of the simple shear device is depicted in Figure 3.2 . The $63.5 \mathrm{~mm}$ diameter specimen is typically about $20 \mathrm{~mm}$ in height. Such a small height to diameter ratio reduces the stress non-uniformities that arise due to the lack of complementary shear stress in a simple shear device. The steel wire reinforced rubber membrane enables $K_{0}$ consolidation, and permits constant volume testing during monotonic or cyclic shear loading. The vertical load is applied 
by a pneumatic piston located at bottom and measured by load cell fixed inside the frame. Horizontal stresses are not applied externally, and are mobilized depending on the constitutive characteristics of the material. Each soil can thus be tested at its natural state without a need to explicitly specify the horizontal stresses. This is a major advantage compared to triaxial tests, since tests at $K_{o}$ conditions are more representative of the field. Shear stress in this device can be applied by either a double acting pneumatic piston, or a stepper motor drive. Both vertical and horizontal forces were controlled by electronic transducers and monitored by using automated data acquisition system connected to a personal computer. Advanced electronic circuitry minimizes system noise, and stresses are measured with resolution better than $0.2 \mathrm{kPa}$, and strain with a resolution of about $0.01 \%$ up to $10 \%$ shear strain, and about $0.05 \%$ beyond.

This device allows maximum consolidation stress levels of $1600 \mathrm{kPa}$, and cyclic shear stress of about $\pm 250 \mathrm{kPa}$. The vertical and horizontal displacements were measured by using two LVDT's on the outside of the device. The use of two LVDTs enhances measurement resolution at low strains, and permit testing to larger strains. The top platen is connected to a relatively rigid cross beam, and the bottom platen can be clamped at to fix the height of sample. The end platens have thin ribs spaced evenly to ensure proper transfer of shear stresses and to prevent sliding during monotonic and cyclic loading.

\subsection{Hollow Cylinder Torsional Shear Tests}

A hollow cylinder torsional shear device is a versatile apparatus for measuring the mechanical behaviour of soils under generalized loading. The general outlook is similar to a traditional triaxial test, but the specimen is an annular ring, and thus permits application of internal pressure and torque (to control the shear stress on the horizontal plane), in addition to the external cell pressure and the vertical load. 


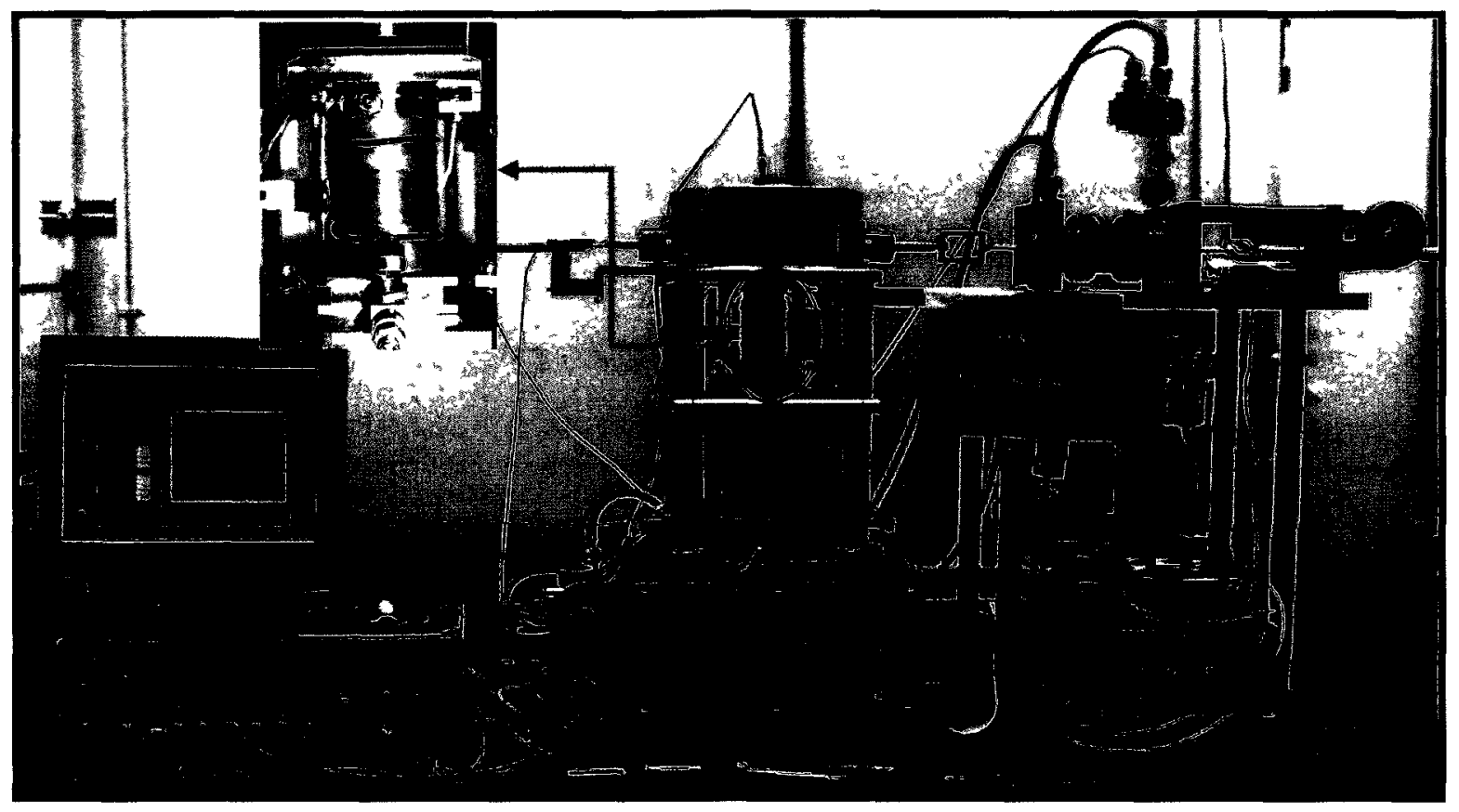

Fig. 3.2: $\quad$ Simple Shear device at Carleton University

These variables can be independently controlled, and thus this test permits independent control of the three principal stresses $\sigma_{1}, \sigma_{2} \& \sigma_{3}$ and the inclination $\alpha_{\sigma}$ of $\sigma_{1}, \sigma_{3}$ in one plane. Comparatively, a true triaxial test can control all three principal stresses, but it cannot enforce stress rotation. Traditional triaxial and simple shear tests can only control two independent parameters. Hollow cylinder tests have been in use for many years, but recent advances in data acquisition and control have enabled tests along relatively complex paths (Broms \& Casbarian, 1965; Hight et al., 1983; Sayao \& Vaid, 1988; Uthayakumar, 1995; Sivathayalan, 2000; Logeswaran 2010).

Shear stresses induced on account of torsion vary with radius, and thus hollow cylinder specimens typically use relatively thin walls (10-20\% of the diameter) to minimize shear stress non uniformities. In addition, differences between the internal $\left(\mathrm{P}_{\mathrm{i}}\right)$ and external $\left(P_{e}\right)$ pressures lead to a stress gradient across the wall. These pressures depend on prescribed test parameters, 
and are generally kept closer to each other to minimize the stress non-uniformities. Significant research efforts over the years have identified suitable sizing to minimize the stress nonuniformities (Symes 1985; Sayao, 1990).

\subsubsection{Stress and Strains in a Hollow Cylindrical Specimen.}

The three dimensional stress state in a hollow cylinder test can be conveniently described using a cylindrical coordinate system $(r-\theta-z)$. Vertical stress $\sigma_{\mathrm{z}}$, radial stress $\sigma_{\mathrm{r}}$ and tangential stress $\sigma_{\theta}$ define the normal stresses, and the shear stress on the z- $\theta$ plane, $\tau_{z} \theta$ represents the shear stress. As illustrated in Figure 3.3, vertical load $F_{z}$, torque $T_{h}$, external chamber pressure $P_{e}$ and inner chamber pressure $P_{i}$ are the actual surface tractions applied in the hollow cylinder test. Vertical stress $\sigma_{z}$ is readily calculated from the measured vertical load $F_{z}$ with appropriate consideration of the additional forces generated due to inner and outer chamber pressures as shown in equation 3.1.

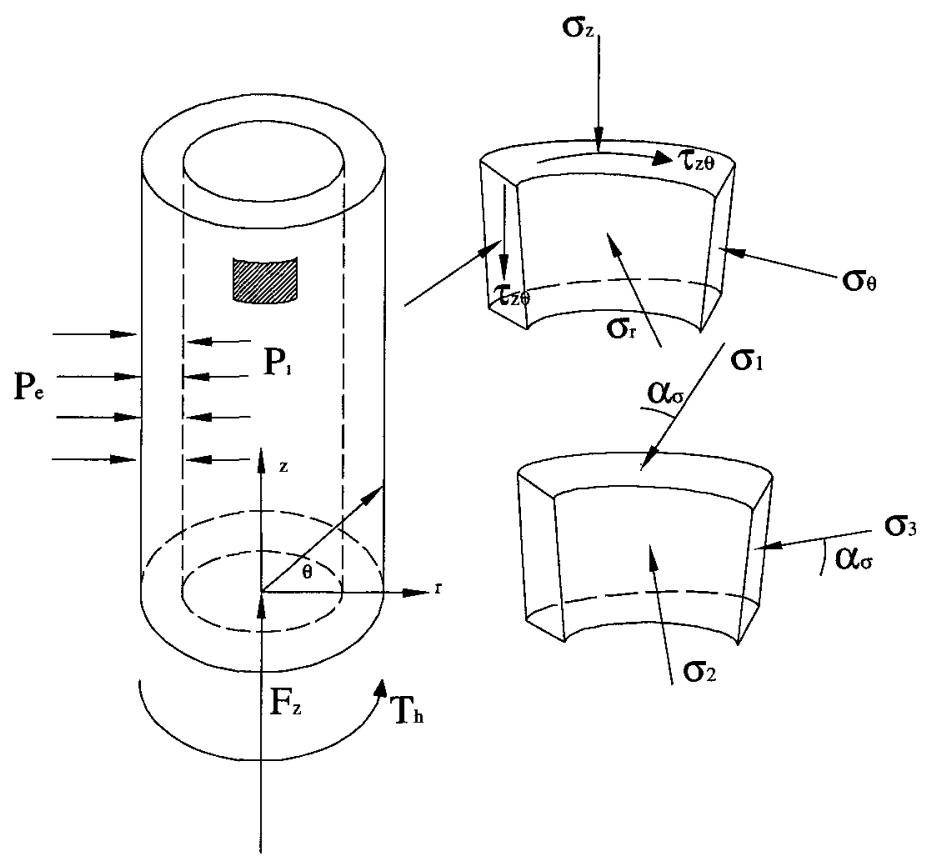

Fig. 3.3: $\quad$ Surface traction and stress state of soil element 


$$
\sigma_{z}=\frac{F_{z}+\pi\left(P_{e} \cdot R_{e}^{2}-P_{i} \cdot R_{i}^{2}\right)}{\pi\left(R_{e}^{2}-R_{i}^{2}\right)}
$$

The stress state in a thick cylinder subjected to pressures and torque cannot be solved using force equilibrium considerations alone, and a hence knowledge of the constitutive relations of the material is required to calculate the values of $\sigma_{\theta}, \sigma_{\mathrm{r}}$ and $\tau_{z \theta}$. Sayao (1989), and Wijewickreme (1990) showed that estimates based on the assumption of linear elastic response yield acceptable values. As noted earlier, $\sigma_{\theta}, \sigma_{\mathrm{r}}$ and $\tau_{z \theta}$ vary with the radius across the wall, and hence average values are used. Different formulations have been proposed in the literature to determine a representative average value, and those proposed by Vaid et al. (1990) considering force equilibrium, and shown in equations 3.2 to 3.4 are used in this research.

$$
\begin{gathered}
\sigma_{r}=\frac{\left(P_{e} \cdot R_{e}^{2}-P_{i} \cdot R_{i}^{2}\right)}{\left(R_{e}^{2}-R_{i}^{2}\right)}-\frac{2\left(P_{e}-P_{i}\right) R_{e}^{2} R_{i}^{2} \ln \left(\mathrm{R}_{\mathrm{e}} / \mathrm{R}_{\mathrm{i}}\right)}{\left(R_{e}^{2}-R_{i}^{2}\right)^{2}} \\
\sigma_{r}=\frac{\left(P_{e} \cdot R_{e}^{2}-P_{i} \cdot R_{i}^{2}\right)}{\left(R_{e}^{2}-R_{i}^{2}\right)}+\frac{2\left(P_{e}-P_{i}\right) R_{e}^{2} R_{i}^{2} \ln \left(\mathrm{R}_{\mathrm{e}} / \mathrm{R}_{\mathrm{i}}\right)}{\left(R_{e}^{2}-R_{i}^{2}\right)^{2}} \\
\tau_{z \theta}=\frac{4 T_{h}\left(R_{e}^{3}-R_{i}^{3}\right)}{3 \pi\left(R_{e}^{4}-R_{i}^{4}\right)\left(R_{e}^{2}-R_{i}^{2}\right)}
\end{gathered}
$$

Since no shear stresses act along the $r-\theta$ and $r-z$ planes, the radial direction becomes a principal stress direction. Under most loading conditions, radial stress $\sigma_{\mathbf{r}}$ becomes the intermediate principal stress (Sayao, 1989; Wijewickreme, 1990), and the major and minor principal stresses, and their direction are calculated from stress components $\sigma_{\mathrm{z}}, \sigma_{\theta}$ and $\tau_{z \theta}$ as shown in equations 3.5 and 3.6. 


$$
\begin{gathered}
\sigma_{1}=\frac{\left(\sigma_{z}+\sigma_{\theta}\right)}{2}+\sqrt{\frac{\left(\sigma_{z}-\sigma_{\theta}\right)^{2}}{4}+\tau_{z \theta}^{2}} \\
\sigma_{3}=\frac{\left(\sigma_{z}+\sigma_{\theta}\right)}{2}-\sqrt{\frac{\left(\sigma_{z}-\sigma_{\theta}\right)^{2}}{4}+\tau_{z \theta}^{2}} \\
\alpha_{\sigma}=\tan ^{-1}\left(\frac{\tau_{z \theta}}{\sigma_{z}-\sigma_{3}}\right)
\end{gathered}
$$

Stress state in a hollow cylindrical specimen can be specified in terms of $\sigma_{1}, \sigma_{2}, \sigma_{3}$ and inclination of the major principal stress $\alpha_{\sigma}$. However, it is common practice to represent the above four independent variables using derived parameters, mean normal stress $\sigma_{m}$, principal stress ratio $\mathrm{K}=\sigma_{1}^{\prime} / \sigma_{3}^{\prime}$, intermediate principal stress parameter, $\mathrm{b}=\left(\sigma_{2}-\sigma_{3}\right) /\left(\sigma_{1}-\sigma_{3}\right)$ and the inclination of major principal stress to the vertical axis $\alpha_{\sigma}$ for convenience. During consolidation these four surface tractions are controlled to target the required $\sigma_{m c}, K_{c}, b_{c}$ and $\alpha_{\sigma c}$ values (A subscript $c$ is used to denote stress states at the end of consolidation).

Similar to the stress components, four strain components are determined from the measured displacements and volume changes. Vertical strain $\varepsilon_{z}$, and shear strain $\gamma_{\mathrm{z} \theta}$ are calculated from the measured vertical displacement $\Delta H$, and torsional displacement $\Delta \theta$ as shown in equations 3.7 and 3.8, where $\mathrm{H}$ is the sample height, and $R_{e}$ and $R_{i}$ are the external and internal radii.

$$
\begin{gathered}
\epsilon_{z}=-\Delta H / H \\
\gamma_{z \theta}=\frac{2 \cdot \Delta \theta \cdot\left(R_{e}^{3}-R_{i}^{3}\right)}{3 H\left(R_{e}^{2}-R_{i}^{2}\right)}
\end{gathered}
$$


Tangential strain $\varepsilon_{\theta}$, and radial strain $\varepsilon_{\mathrm{r}}$ are calculated from the radii changes $\Delta \mathrm{R}_{\mathrm{e}}$ and $\Delta R_{i}$ as shown in equations 3.9 and 3.10. The change in inner radius $\Delta R_{i}$ is computed from the measured $\Delta H$ and volume change of the inner chamber $\Delta \mathrm{V}_{\mathrm{i}}$, and the change in outer radius $\Delta \mathrm{R}_{\mathrm{e}}$ is determined from the measured $\Delta H, \Delta \mathrm{V}_{\mathrm{i}}$ and volume change of the sample $\Delta \mathrm{V}_{\mathrm{s}}$.

$$
\begin{gathered}
\varepsilon_{r}=\left(\Delta R_{e}-\Delta R_{i}\right) /\left(R_{e}-R_{i}\right) \\
\varepsilon_{r}=-\left(\Delta R_{e}+\Delta R_{i}\right) /\left(R_{e}+R_{i}\right)
\end{gathered}
$$

The strain components $\varepsilon_{1}, \varepsilon_{2}, \varepsilon_{3}$ and $\gamma_{z \theta}$ permit the determination of the principal strains $\varepsilon_{1}, \varepsilon_{2}, \varepsilon_{3}$ and the inclination of the major principal strain to vertical, $\alpha_{\varepsilon}$ using calculations similar to those noted in stresses.

\subsubsection{CU Hollow Cylinder Torsional Shear Device.}

The relatively new hollow cylinder torsional shear device at Carleton University was custom made by AllpaTech Inc. by following the recommendations made by Vaid et al (1990) to minimize stress non-uniformities. It uses an advanced data acquisition system developed inhouse to enable tests along complex stress/strain paths during both monotonic and cyclic loading. A Schematic diagram of the CU hollow cylinder torsional device is depicted in Figure 3.4(a) and a photograph in 3.4(b). The nominal specimen height is $30 \mathrm{~cm}$, internal and external diameters $10 \mathrm{~cm}$ and $15 \mathrm{~cm}$ respectively, wall thickness of $2.5 \mathrm{~cm}$. This yields a cross sectional area of about $100 \mathrm{~cm}^{2}$ and sample volume of $3000 \mathrm{~cm}^{3}$. These larger dimensions enable better measurement resolution, and the geometry reduces stress non-uniformity to within the acceptable levels (Sayao, 1989).

The vertical load is applied by double-acting piston located at the bottom of the supporting table (Fig.3.6). Torsional load is applied by two pairs of identical torque-motors with belt 
guiding pulleys (Fig.3.6). The vertical and torsional loads are transferred to the specimen through polished stainless steel ram, and interface slip is prevented by the polished ribbed aluminum platens ( $1 \mathrm{~mm}$ thickness and $2.3 \mathrm{~mm}$ deep) placed on both top and bottom ends (Fig.3.5). The internal and external pressures are applied on rubber membrane with thickness of about $0.3 \mathrm{~mm}$. Drainage from the specimen is facilitated by six $12.8 \mathrm{~mm}$ diameter porous stones embedded 60 degree apart into the top and bottom platens (Fig.3.5). The inner volume, pore volume and vertical displacement can be controlled by using dedicated Digital Pressure/Volume Controllers (DVPC), or the corresponding pressures using electro-pneumatic transducers or regulators.

\subsubsection{Measurement and control of stresses and strains}

CU HCT device uses nine input channels, and seven output channels to monitor and control the stress/strain state during the test. The input channels are used to monitor the internal pressure, external pressure, pore pressure, vertical load, torque, vertical displacement, torsional displacement, inner chamber volume change and sample volume change. Three of the output channels are used to control the inner chamber pressure, external chamber pressure and the vertical load using electro-pneumatic transducers which leads to stress controlled loading. The other four output channels are used for strain controlled loading, and can control vertical displacement, inner chamber volume, sample volume and torsional displacement. Internal, external chamber pressures, and pore pressure are directly measured using precision pressure transducers (PT). Vertical load and axial torque are measured using a strain-gauge type load cell and torque cell respectively. Inner chamber and sample volume changes are recorded using differential pressure transducers (DPT), and both vertical and torsional displacements are measured using as Linear Variable Displacement Transducers (LVDT). 


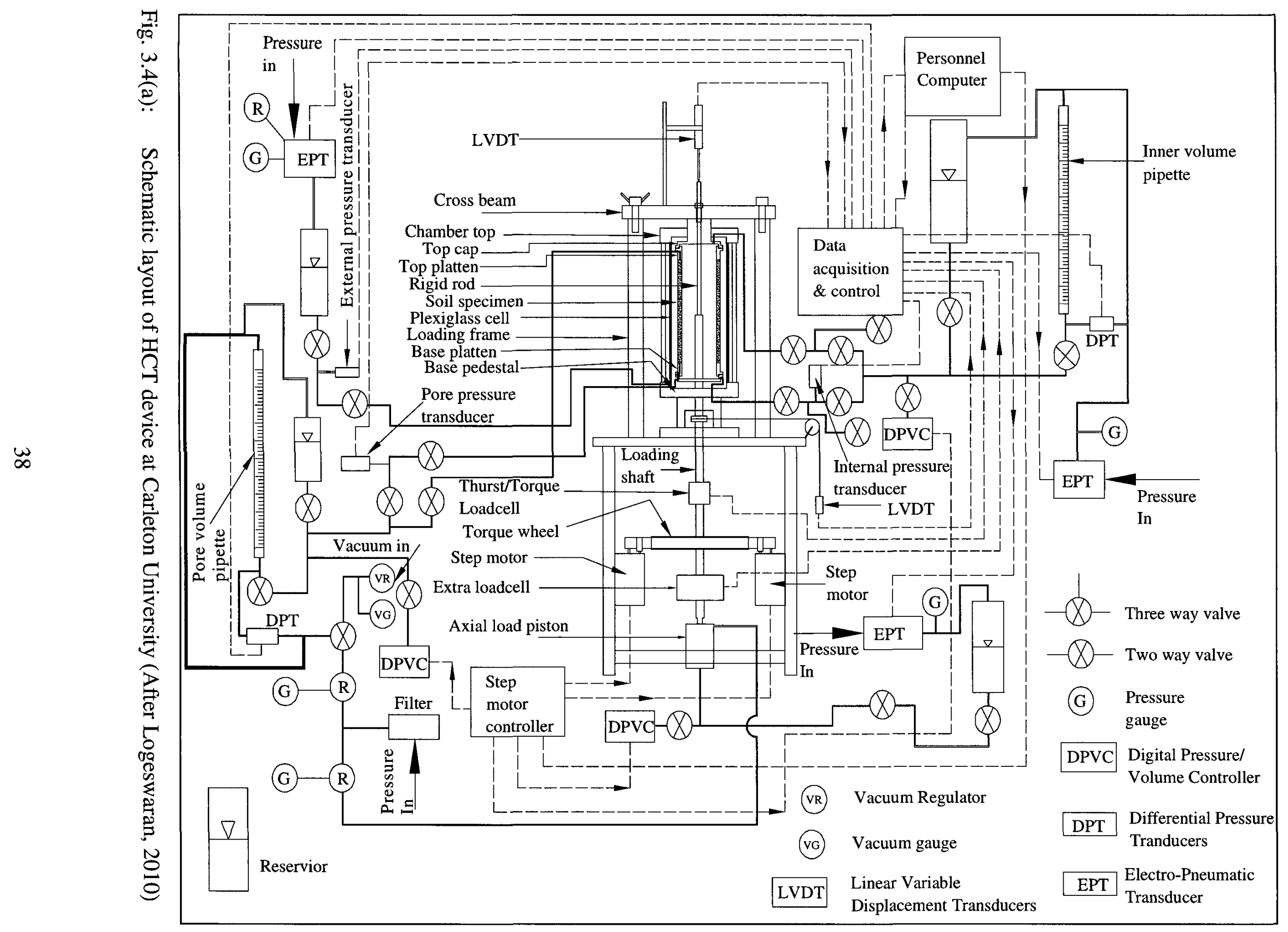




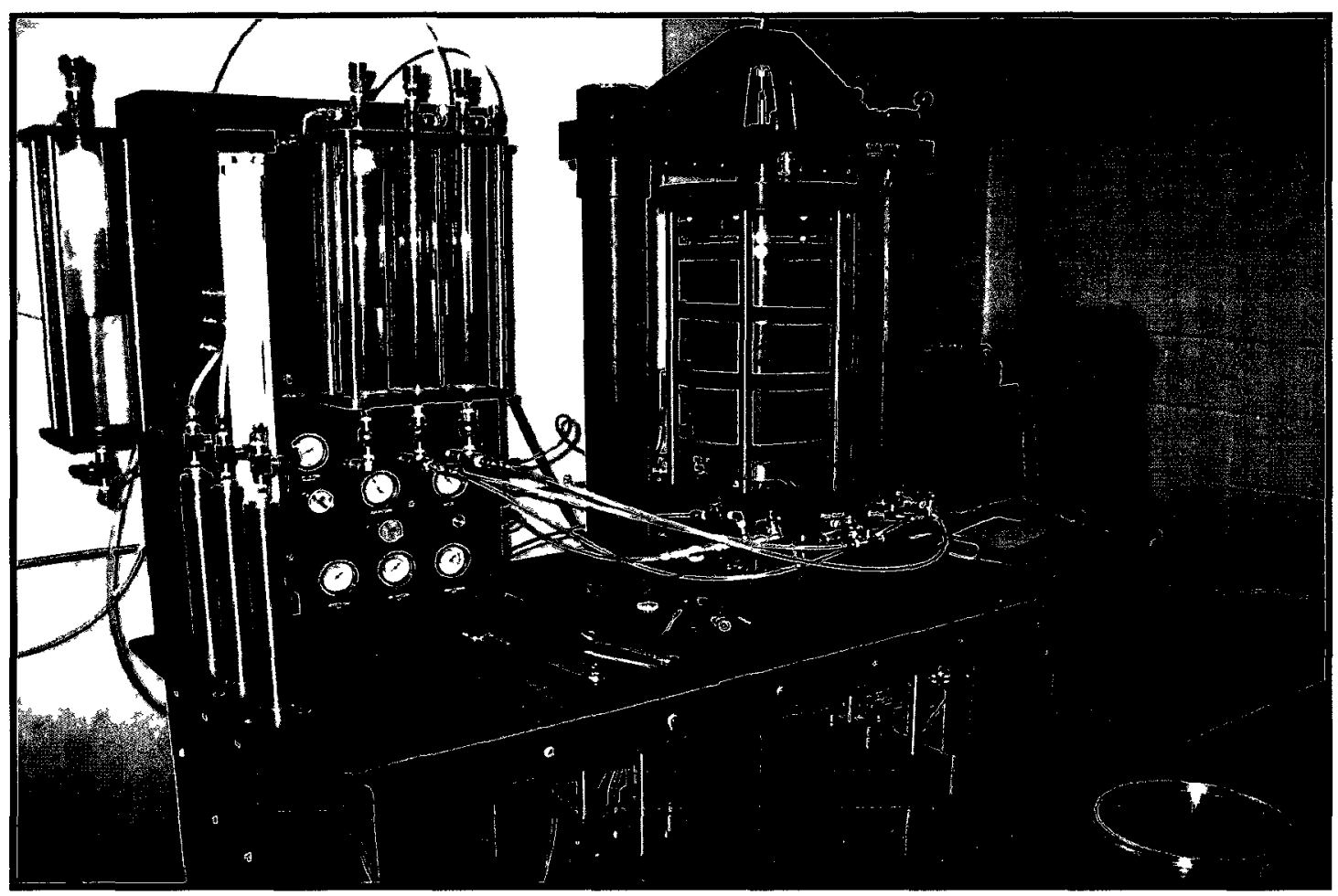

Fig3.4 (b): Hollow cylinder torsional device at Carleton University

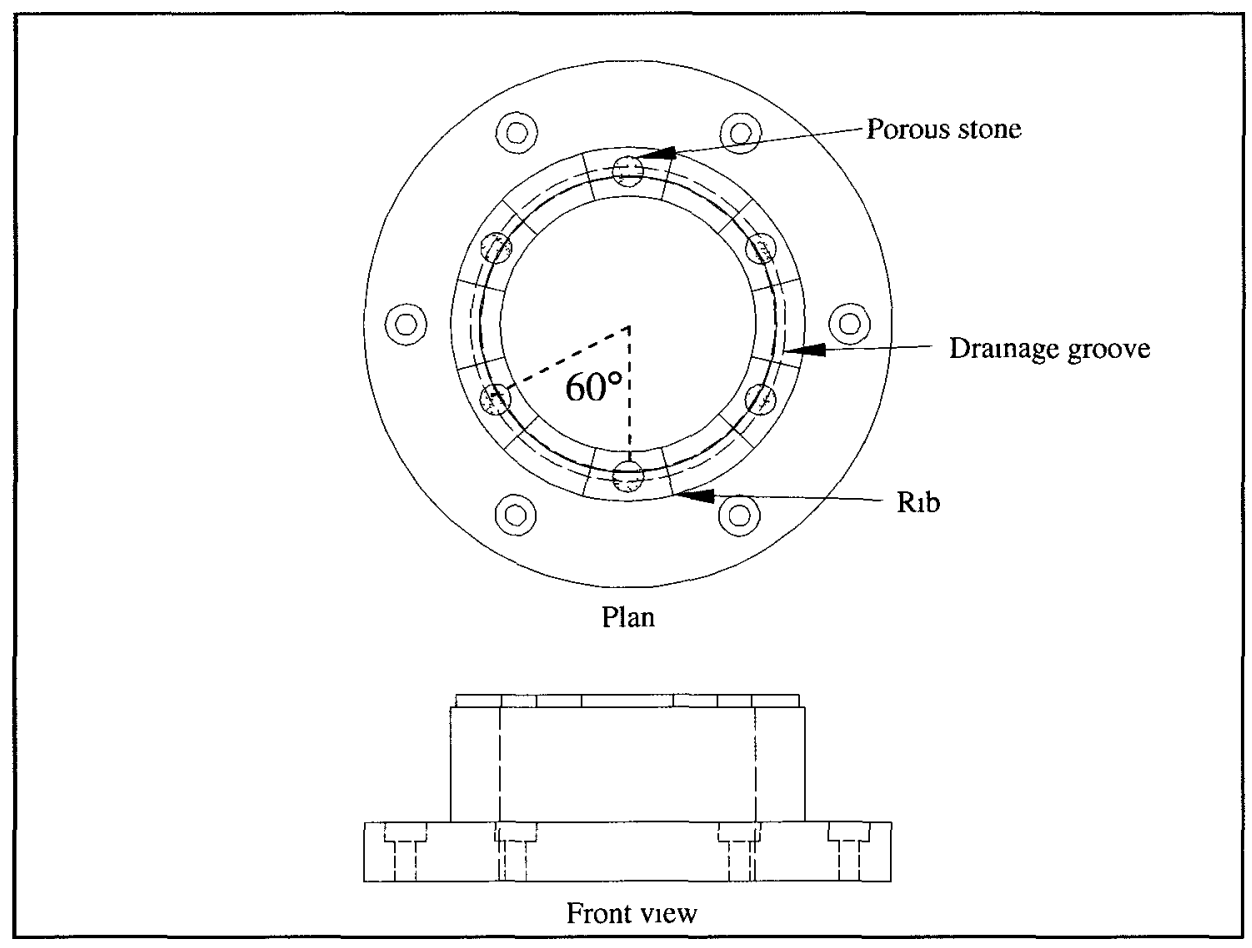

Fig. 3.5: Porous stones embedded into end platen with radial ribs (After Logeswaran 2010) 


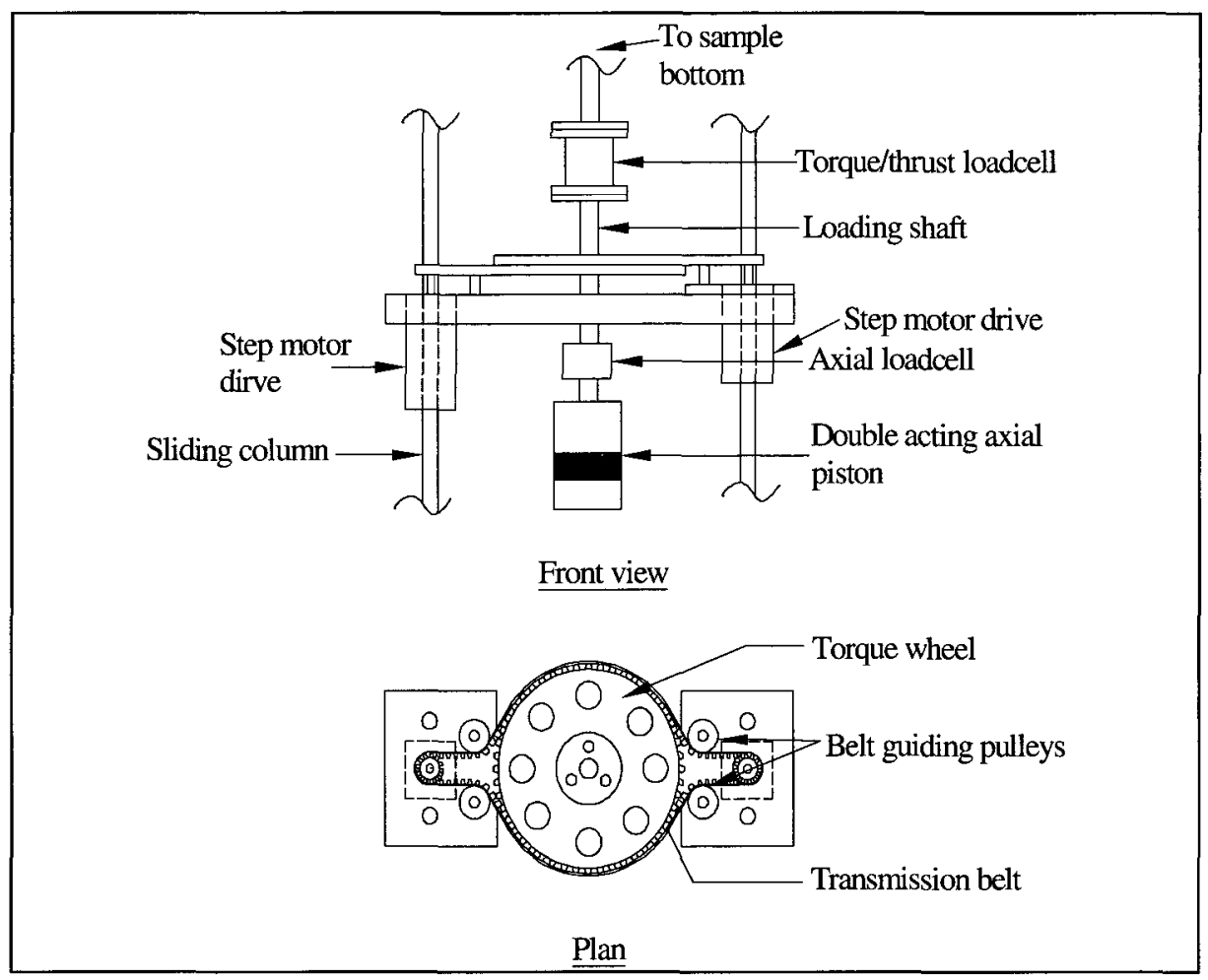

Fig. 3.6: $\quad$ Vertical and Torsional load applying system (After Logeswaran 2010)

The vertical LVDT which is mounted above the cross beam, acts due to the movement of a thin vertical rod connected to the base pedestal along the axis of the cylinder, and measures the total height change across the specimen. The torsional LVDT is used to measure the torsional displacement by converting the rotation of a log arm into a linear tangential displacement.

\subsubsection{Measurement resolutions}

The precision pressure transducers have a resolution of better than $0.1 \mathrm{kPa}$, and hence the resolution of pore, internal and external pressures are $\pm 0.1 \mathrm{kPa}$. The vertical load and torque measurements are made with a thrust/torque cell which has the ability to measure both vertical and torque loads. The cross-talk between the measurements is negligibly small. Vertical load cell can detect a change of about $1 \mathrm{~N}$, and the torque cell about $0.05 \mathrm{Nm}$. While these directly translate to about $0.1 \mathrm{kPa}$ in vertical stress and $0.01 \mathrm{kPa}$ in shear stress, the actual resolution of 
the measurements is about $\pm 0.5 \mathrm{kPa}$ in vertical stress and torsional shear stress due to electrical noise/interference. The LVDTs used in the system can detect displacements in the order of $10^{-3}$ $\mathrm{mm}$, and these translate to axial strain $\varepsilon_{z}$ and shear strain $\gamma_{z \theta}$ resolutions of about $5 \times 10^{-4}$ and $5 \times 10^{-4}$ respectively. The differential pressure transducers can detect $1 \mathrm{~mm}^{3}$ volume change, and thus leads to a volumetric strain resolution of $10^{-4}$.

\subsubsection{Stress/strain controlled loading systems}

A stress controlled loading system is generally simpler and permits prescribed stress paths to be followed with ease. However, it cannot properly measure the post-peak response in strain softening sands. A strain controlled loading system enables proper characterization of strain softening materials. Prescribed stress paths using strain controlled loading will have to be followed by using a closed-loop feedback system. The stress-controlled loading system in the CU HCT device is controlled by three Electro-Pneumatic transducers (EPT) that control the axial load piston, inner chamber and external chamber pressures. Two stepper motors mounted at the bottom of the supporting table control the torque (Figure 3.6).

Strain controlled loading in CU HCT device is accomplished by using the torque motor and/or the three of digital pressure-volume controllers (DPVC) which are connected to vertical loading piston to control vertical displacement, inner volume, and sample volume in order to produce desired radial and tangential strains. Menzies (1987) pioneered the use of DPVCs in geotechnical research, which simply consists of a water saturated cylinder, and a piston with attached ball screw moved by stepper motor to provide displacement or volume control. 


\subsubsection{Data acquisition system}

Three National Instruments data acquisition and control interface cards (PCI-6052E, PCI6601, and PCI-6703) installed in the personal computer are connected to the signal conditioner and the stepper motor controller. The system consists of five stepper motors, three of which control the DPVCs and the remaining two controls the torque loading system. The MSC-10 provides excitation, amplification, and filtration for the different transducers used, and consists of six analog outputs, three of which are directly attached to the HCT device in order to control the three EPTs. Additional channels are available for future expansion. A multithreaded data acquisition program was developed in-house in order to acquire the data and control the system. Multiple execution threads within a single process enable smooth operation of hardware and proper sampling of input channels without interruption or delay. A lot of care was taken in selecting this hardware keeps low noise level, accurate measurements and application of tractions. 


\section{EXPERIMENTAL WORK}

\subsection{INTRODUCTION}

Monotonic and cyclic undrained tests were conducted on reconstituted sand specimens to achieve the objectives identified in Chapter 1. Cyclic tests conducted using hollow cylinder device were intended to provide insights into the effects of stress rotation, and to assess the general perception that simple shear device is the most appropriate for liquefaction susceptibility assessment. A very comprehensive research program was undertaken under the simple shear mode to assess the effects of prior stress history on liquefaction susceptibility. This chapter provides details of the test materials, and experimental work including specimen reconstitution techniques, specimen assembly, and testing methods.

\subsection{MATERIAL TESTED}

Hollow cylinder tests were conducted on Fraser River sand (FRS), which predominantly has semi-angular particles. Simple shear tests were conducted on two sands; Fraser River sand, and Silica sand which predominantly has sub-rounded particles. The compositional characteristics of soils are known to significantly influence their behaviour. Both of these sands are fairly uniform, and the main difference between them would be the particle shapes. 


\subsubsection{Fraser River Sand}

Most of the tests in this research program were conducted on sand dredged from the Fraser River near Abbotsford in British Columbia. This sand underlies large portions of the heavily populated and seismically active lower mainland, and its seismic performance is of direct practical interest. The dredged material consisted about $2 \%$ of fine material passing \#200 sieve, and essentially no particles larger than $0.85 \mathrm{~mm}$. The sand was processed by wet-sieving and any particles retained on \#20 sieve $(0.850 \mathrm{~mm})$ and passing through \#200 sieve $(0.074 \mathrm{~mm})$ were discarded. This would minimize particle segregation and thus produce uniform specimens. Particle size distribution of the tested sand is shown in Figure 4.1. The average particle size $D_{50}$ is 0.28 , uniformity coefficient $C_{u}$ is $2.92(<4)$, specific gravity $\left(G_{s}\right)$ is 2.72 and coefficient of curvature $C_{c}$ is 1.27 (Logeswaran 2010). The maximum and minimum void ratios of this sand were determined using ASTM standard tests methods. The maximum void ratio, $e_{\max }$ was determined to be 0.806 (ASTM D4253, 2001) and the minimum void ratio, $e_{\min }$ was determined to be of 0.509 according to ASTM D4254 (2001b).

\subsubsection{Silica Sand}

The Silica sand used in this study conforms to the ASTM C-778 designation, and was dredged from the deposits of the Illinois River in the United States. This sand is fairly similar to the widely used Ottawa sand in the literature, and is poorly graded (well sorted) with subrounded quartz particles. The specific gravity of the Silica sand is 2.66 according to ASTM D854. Average particle size, $D_{50}=0.43 \mathrm{~mm}$, uniformity coefficient $C_{u}=1.93$, and coefficient of curvature, $C_{c}=1.15$ were obtained from particle size distribution plot depicted in Figure 4.1 on the basis of sieve analysis accordance with ASTM D422. The maximum and the minimum void ratios, determined using ASTM D4252 and D4253, are $e_{\max }=0.723$ and $e_{\min }=0.478$. 


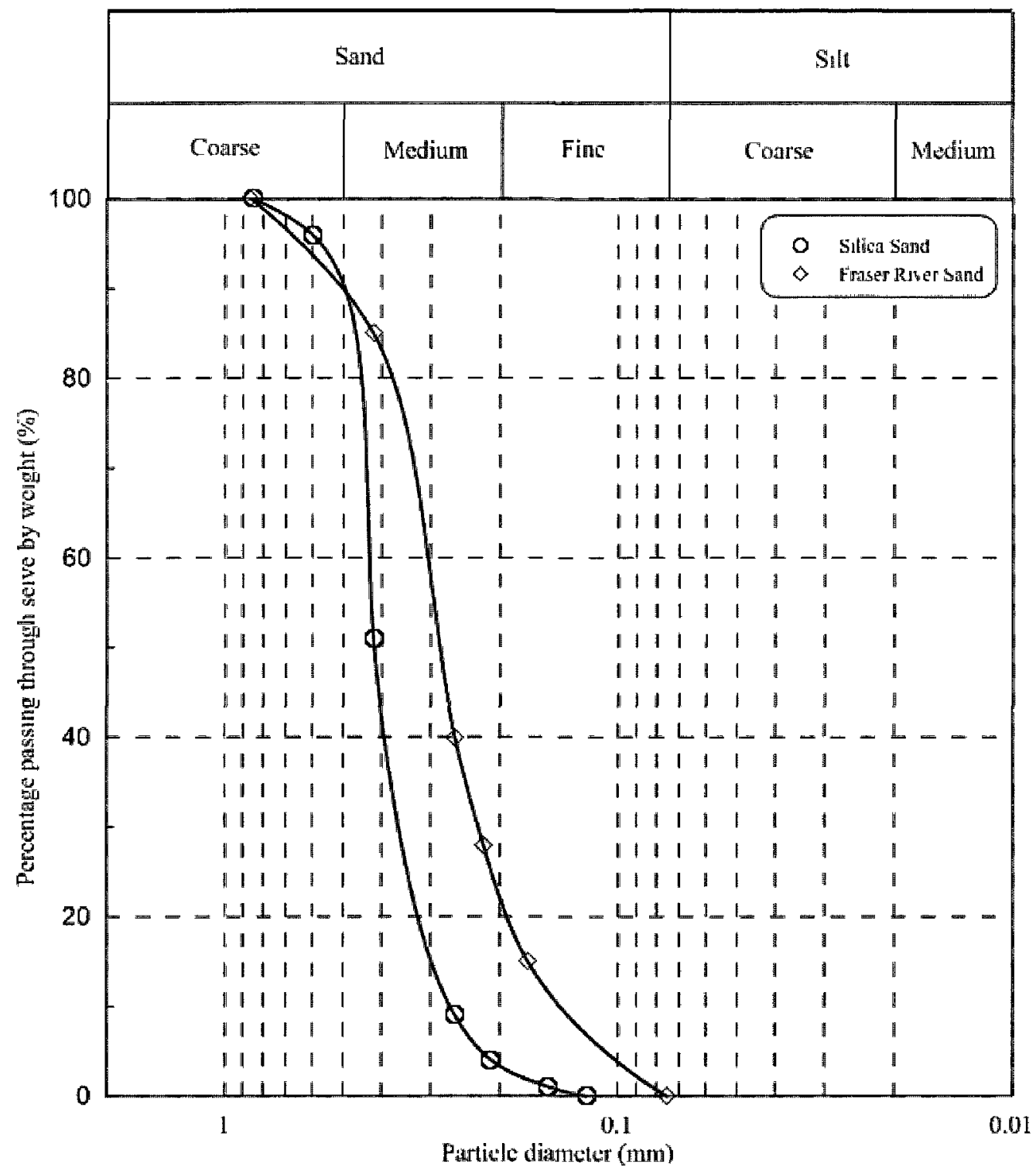

Fig.4.1: $\quad$ Grain Size distribution of Fraser River sand, and Silica Sand

\subsection{SPECIMEN Preparation}

Soil specimens tested in the laboratory are presumed to represent elements of in-situ soil. It is therefore essential that laboratory specimens are as homogeneous as possible. Several specimen reconstitution methods (e.g., moist tamping, dry pluviation, water pluviation, slurry deposition) have been used in laboratory testing over the years. The ability of the method to 
produce homogeneous and repeatable specimens of the studied material is a fundamental requirement, and in most cases the adopted reconstitution method is chosen to meet this requirement. However, undrained behaviour of soils is profoundly affected by the soil fabric, and it is known that different reconstitution methods give rise to different fabric. Therefore, the reconstitution method adopted in the laboratory should simulate the natural deposition process, if the laboratory tests results are to be applied to in-situ soils with confidence. Both air and water pluviation methods produce repeatable and homogeneous specimens and thus are well suited to fundamental studies that require several identical specimens. Specimens of clean sands pluviated in air and water have been shown to yield similar behaviour (Finn et al. 1977), but obtaining full saturation in air pluviated specimens in a difficult, and time consuming process.

Specimens reconstituted by wet pluviation have been shown to duplicate the behaviour of fluvial soil deposits (Vaid et al. 1999). In addition, undrained tests require fully saturated specimens for appropriate generation of excess pore water pressure during shearing, and water pluviated specimens have a great advantage in this regard. Thus, all specimens in the hollow cylinder tests were prepared by water pluviation. $\mathrm{CU}$ simple shear device permits undrained shear at constant volume and thus saturation is not a requirement even in tests that simulate the undrained deformation (Finn \& Vaid, 1977). As a result all simple shear specimens were reconstituted using dry pluviation since it is a faster method compared to water pluviation. Both sands tested in this study are fairly uniform, with essentially no silt or clay sized particles (Figure 4.1), and thus would yield similar fabric regardless of whether they were deposited in air or water. The measured responses should therefore be comparable, and applicable to natural soils deposited under gravity in hydraulic environments. 


\subsubsection{Specimen Preparation in HCT}

The CU HCT device uses relatively larger specimen dimensions to enhance measurement resolutions and confidence. As noted earlier, all specimens are prepared using water pluviation.

The specimen cavity is about $3000 \mathrm{~cm}^{3}$ and thus each test requires about $4-5 \mathrm{~kg}$ of soil (depending on void ratio), and about 15 liters of de-aired water. The typical test preparation procedure involving the preliminary steps (a day before the actual test), and the test set-up details are provided below.

\subsubsection{Preliminary Steps}

A known weight of sand (around $5000 \mathrm{~g}$ ) was boiled for about 30 minutes in four flaks to remove air entrapped between soil particles. The flask was then filled with de-aired water and the top of the flask was covered in order to prevent air contact, and was allowed to cool under room temperature. All porous stones used in the tests were also boiled to expel entrapped air and allowed to cool in water at room temperature. The porous stones and the sand were not allowed to come in with significant air contact until after the test was completed to facilitate better saturation. Adequate amount of de-aired water was prepared either by boiling the water and then allowing it to cool down to room temperature, or by using the $N$ old de-aerator device. Once deaired the water was kept in sealed containers under suction. Both the inner membrane and outer membranes were checked to ensure they were not punctured. The O-rings used in the system (two each to hold the inner and outer membranes, two to seal the top and bottom platens to the bases, and one on the bottom platen and two on the top platen that facilitate drainage and saturation) were checked to ensure they have no damage. 


\subsubsection{Specimen preparation steps}

All drainage and pressure lines were flushed by de-aired water until all air was removed. The reference height reading was taken on a sample block with known height using a dial gauge to enable accurate determination of the initial sample height, and the data acquisition program was started and appropriate reference offset reading were noted. An inner rubber membrane was positioned on the inner surface of bottom platen, and held in place by using an O-ring. The inner cavity was created by assembling the four-piece split mould, and the space enclosed between the membrane and the bottom platen was filled with water to minimize system compliance. The inner former was held together with the membrane at the bottom by a thick internal metallic ring that snugly fits to the axial shaft, and at the top by an annular platen and by an O-ring. Bottom platen was fixed to the base of the device at this stage by using six evenly spaced screws. Deaired water was circulated through the bottom drainage lines to saturate the base platen, and porous stone cavities. Six porous stones were transferred to the water filled cavities from the water filled container. A small amount of de-aired water was allowed to drain through the porous stones and flood the top surface of the bottom platen. The outer rubber membrane was positioned at this stage, and sealed with outer surface of bottom platen using O-ring(s).

The two-piece split outer mould was carefully placed (to avoid damaging the membrane) and the membrane was flipped over the mould at the top, and held in place by an O-ring, prior to the application of a small amount of suction. The inner surface of the outer mould is lined with porous plastic, and pulls the outer membrane taut under the applied suction. This created a smooth membrane lined annular cavity, which was filled with de-aired water. An extension container was placed on the outer mould to facilitate pluviation and level of the top surface. The flask, which contains boiled sand, was inverted and the sand was deposited in the annular cavity under gravity through mutual displacement of water and sand particles. The submerged tip of 
flask was slowly moved along annular area to deposit the sand with approximately level surface at all time during water pluviation. The set up related to the deposition process is illustrated in Figure 4.2.

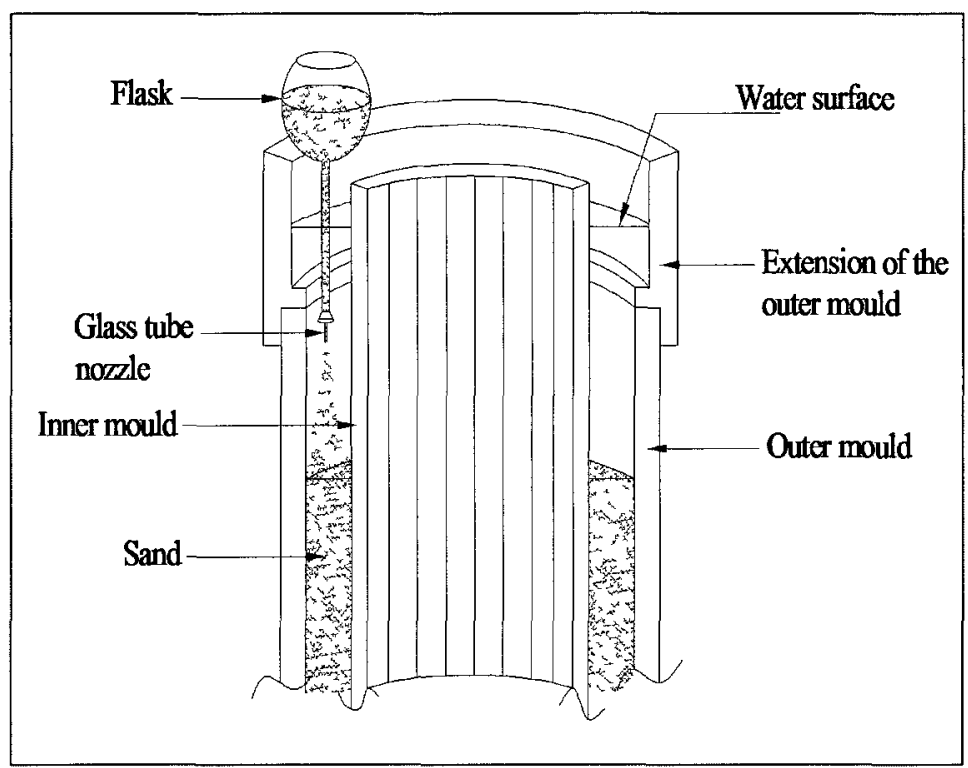

Fig. 4.2: $\quad$ Specimen preparation by water pluviation

The final velocity of falling soil particles was reached within shorter depth; therefore, the dropping height does not affect the density significantly (Vaid and Negussey, 1988). Deposition was continued until required level reached, and then the top surface was leveled by siphoning off the excess sand using a small suction. This produces the best means of ensuring a leveled surface with minimal disturbance. The excess sand was oven-dried and weighed to obtain the amount of sand used, which is a key parameter when calculating the density or void ratio.

The bottom half of the top platen with saturated porous stones was carefully seated on the top levelled surface. The dial gauge was set in place to provide the initial reading, and continuous monitoring of the height changes from this stage forward. De-aired water from the 
pore water reservoir was allowed to percolate slowly upwards through the specimen with small gradient to remove entrapped air bubbles between the outer wall of the top platten and the outer membrane. The gradient has to be very small to avoid piping at the top of the specimen. The outer membrane was flipped on to the top platen and sealed with an O-ring. The drainage ports of the top platens were opened, and de-aired water was allowed to percolate again slowly upwards through the specimen with small gradient to remove entrapped air bubbles between the top platen and the specimen, and between the inside wall of the top platten and the inner membrane. After saturation the ports were closed, and the inner membrane was flipped, and sealed using O-rings. Approximately $20 \mathrm{kPa}$ suction was applied at this stage through the bottom drainage line to provide an effective confinement stress, prior to removing the moulds. The effective stress provided by the suction ensures that the sample can stand on its own when the outer and inner moulds are removed. The top half of the top platen was then placed, and tightend to the bottom half using six evenly spaced screws. The initial values of inner and outer diameters used in calculations were determined based on mass measurements as suggested by Vaid \& Sivathayalan (1996b). The outer diamter of the specimen was determined using circumferencial measurement, and compared to the previously established values for confirmation.

The cell chamber was placed in position and de-aired water was filled in inner and outer chamber at approximately the same rate to avoid disturbing the specimen. The inner chamber has to be well saturated to improve the accuracy of volume measurements. The top cross beam was swivelled into position and fixed by threaded bolt to the reaction frame. The central rod, which is used to record the vertical displacement was installed to seal the inner chamber. The specimen was moved up until the top cap contacts the cross beam by pressuring the bottom chamber of 
vertical loading piston. The top cap was attached with cross beam by a bolt in order to ensure vertical alignment of the axes of the specimen and the frame. The two locating pins protruding from the cross beam were inserted into loading cap in order to prevent rotational movement during the application of torque loading. The total height changes, and volume changes were tracked up to this point to yield the height, diameter and volume of the specimen at the end of the set up. All stresses, and deformations are monitored continuously through the data acquisition program from this stage forward. The specimen was made undrained, and about $25 \mathrm{kPa}$ pressure was applied to the inner and outer chambers to bring the pore pressure in the specimen close to or just above atmospheric with no pressure.

\subsubsection{Test Procedure}

The first step in an undrained hollow cylinder test is to confirm that the prepared specimen is fully saturated prior to shear. This was confirmed by measuring Skempton's B value, which is the ratio of the generated pore pressure to the applied hydrostatic (all-around) stress increment, $\Delta u / \Delta \sigma$. Good saturation levels were noted in most tests, which is typical in water pluviated specimens. Lower saturation levels due to entrapped air occurred in some tests and these were rectified by back pressure saturation which is a common technique. A Skempton's B-value greater than 0.99 was required, and achieved before testing a specimen.

Specimens were consolidated to the target initial stress state following the B-value phase using an automated consolidation routine. The desired target stress state, and the required number of increments, and loading rates were prescribed in the data acquisition and control program prior to activating the consolidation module. All hollow cylindrical specimens were consolidated to a hydrostatic effective stress state of $200 \mathrm{kPa}$ in this research. The consolidation stresses were applied slowly, in $25 \mathrm{kPa}$ increments followed by a five minute wait until reaching 
the effective stress state of $200 \mathrm{kPa}$. Each $25 \mathrm{kPa}$ increment was applied in three minutes in ten increments (2.5 kPa per 18 seconds). Such a step-wise loading was considered appropriate to ensure that the loading closely follows the prescribed paths. While this may not be critical in hydrostatic consolidation, it would be relevant when specimens are consolidated to generalized stress states.

The required undrained cyclic loading path was followed using feedback controlled loading and adjusting three of the four tractions. The fourth traction component that corresponds to independent variable was selected to improve the sensitivity of the control program. Vertical displacement, applied using the DPVC was used as the independent variable when the maximum inclination of the principal stresses were between 0 and 15 degrees, or when they were between 75 and 90 degrees. Torque motor was used as the independent control when the maximum inclination of the principal stress was between 15 and 75 degrees. Stress state based feedback control using EPT regulators was used whenever possible. Target torsional shear stresses were achieved by using a closed-loop strain control of the torque motor to target the stresses. This necessitated the use of relatively slower loading rates, and all cyclic tests reported herein were conducted at the rate of 240 seconds per cycle.

\subsubsection{Specimen Preparation in Simple Shear Test}

Specimens were reconstituted by air pluviation in simple shear. The $63.5 \mathrm{~mm}$ diameter simple shear mould yields a specimen of about $63 \mathrm{~cm}^{3}$, and about $100-110 \mathrm{~g}$ of soil is used in each test. A dummy sample block of known height is initially used to establish a reference height using a dial gauge. Unlike in the hollow cylinder test, the specimen in simple shear is prepared away from the apparatus, and then moved into place. 


\subsubsection{Specimen preparation steps}

The steel-wire reinforced membrane was placed on the bottom pedestal and sealed with an O-ring. The split sample former was placed around the membrane, and the top of the membrane was flipped and covered by the top brass ring. This top ring holds the membrane in place, and facilitates the leveling of the top surface. Approximately $20 \mathrm{kPa}$ of suction was applied through the ports to hold the membrane in place, and create the membrane lined cavity. About 130g of soil was pluviated in air through a funnel that was traversed across the surface to maintain an approximately level surface during deposition. After deposition, the excess soil was siphoned off as illustrated in Figure 4.3(a) to create a leveled top surface, and obtain the actual weight of the soil used. The top cap was then placed and the first height reading was taken at this stage. The membrane flipped and sealed using an O-ring and the height of the specimen was monitored at each stage (Figure $4.3 \mathrm{~b}$ ).

The void ratio of the specimen can be controlled through the drop height, and/or falling rate of soil particles during deposition. However, an essentially zero drop height was used in all tests, and denser states when needed were achieved by tapping the table using a wooden soft hammer after placing the top cap. The dial gauge on the top cap was used to continually monitor the density changes during this vibration process, and allows targeting desired density states. The data acquisition program was started and required reference offset values were taken prior to moving the specimen to the simple shear apparatus.

\subsubsection{Test Procedure}

The pressure in the vertical loading piston was slowly increased to a small value to move the specimen and the mould up to make contact with the top loading plate. A seating load of about $10 \mathrm{kPa}$ was applied prior to removing the split mould. Most of the tests were conducted on 
specimens consolidated to specific vertical stress levels without initial static shear. Vertical stress was adjusted manually in increments until reaching the target stress state which varied from $100 \mathrm{kPa}$ to $1600 \mathrm{kPa}$. A load increment ratio of two $(\Delta \sigma=2)$ was used when possible until reaching the target vertical stress, and the sand was allowed to consolidate for about 10 minutes under each load increment. Overconsolidated states were achieved by loading the materials to the higher effective stress prior to unloading to the final consolidation stress level.
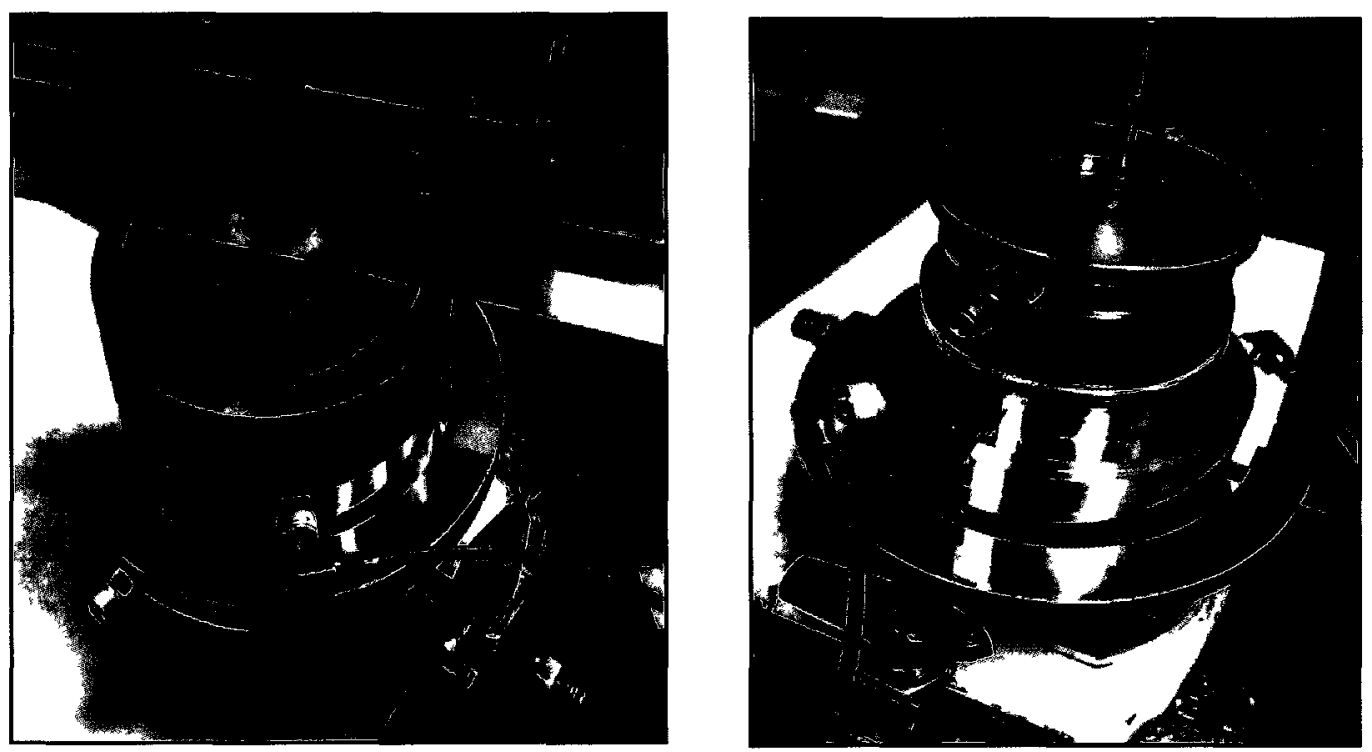

Fig. 4.3: $\quad$ Sample preparation during (a) siphoning and (b) with top cap in place

Initial states with static shear were realized by using a feedback controlled routine to apply the target shear stress. Target shear stress was prescribed as the ratio $\alpha=\tau_{\mathrm{st}} / \sigma^{\prime}{ }_{\mathrm{vc}}$, and the vertical stresses were manually increased as before. However, the DAQ program automatically adjusted the shear stress on the horizontal plane to maintain the required $\alpha$ ratio throughout the consolidation process. $\alpha$ values of $0.1,0.2$ and 0.3 were in specimens consolidated to $100 \mathrm{kPa}$ vertical confining stress 
Monotonic and cyclic shear were applied under constant volume conditions. As discussed previously, the change in total vertical stress in constant volume tests equals the excess pore pressure generated in undrained test (Dyvik et al., 1987). Constant volume state was realized by arresting the vertical deformation (using the locking clamp) in the specimen contained within the reinforced membrane. Monotonic shear was imposed under displacement controlled loading at a constant shear strain rate of $12 \%$ per hour. Cyclic shear stress was applied under load controlled loading mode, at a frequency of about $0.1 \mathrm{~Hz}$, and each stress cycle was made of 128 points. The frequency of loading was not a concern since it has a little influence on the truly undrained response of sands (Yoshimi and Oh-Oka, 1975). Cyclic loading was terminated by the DAQ program when the shear strains exceeded 3.75\%. Post cyclic undrained shear was applied under stain controlled loading at the rate of $12 \%$ shear strain per hour.

\subsection{Test Program}

A limited number of cyclic hollow cylinder torsional shear tests were conducted on Fraser River sand. The scope of the research program using simple shear was quite extensive, and included monotonic, cyclic and post cyclic tests on both Fraser River and silica sands. Details of the tests, and tables identifying the test parameters are provided below.

\subsubsection{Hollow Cylinder Tests}

Hollow cylinder torsional shear tests were conducted on the loosest deposited Fraser River sand hydrostatically consolidated to a mean normal effective stress, $\sigma_{m c}^{\prime}=200 \mathrm{kPa}$. Sand specimens were reconstituted using water pluviation, to simulate the natural deposition process in fluvial environments, and to ensure full saturation. Measured Skempton's B-value exceeded 0.993 in all tests, and was considered evidence of adequate levels of saturation. The final consolidation stress state corresponds to a total hydrostatic stress level, $\sigma_{m c}=450 \mathrm{kPa}$ and a 
back pressure, $u_{0}=250 \mathrm{kPa}$. The relative density at the end of the consolidation was about $22 \%$ in all tests.

Cyclic shearing was imposed on sand at the desired cyclic stress ratio, and the direction of the principal stresses during cyclic loading was varied either smoothly with the shear stress on the horizontal plane, or held constant and switched by a sudden jump when the direction of the shear stress changed. Details about the stress rotation mechanisms are discussed in chapter 5. The total mean normal stress $\sigma_{m c}$ was held constant during cyclic loading. Feedback controlled loading was used to apply different rates on stress rotation with cyclic loading based on the magnitude and the direction of the cyclic shear stress. Cyclic loading was applied at the rate of 240 seconds per cycle to ensure to satisfactory feedback control of the required tractions. Liquefaction was defined based on the strain criterion, and sample was deemed to have liquefied when the maximum shear strain $\gamma_{\max }$ ceeded $3.75 \%$ (NRC, 1985). A constant $b=\left(\sigma_{2}-\sigma_{3}\right) /\left(\sigma_{1}-\sigma_{3}\right)=0$ value was maintained during cyclic shear.

Tests with smooth principal stress rotation were conducted at different cyclic stress ratio levels at select values of $\Delta \alpha$. Initial direction of the major principal stress $\alpha_{0}$ in smooth rotation tests was always set to zero, and tests were conducted at rotation amplitude $\Delta \alpha$ values of 15,30 , 45, 60, $75 \& 90$ degrees. Jump rotation tests were conducted at $\alpha_{0}$ values of 75 and 90 . Since, all tests were conducted on hydrostatically consolidated specimens, there was no initial static shear, and hence $\beta_{0}=0$. Only two tests with jump rotation were conducted in this study, since the intent was to complement the gaps in the data reported by Logeswaran (2010) at CSR $=0.20$. Table 4.1 provides details of the testing program. 
Table 4.1: $\quad$ Cyclic hollow cylinder torsional shear tests

\begin{tabular}{|c|c|c|c|c|c|}
\hline \multirow{2}{*}{ Test No } & \multirow{2}{*}{ Consolidation State } & \multicolumn{2}{|c|}{ Loading State } & \multirow{2}{*}{$\begin{array}{l}\text { Number } \\
\text { of } \\
\text { Cycles }\end{array}$} & \multirow{2}{*}{ Notes } \\
\hline & & $\alpha_{\sigma}(D e g)$ & $\sigma_{d} / 2 \sigma_{3 c}^{\prime}$ & & \\
\hline HTC_CY01 & \multirow{11}{*}{$\begin{aligned} \sigma_{m c}^{\prime}(k P a) & =200 \mathrm{kPa}, \\
K_{c} & =1, \\
D_{r c}(\%) & =21.70 .3 \%\end{aligned}$} & $-75-+75$ & \multirow{2}{*}{0.2} & 32 & \multirow{2}{*}{ Jump } \\
\hline HTC_CY02 & & $-90-+90$ & & 63 & \\
\hline HTC_CY03 & & $-30-+30$ & \multirow{6}{*}{0.15} & 118 & \multirow{9}{*}{ Smooth } \\
\hline HTC_CY04 & & $-45-+45$ & & 31 & \\
\hline HTC_CY05 & & $-60-+60$ & & 26 & \\
\hline HTC_CY06 & & $-60-+60$ & & 33 & \\
\hline HTC_CY07 & & $-75-+75$ & & 40 & \\
\hline HTC_CY08 & & $-90-+90$ & & 93 & \\
\hline HTC_CY09 & & $-90-+90$ & 0.2 & 15 & \\
\hline HTC_CY10 & & $-30-+30$ & \multirow{2}{*}{0.25} & 5 & \\
\hline HTC_CY11 & & $-75-+75$ & & 15 & \\
\hline
\end{tabular}

\subsubsection{Simple Shear Tests}

Monotonic, cyclic and post cyclic tests were conducted under simple shear loading mode on two uniform sands. Cyclic simple shear tests on air pluviated Fraser River sand specimens over a range of density states, initial stress levels and overconsolidation ratios form the majority of the simple shear tests. Fraser River sand was also tested under monotonic loading over a range of OCR values and stress levels. Tests on sub-rounded silica sand were somewhat limited compared to those on Fraser River sand. These tests were intended to identify potential effects of particle shape on the measured liquefaction characteristics. 


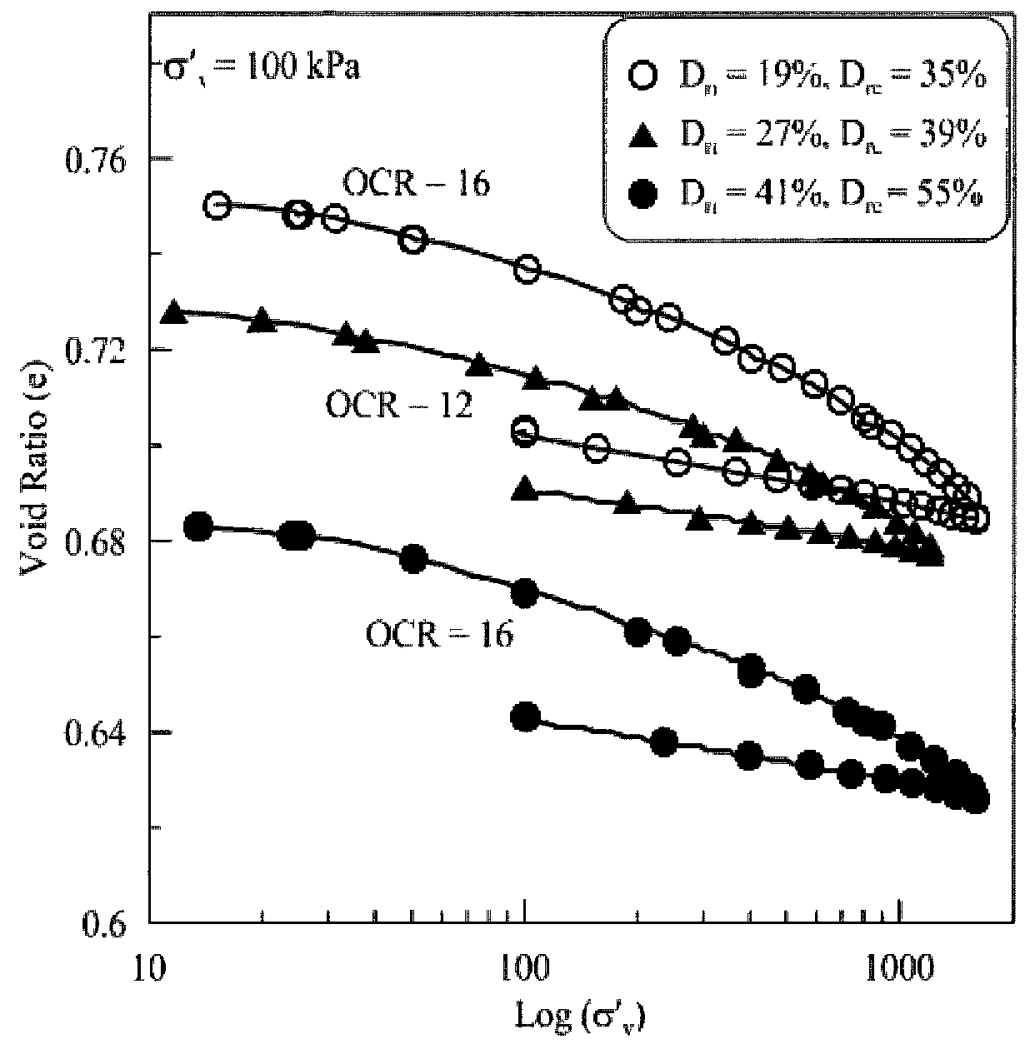

Fig. 4.4: Compressibility characteristics of FR sand at different initial void ratio states

Figure 4.4 illustrates the variation of void ratio with effective vertical stress level during consolidation and subsequent rebound at three different initial void ratio states. A systematic, but relatively insignificant reduction in compressibility is observed with increasing density (Compressibility index, $\mathrm{C}_{\mathrm{C}}$ varied from 0.029 to 0.026 to 0.025 as the initial density increased from 19 to 27 , to $41 \%$. Corresponding rebound index values were $0.008,0.012$ and 0.010 respectively. The apparent inconsistency is a reflection of the very small void ratio changes in sands at these stress levels.

\subsubsection{Simple shear tests of Fraser River sand}

Monotonic tests on normally consolidated Fraser River sand were run at 100, 200, 400, 800 and $1200 \mathrm{kPa}$ confining stress levels at select density states and OCR values. Attempts were made to facilitate comparisons at identical void ratio (or relative density) states. But, the loosest 
density state attainable is dependent on the consolidation stress level due to stress densification, and thus direct comparisons are not always possible. The loosest relative density state attainable is about $28 \%$ at $100 \mathrm{kPa}$ confining stress, but is just over $40 \%$ at $1200 \mathrm{kPa}$ confining stress level. Table C.1 provides the test details for monotonic tests on Fraser River sand.

Cyclic tests were conducted at specific cyclic stress ratio values (CSR $=0.10,0.15,0.18$, $0.20,0.25,0.30$ ) over a range of density and stress states and at OCR values of 1.0, 1.5 and 2.0. A select number of cyclic tests were conducted at higher OCR values of 3 and 4 . All tests with initial static shear were conducted at a confining stress level of $100 \mathrm{kPa}$. Post cyclic tests were conducted following cyclic loading. Table C. 2 provides the test details for the cyclic tests on Fraser River sand.

\subsubsection{Simple shear tests on silica sand}

Cyclic simple shear tests on silica sand were conducted at different density states, stress and OCR levels to compare the $K_{\sigma}$ values obtained in silica sand to that obtained from Fraser River sand. Tests with initial static shear were conducted on sand overconsolidated to an OCR value of two and subjected to different levels of initial static shear. Table C.3 provides the list of cyclic tests. 


\section{EFFECTS OF PRINCIPAL STRESS ROTATION ON CYCLIC RESISTANCE}

\subsection{INTRODUCTION}

This chapter presents hollow cylinder torsional (HCT) shear test results to evaluate the influence of principal stress rotation on liquefaction susceptibility. While very versatile, an HCT device is quite complex, and not widely available. As a result, laboratory assessment of liquefaction potential is mostly based on cyclic triaxial tests, and infrequently on cyclic simple shear tests. In-situ loading conditions invariably involve smooth and continuous rotation of principal stresses, but a cyclic triaxial test often leads to a sudden jump rotation of principal stresses, or no rotation at all depending on the relative values of the static and cyclic shear stress levels. However, cyclic triaxial tests can invoke the weakest triaxial extension mode, and hence might be expected to yield conservative estimates. On the other hand, principal stresses in cyclic simple shear rotate smoothly during cyclic loading, but the amount of rotation cannot be controlled.

A better understanding of the effects of principal stress rotation is required to properly evaluate the suitability of the laboratory test devices that are commonly used for the assessment of liquefaction potential in natural soils during earthquakes. While such loading is not commonly applied in laboratory testing, principal stress rotation during earthquake loading is the norm insitu. These results can provide additional insights into the applicability of cyclic simple shear and cyclic triaxial tests for liquefaction susceptibility assessment. 


\subsection{Cyclic LoAding in Hollow Cylinder Tests}

Cyclic shear in a HCT test can be imposed in a multitude of ways, but the most common means of cyclic shearing involves the application of cyclic stress $\tau_{z \theta}$ on the horizontal plane, or by changing the vertical stress, $\sigma_{z}$ or a combination of the two. Principal stress direction $\alpha_{\sigma}$ is represented by the inclination of the major principal stress to the vertical axis, and the sign convention adopted herein treats counter-clockwise shear and rotation as positive. The direction of major principal stress is governed by the relative value of $\tau_{z \theta}$ with respect to $\sigma_{z}$ and $\sigma_{\theta}$ as noted in equation 5.1. Minor principal stress is inclined at $90^{\circ}$ to the major principal stress in the $\mathrm{z}-\theta$ plane. Intermediate principal stress, which is orthogonal to both major and minor principal stresses, is always horizontal in a HCT device.

$$
\alpha_{\sigma}=\tan ^{-1} \frac{2 \tau_{z \theta}}{\left(\sigma_{z}-\sigma_{\theta}\right)}
$$

Principal stress direction can be held constant, or rotated in a pre-determined pattern during cyclic loading. The term 'jump rotation' is used herein to represent a sudden and instantaneous change in the direction of the principal stresses. Both smooth and jump rotation of principal stresses were simulated in this study. Smooth rotation tests simulate in-situ loading during earthquakes, and jump rotation tests were intended to assess the applicability and effects of the nature of stress rotation encountered in cyclic triaxial tests. During smooth rotation, principal stress directions were continually rotated through the maximum amplitude of the rotation angle, denoted by $\Delta \alpha_{\max }$ herein, about the vertical deposition axis. The direction of principal stress was controlled in a sinusoidal form with the same period as the cyclic stresses. This implies that the occurrence of the maximum cyclic shear stress will correspond to the largest inclination of the principal stresses. The direction of the major principal stress to the vertical axis at time instant $t$ 
is given by equation 5.2 where $\alpha_{0}$ represents the initial inclination (zero in all tests reported herein), and $\mathrm{T}$ is the period of the cyclic loading.

$$
\alpha_{\sigma}=\alpha_{0}+\Delta \alpha_{\max } \cdot \sin \left[\frac{2 \pi t}{T}\right]
$$

The direction of the major principal stress in jump rotation tests is instantaneously switched to the other side of the vertical axis (back and forth) as the direction of the cyclic shear stress changes (equation 5.2).

$$
\begin{aligned}
& \alpha_{\sigma}=\alpha_{0} \text { when } \tau_{z \theta}>0 \\
& \alpha_{\sigma}=-\alpha_{0} \text { when } \tau_{z \theta}<0
\end{aligned}
$$

Figure 5.1 illustrates the variation of the applied cyclic shear stress, and the direction of the major principal stress in both smooth rotation, and jump rotation tests. The cyclic shear stress ratio, CSR in hollow cylinder tests is generally defined as the ratio of peak shear stress normalized by the effective mean normal stress, $\sigma_{m c}^{\prime}$. In general, HCT specimens can be nonhydrostatically consolidated to yield an initial static shear, denoted by the ratio, $\beta_{0}=$ $\left(\sigma_{1 c}^{\prime}-\sigma_{3 c}^{\prime}\right) / 2 . \sigma_{m c}^{\prime}$. The variation of cyclic shear stress on the plane of maximum shear stress can be expressed by equation 5.4 .

$$
\tau_{c y}=\sigma_{d, c y} / 2=\left\{\beta_{0}+[C S R] \times \sin \left[\frac{2 \pi t}{T}\right]\right\} \times \sigma_{m c}^{\prime}
$$

The vertical effective stress $\sigma_{v c}^{\prime}$, and major and minor principal stresses $\sigma_{1 c}^{\prime}, \sigma_{3 c}^{\prime}$ would be equal to $\sigma_{m c}^{\prime}$ in hydrostatically consolidated sands. Thus this formulation would be identical to those used in triaxial and simple shear loading modes when the HCT specimen is hydrostatically consolidated. 

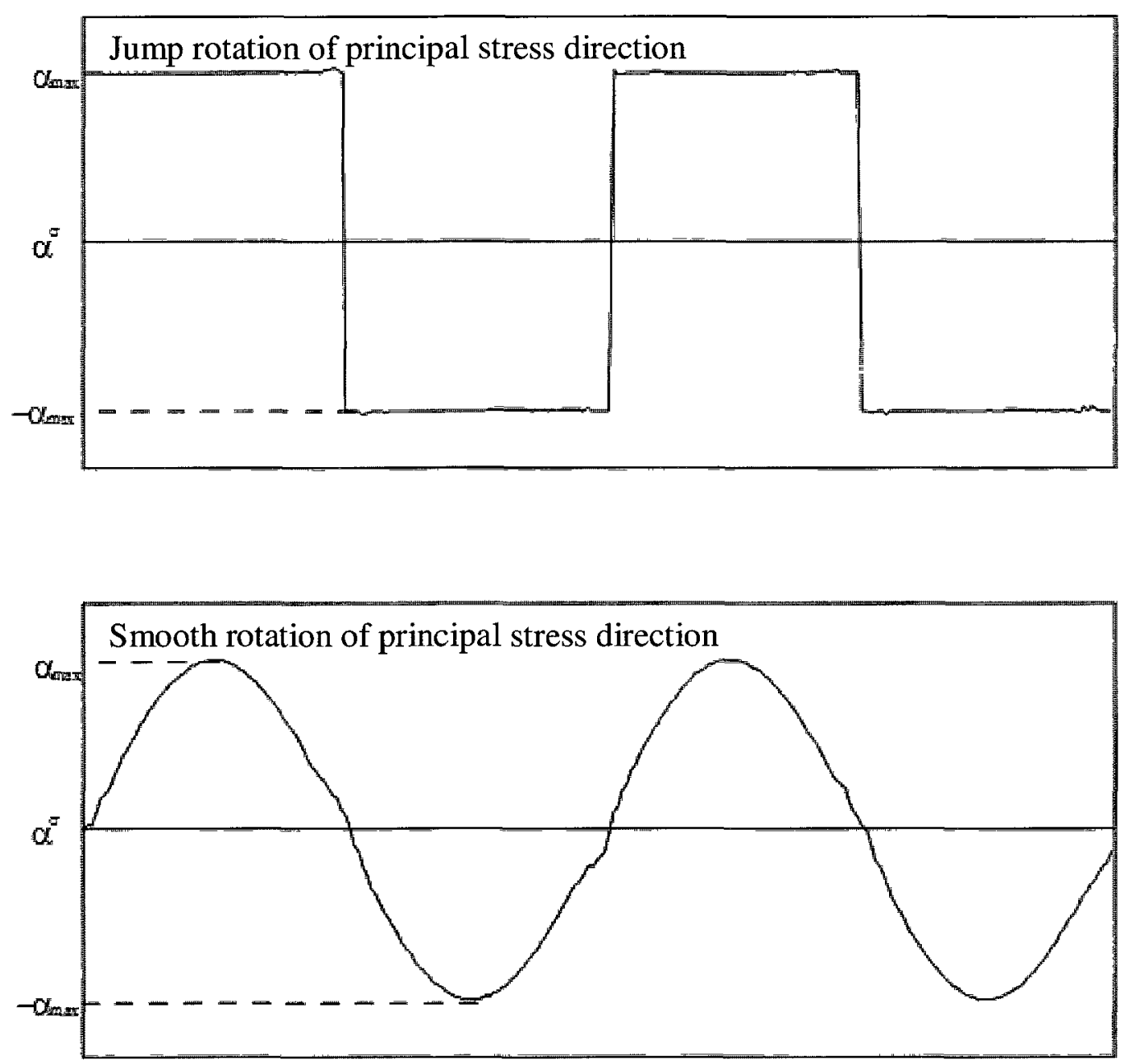

No. of cycles

Fig 5.1: $\quad$ Cyclic shear stress and direction of principal stresses

\subsection{Test Program}

Hollow cylinder torsional shear tests were conducted on the loosest deposited Fraser River sand hydrostatically consolidated to a mean normal effective stress, $\sigma_{m c}^{\prime}=200 \mathrm{kPa}$. The relative density at the end of the consolidation was about $22 \%$. Cyclic shearing was imposed on sand at the desired cyclic stress ratio, and the direction of the principal stresses during cyclic loading was varied either smoothly or suddenly, as prescribed. Liquefaction was defined based on strain criterion, and specimens were deemed to have liquefied when the maximum shear strain $\gamma_{\max }$ 
exceeded 3.75\% (NRC, 1985). A constant $b=\left(\sigma_{2}-\sigma_{3}\right) /\left(\sigma_{1}-\sigma_{3}\right)=0$ value was maintained during cyclic shear.

Tests with smooth principal stress rotation were conducted at different cyclic stress ratio levels at select values of $\Delta \alpha$. Initial direction of the major principal stress $\alpha_{0}$ in smooth rotation tests was always set to zero, and tests were conducted at rotation amplitude $\Delta \alpha$ values of 15,30 , 45, 60, $75 \& 90$ degrees. Jump rotation tests were conducted at $\alpha_{0}$ values of 75 and 90 . Since, all tests were conducted on hydrostatically consolidated specimens, there was no initial static shear, and hence $\beta_{0}=0$. A total of ten cyclic hollow cylinder torsional shear tests were conducted as previously noted in Table 4.1 .

\subsection{TEST RESULTS AND DISCUSSION}

The undrained behaviour of sand under the imposed cyclic loading is assessed in terms of pore pressure, shear strain development during cyclic loading, and the number of cycles required triggering liquefaction. The prescribed stress states (total mean normal stress, intermediate principal stress, principal stress direction, and the cyclic shear stress) were reached using a feedback controlled data acquisition program throughout the test. As a result the 'noise' in the measurements was significantly higher compared to tests without feedback control, or with feedback control but at a slower loading rate. These minor oscillations are not captured in typical geotechnical laboratory testing with feedback, since it is common practice to record data once the target state was reached. Such, practice is somewhat misleading as it hides the true nature of the oscillations while the stress state is being targeted. The measured response in jump and smooth rotation tests are presented, followed by a discussion of the possible reasons for the observations, and their implications in traditional cyclic testing in geotechnical engineering. 


\subsubsection{Smooth rotation of principal stresses}

Figure 5.2 shows the cyclic undrained behaviour of Fraser River sand subjected to smooth rotation of principal stresses between $+45^{\circ}$ and $-45^{\circ}$ at a cyclic stress ratio, CSR $=0.15$. The direction of the principal stresses was related to the cyclic shear stress at every instant, and the maximum inclinations correspond to the peak shear stress state. As noted in the tests with symmetric jump rotation in the following section, symmetric smooth rotation leads to fairly symmetric effective stress paths that are not dependent on the direction of shearing. The effective stress path gradually moves toward the origin, and strain development was fairly small until the sand suddenly develops large strain during the $30^{\text {th }}$ cycle. Such sudden strain development is characteristics of true and limited liquefaction type of response. The maximum excess pore pressure generated due to liquefaction was about $160 \mathrm{kPa}$, which is equivalent to about $80 \%$ of the initial confining stress. Similar data at a higher $\operatorname{CSR}=0.25$ level, but with rotation limited to $30^{\circ}$ is shown in Figure 5.3. The sand liquefied in 5 cycles on account of the higher cyclic stress ratio, even though the rotation angle was limited to $30^{\circ}$.

Figure 5.4 shows the dependence in number of cycles to liquefaction at different CSR values for a constant level of principal stress rotation. The number of cycles to liquefaction decreased from 118 cycles at $\mathrm{CSR}=0.15$ to 15 cycles at $\mathrm{CSR}=0.2$, and to 5 cycles at $\mathrm{CSR}=0.25$. The rate of reduction noted is fairly consistent with the experience derived from cyclic simple shear and cyclic triaxial tests.

Figure 5.5 shows the variation of the number of cycles to liquefaction as a function of the degree of stress rotation at $\mathrm{CSR}=0.15$. A reduction in cyclic resistance is noted as the magnitude of stress rotation increases to $45^{\circ}$, and essentially similar resistance was noted at $45^{\circ}$ and $60^{\circ}$, but the resistance increases with further increase in stress rotation. Similar data during smooth principal stress rotation, reported by Logeswaran (2010) at a higher CSR $=0.2$ is also 
shown in the Figure for comparison. These observations indicate that the lowest cyclic resistance occurs when the peak $\alpha_{\sigma}$ is about $45^{\circ}$ to $60^{\circ}$ under the given loading conditions. This observation is somewhat contrary to the current understanding that progressively weaker responses are to be expected as the major principal stress aligns toward the weaker horizontal direction.
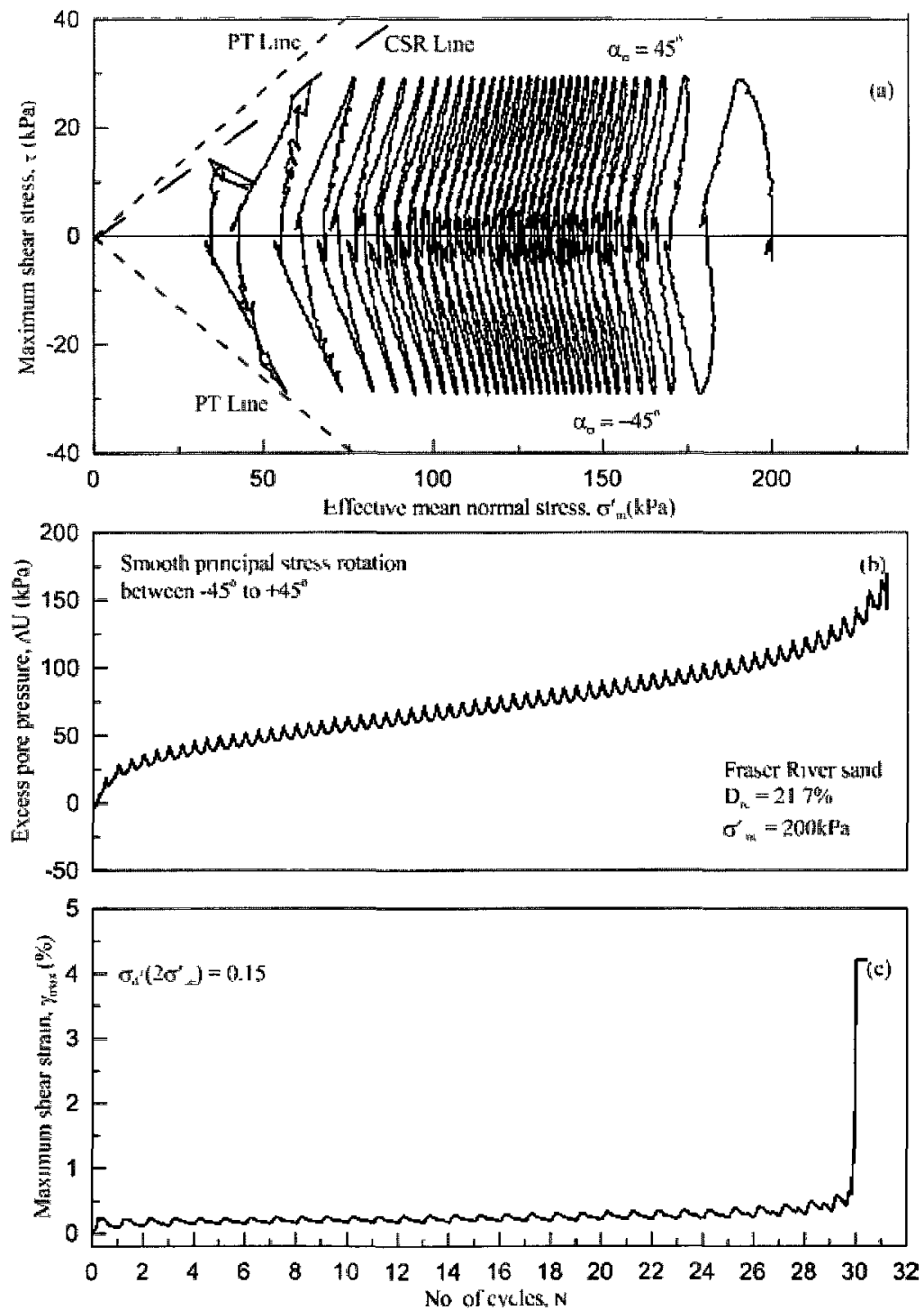

Fig. 5.2: Stress path of Fraser River sand during cyclic loading of $\sigma_{d} /\left(2 \sigma_{m c}^{\prime}\right)=0.15$ with Smooth rotation of $\alpha_{\sigma}$ between $-45^{\circ}$ and $+45^{\circ}$ 

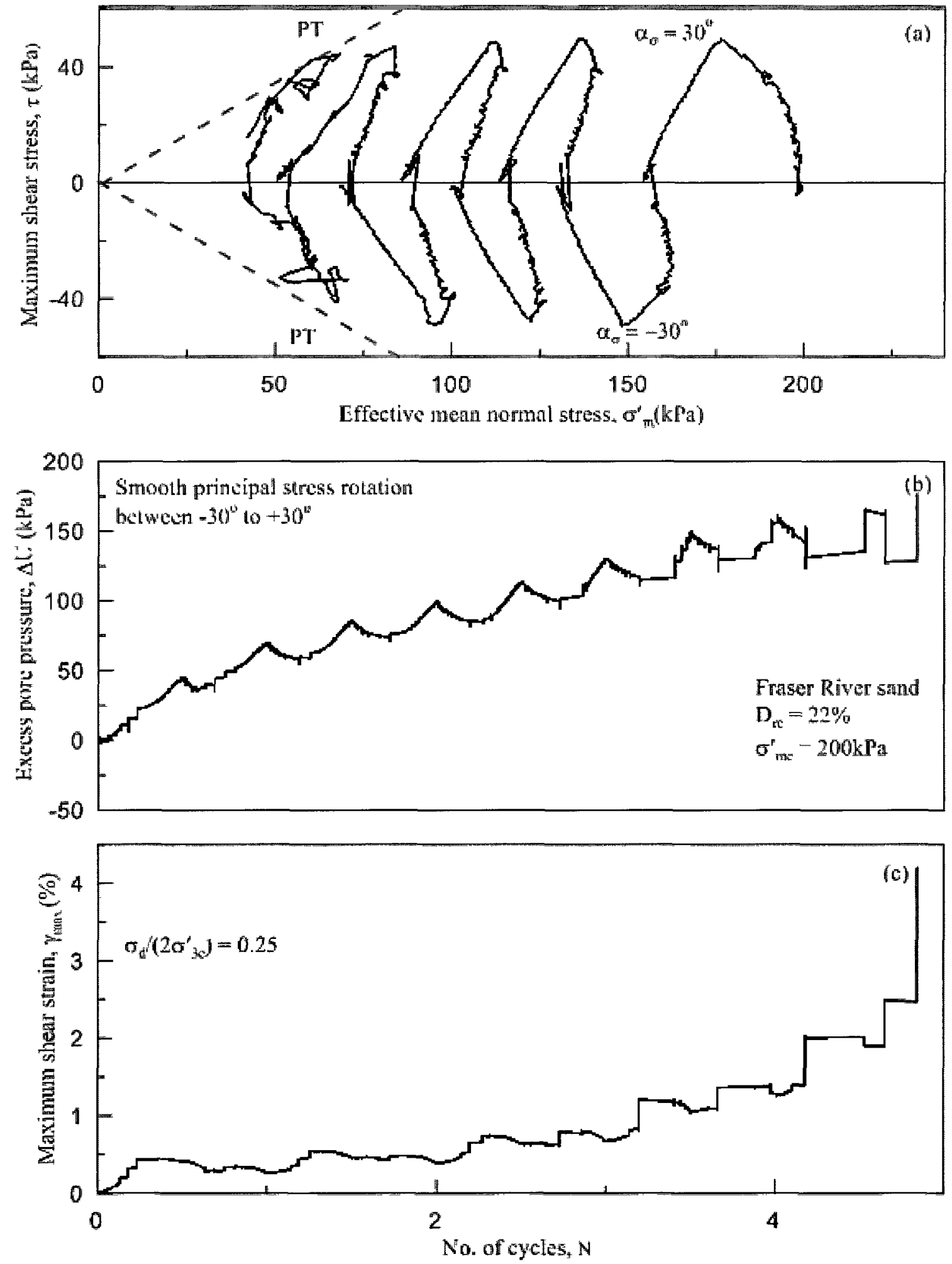

Fig. 5.3: Stress path of Fraser River sand during cyclic loading of $\sigma_{d} /\left(2 \sigma_{m c}^{\prime}\right)=0.25$ with Smooth rotation of $\alpha_{\sigma}$ between $-30^{\circ}$ and $+30^{\circ}$ 


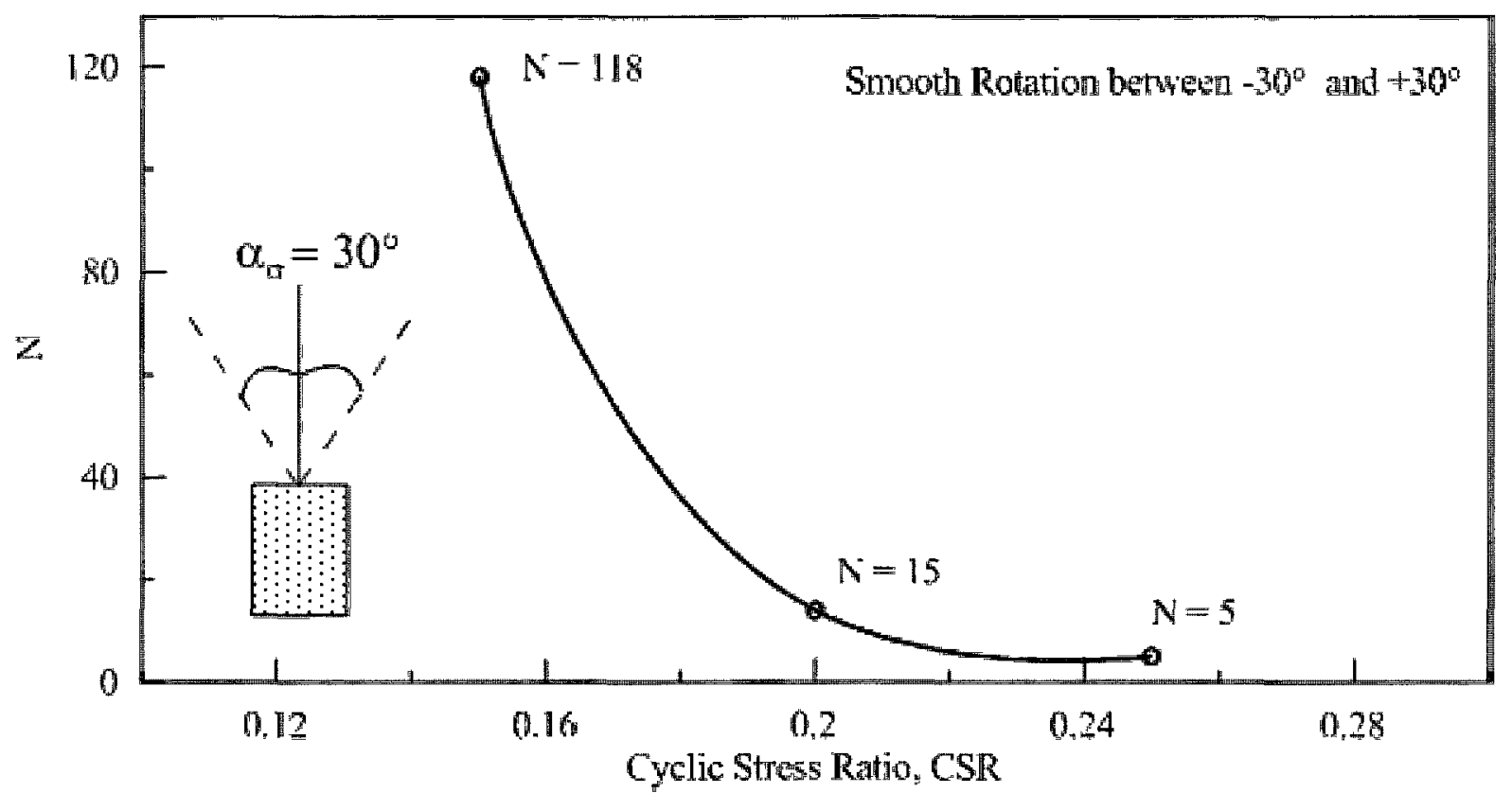

Fig. 5.4: The Number of cycles to liquefaction at different CSR values

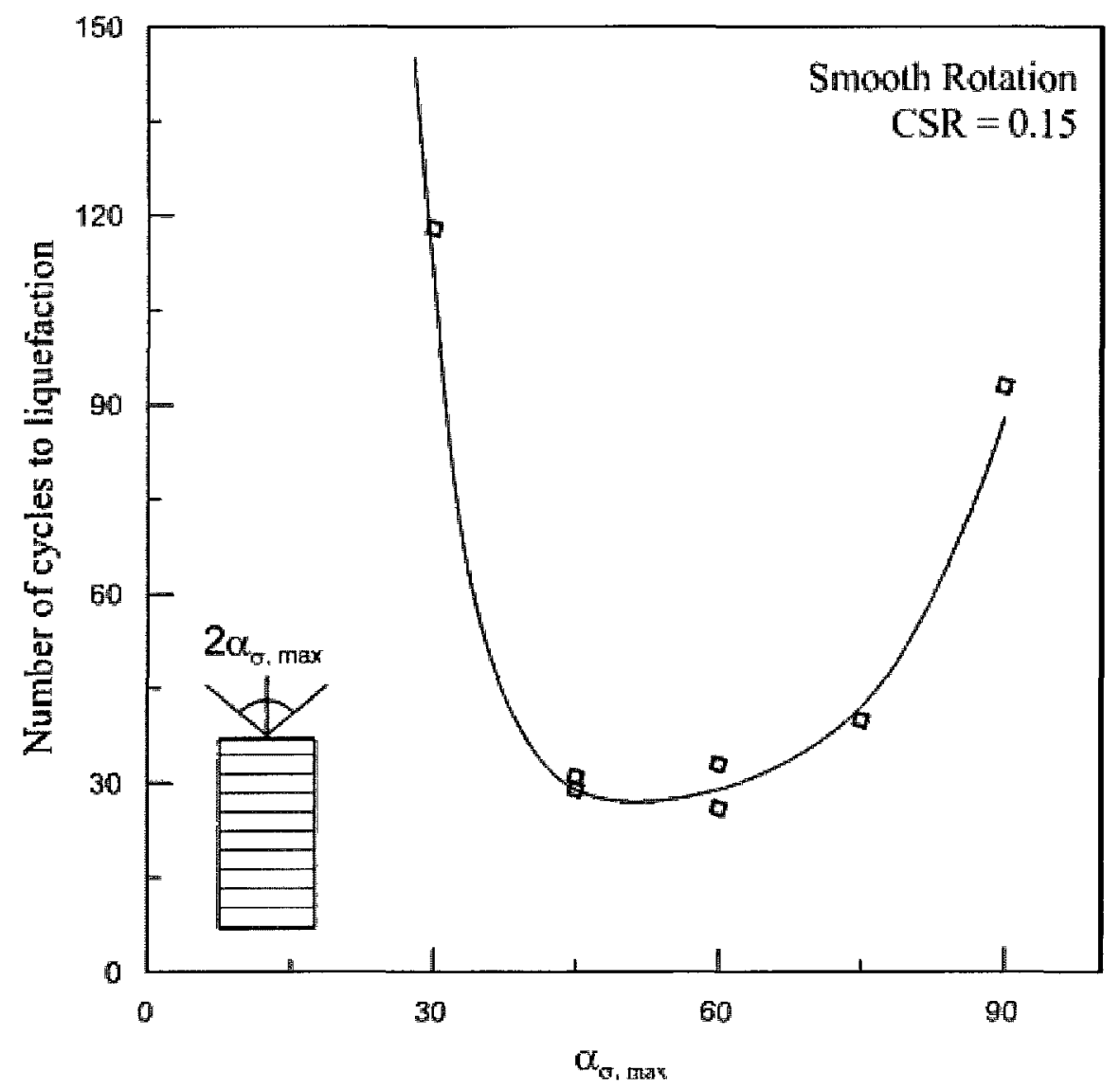

Fig. 5.5: Variation of number of cycles at $\sigma_{d} /\left(2 \sigma_{m c}^{\prime}\right)=0.15$ in Smooth rotation 


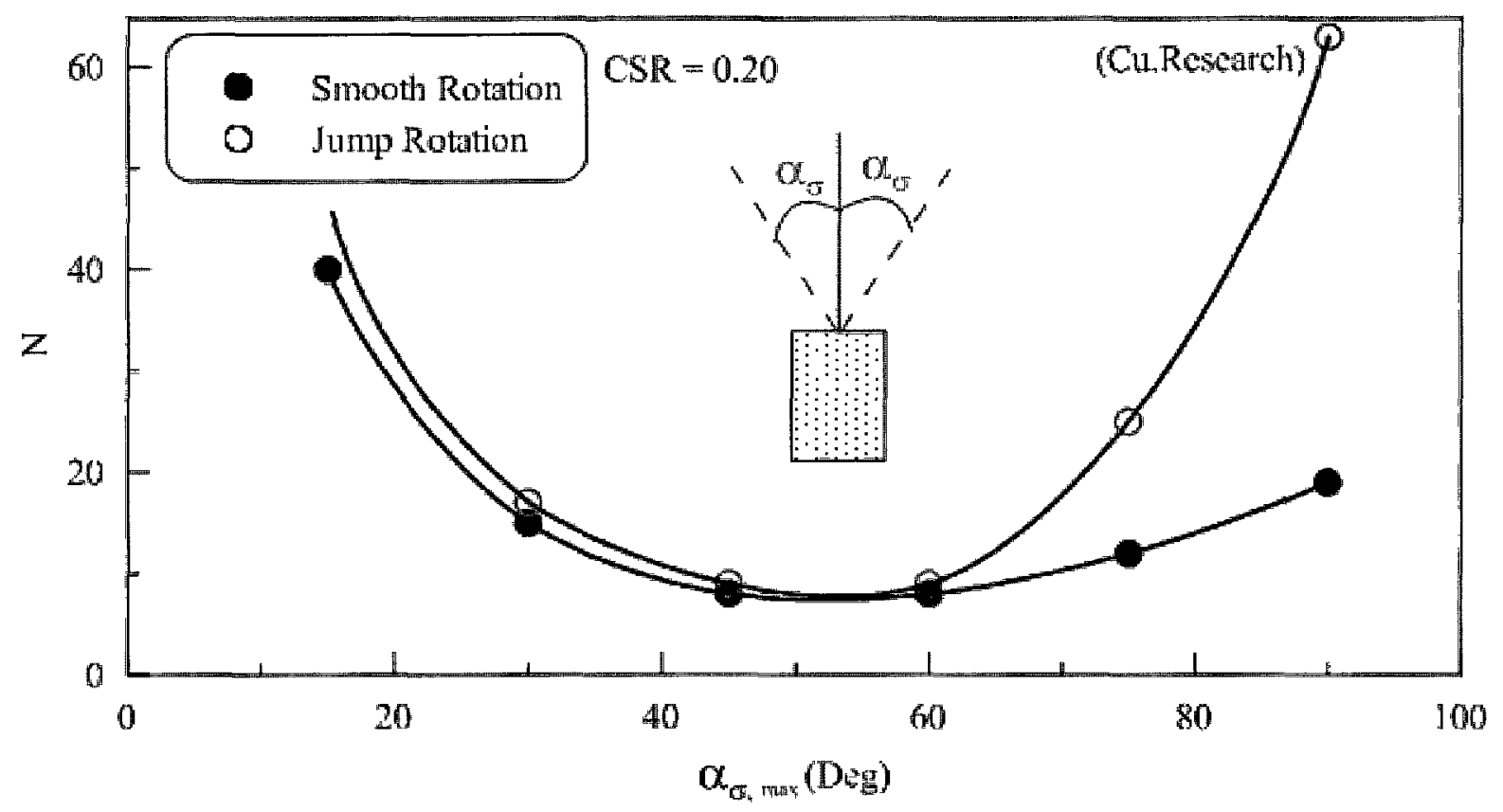

Fig 5.6: Comparison of number of cycles required for liquefaction during smooth and jump rotation of principal stress direction (After Logeswaran, 2010)

\subsubsection{Jump rotation of principal stresses}

Figure 5.7 shows the measured behaviour of the sand subjected to undrained cyclic shear with jump rotation of principal stresses. The direction of major principal stress alternated between $+75^{\circ}$ and $-75^{\circ}$ as the direction of the shear stress on the horizontal plane changed. Unlike the effective stress paths in cyclic triaxial tests (with jump rotation between $0^{\circ}$ and $90^{\circ}$ ) which show significant non-symmetry, the effective stress path in this case can be noted to be fairly symmetric (except at the early stages of the loading). One cannot expect perfect symmetry since the effective stresses are changing during the loading, but changes within each half-cycle are fairly small as noted below, and hence reasonable symmetry is noted in the stress path. Such symmetry is reflective of the existence of an isotropic fabric in the horizontal direction. The first loading cycle caused a fairly large excess pore pressure development (about $60 \mathrm{kPa}$ ) compared to subsequent cycles. The excess pore pressure in subsequent load cycles oscillated by 
about $20 \mathrm{kPa}$ with peaks and troughs within each cycle. However, the average increase as loading progresses was about $3 \mathrm{kPa}$ per cycle. The maximum excess pore pressure when the specimen liquefied in 32 cycles was $160 \mathrm{kPa}$.
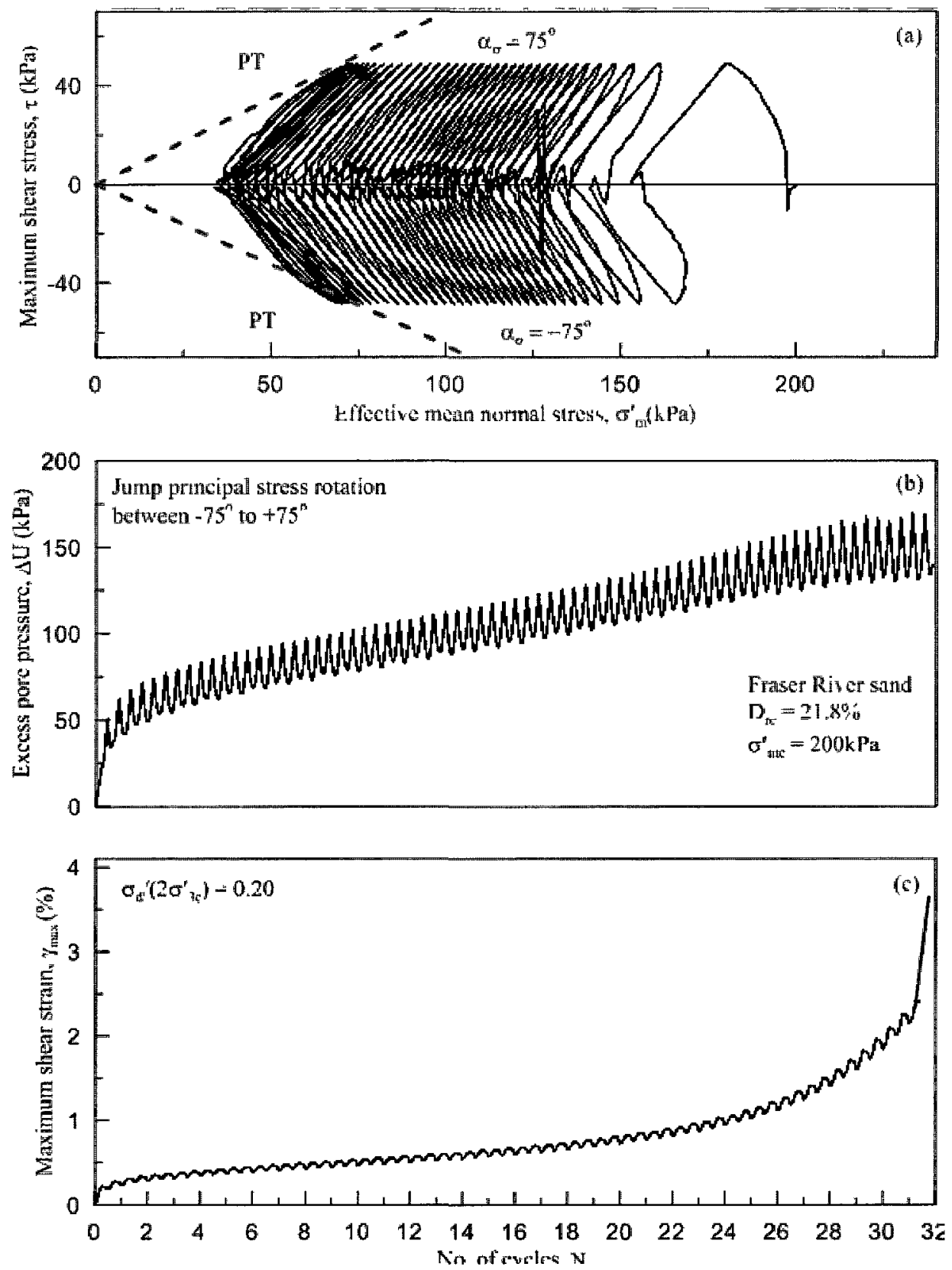

Fig.5.7: Stress path of Fraser River sand during cyclic loading of $\sigma_{d} /\left(2 \sigma_{m c}^{\prime}\right)=0.20$ with Jump rotation of $\alpha_{\sigma}$ between $-75^{\circ}$ and $+75^{\circ}$ 
Figure 5.8 compares the excess pore pressure generated in five cycles of loading at CSR $=$ 0.2 in smooth rotation tests along different principal stress directions. Higher rates of excess pore pressure generation is noted when the principal stress direction $\alpha_{\sigma}$ are inclined at $45^{\circ}$ or $60^{\circ}$. The plane of maximum shear stresses are inclined at $45^{\circ}$ to the principal stress directions, and thus the horizontal plane would be a plane of maximum shear when $\alpha_{\sigma}=45^{\circ}$.

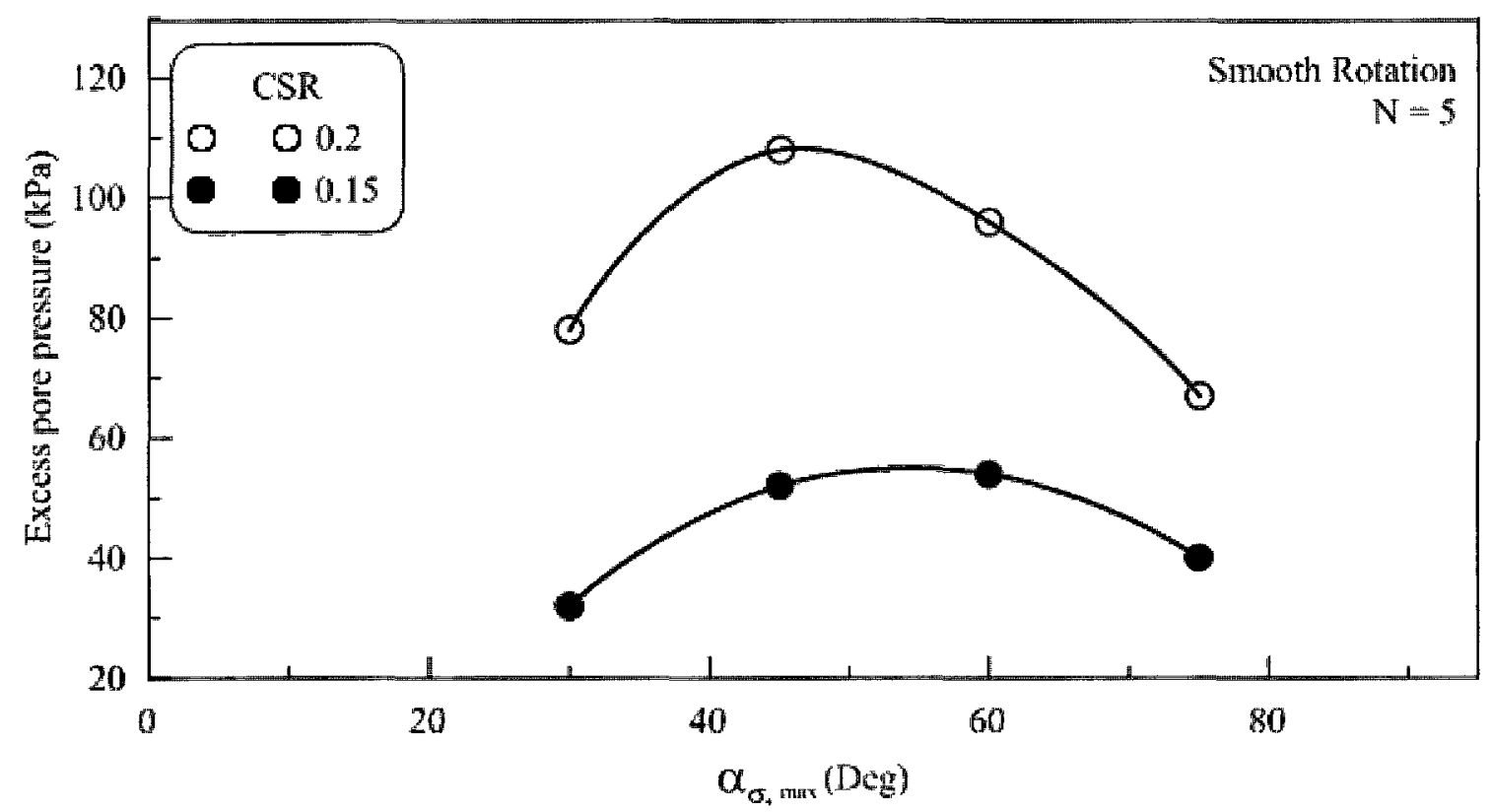

Fig.5.8: $\quad$ Excess pore pressure response of Fraser River sand during cyclic loading with principal stress direction at 5 cycles.

\subsubsection{Stress rotation and liquefaction susceptibility: Discussion}

Figures 5.5 and 5.6 show that sand at similar initial conditions and subjected to a constant CSR level is most prone to liquefaction when the direction of major principal stress $\alpha_{\sigma}$ was inclined at $45^{\circ}$ to vertical throughout the loading (in jump rotation tests), or at the peak shear stress states (in smooth rotation tests). The resistance was only marginally higher at $\alpha_{\sigma}=60^{\circ}$, 
but significantly higher resistance was noted at $\alpha_{\sigma}$ values less than $45^{\circ}$ and at $\alpha_{\sigma}$ values of $75^{\circ}$ and $90^{\circ}$. This finding appears to be not consistent with the current understanding of systematic softening as the direction of major principal stress aligns toward the horizontal plane. It has been well established that gravity deposited materials are well packed in the vertical direction compared to horizontal. As a result, horizontal plane is the weakest in such material, and shearing along such direction is expected to yield the softest response. If the direction of the major principal stress is the only consideration then the sand should have exhibited the lowest resistance when $\alpha_{\sigma}=90^{\circ}$. Current research and previous studies by Logeswaran (2010) clearly indicate that the lowest resistance corresponds to $\alpha_{\sigma}=45^{\circ}$. Two inter-linked reasons for such behaviour are identified to explain this apparent deviation from expected behaviour.

\subsubsection{Bedding Planes \& stresses}

While literature correctly identifies the horizontal plane as the weakest, these results indicate that it is not entirely correct to expect the direction of the major principal stress to be the sole contributing factor. Deformation and failure in soils is generally associated with shear, and hence the plane on which the largest shear stresses act would also be of interest. Due to complementary shear, maximum shear stresses would act on two orthogonal planes, which are inclined at $45^{\circ}$ to the major and minor principal stress directions. The shaded regions in Figure 5.9 illustrate the planes of maximum shear stress for different principal stress orientations. Relatively softer response can be expected when the plane of the maximum shear stress coincides with the plane with weakest strength (i.e. horizontal plane), and thus the largest shear stresses are applied along this plane. It is postulated that the alignment of both the plane of maximum shear stress, and the direction of the major principal stress toward the weaker horizontal plane would be responsible for strength degradation. Further $\alpha_{\sigma}$ deviates from $45^{\circ}$ the 
further the plane of maximum shear stress moves away from the weakest horizontal plane. Thus, the plane of maximum shear stress would be furthest away from the horizontal plane when $\alpha_{\sigma}=0^{\circ}$ or $90^{\circ}$. Given the limited shear capacity of soils, it can be reasonably expected that alignment of the plane of maximum shear stress along the weakest plane would lead to the lowest resistance. This postulate is supported by the test data presented since the weakest response was noted when $\alpha_{\sigma}=45^{\circ}$, and not when $\alpha_{\sigma}=90^{\circ}$.

If the plane of maximum shear stress is the only consideration then essentially similar response would be expected at complementary inclinations about the $45^{\circ}$ axis (e.g., $30^{\circ} \& 60^{\circ}$; $15^{\circ} \& 75^{\circ}$; and $0^{\circ} \& 90^{\circ}$ ). This is not the case due to the influence of the direction of major principal stress. At $\alpha_{\sigma}$ values greater than $45^{\circ}$ the major principal stress aligns more closely with the bedding planes and leads to comparatively weaker response even if the orientation of the planes of maximum shear stress are identical, for example at $\alpha_{\sigma}=0^{\circ} \& 90^{\circ}$. Preceding discussion suggest that combined effects of the alignment of both the direction of the major principal stress, and the plane of the maximum shear lead to the observed lowest cyclic resistance direction when $\alpha_{\sigma}$ are inclined at $45^{\circ}$ or $60^{\circ}$.

\subsubsection{Maximum shear stress $\tau_{\max } v$ s the Shear stress on the horizontal plane $\tau_{z \theta}$}

The cyclic stress ratio, CSR defined as the ratio of the maximum shear stress normalised by the effective mean normal stress has been to quantify the intensity of the cyclic loading. Comparisons are made at constant CSR values. While this approach is consistent with current literature, it fails to recognize the fact the shear stress acting on the weaker horizontal plane varies depending on the nature and magnitude of stress rotation.

Shear stress on the horizontal bedding plane is related to the cyclic deviatoric stress $\sigma_{d, c y}$ and the inclination of the major principal stress by equation 5.5 . 


$$
\tau_{z \theta, c y}=\frac{\sigma_{d, c y} \times \sin \left(2 \alpha_{\sigma}\right)}{2}
$$

The deviatoric stress $\sigma_{d, c y}$ is a sinusoidal function of time, and the variation of $\tau_{z \theta}$ for hydrostatic consolidation is given by equation 5.6.

$$
\tau_{z \theta, c y}=\operatorname{CSR} \times \sigma_{m c}^{\prime} \times \sin \left(2 \alpha_{\sigma}\right) \times \sin \left[\frac{2 \pi t}{T}\right]
$$

Cyclic stress ratio, CSR and effective mean normal stress $\sigma_{m c}^{\prime}$ are constants in a given test. In jump rotation tests, $\alpha_{\sigma}$ can only assume two values; either $+\alpha_{0}$ or $-\alpha_{0}$. Hence the variation of $\tau_{z \theta}$ is simply a sine function with amplitude $\left|\operatorname{CSR} \times \sigma_{m c}^{\prime} \times \sin \left(2 \alpha_{0}\right)\right|$. However, $\alpha_{\sigma}$ is a time function in smooth rotation tests (equation 5.2) and the variation of $\tau_{z \theta}$ in smooth rotation tests about the vertical axis is an amplitude modulated sine wave given by equation 5.7.

$$
\tau_{z \theta, c y}=C S R \times \sigma_{m c}^{\prime} \times\left|\sin \left(2 . \Delta \alpha_{\max } \cdot \sin \left[\frac{2 \pi t}{T}\right]\right)\right| \times \sin \left[\frac{2 \pi t}{T}\right]
$$

Figures 5.10 depict the variation of $\tau_{z \theta}$ with time during one cycle. It can be noted that maximum shear stresses on the horizontal plane occurs when $\alpha_{0}=45^{\circ}$ in jump rotation tests, and when $\Delta \alpha_{\max }=45^{\circ}$ in smooth rotation tests. These are the two cases that yielded the weakest response during cyclic loading. The peak shear stress on the horizontal bedding plane in smooth rotation tests with $45^{\circ}$ rotation is only about half as that in $45^{\circ}$ rotation tests. Given the discussions in previous section, it therefore is not unexpected to have the weaker response when principal stress rotation is limited to $45^{\circ}$. 

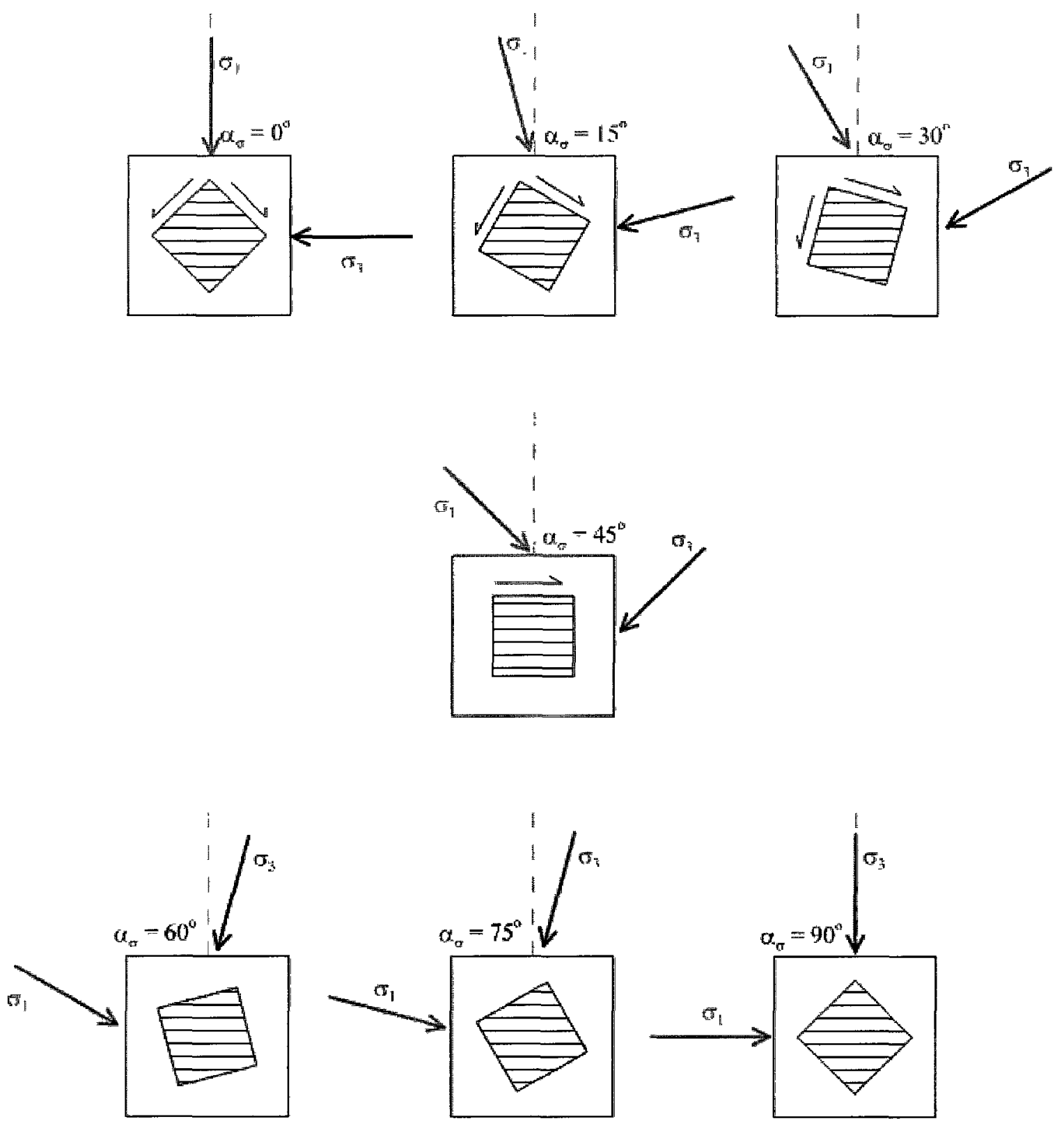

Fig. 5.9: The planes of maximum shear stress for different principal stress orientations 


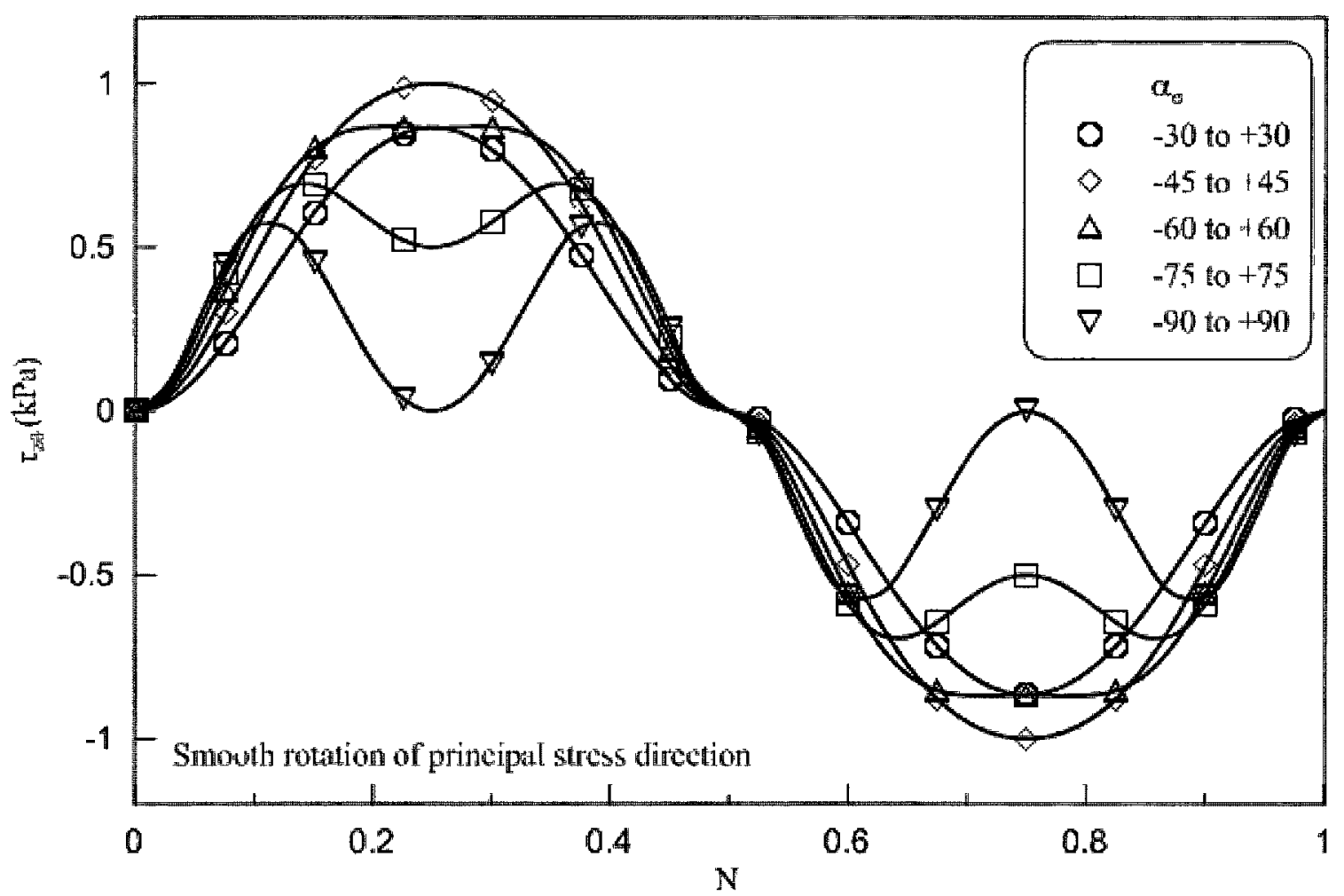

Fig 5.10: Imposed torsional shear stress during smooth rotations of principal stress direction

\subsection{SUMMARY AND IMPLICATIONS}

Cyclic tests conducted using hollow cylinder torsional shear device provide insights into the effects of stress rotation, and its link to the bedding planes. The orientation of the planes of maximum shear stress with respect to the horizontal bedding planes appears to be the key parameter dictating the potential for liquefaction. The direction of the major principal stress also influences cyclic resistance. Test results suggest that the alignment of the plane of maximum shear stress is more critical than the alignment of the direction of the major principal stress. These tests results, combined with the findings of Logeswaran indicate that the differences noted between jump rotation and smooth rotation are not very significant. However, the key parameter of consequence in stress rotation is the rotation angle, and soils are most prone to liquefaction when principal stresses rotate between $+45^{\circ}$ and $-45^{\circ}$. While the tests conducted herein were 
limited to specific paths, the same trends noted here are expected to prevail in other loading paths. Additional tests are required to verify this presumption.

Most preferred means of assessing liquefaction potential of in-situ soils should be to duplicate the actual field loading conditions including initial state, and stress rotation in the laboratory. However, in most cases, duplication of actual three dimensional states may not be feasible in the laboratory. In such, cases it would be appropriate to determine liquefaction potential under the weakest mode. The cyclic simple shear test provides such functionality in more broadly available and relatively simple test equipment.

The number of cycles is observed to be 15 with CSR of 0.20 under $90^{\circ}$ rotation angle. Logeswaran (2010) has reported that 18 cycles were noticed in above condition at the same density state. The result of principal stress rotation in this research (31cycles) between $-45^{\circ}$ and $+45^{\circ}$ is consistent with Logeswaran (2010) ( 29 cycles). 


\section{EFFECTS OF OVERCONSOLIDATION ON LIQUEFACTION POTENTIAL}

\subsection{INTRODUCTION}

The Undrained behavior of Fraser River (FRS) and Silica sand (SS) under static, cyclic, and post-cyclic loading is presented and discussed in this chapter. A series of tests at different initial stress states characterized by confining and static shear stress levels were conducted over a range of void ratio and OCR values under simple shear loading mode. Static loading behavior, assessed to provide a baseline for evaluating the cyclic and post cyclic response, is presented first, followed by cyclic and post-cyclic behaviour. These test results strengthen the existing understanding regarding the effects of initial states represented by relative density $D_{r}$ (or void ratio), and confining stress $\left(\sigma_{v c}^{\prime}\right)$, and static shear stress $\left(\tau_{\mathrm{h}}\right)$, by refining the existing knowledge. In addition, it addresses a gap in the literature with respect to the effects of OCR. In addition, the effect of over consolidation ratio was discovered under simple shear condition for both sands at first time.

The specimen was air pluviated in the loosest state resulting approximately maximum void ratio (lower relative density). Higher densities, if needed, were achieved under a small seating load by wooden hammer tapping. All densities presented in this thesis, were calculated at the end of consolidation under $\mathrm{K}_{\mathrm{o}}$ (no lateral strain during consolidation) condition. Therefore, the initial stress state prior to undrained deformation corresponds to vertical stress $\left(\sigma_{\mathrm{vc}}^{\prime}\right)$ and horizontal consolidation stress $\left(\tau_{\mathrm{hc}}\right)$. 
Comparison between static and cyclic was explored. The cyclic resistance of both sands is presented on the basis of densities and over consolidation ratios and its dependency on effective vertical stress also studied. In order to assess the potential of liquefaction, the correction factor $\mathrm{K}_{\sigma}$ was plotted at ten cycles $(\mathrm{M}=6.75)$ by taking the ratio of cyclic resistance ratio at different vertical stress $(200 \mathrm{kPa}, 400 \mathrm{kPa})$ to cyclic resistance ratio at $100 \mathrm{kPa}$ and explained its variation with initial state of both sands. The relationship between pre and post liquefaction was studied in this chapter. Most of the tests were conducted on Fraser River sand, and the results presented are from this sand. Tests on Silica sand are used for comparison purposes, and those results are explicitly identified.

\subsection{UNDRAINED MONOTONIC RESPONSE}

The undrained behaviour of sand under static loading was tested at several vertical effective stress levels over a range of density states. Tests were conducted both on normally consolidated soils, and those over consolidated to different OCR values (ranging from 2 to 16). These results provide insights into the dependence of modulus, and modulus degradation with OCR, and a basis for assessing the cyclic response.

\subsubsection{Response at the loosest state}

Figure 6.1 shows the stress-strain and pore pressure response of specimens deposited at the loosest possible state, and normally consolidated to different stress levels. The loosest density state attainable is a function of the initial deposition density, consolidation stress level and the OCR. As noted in the information provided in the figure, stress densification causes a gradual increase in density as confining stress level increases from 100 to $1200 \mathrm{kPa}$. The behaviour is noted to be strain hardening at all stress levels even though these states represent the loosest attainable by pluviation. Such dilative tendencies are common in pluviated angular sands. The 
same tests are shown in Figure 6.2 in a normalised (by the consolidations stress) form to assess the effect of stress level. No clear trends are noted in the normalised plots since two balancing factors, increasing density which promotes more dilative response and increasing confining stress level which promotes more contractive response are at play here. The normalised excess pore pressure plot shows that even though the peak excess pore pressure was essentially similar across the tests, the rate of dilation is clearly dependent on the level of confining stress.

Data similar to that in Figure 6.1, but at slightly denser states at the lower confining stress levels is shown in Figure 6.3. The density states are somewhat different, but are much closer than those in Figure 6.2. The normalised shear strength plots clearly show that the sand is gradually becoming softer as consolidation stress increases. Such increase in contractive tendencies is the cause for the noted reduction in cyclic resistance at higher stress levels. Sand at $100 \mathrm{kPa}$ has the most dilative tendencies, and generates negative excess pore pressures at a comparatively faster rate even though it is at the loosest density state. These results clearly indicate that increasing confining stress at a fixed density would increase the contractive tendency in sands. Similar normalised data, but of sands over consolidated to OCR $=2$ shown in Figure 6.4 shows similar characteristics. The pore pressure response shows the same trends as before, but with an added initial region of negative pore water pressure. The additional range over which contractive response (positive excess pore water pressures) are noted at higher stress levels is a reflection of the increased contractive tendencies at higher confining stress levels. 


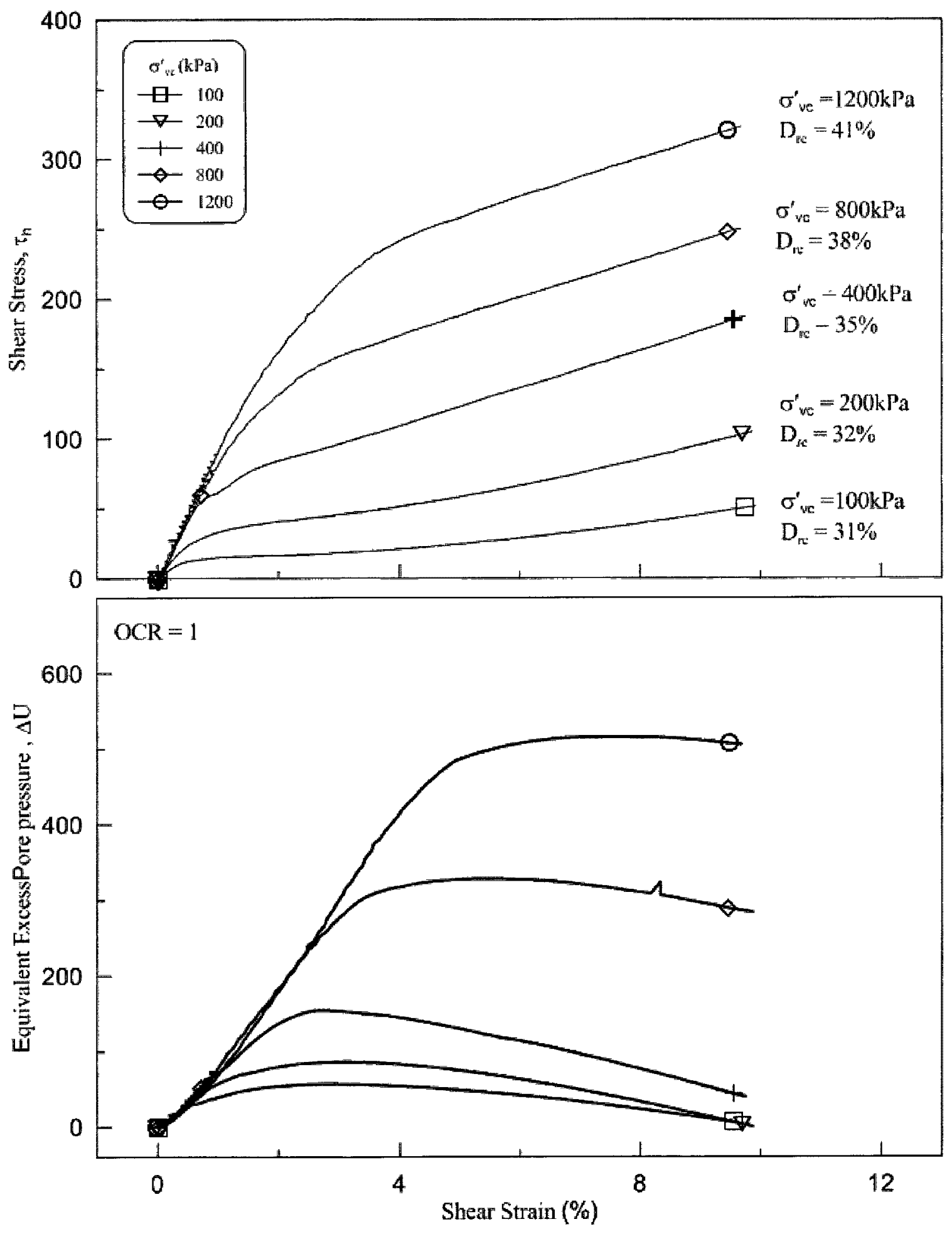

Fig. 6.1: Static behaviour of FRS at loosest state 

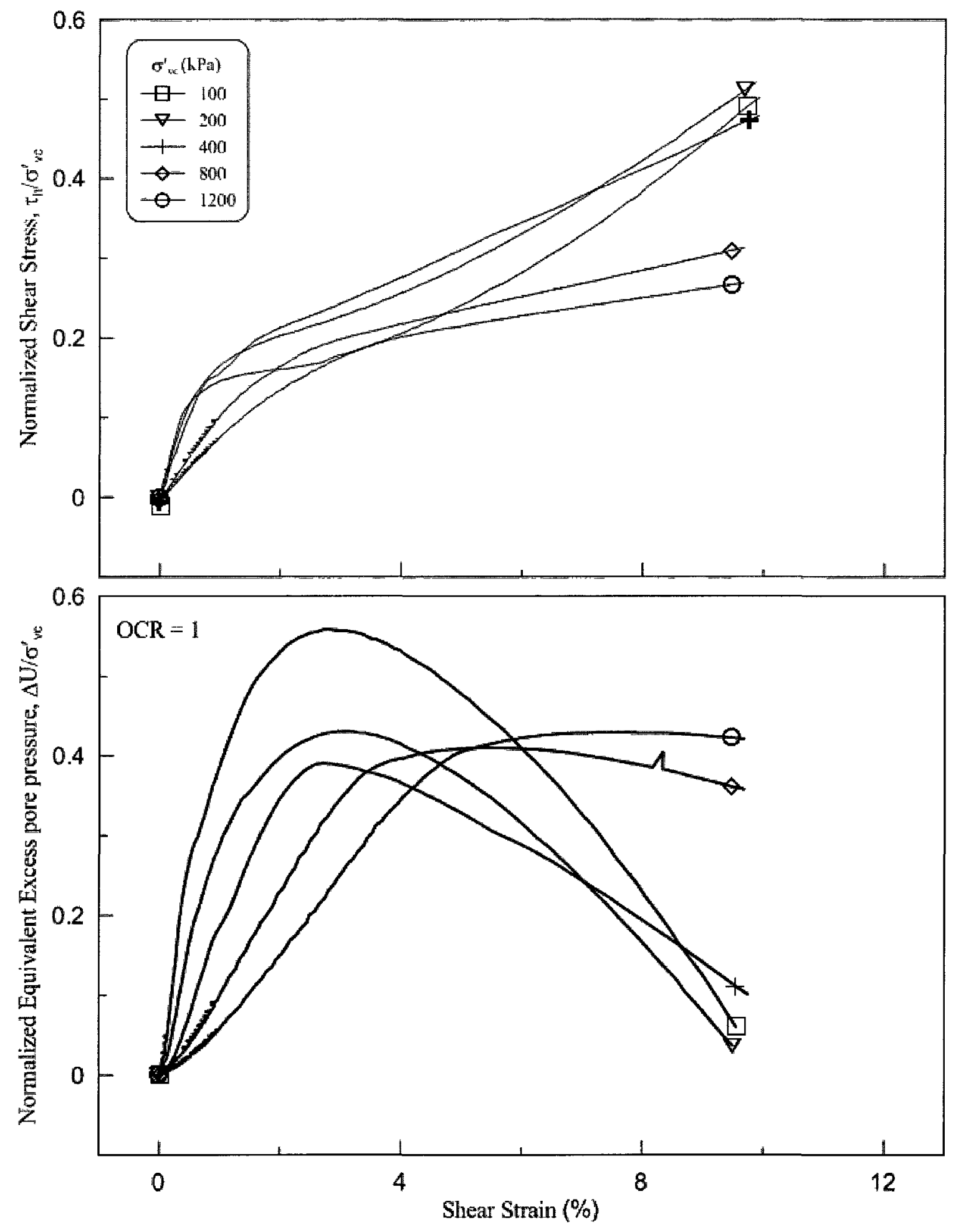

Fig. 6.2: Normalized shear stress and excess pore pressure at loosest state 


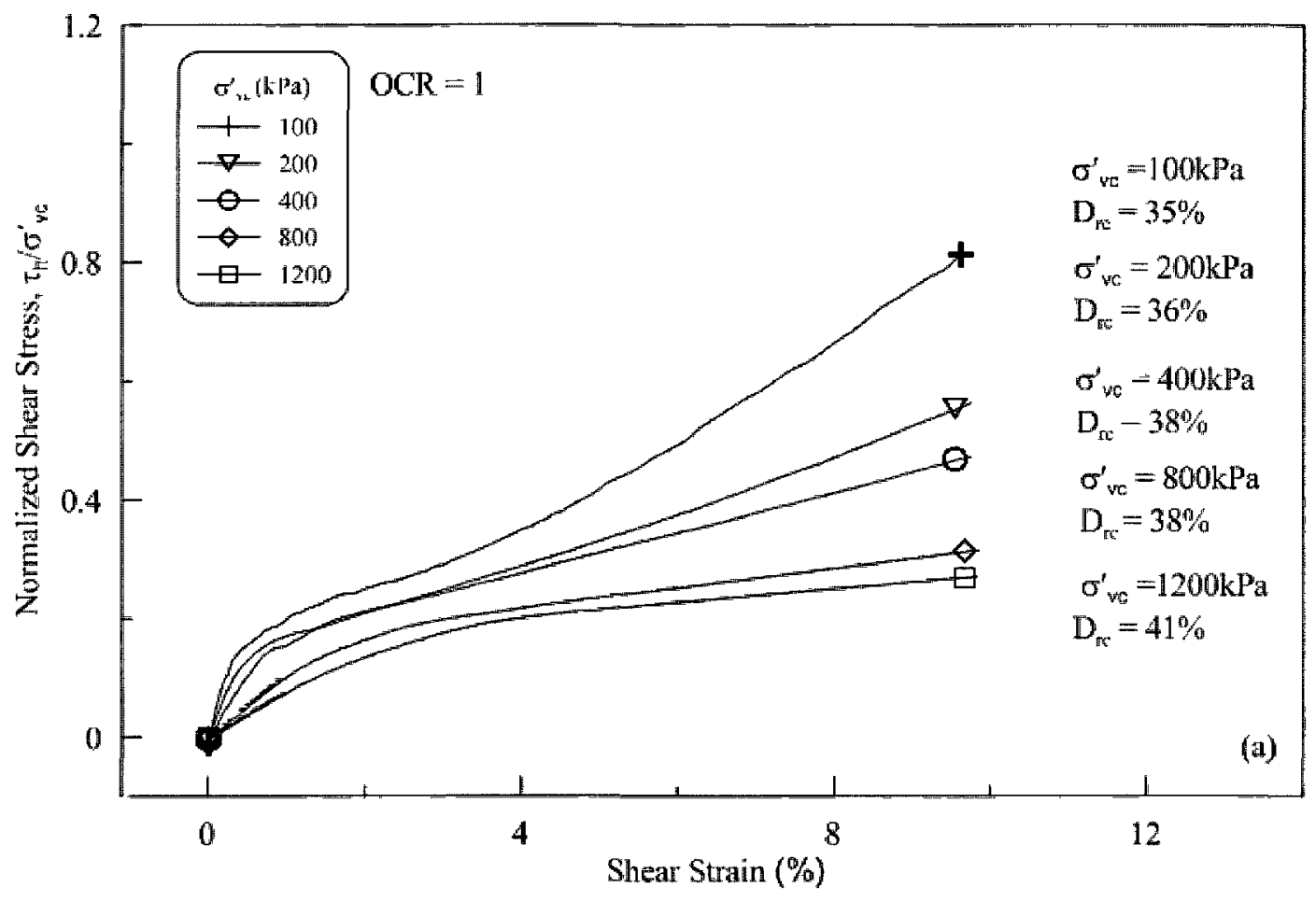

Fig. 6.3: Static behaviour of FRS.

\subsubsection{Dependence on OCR}

The dependence of undrained behaviour on the level of overconsolidation is demonstrated in Figure 6.5. All specimens were sheared undrained following consolidation to a stress level of $100 \mathrm{kPa}$. However, they were preloaded to yield different OCR values. A systematic increase in shear resistance, and dilation can be noted with increasing OCR. The relative densities of the specimens are somewhat different on account of the added stress history, but these differences are minor, and would not cause significant differences in the response. Such increase in resistance due to overconsolidation is consistent with the literature. Similar response was noted at other confining stress levels as well. 

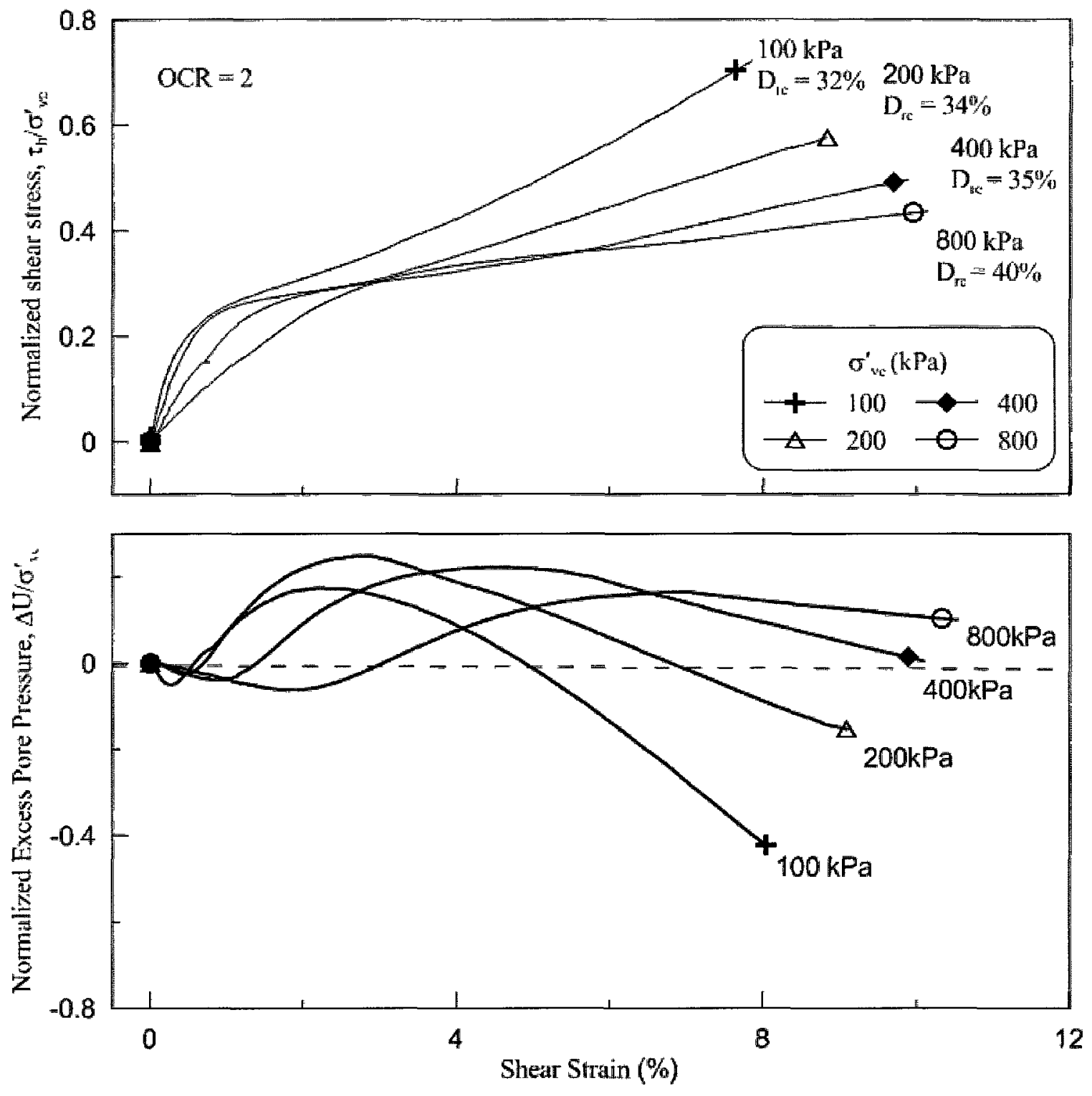

Fig. 6.4: Static behaviour at a given overconsolidation ratio.

The data presented in Figure 6.5 was used to derive the variation of initial modulus with overconsolidation ratio. Simple shear device normally yields a softer initial modulus, and it is recognized that this value would be smaller than the elastic $\mathrm{G}_{\max }$ of the material. However, they would be indicative of the dependence of $G_{\max }$ on OCR, and the modulus degradation characteristics. The variation of initial modulus $G_{i}$ as a function of OCR at different stress levels is shown in Figure 6.6(a), and as a function of the stress level in Figure 6.6(b). The significant 
increase in the modulus with confining stress level noted in the Figure is consistent with the data reported in the literature based mainly on studies on clays. Shear modulus is generally related to the stress level by $G_{i}=C_{1}\left(\sigma_{m c}^{\prime}\right)^{m}$, and exponent $m$ is generally considered to be 0.5 . Data presented in Figure 6.6(b) suggests that 0.5 might be somewhat conservative. Figure 6.7 shows the variation of modulus reduction with strain level. A clear dependency on OCR can be noted. The rate of modulus reduction decreases with increasing OCR. Such modulus reduction curves are widely employed in site response analyses using the equivalent linear method.
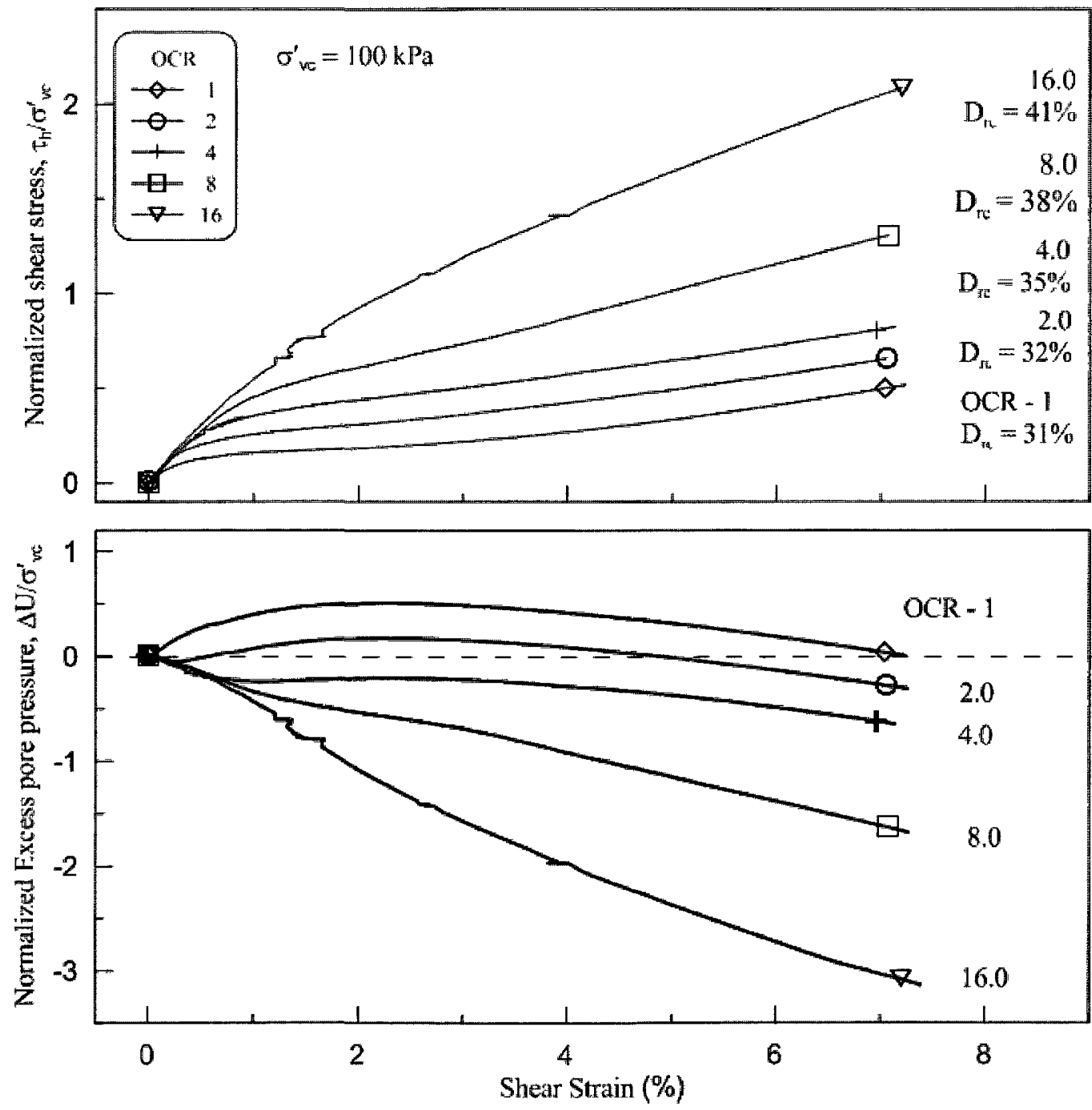

Fig. 6.5: $\quad$ Effect of OCR on static behaviour at a given confining stress level. 

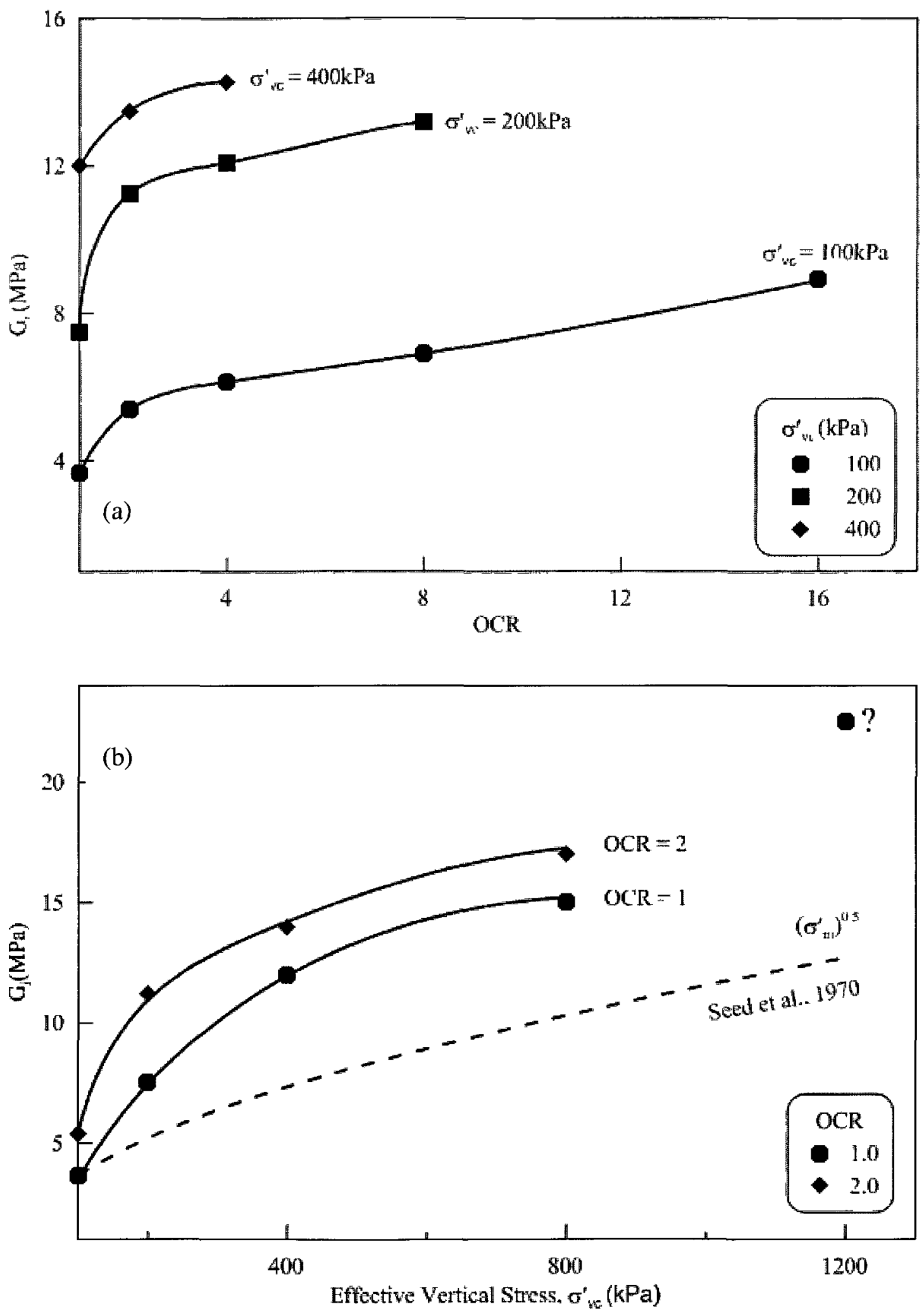

Fig. 6.6: $\quad$ Initial shear modulus changes with OCR (a) and confining stress level (b) 


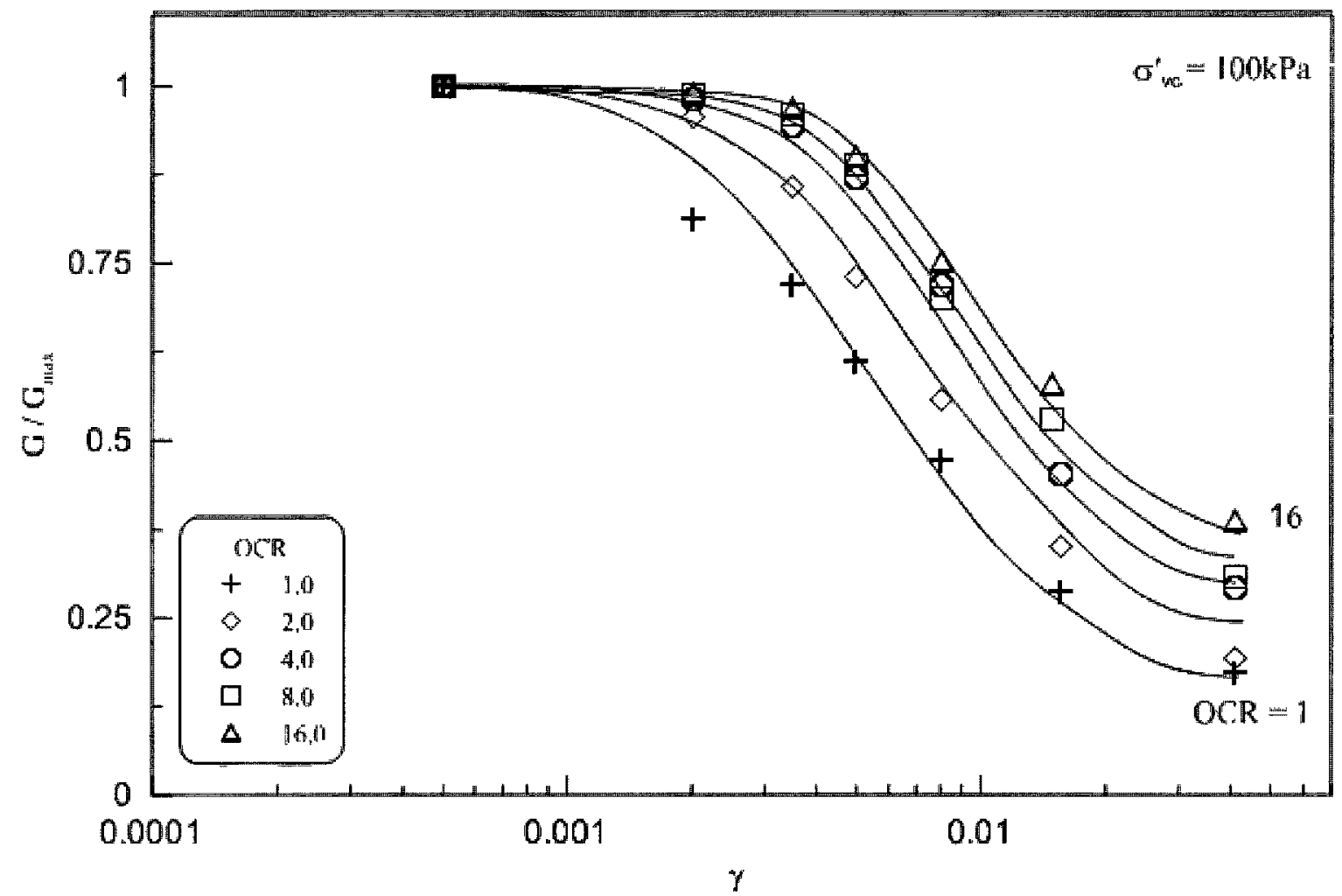

Fig. 6.7: Modulus reduction behaviour of FRS.

\subsection{Cyclic Liquefaction Potential}

Cyclic simple shear response of sands was assessed to better understand the effects of confining, static shear stress levels and overconsolidation ratio on liquefaction potential, and to establish the dependence, if any, of the $K_{\sigma}$ and $K_{\alpha}$ factors on overconsolidation. A series of tests at different cyclic stress ratio (CSR) values were conducted at each stress and OCR level over a range of relative density states. Because of the higher practical relevance, most of the tests were conducted at 100, 200 or $400 \mathrm{kPa}$ confining stress level, and OCR $=1$ (normally consolidated), 1.5 or 2 . A limited number of tests were conducted at higher stress levels of $800 \& 1200 \mathrm{kPa}$, and higher OCR values of $3,4 \& 8$. The CSR applied ranged from 0.125 to 0.260 depending on OCR and density, and was selected to yield a cyclic resistance curve covering the range of interest for typical earthquake magnitudes. This was required to obtain confident values of the 
cyclic resistance ratio. Tests were conducted on semi-angular Fraser River sand, and subrounded silica sand to assess possible effects of particle shape.

As noted earlier, liquefaction in simple shear has been defined as the exceedance of single amplitude of shear strain of $3.75 \%$ without any regard to the mechanism responsible. The strain can develop during cyclic loading as a result of contractive flow deformation or cyclic mobility depending on stress level, applied cyclic amplitude, over consolidation ratio, and relative density. Behaviour of Fraser River sand with no initial static shear is presented and discussed first, followed by the response of FRS subjected to initial static shear.

\subsubsection{Cyclic Response \& Overconsolidation}

Figure 6.8 compares the cyclic behaviour of Fraser River sand deposited essentially at the loosest state, and consolidated to $200 \mathrm{kPa}$ confining stress level with no initial static shear, but with different stress histories. One of the specimens was normally consolidated, but others were pre-loaded to $300,400 \& 600 \mathrm{kPa}$ vertical effective stress prior to unloading to the final consolidation stress level of $200 \mathrm{kPa}$ to yield OCR values of 1.5, 2 and 3. The final consolidated void ratio varies somewhat on account of the different stress-histories, but the changes are minor, and would not influence the cyclic resistance in any significant way. All specimens were subjected to a cyclic shear stress of $30 \mathrm{kPa}(\mathrm{CSR}=0.15)$.

A significant dependence of cyclic resistance on OCR can be clearly noted in the Figure. The number of cycles to liquefaction based on a strain criteria was $6,13,59$ and 119 for OCR $=$ $1.0,1.5,2.0$, and 3.0 respectively. The maximum excess pore pressure in the tests varies between $95-98 \%$, and no trend was noted depending on OCR. However, the rate of excess pore pressure generation decreases with increasing OCR on account of the increasing dilative tendencies in the soil. After 5 cycles of loading at CSR $=0.15$, the normally consolidated soil generated about 
$92 \%$ of peak excess pore water pressure, but the peak excess pore pressure in sands at OCR values of 1.5 and 2 , and were about $30 \%$, and $2 \%$ respectively. Sand at OCR $=3$ and higher developed negative excess pore water pressures during the early stages of loading. Such reduction in excess pore pressure generation is the key reason for the increased cyclic capacity in overconsolidated sands. The stress-strain responses of the four tests are shown in Figure 6.9. Cyclic mobility was clearly the mechanism leading to liquefaction in overconsolidated soils, and no significant strain softening or flow deformation was noted in any of the tests, even though the relative density levels are fairly low, and close to the loosest possible states at the given initial state. Such dilative tendencies in water deposited Fraser River sand has been well established in the literature (Vaid \& Thomas, 1994; Vaid and Sivathayalan, 1996; Vaid et al 2001), and occurs of account of the soil fabric that ensues following pluviation of the sub-angular particles. Similar dependency of cyclic resistance on OCR was noted at all stress and CSR levels, and these finding are analysed and summarised below.

\subsubsection{Number of cycles to liquefaction}

The variation of the number of cycles required to trigger liquefaction at a given CSR is shown in Figure 6.10 as a function of the relative density. Tests were conducted over a range of relative densities, and a plot in this form permits the estimation of the number of cycles to liquefaction at select density states (e.g, $\mathrm{Dr}=40 \%$ or $70 \%$ ) using interpolation. These values are used in subsequent discussion to discuss the effects of a select variable, but at a constant density. As expected, the number of cycles to liquefaction increases with density, and an essentially linear variation is noted between $\log (N)$ and $D_{r}$ regardless of the CSR or OCR. The rate of increase is dependent on CSR, and this dependency is only marginally affected by the level of OCR. 

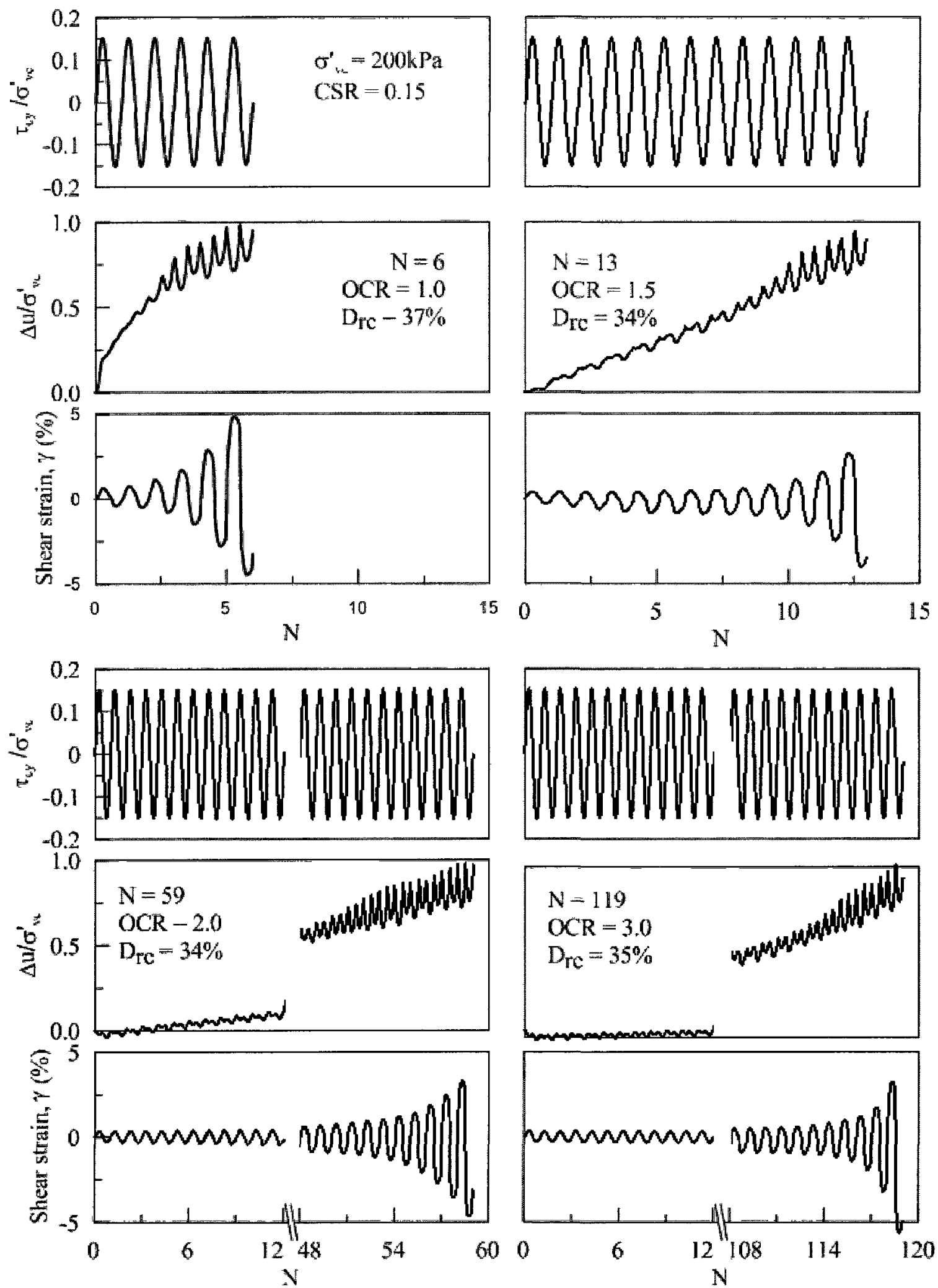

Fig. 6.8: Cyclic test results at different OCR levels 

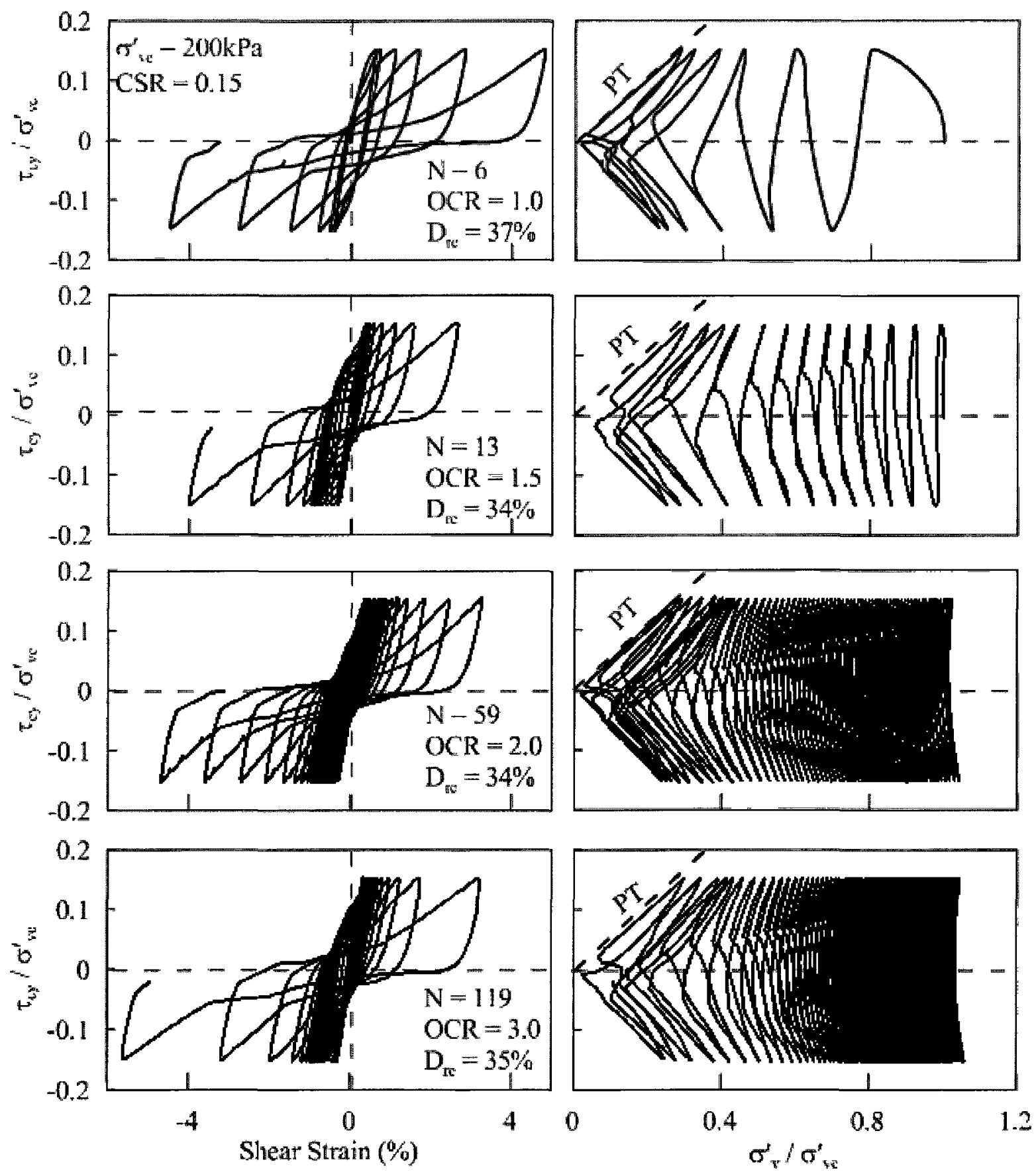

Fig.6.9: $\quad$ Stress-Strain and stress path responses at different OCR levels 
For example, the number of cycles to liquefaction at $\mathrm{CSR}=0.18$ increases from about 3 to 27 in normally consolidated sand and from about 220 to 2040 at $\mathrm{OCR}=4$, as $D_{r}$ increases from $40 \%$ to $70 \%$. Both cases represent an increase of about nine-fold. However, at CSR $=0.26$, the number of cycles increase from 1 to 4 in the normally consolidated soil, and from 30 to 98 at $\mathrm{OCR}=4$, which represents a lower rate of increase. This indicates that density plays a much more prominent role at low levels of shaking compared to higher levels of shaking.

Figure 6.11 shows the variation of number of cycles to liquefaction with relative density at a given CSR but at different confining stress levels. At a given relative density, the number of cycles required to trigger liquefaction decreases with increasing stress level. As noted in the section on monotonic response, increasing confining stresses decrease the dilative tendencies (or increase contractiveness) and thus leads to a relatively weaker response. The dependence of cyclic resistance on stress level is also illustrated in Figure 6.12 in the form of number of cycles vs confining stress level.

Number of cycles required to trigger liquefaction in sand at $D_{r}=50 \%$ decreases from 8 to 5 in Normally consolidated sand as the confining stress level increases from $100 \mathrm{kPa}$ to $400 \mathrm{kPa}$. This figure demonstrates that while confining stress level influences the number of cycles to liquefaction at a given CSR and $D_{r}$, its effect is relatively small compared to that of OCR. Figure 6.13 shows the variation of the number of cycles to liquefaction as a function of OCR at a fixed relative density state $\left(D_{r}=41 \%\right)$ and confining stress $\left(\sigma_{v c}^{\prime}=200 \mathrm{kPa}\right)$ state. An essentially linear variation of $\log (N)$ with OCR is noted at each CSR level. As noted earlier, the rate of increase is larger at lower CSR levels. This figure allows quantification of the levels of additional load cycles that can be supported by an overconsolidated soil at a given CSR. 


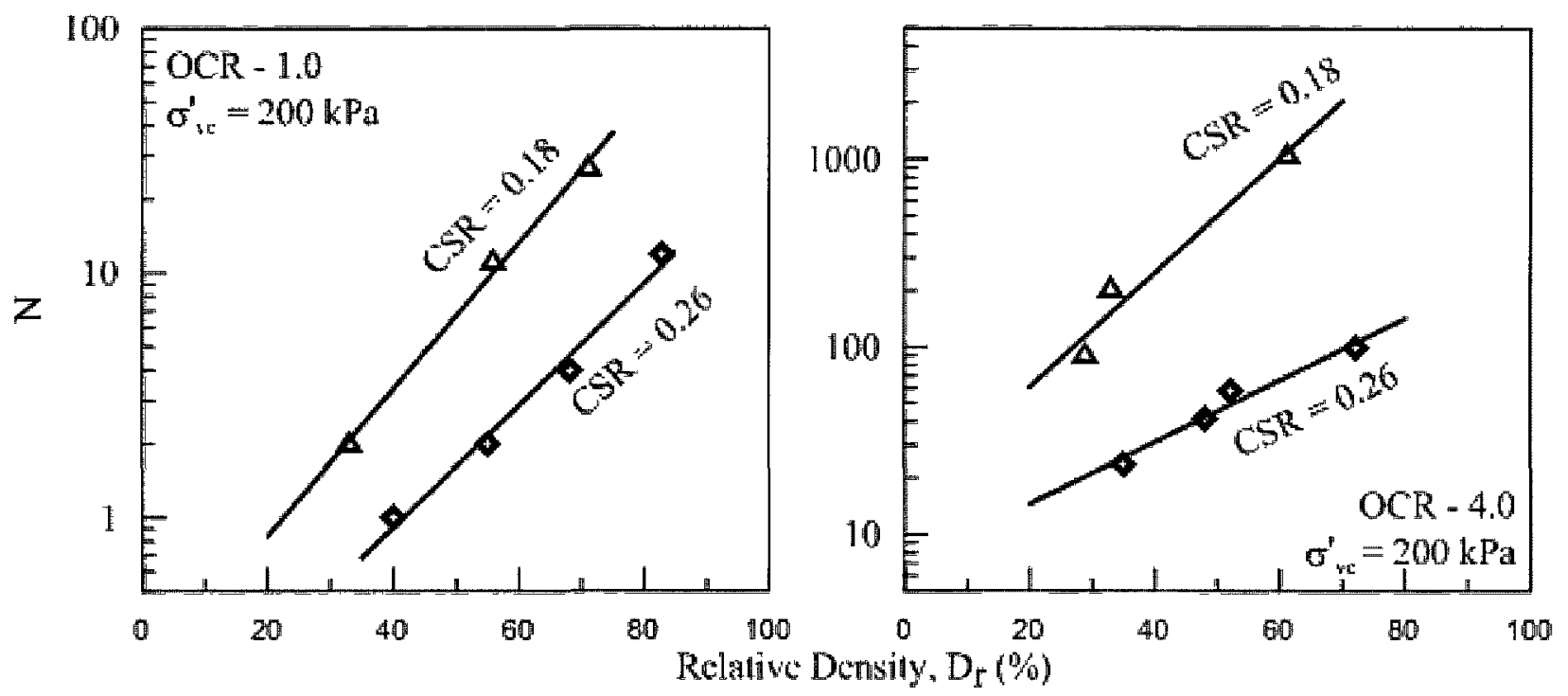

Fig 6.10: Dependence of cyclic simple shear resistance at different OCR values

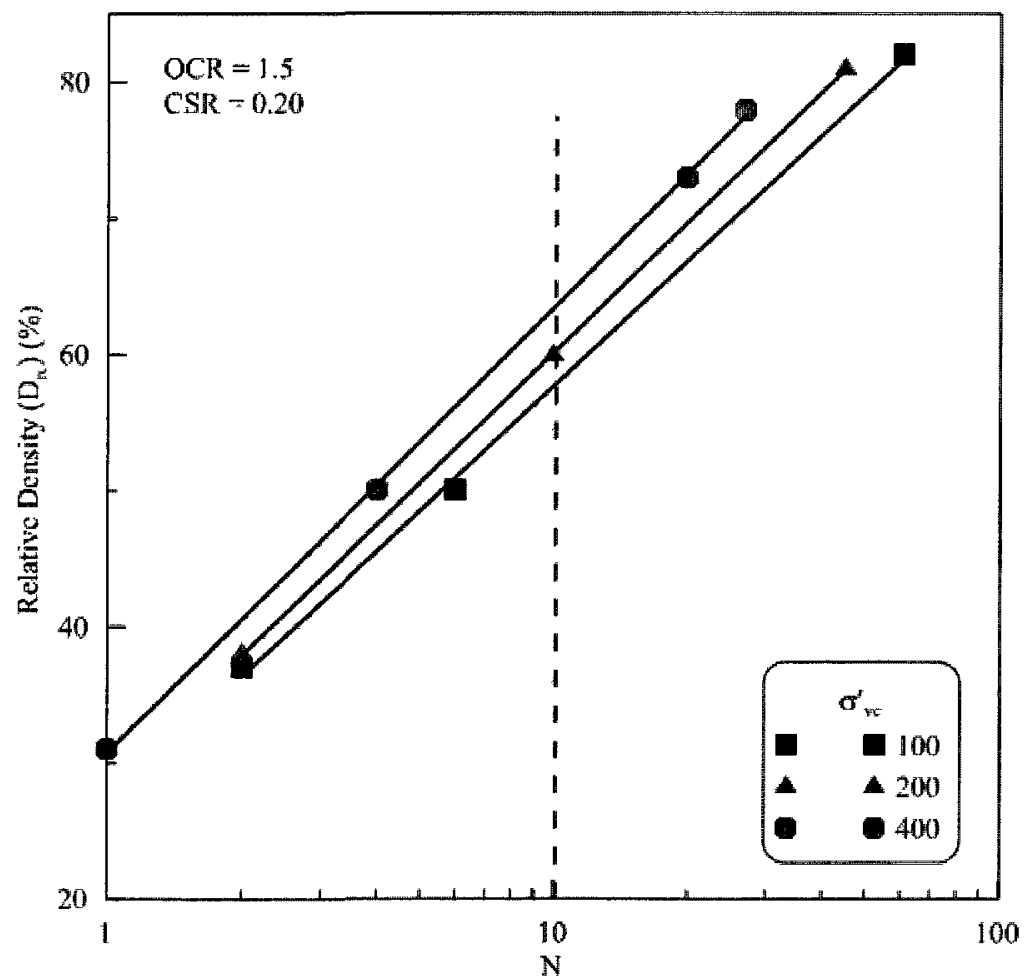

Fig. 6.11: Variation of number of cycles to liquefaction at a given CSR and OCR level 


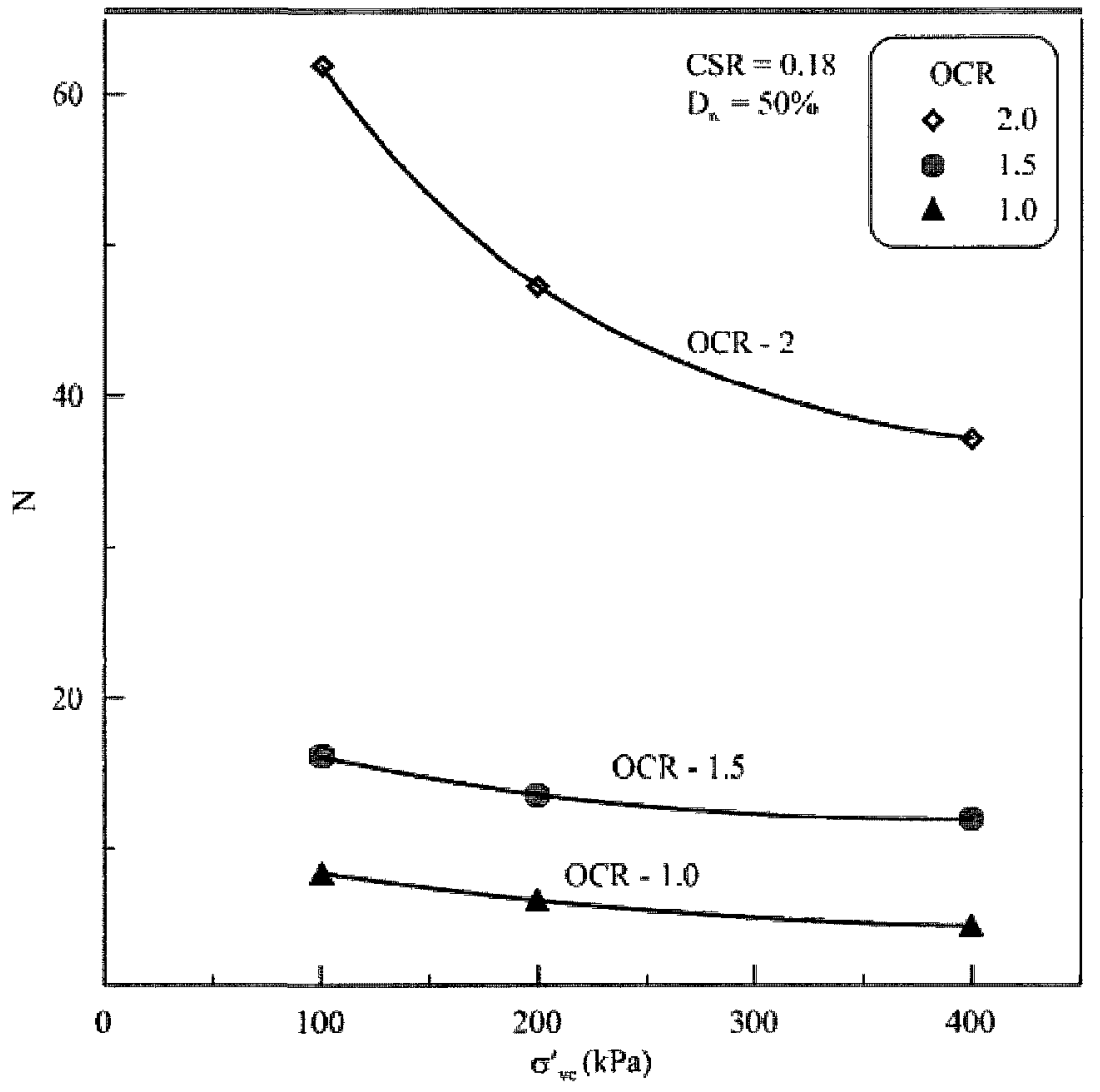

Fig 6.12: Variation of number of cycles with confining stress at a given relative density.

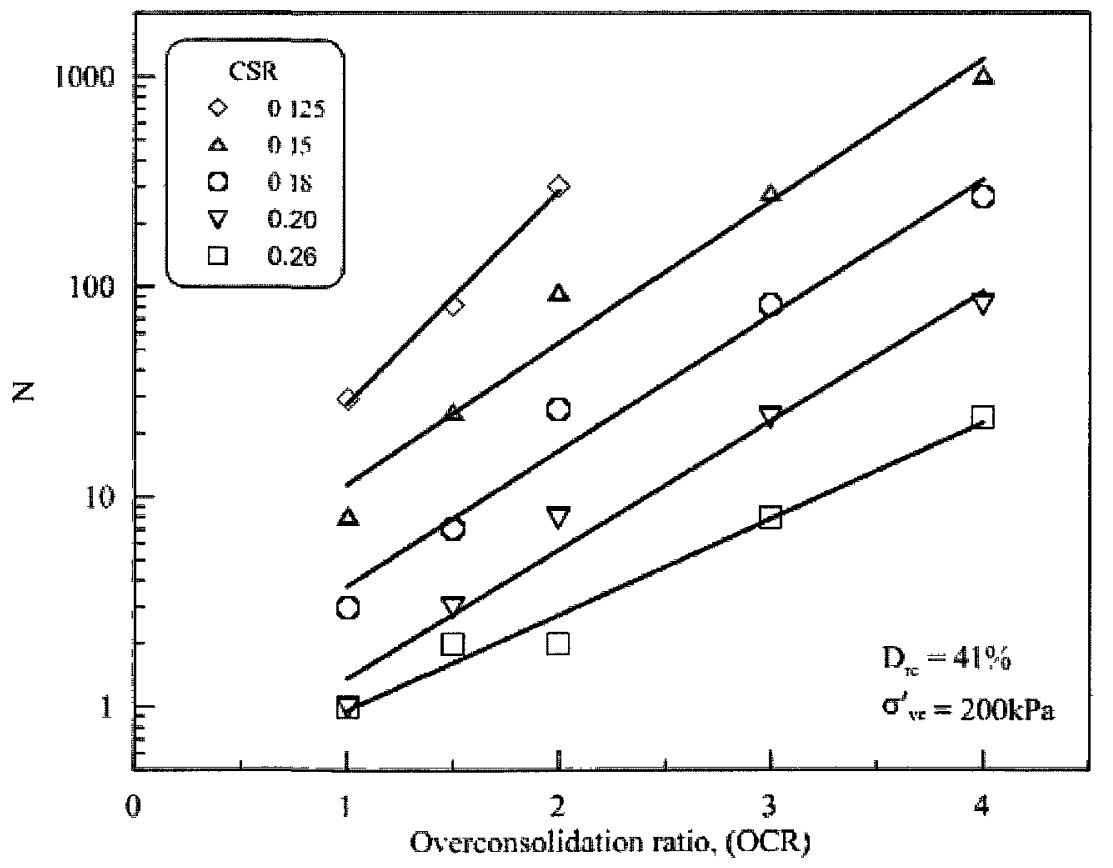

Fig. 6.13: Variation of number of cycles to liquefaction with OCR at a given $D_{r}$ of $41 \%$ 
Cyclic stress ratio values, in practice, are related to the peak ground acceleration, and it is evident that for a given peak ground acceleration overconsolidated soils can sustain larger number of load cycles that are expected with larger earthquake magnitudes. The data shown in Figure 6.13 is used to derive a ratio of the number of cycles to liquefaction at a given OCR to that of normally consolidated sand. This ratio, named $K_{O C N}$ herein, and is defined as

$$
K_{O C N}=\frac{\text { No. of cycles to liquefaction at a given } O C R, D_{r} \& \sigma_{v c}^{\prime}}{\text { No. of cycles to liquefaction in } N C \text { soil at the same } D_{r} \& \sigma_{v c}^{\prime}}=\frac{N_{O C R}}{N_{N C}}
$$

$K_{O C N}$ represents the increase in number of cycles to liquefaction due to overconsolidation alone. Figure 6.14 shows the variation of $K_{O C N}$ with OCR at a given density and stress level at different CSR levels. A significant increase in the number of cycles to liquefaction at a given CSR can be noted with increasing OCR. The rate of gain in cyclic strength is dependent on CSR and increases with decreasing CSR. The variation of $K_{O C N}$ with OCR is approximately exponential (except near the NC region), and this suggests that equation (6.2) can be used to estimate the number of cycles to liquefaction in overconsolidated Fraser River sand at a given OCR, if the number of cycles to liquefaction in normally consolidated sand is known

$$
N_{O C R}=M e^{n O C R} N_{N C}
$$

Where, $M$ and $n$ are empirical constants, and would be expected to be $f\left(D_{r}, \sigma_{v c}^{\prime}, C S R\right)$ in general. Plots similar to that of Figure 6.14 but at different confining stress levels, shown in Figure 6.15 indicate that $\mathrm{M}$, and $\mathrm{n}$ are not significantly influenced by the effective confining stress level. The variation when considering different stress levels is less than $10 \% \mathrm{in} \mathrm{n}$, and less than $2 \%$ in $\mathrm{M}$. This indicates that the effect of confining stress level is essentially uniform across the various OCR values. The initial increase in $K_{O C N}$ as OCR increases from one is somewhat larger compared to the variation noted for OCR values ranging from 1.5 to 4 in general. 


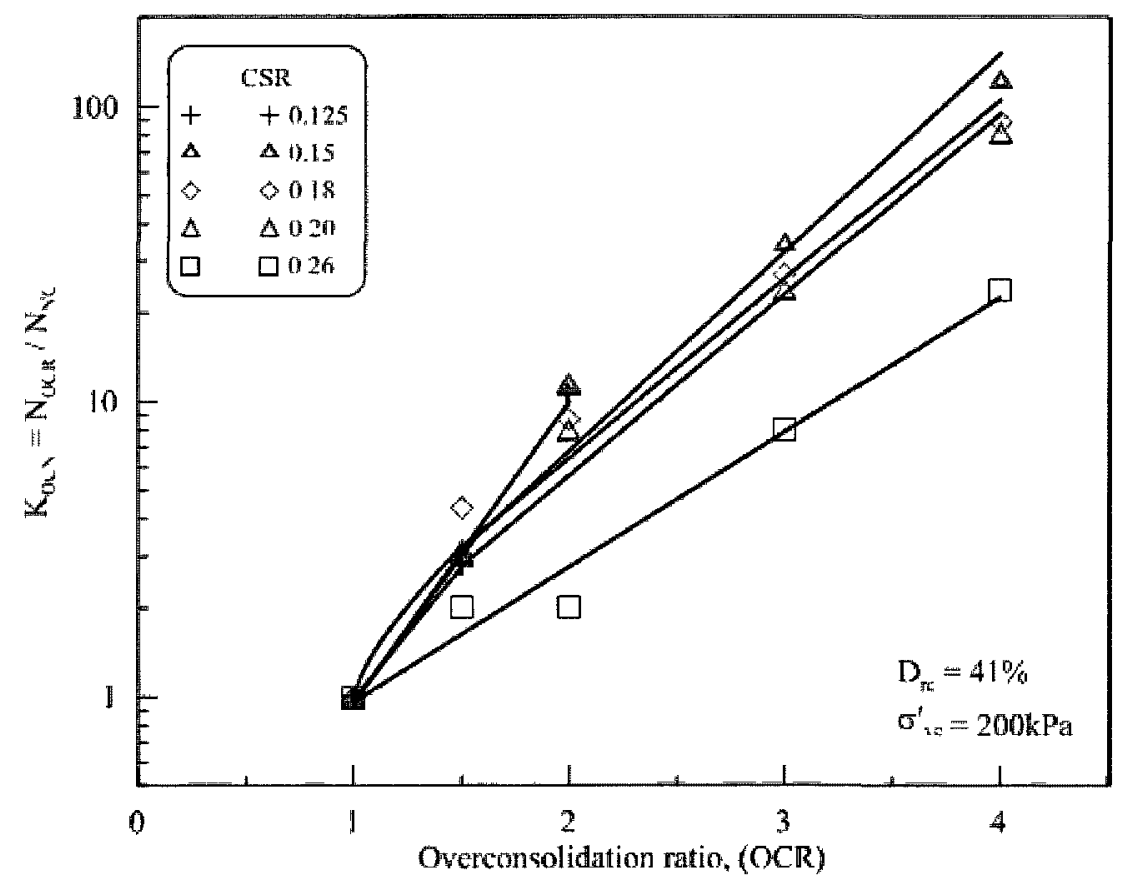

Fig. 6.14: $\quad$ The variation of $K_{O C N}$ with OCR at several CSR levels

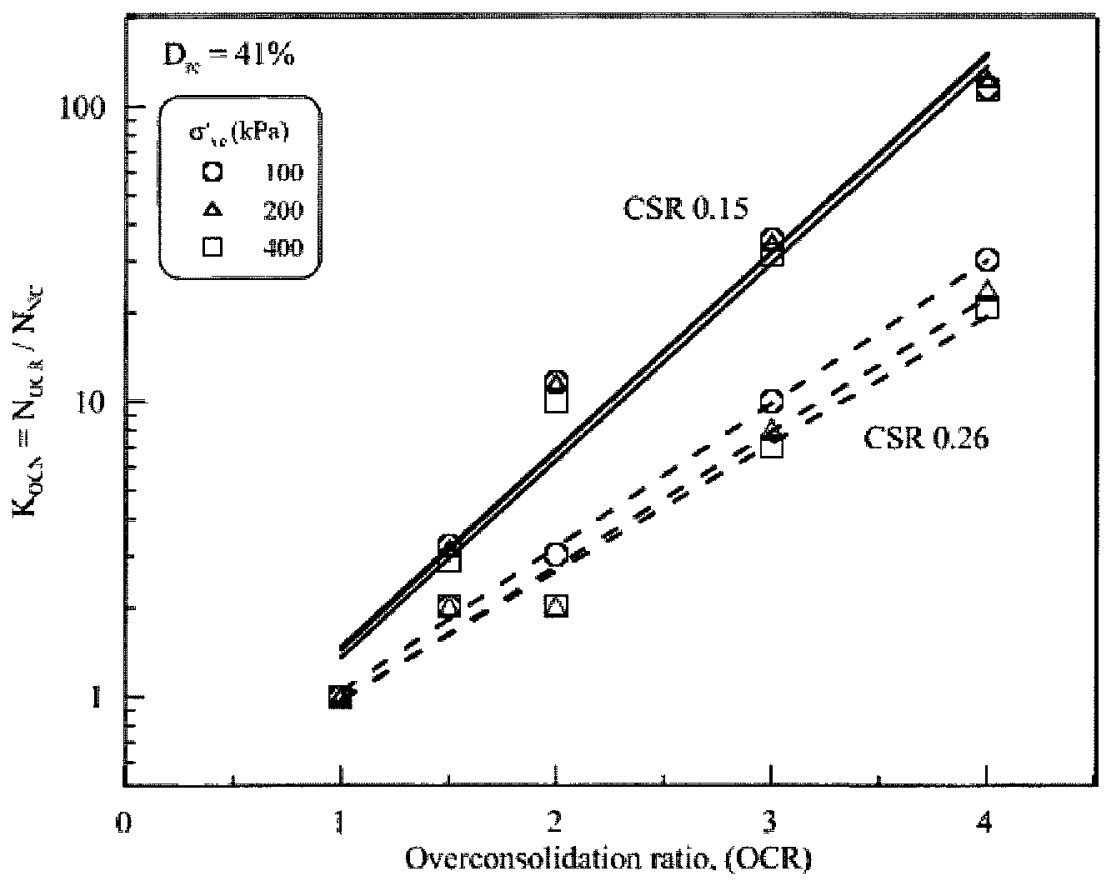

Fig. 6.15: The variation of $K_{O C N}$ with OCR at stress levels for selected CSR levels 


\subsubsection{Cyclic Resistance Ratio, CRR}

The variation of the cyclic resistance ratio, CRR of the sand with relative density is shown in Figure 6.16 at different OCR levels, but at a fixed confining stress level of $100 \mathrm{kPa}$. CRR values reported herein correspond to liquefaction in 10 cycles, which is characteristic of an M 6.75 earthquake. These CRR values were determined from plots similar to Figure 6.11 by estimating the relative density state at which a given CSR would cause liquefaction in 10 cycles. Similar data, but at higher confining stress levels of $200 \& 400 \mathrm{kPa}$ is shown in Figures 6.16 (b) \& 6.16(c). These figures clearly show that the CRR of the sand at a given stress level increases with increasing relative density and OCR. Best fit trend lines for the data, shown in Figure 6.16 indicate that the nature of the trend is essentially similar at all stress levels. These trend lines enabled interpolation, and determination of CRR values at select density states for further analysis.

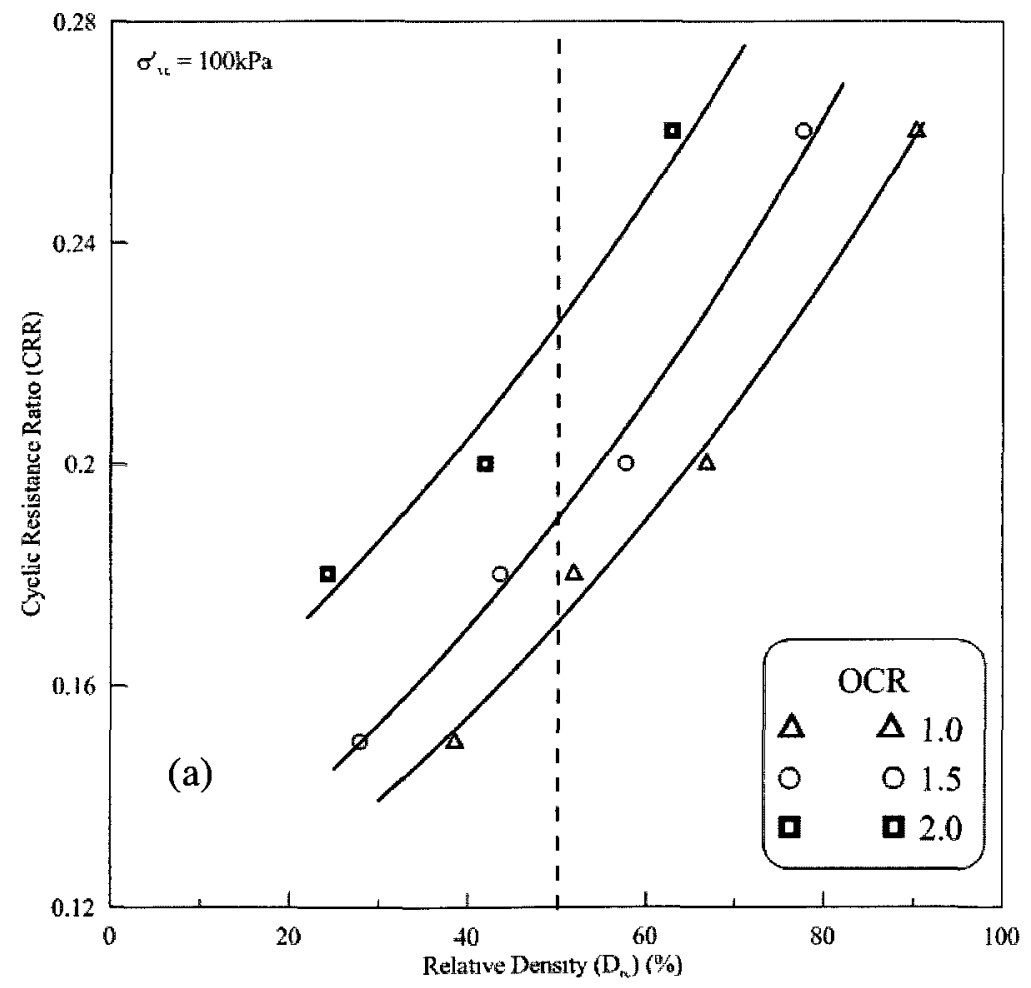

Fig 6.16(a): The variation of the cyclic resistance ratio, CRR of the sand at $100 \mathrm{kPa}$ 

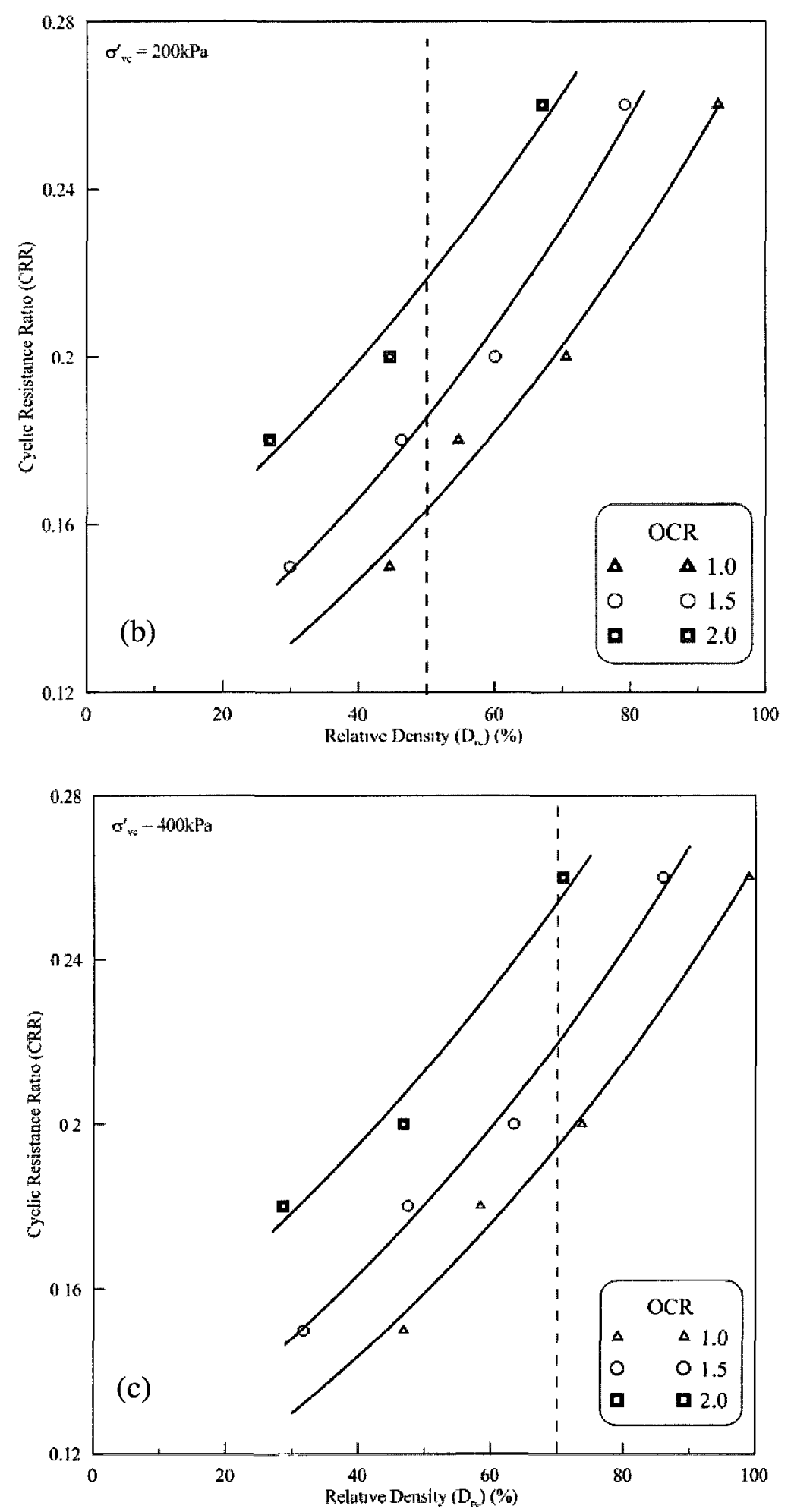

Fig. 6.16: The variation of CRR of the sand at (b) $200 \mathrm{kPa}$, and (c) $400 \mathrm{kPa}$ 
As noted in the literature review, site specific values of cyclic resistance CRR are generally determined by establishing a reference CRR, and correcting it with appropriate $K_{\sigma}$ and $K_{\alpha}$ values to account for the effects of confining stress level, and static shear. Current design practice generally ignores the effects of overconsolidation, and establishes the reference CRR at the normally consolidated state. A new correction factor, called $K_{O C R}$ herein is used to enable corrections to the calculated CRR to account for the effects of overconsolidation. $K_{O C R}$ is defined as the ratio of the cyclic resistance of overconsolidated soil to that of normally consolidated soil, $\left(K_{O C R}=C R R_{O C R} / C R R_{N C}\right)$ at a given density and stress state as shown in equation (6.3)

$$
K_{O C R}=\frac{C R R_{O C R,} \sigma, D_{r}}{C R R_{N C,} \sigma, D_{r}}
$$

The CRR data shown previously has been used to calculate the $K_{O C R}$ values shown in Figure 6.17(a) over a range of consolidation stress levels, but at a fixed $D_{r}=40 \%$ density states. The data clearly indicates that increasing stress levels do not affect the relative performance at a given OCR. The level of consistency in $K_{O C R}$ at different stress levels, but at the same OCR, is remarkable. Similar data, but at different relative density states is shown in Figures 6.17(b) to (d) confirms that the same level of consistency exists across all density states.

Dependence of $K_{O C R}$ on relative density state is assessed in Figure 6.18, which shows its variation with relative density at two OCR levels. The scatter in the data makes proper evaluation of the dependence of $K_{O C R}$ on density difficult, but the data suggests the influence of density, if any, would be fairly minimal compared to the influence of OCR. The relationship suggested by Ishihara et al (1979) based on tests results on Fuji River sand at $D_{r}=55 \%$ would significantly overestimate this correction factor. In addition Ishihara et al.'s formulation implies a linear relationship on a log-log scale, but these results suggest that a much simpler linear relationship on an arithmetic scale can be a reliable approximation. The test data reported herein 
indicates that simple equation given by $K_{O C R}=1+0.3(O C R-1)$ can be used as a first approximation to correct for the effects of overconsolidation in Fraser River sand regardless of the stress or density state. Obviously, the use of this equation should not be extended to OCR values larger than two unless additional test data supporting this equation has been established. The results reported suggest that increasing the OCR of in-situ soils (e.g., pre-loading) can be effective in safeguarding against soil liquefaction.

A comparison of the magnitude of the changes in $K_{O C R}$ in Fig. 6.17 with those of $K_{O C N}$ in Fig. 6.15 clearly indicates that the effect of OCR on number of cycles to liquefaction at a given CSR is much larger than its effect on CRR, which represents the ability of the soils to resist the applied CSR in a given number of cycles.

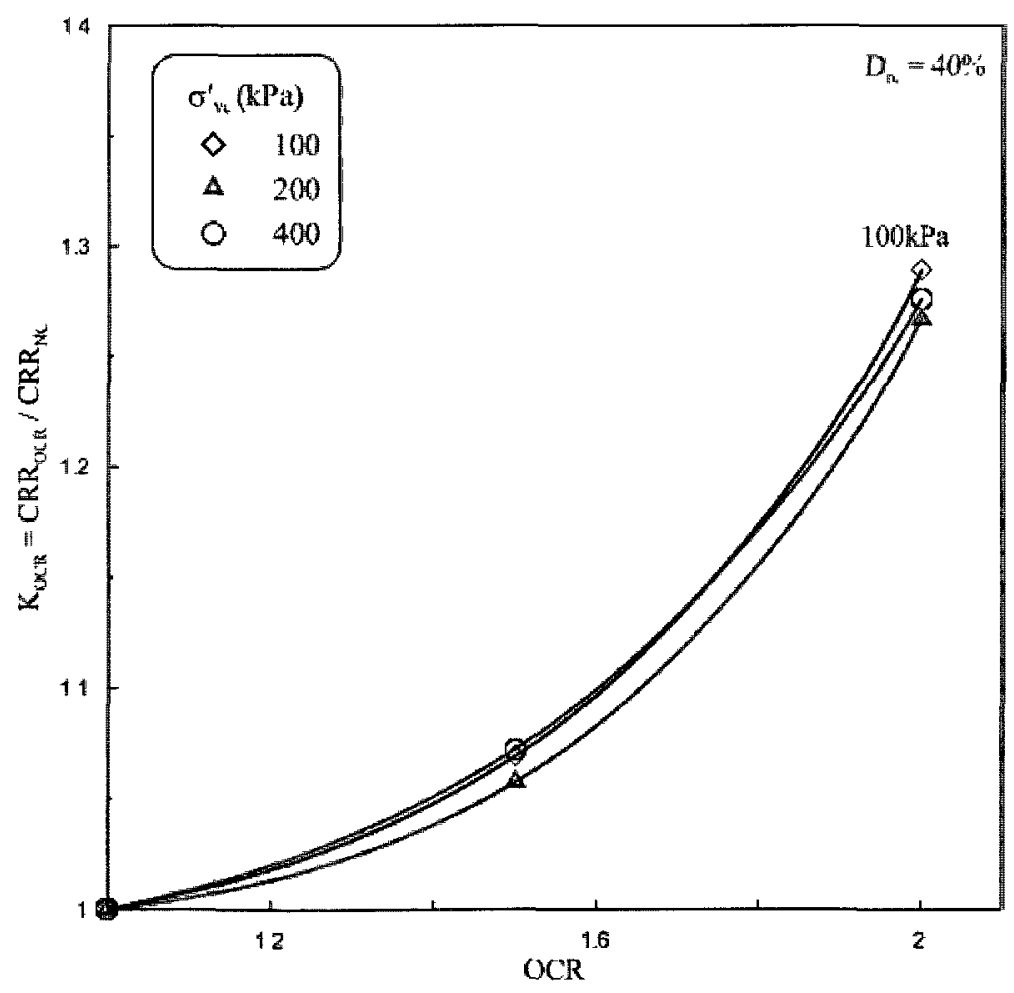

Fig. 6.17 (a): Variation of $\mathrm{K}_{\mathrm{ocr}}$ over the range of OCR at $40 \%$ relative density. 

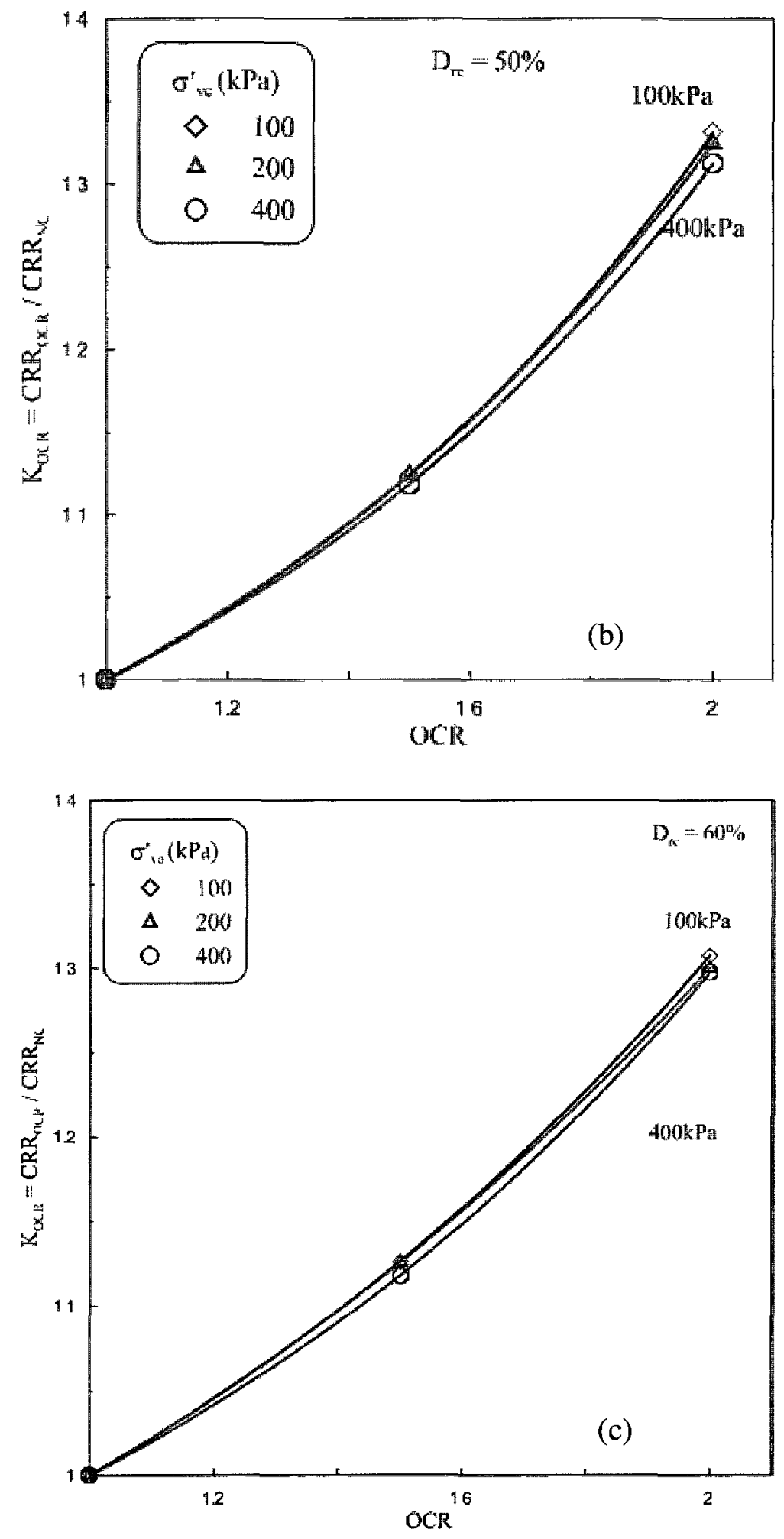


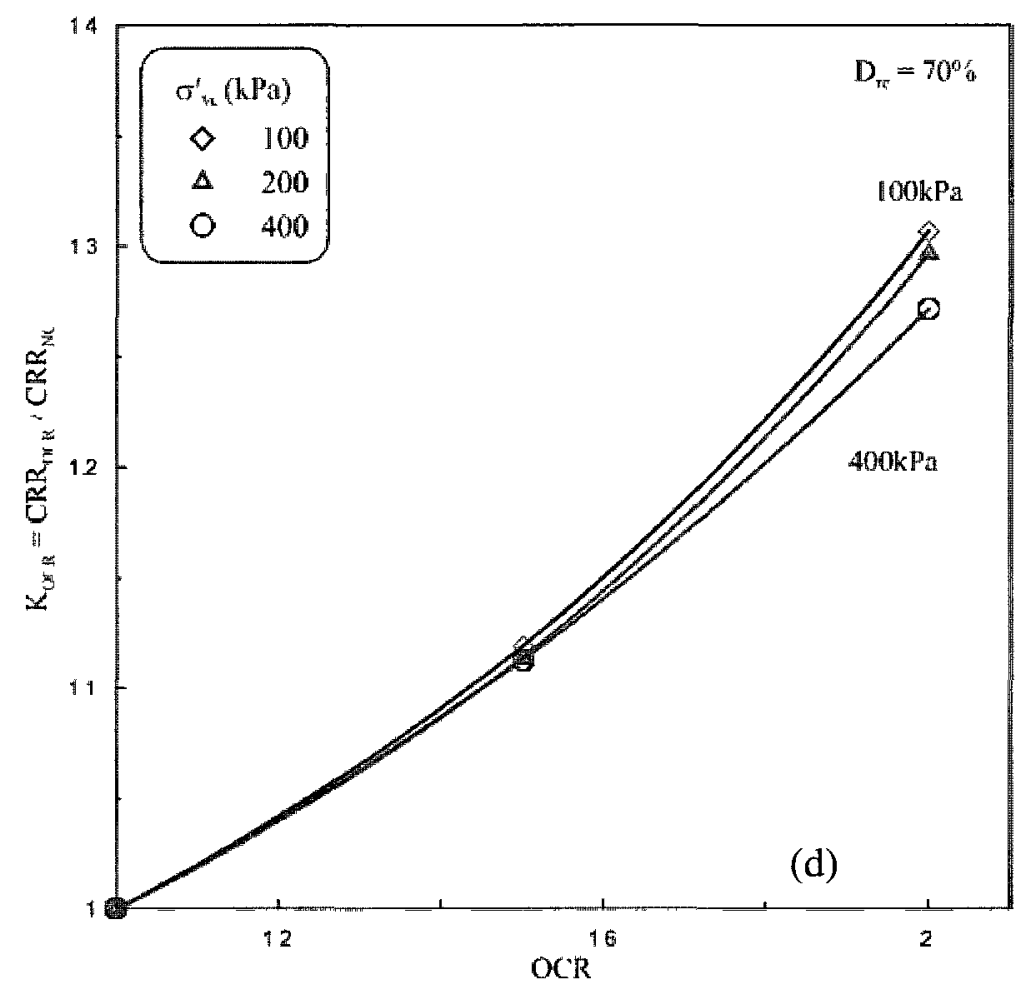

Fig. 6.17: Variation of $\mathrm{K}_{\mathrm{ocr}}$ with $\mathrm{OCR}$ at (b) $50 \%$, (c) $60 \%$, and (d) $70 \%$ relative density.

Current design practice typically deals with the consequences of a design earthquake of a given magnitude, and thus the interest is often on CRR, and not the number of cycles. Number of significant load cycles is related to the magnitude of the earthquake and thus is considered fixed once a design earthquake magnitude is selected. In that sense, the factor $K_{O C N}$ does not have the same level of practical relevance compared to $K_{O C R}$.

\subsection{4 $K_{\sigma}$ Correction factor}

$K_{\sigma}$ correction factor is widely used in practice to account for the influence of confining stress level of cyclic resistance. Values recommended by Youd et al (2001) based on the data available in the literature (Vaid \& Chern, 1985; Seed \& Harder, 1990; Vaid \& Sivathayalan, 1996, Vaid et al 2001) are routinely adopted in practice, but these values do not consider the possible effects of OCR on this factor. The traditional definition of $K_{\sigma}$ is extended herein to 
compare the CRR at a given stress level and OCR to that at $100 \mathrm{kPa}$ but the same OCR as shown as shown in equation (6.4)

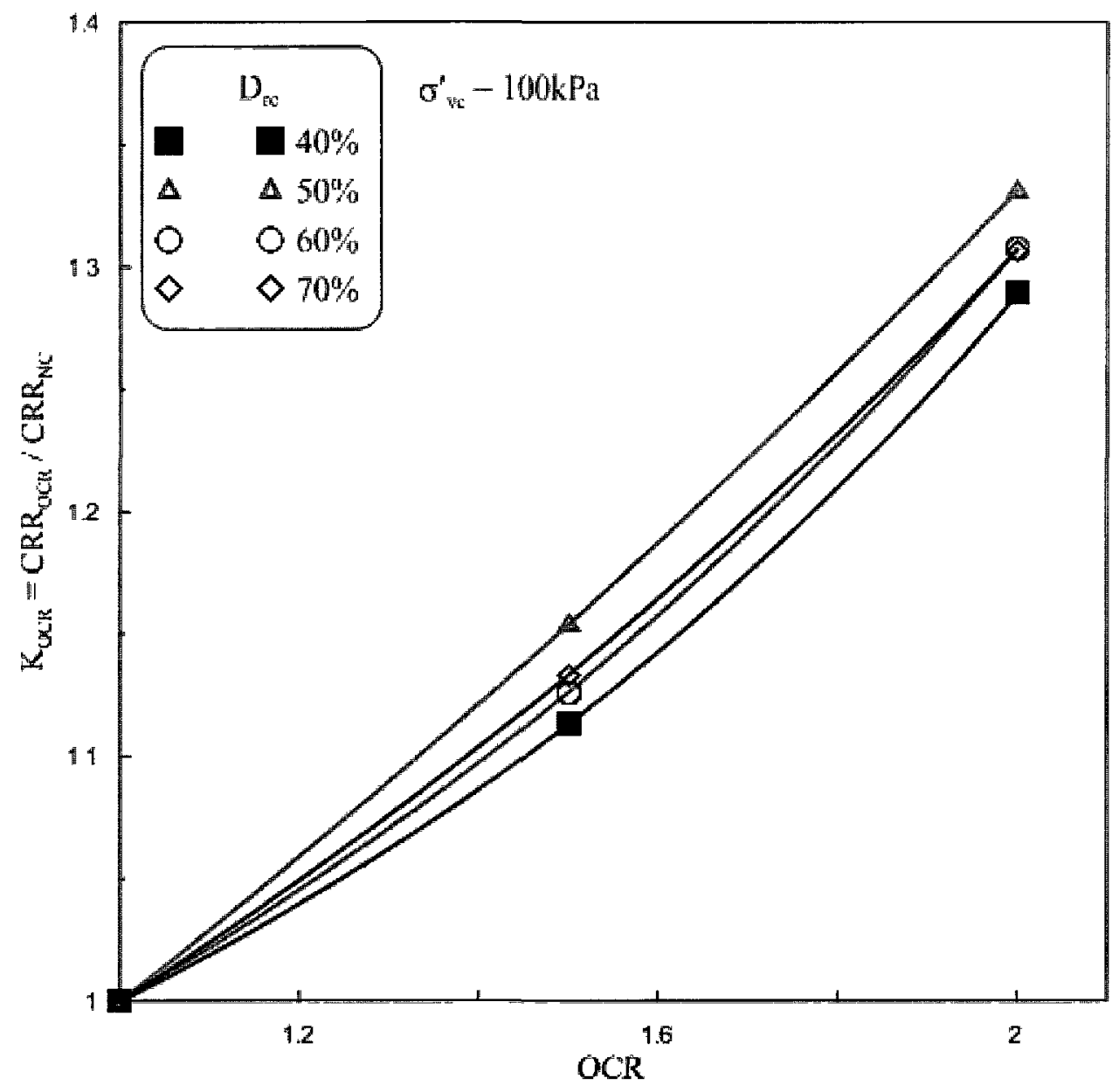

Fig 6.18: $\quad$ Dependency of $\mathrm{K}_{\mathrm{OCR}}$ on relative density.

$$
K_{\sigma}=\frac{C R R_{\sigma,} \text { oCR }}{C R R_{\sigma=100 k P a,} \text { oCR }}
$$

This will permit an assessment of the effects of OCR on $K_{\sigma}$ be made from the data presented previously. Figure 6.19 (a) shows the variation of $K_{\sigma}$ with confining stress level at a relatively loose $D_{r}=40 \%$ state, and Figure 6.19(b) at a dense $D_{r}=70 \%$ state. A systematic reduction in 
$K_{\sigma}$ can be noted with increasing OCR regardless of the density state. However, the magnitude of change is fairly small (about $2-3 \%$ ) at both density states. This suggests that existing $K_{\sigma}$ correlations based on normally consolidated sands can be used in overconsolidated sands with reasonable accuracy.

Relatively higher $K_{\sigma}$ values are observed at the looser density state of $40 \%$ compared to the denser state. Such dependency of $K_{\sigma}$ on density level has been reported by Vaid \& Sivathayalan (1996) and Haynes \& Olsen (1998), and is reflected in the NCEER summary report (Youd et al., 2001). $K_{\sigma}$ values calculated herein for the normally consolidated sand at the loose density state are quite comparable to those reported in the literature for similar sand. However, the values at higher density state calculated in current research are about $10 \%$ larger compared to the values in the literature for Fraser river sand. These differences are probably due to the differences in the gradation and composition of the sands used in the research programs.

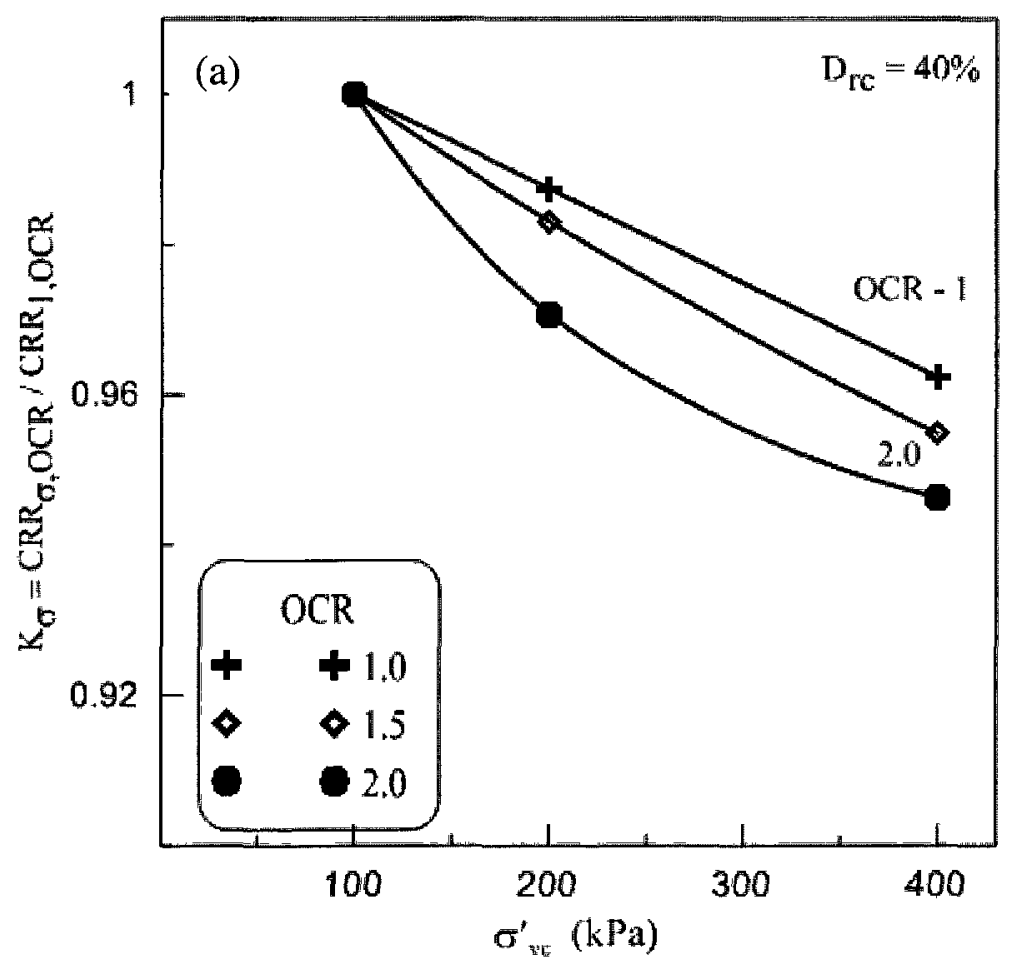




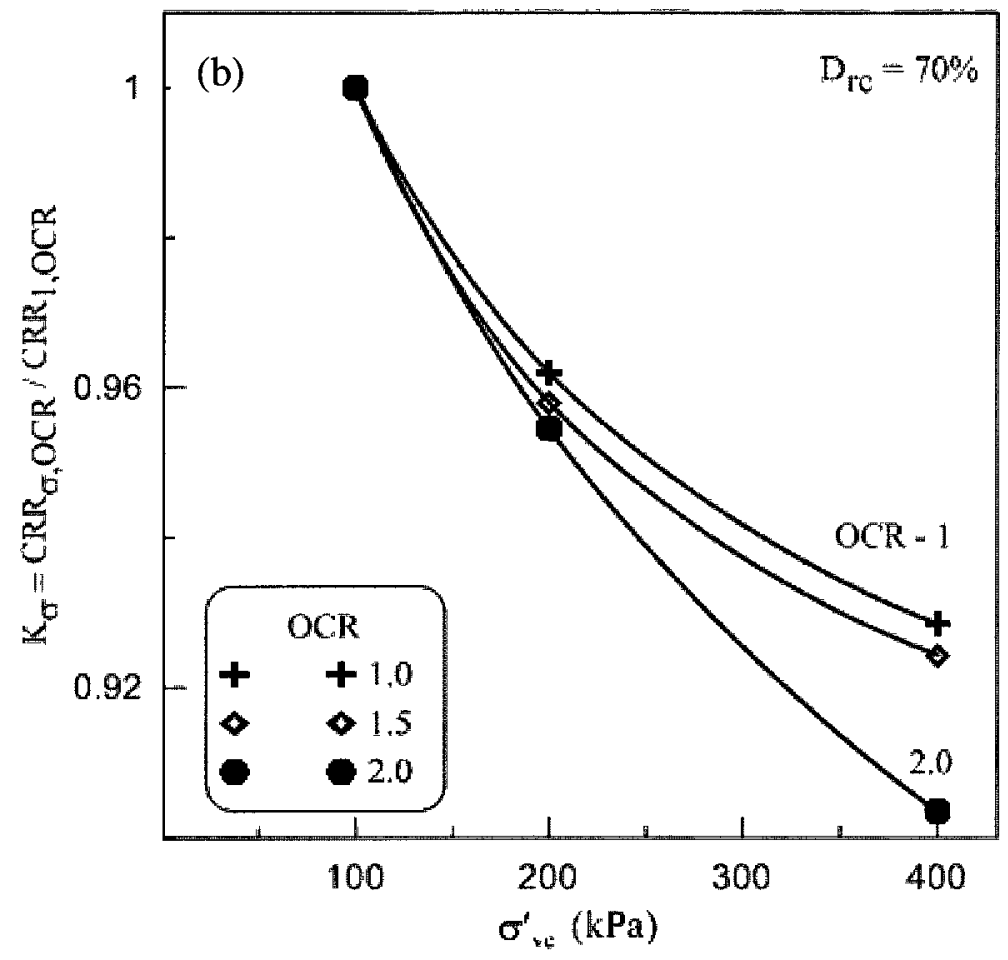

Fig. 6.19: The variation of $K_{\sigma}$ with confining stress level at $40 \%$ (a) and $70 \%$ (b) of FRS.

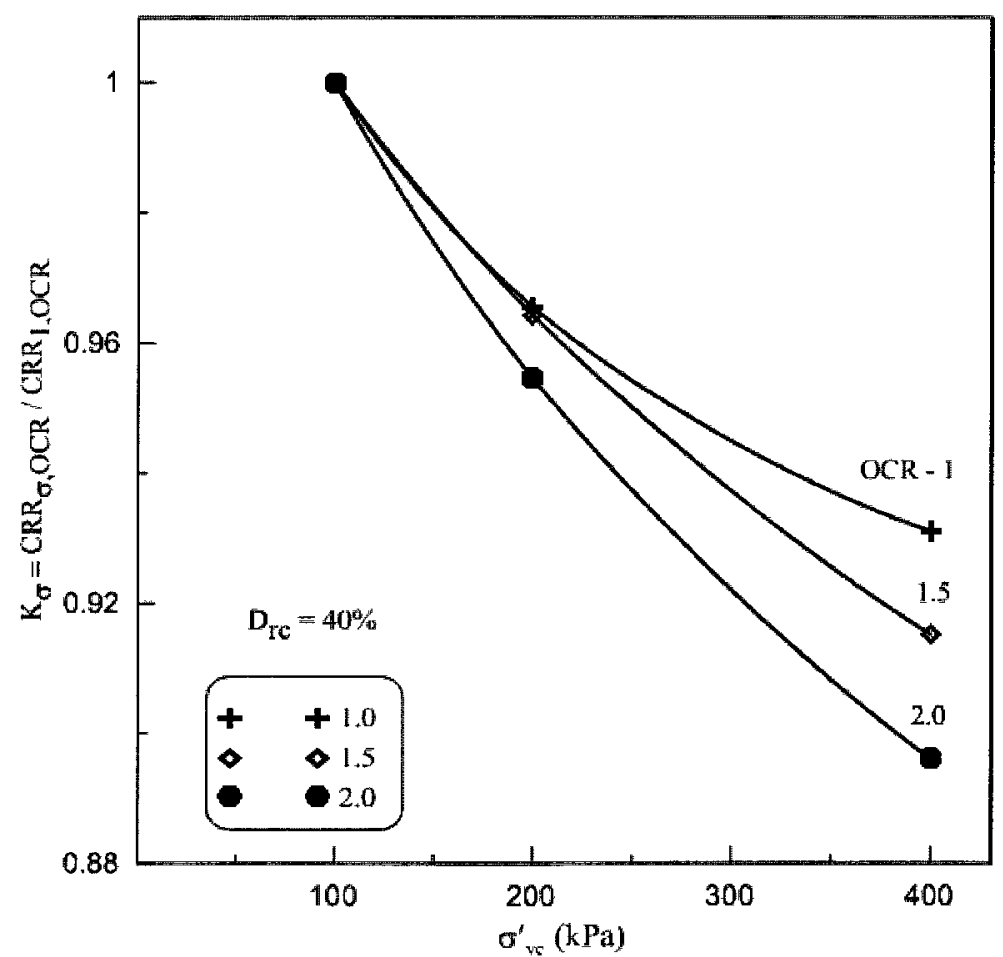

Fig. 6.20: The variation of $K_{\sigma}$ with confining stress level at $40 \%$ of Silica Sand. 
As reported above on Fraser delta sand, similar assessment was done on sub-rounded silica sand, and the results are shown in Figure 6.20 at the loosest attainable density state $\left(D_{r}=40 \%\right)$ and Figure 6.21 at a denser $D_{r}=70 \%$ state. A systematic reduction is noted with increasing confining stress level and overconsolidation ratio. The rate of somewhat larger compared to that of Fraser River sand (Figure 6.19 (a)). $K_{\sigma}$ values in silica sand is about 5-6\% higher than Fraser sand at loosest states, but the differences are even minor (about $2 \%$ differences) at densest state at a given confining stress and overconsolidation ratio. These differences are quite minor, and have no real significance in design practice.

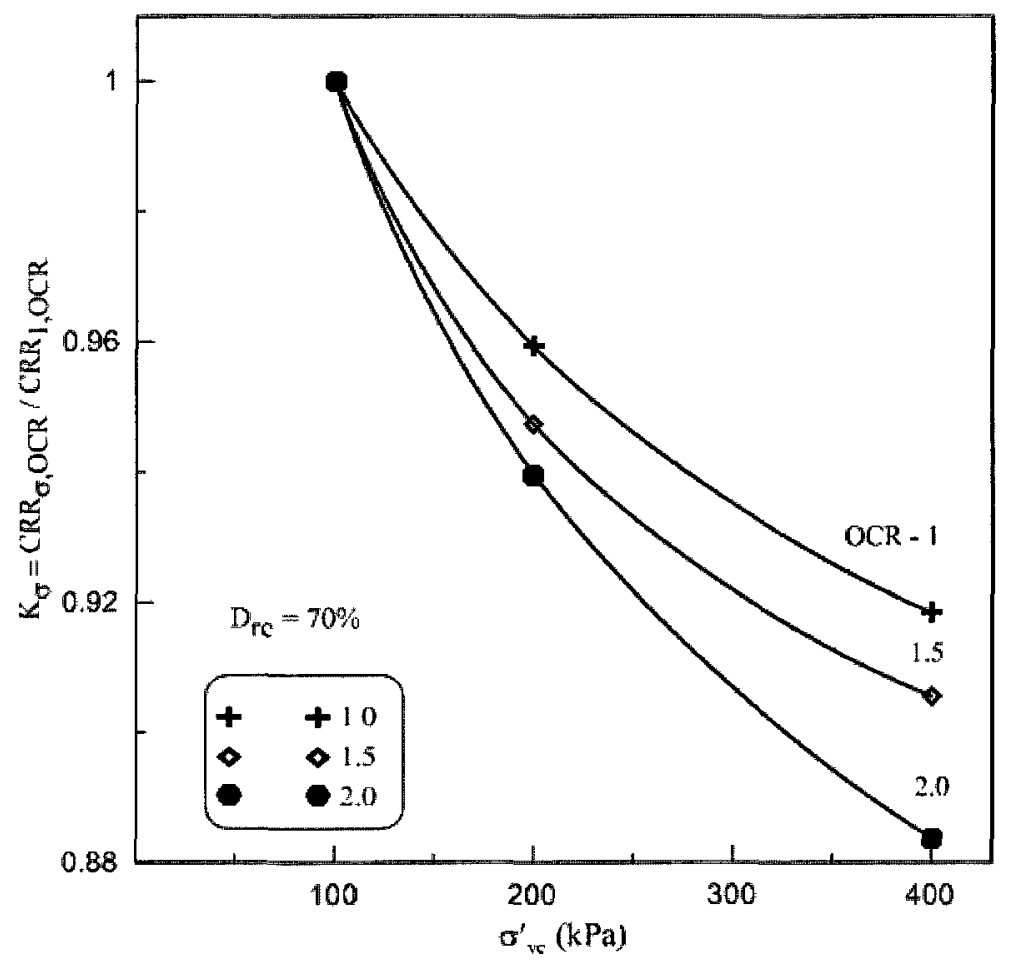

Fig 6.21: The variation of $K_{\sigma}$ with confining stress level at $70 \%$ of Silica Sand.

\subsubsection{Behaviour of sand subjected to initial static shear}

Figure 6.22 compares the cyclic behaviour of Fraser River sand consolidated to initial states with static shear. Relative values of the initial static shear $\tau_{s t}$, and cyclic stress $\tau_{c y}$ (or 
alternatively, $\alpha=\tau_{s t} / \sigma_{v c}^{\prime}$ and CSR $\left.=\tau_{c y} / \sigma_{v c}^{\prime}\right)$ determine whether shear stress reversals occurs during cyclic loading. The specimen cannot reach a state of zero effective stress, if shear stress reversals do not occur, and thus significantly different strain development mechanisms can be responsible for the triggering of liquefaction as seen in the Figure. A series of tests at different CSR and $\alpha$ values were conducted over a range of density states at $100 \mathrm{kPa}$ confining stress level. Normally consolidated specimens, and specimens with OCR $=1.5$ and 2 were tested. CRR values at specific density, OCR and $a$ levels were derived from these tests as discussed in the earlier section. All prior studies in the literature were limited to normally consolidated sands, and to the best of my knowledge, this is the first research study that assess the effect of OCR on the $\mathrm{K}_{\alpha}$ correction factor.

\subsubsection{Effect of Static Shear on Cyclic Resistance Ratio}

Figure 6.23 shows the variation of cyclic resistance ratio with relative density in overconsolidated Fraser River sand subjected to different levels initial static shear, and compares it to the sand at the same initial states, but without static shear. At a given relative density, the cyclic resistance CRR decreases with increasing static shear stress ratio at this OCR value. The reduction in CRR is quite significant at loose density states, and gradually becomes less significant as the density increases. The trends suggest that increasing $\alpha$ would increase the cyclic resistance at $\mathrm{OCR}=2$, but only at very dense states. But, sand at such density states is not generally susceptible to liquefaction, and therefore such increase is of little relevance to practice. 

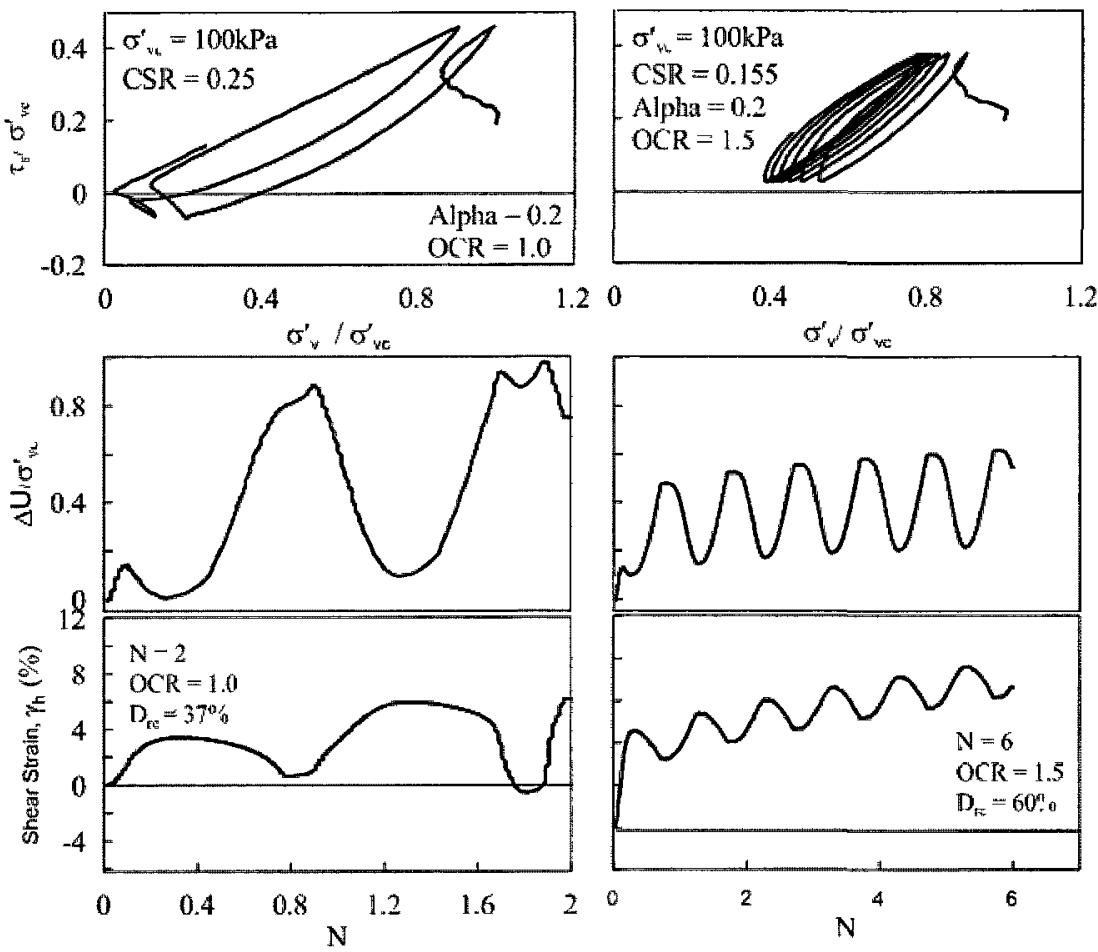

Fig. 6.22: Cyclic tests with initial static shear stress.

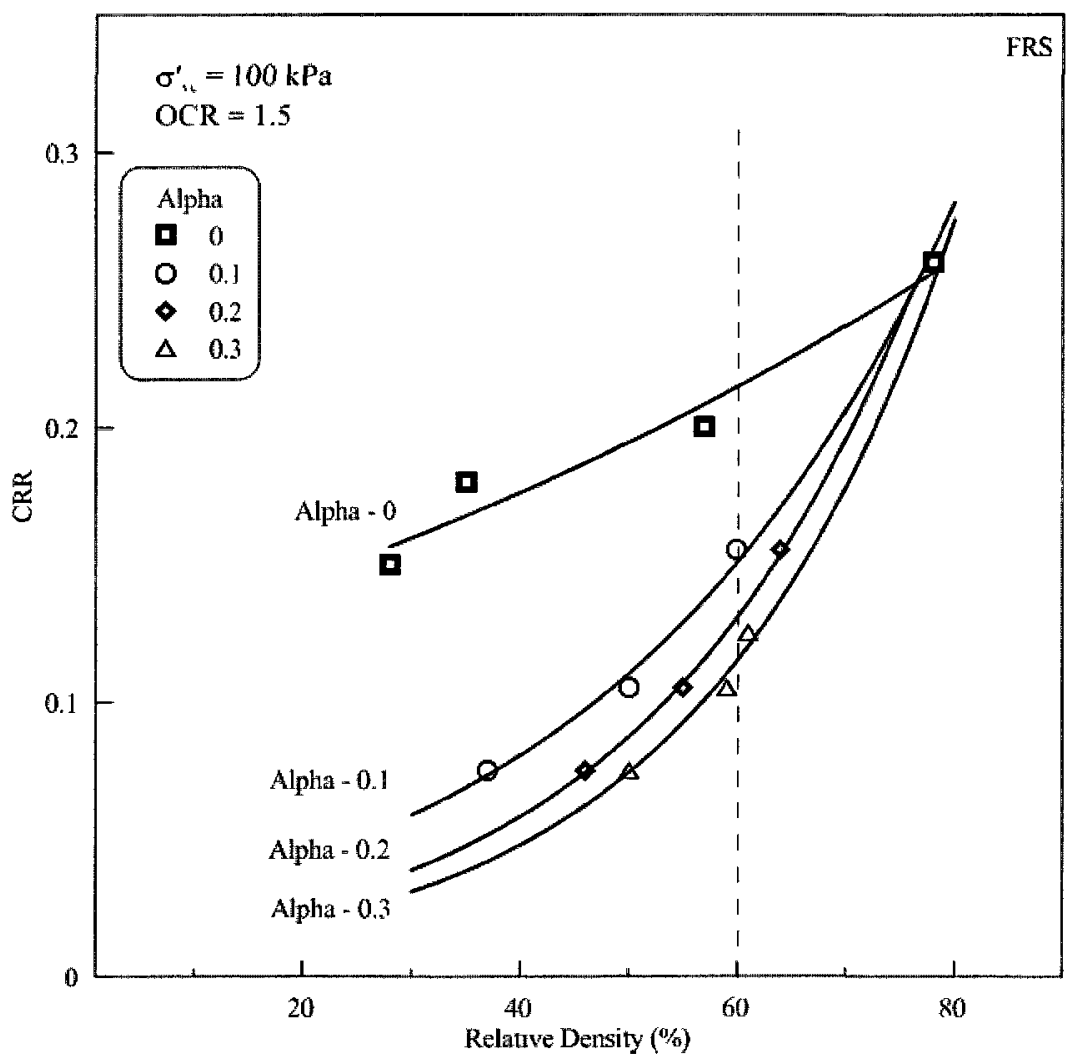

Fig. 6.23(a): The variation of CRR with relative density at $\mathrm{OCR}=1.5$ 


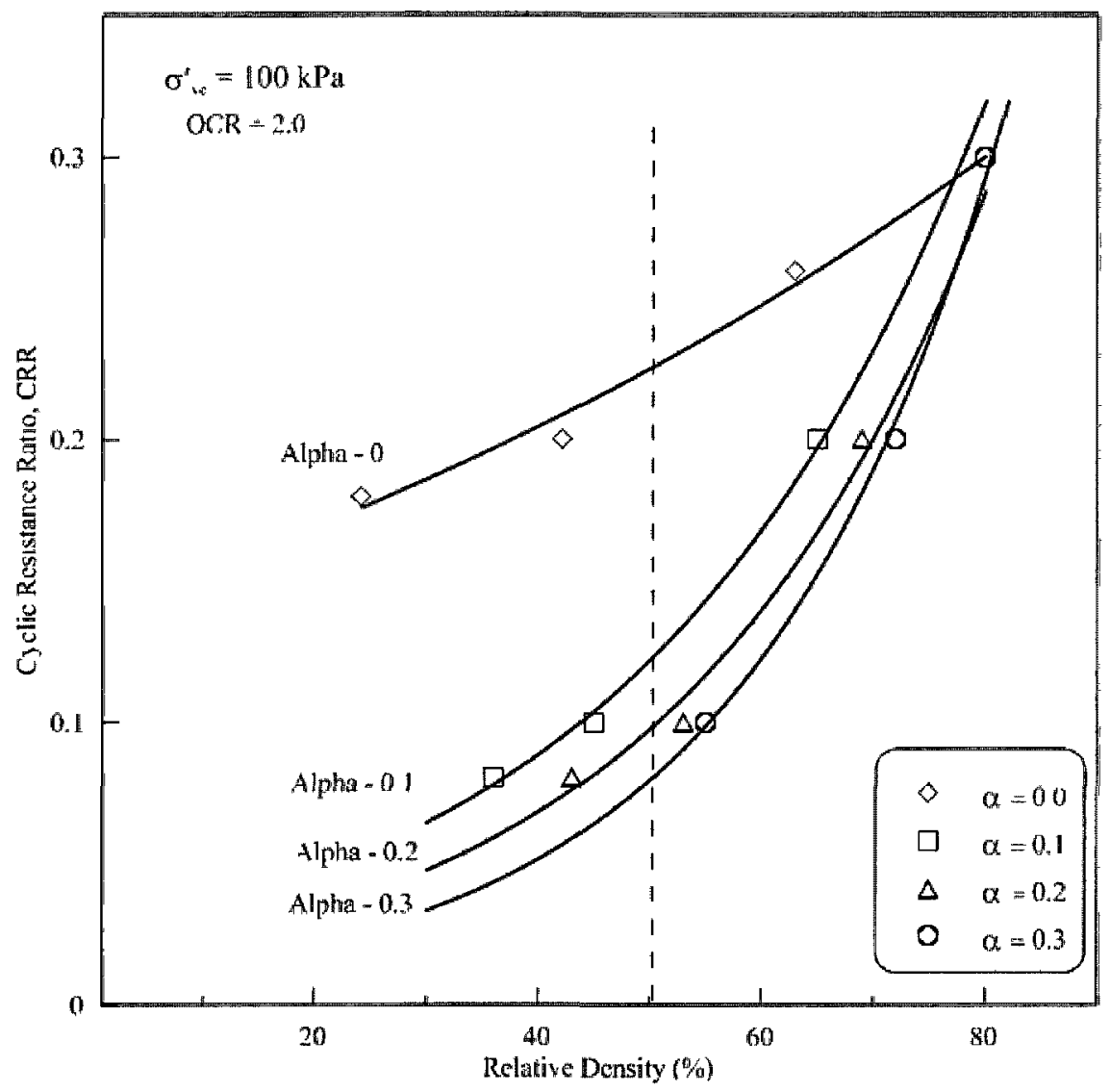

Fig. 6.23 (b): The variation of CRR with relative density at $\mathrm{OCR}=2$

Previous studies on normally consolidated Fraser River sand paint quite a different picture of the effect of initial static shear stresses. Figure 6.24 shows the variation of CRR with density for normally consolidated Fraser river sand (Ha, 2004). Marginal reductions in CRR are noted at the loosest density states, and the CRR is higher in soils subjected to initial static shear at denser states. Such increase in CRR with $\alpha$ at higher density has been widely reported in literature. However Sivathayalan \& Ha (2004) demonstrated that generalization that implies increasing $a$ increases cyclic resistance at higher density states is not always valid. Their conclusion was arrived at by researching the effects of the type of material, and particle shapes. Similar observations can be noted in the data reported herein, but on account of overconsolidation. 


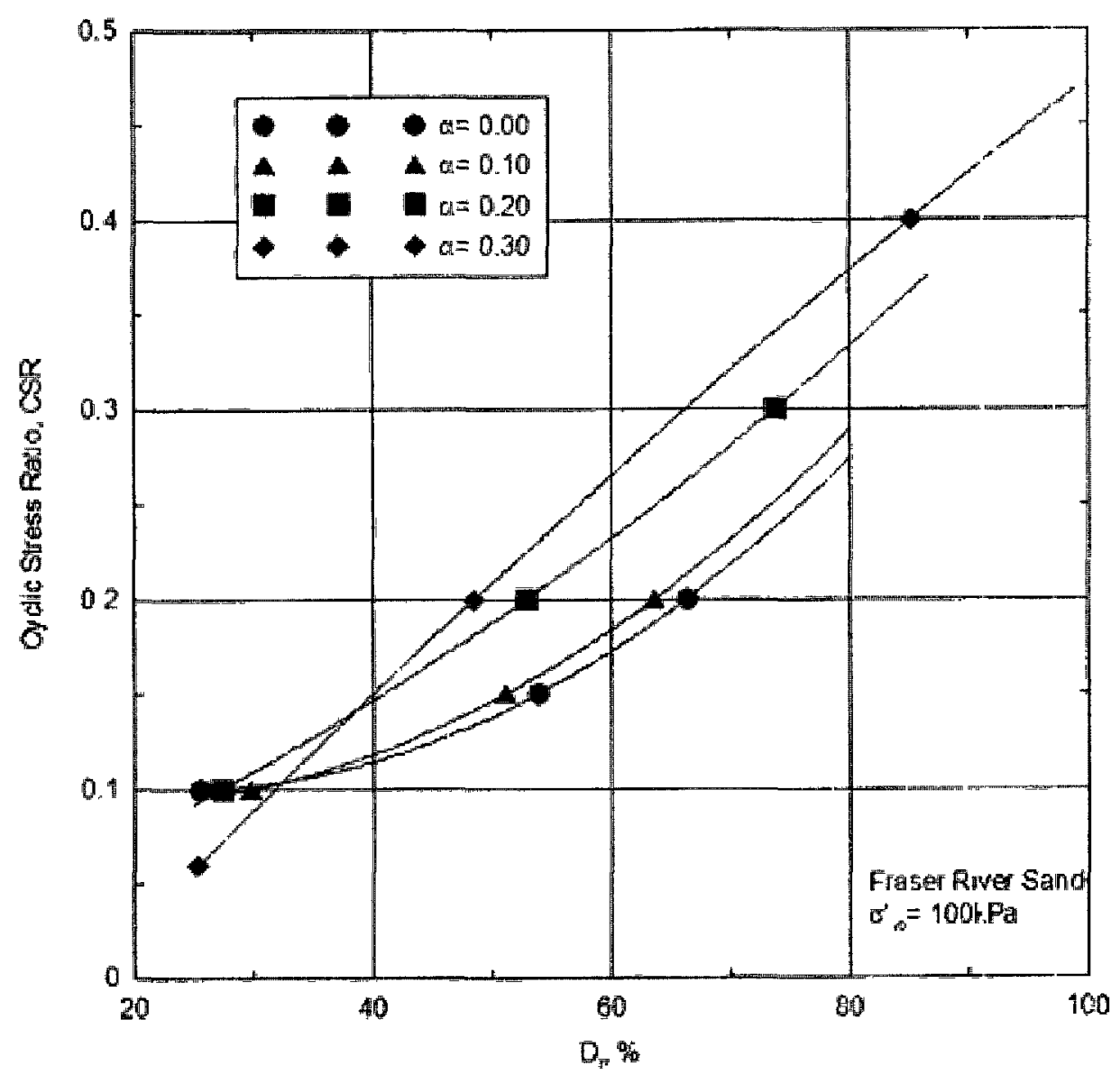

Fig. 6.24: The variation of CRR with relative density at $\mathrm{OCR}=1$ (After $\mathrm{Ha}, 2004)$

\subsubsection{2 $K_{\alpha}$ Correction factor}

$K_{\alpha}$ correction factor, originally proposed by Seed (1983) is used to account for the effects of initial static shear on cyclic resistance. As noted earlier, the $K_{\alpha}$ factors in the literature were derived from tests on normally consolidated sands only. A comparison of $K_{\alpha}$ values derived in this study in normally consolidated sands are compared to the results published by $\mathrm{Ha}$ (2004) at a given initial static shear stress ratio level and over range of density states in Figure 6.25. The fairly close match is regarded as confirmation of the repeatability of the research study, and provides confidence in the test results reported in overconsolidated sands. Figure 6.26 shows the variation of $K_{\alpha}$ factor with $\alpha$ at a relative density state of $40 \%$ but at different values of OCR. A 
significant reduction in $K_{\alpha}$ can be noted as OCR increases regardless of the $\alpha$ level. The differences in the $K_{\alpha}$ values of sands overconsolidated to 1.5 and 2.0 are not significant, but the dramatic reduction in $K_{\alpha}$ as OCR increases from 1.0 to 1.5 has serious practical implications, since current practice is based on $K_{\alpha}$ values obtained from normally consolidated sands.

Fig 6.27 compares the variation of $K_{\alpha}$ in normally consolidated Fraser River sand to that overconsolidated to OCR $=2$ at different density states. $K_{\alpha}$ of the overconsolidated sand is much smaller at each density state at all $\alpha$ levels. $K_{\alpha}$ values increase with increasing relative density in overconsolidated sands, but are still less than one at a density state of about $70 \%$. The data presented in Figure 6.23 indicates that $K_{\alpha}$ values greater than one would be realised in density states in excess of $80 \%$. Generally liquefaction is not a concern at such high density states, and hence the realised strength gains are of no practical benefit. These findings were somewhat unexpected given the current propositions in the literature that $K_{\alpha}$ would increase with $\alpha$ in dilative soils. But, those studies have been based on normally consolidated sands only. As noted in section 6.2.2, sand with OCR $=2$ is highly dilative at all density states. Yet, the $K_{\alpha}$ values are quite small compared to the $\mathrm{NC}$ sands. The relatively higher cyclic resistance of the overconsolidated sands at $\alpha=0$ is partly responsible for the reduction in $K_{\alpha}$ with increasing OCR. However, no such effect is noted in the $K \sigma$ values. This suggests that the reduction in dilative tendencies is relatively more significant when static shear increases compared to increasing confining stress levels. 


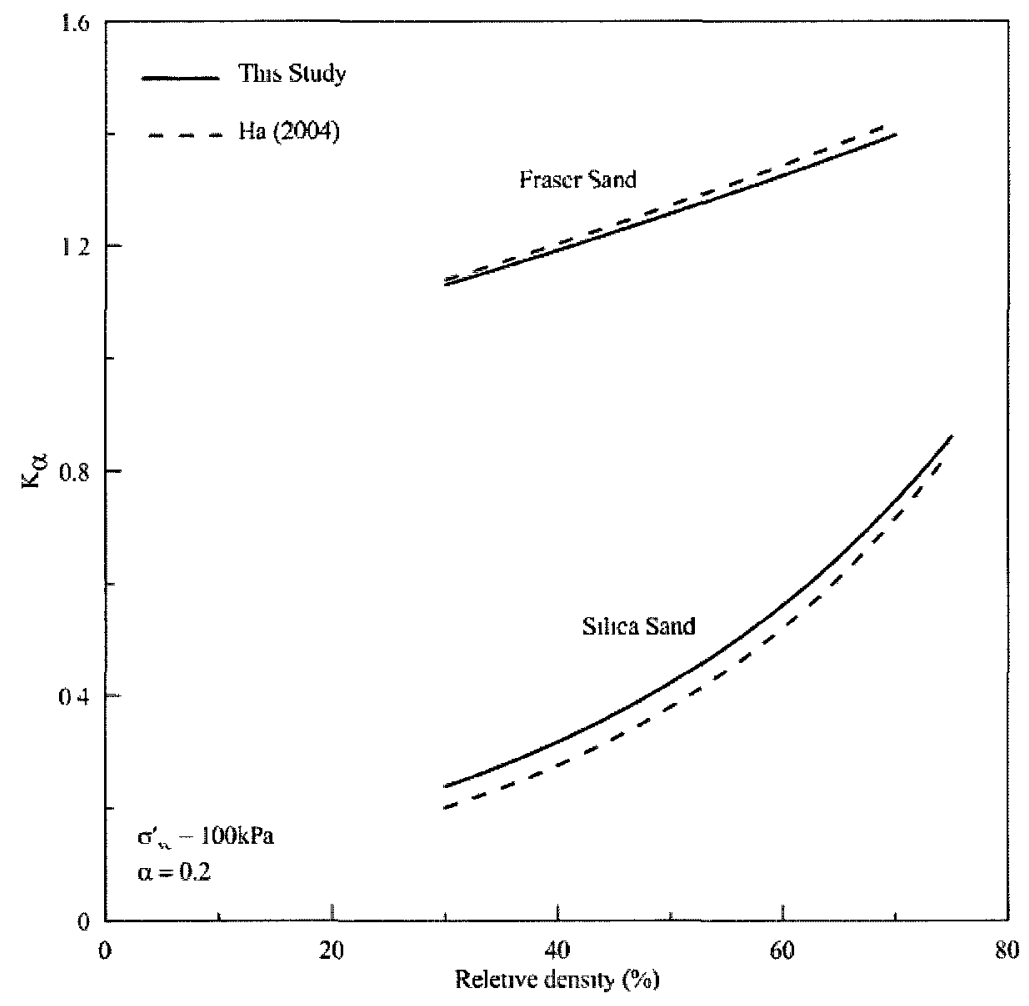

Fig.6.25: $\quad$ Comparison of $K_{\alpha}$ values at a given alpha (0.2) over range of densities

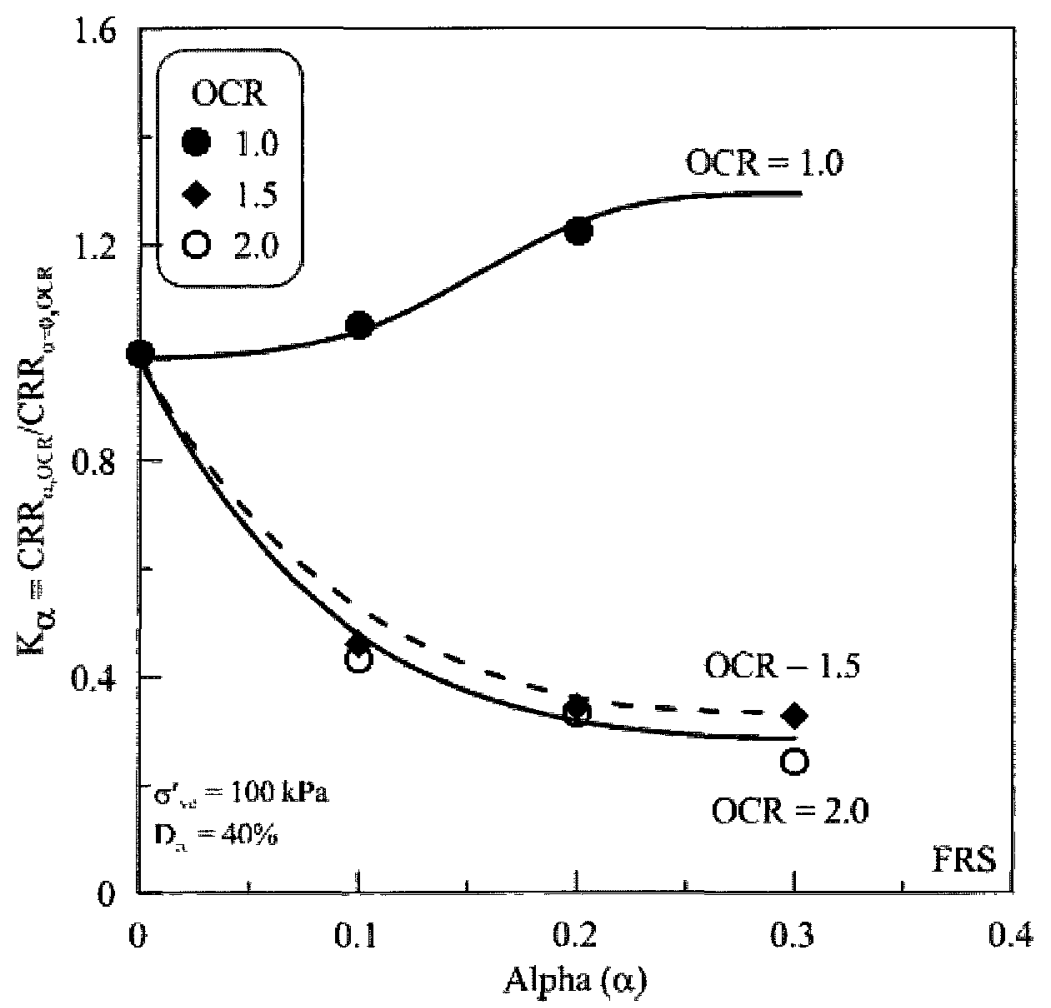

Fig. 6.26: Variation of $K_{\alpha}$ with alpha at different OCR levels at a given relative density 


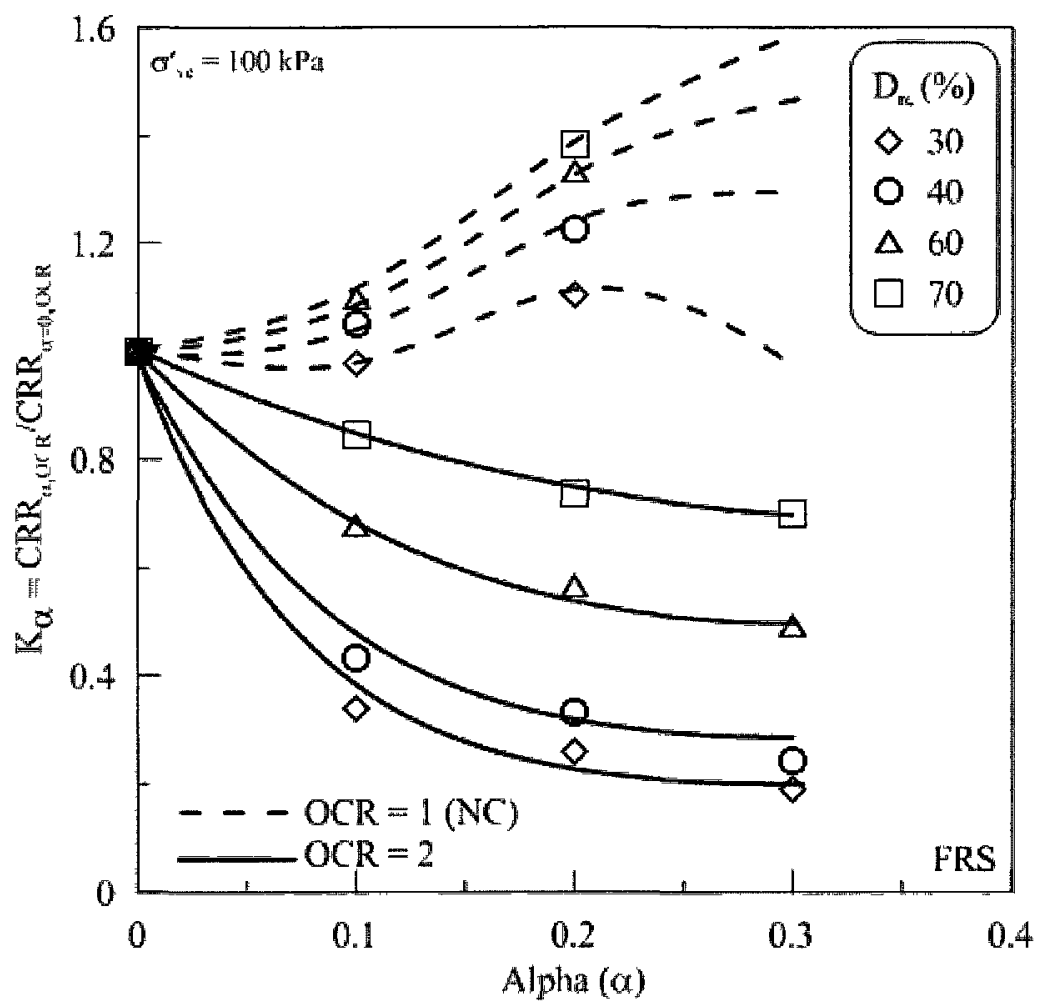

Fig 6.27: Variation of $K_{\alpha}$ with alpha at different OCR levels over range of relative density

The variation of $K_{\alpha}$ in Silica sand is shown in Figure 6.28. Sivathayalan \& Ha (2006) reported fairly small $K_{\alpha}$ values in normally consolidated Silica sand over a range of density states. Increasing OCR appears to further reduce the $K_{\alpha}$ values. The reductions are significant at denser states. The values drop marginally from normally consolidated to overconsolidation ratio at the looser states, but it is expected, since the NC values are already fairly low. The overall reduction is not as significant compared to Fraser sand. Overconsolidation reduces the $K_{\alpha}$ factor in both sands, but the magnitude of the change is dependent on the sand type, and possibly on particle shape. 


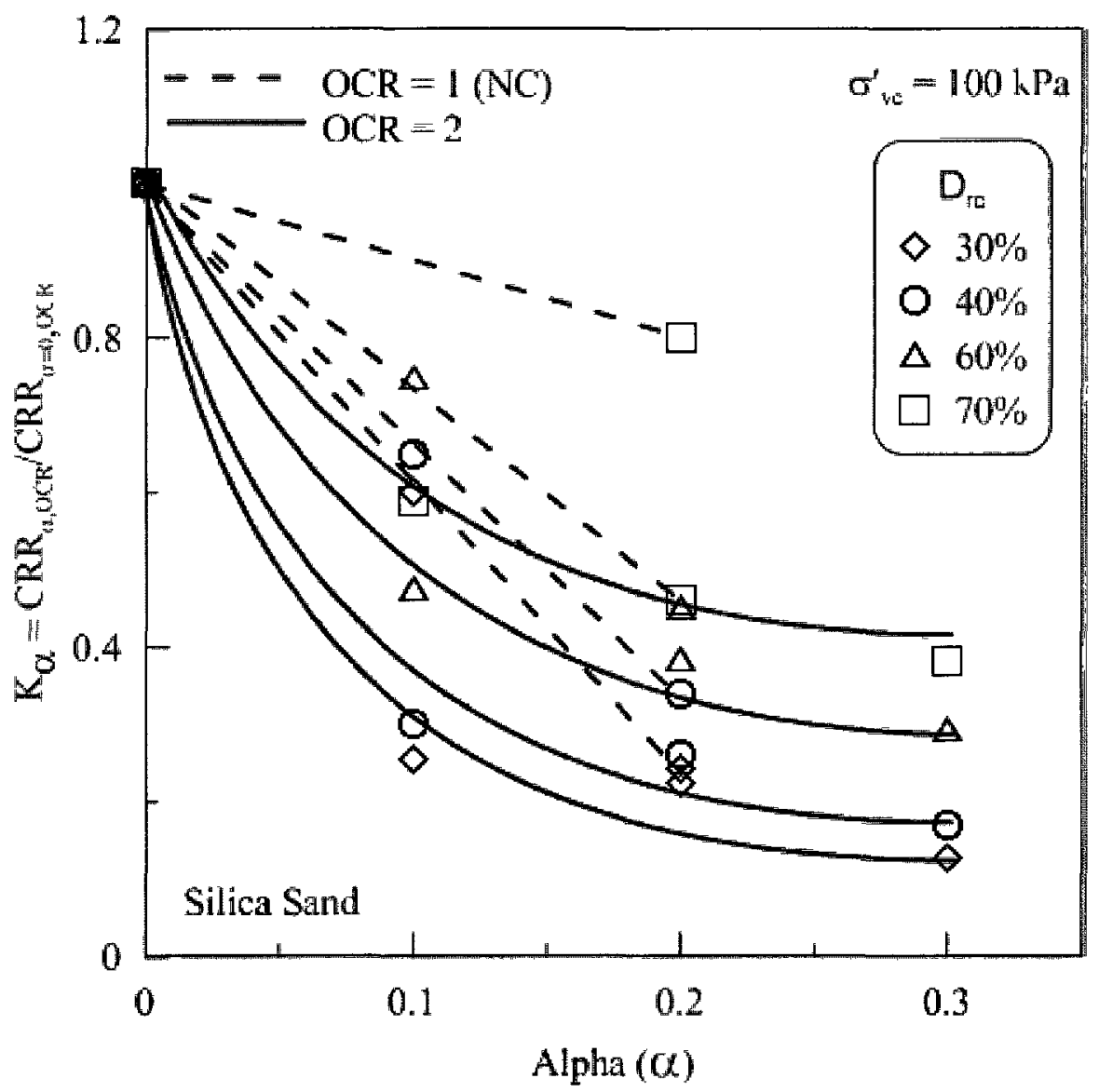

Fig. 6.28: Variation of $K_{\alpha}$ with alpha at different OCR and relative density states

Site specific assessment of liquefaction potential could be simplified if appropriate correction factors are available to estimate site specific CRR at a given OCR, confining and static shear stress level from reference cyclic resistance ratio values. As noted, reference CRR in current practice is estimated in normally consolidated soils at $\sigma=100 \mathrm{kPa}(1 \mathrm{~atm})$, and $\alpha=0$. The results presented herein can be used to estimate CRR at a given OCR, confining and shear stress level as shown in equation 6.3.

$$
C R R_{O C R, \sigma, \alpha}=K_{O C R} \cdot K_{\sigma} \cdot K_{\alpha} \cdot C R R_{O C R=1, \sigma=1, \alpha=0}
$$

The stress levels explored here generally match the overburden stress levels encountered in field problems where liquefaction is a concern. $\alpha=0$ in level ground, and will vary with slope 
angle and soil properties, but is not expected to exceed about 0.3 in practice. CRR of a Fraser River sand at $\mathrm{OCR}=2$ and $\sigma=400 \mathrm{kPa}$ with no static shear would be about $30 \%$ higher than the reference CRR. However same sand on a $20^{\circ}$ slope (typically yield $\alpha$ value between 0.15 to 0.2 ) would only have a CRR of about $25 \%$ of the reference CRR.

\subsection{Post LiQuefaction Behaviour}

There have been many instances reported in the literature where the failure occurred not during the earthquake, but after the cessation of ground shaking (e.g., Lower San Fernando Dam, 1971; Mochikoshi Tailings Dam 1978 etc.) This indicates that ultimate and/or serviceability limit states may be exceeded either during the earthquake or following it. Attempts to assess the stability (and possible violation of the ultimate limit state), or estimate liquefaction induced displacements (and exceedance of the serviceability limit) should therefore consider the loading both during and following an earthquake. Deformation following the earthquake generally occurs on account of the static shear stresses present in the soil mass. Such analysis requires not only the knowledge of the cyclic deformation characteristics of the soil, but also the post-cyclic deformation characteristics. The post-liquefaction behaviour of the sands under undrained conditions was assessed following cyclic loading leading to liquefaction. Undrained conditions were imposed to represent the fact that deformation in liquefied soils would be fairly rapid insitu.

\subsubsection{Post liquefaction stress-strain response}

Figure 6.29 shows that stress path and stress-strain responses of silica sand during cyclic and post-liquefaction monotonic loading. The sand liquefied during the sixth cycle, and the effective confining stress at the end of cyclic loading is essentially zero, since the cyclic loading has led to the development of $100 \%$ excess pore water pressure. This zero effective stress state represents 
the initial stress state for post-cyclic loading, and obviously pore water pressure cannot increase any more. As a result, deformation can only progress with negative pore water pressure development, which gradually increases the effective stress in the sand. Such deformation is similar to the post phase transformation deformation during undrained loading, and progresses along the line of maximum obliquity in the stress space. The very small initial confining stress also leads to a negligibly small initial shear modulus, which is often considered to be zero. However, the shear modulus gradually increases as larger the effective stresses mobilize with deformation.

Three distinct zones of deformation can be noted in the post cyclic stress-strain curve shown in Figure 6.29. The first stage with essentially zero modulus and strength lasts up to about $4 \%$ shear strain. Shear modulus is gradually increasing during this phase, but the rate of increase and the magnitude of the modulus are fairly low. However, the shear modulus increases at a much faster rate beyond about $4 \%$ shear strain to about $12 \%$ shear strain. No significant changes are noted in the modulus after $12 \%$ shear strain and deformation progresses at essentially constant modulus during this stage. The stress path in post liquefaction originating at a state of zero effective stress is unique, and follows the line of maximum obliquity. These observations are consistent with the original findings of Vaid \& Thomas (1995) and many others since then.

\subsubsection{Effect of Relative Density}

Figure 6.30 illustrates that the post-liquefaction behaviour of the silica sand at identical initial confining stress and OCR values and subjected to the same CSR, but at different consolidated relative density states. The number of cycles to liquefaction were somewhat different, and the maximum shear strain during cyclic loading was $5.27 \%$ and $4.77 \%$ at $D_{r}=$ $45 \%$ and $64 \%$ respectively. Even though the general nature of the post-liquefaction stress-strain curves is similar the sand at higher density gains strength at a much faster rate. 

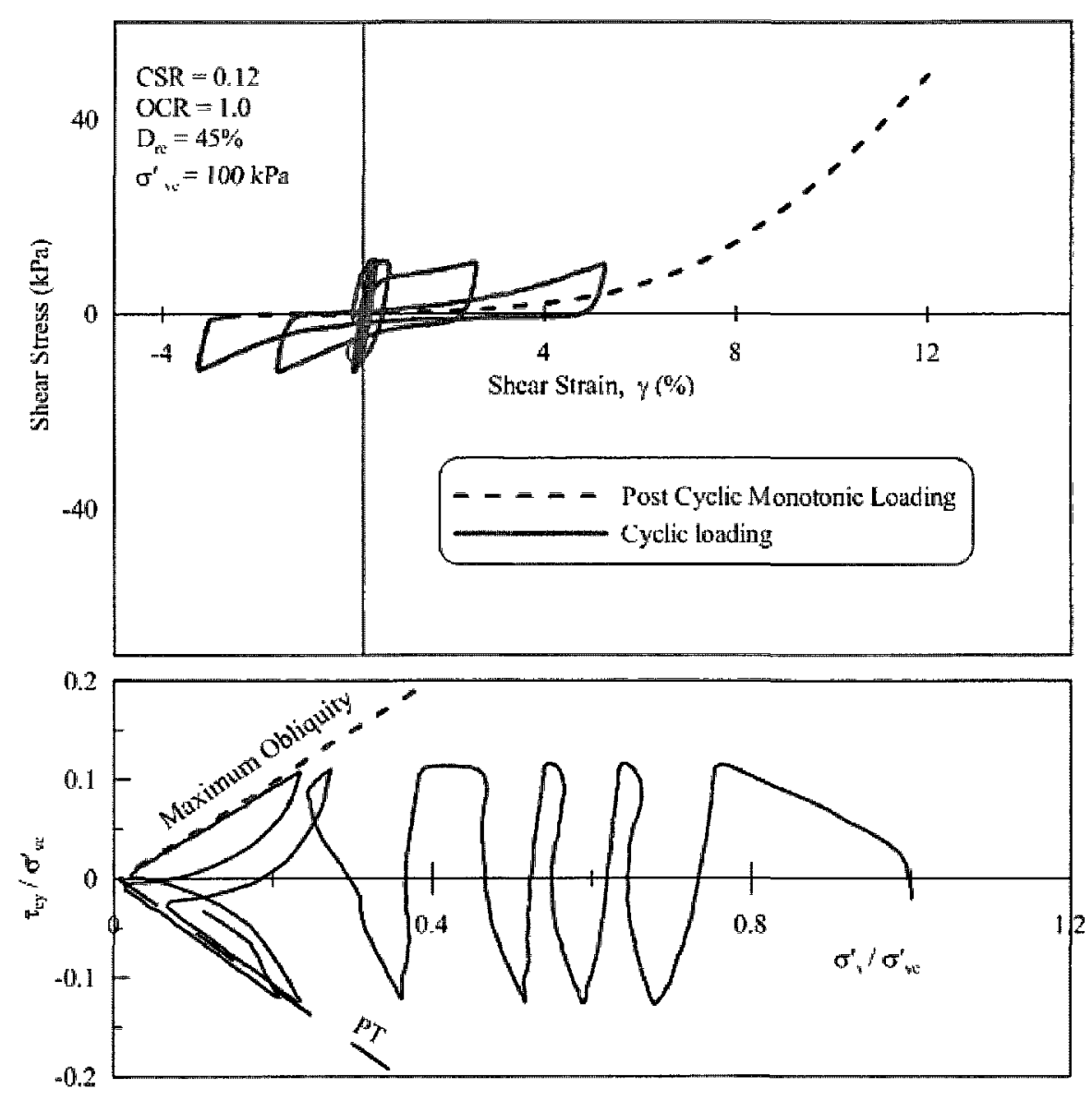

Fig. 6.29: Post Liquefaction response of Silica sand

The dense sand has mobilized about $38 \mathrm{kPa}$ shear stress at about $10 \%$ shear strain from the end of cyclic loading. The corresponding shear stress in loose sands is less than half, at $18 \mathrm{kPa}$. Such dependency of post-liquefaction response on relative density has been reported by Vaid \& Thomas (1995), Vaid and Sivathayalan (1997) and Sivathayalan \& Yazdi (2004).

\subsubsection{Effect of Over Consolidation Ratio}

Figure 6.31 illustrates the dependence of post-liquefaction responses on overconsolidation. The initial state prior to cyclic loading was fairly identical in all aspects, except for the OCR. Similar response was observed in Fraser River sand as illustrated in Figure 6.32. The rate of modulus increase in clearly much faster in soils with higher OCR. In addition, the essentially 
constant shear modulus during the last stage also increases with increasing OCR. This clearly suggests that the material retains memory of its initial pre-cyclic loading stress state, since the effective stresses following cyclic loading are essentially zero and imply an infinitely large OCR. These differences, which might appear rather inconsequential, have significant practical implications. If the static shear stress in-situ is about $10 \mathrm{kPa}$ then about 3.9\%, 3.5\% and 3.0\% shear strain will have to be mobilized at $\mathrm{OCR}=2,3$ and 4 respectively to support this load. Depending on the serviceability limit criteria, obviously the NC soil has the most potential for failure.

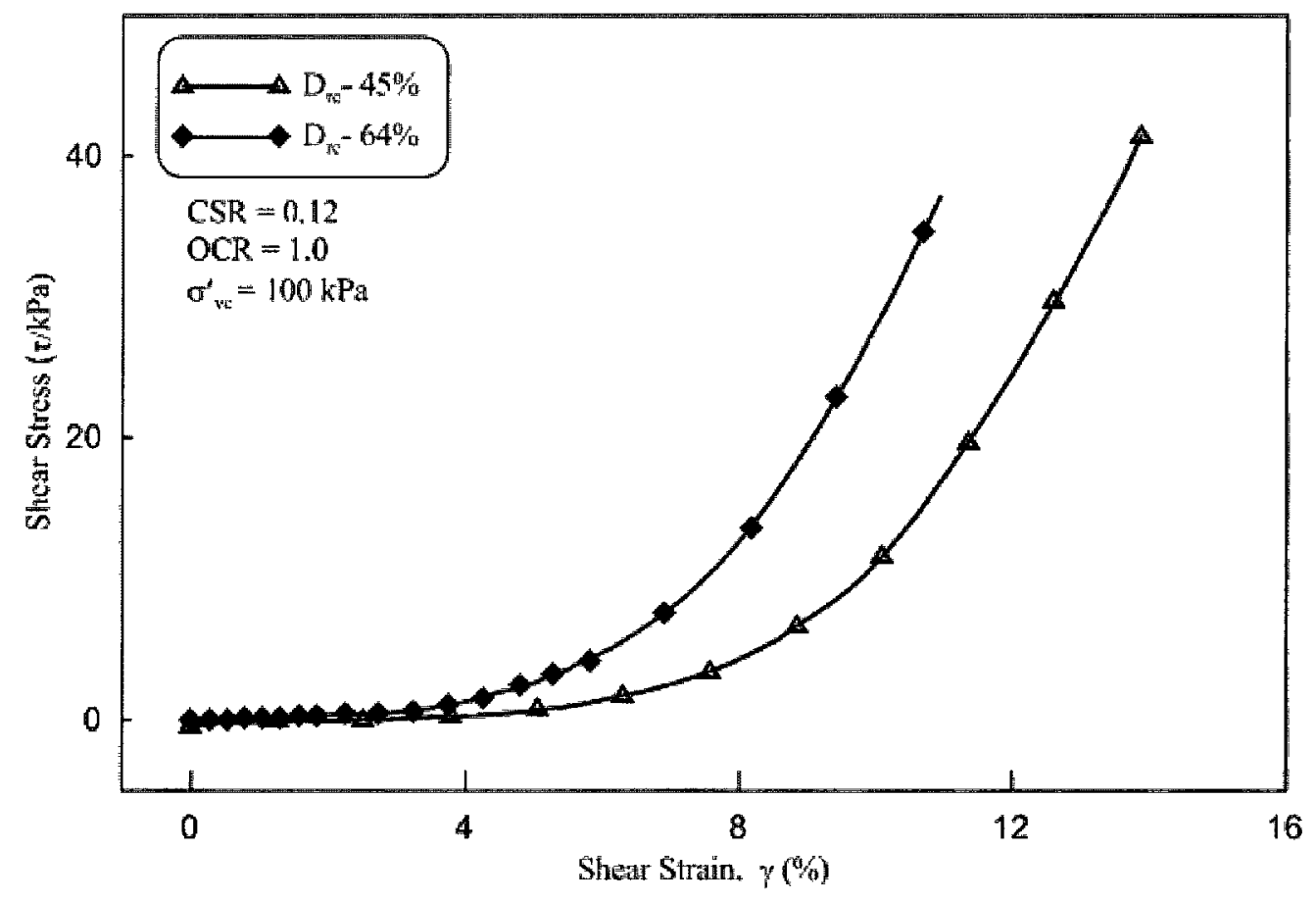

Fig. 6.30: $\quad$ Effect of relative density on post liquefaction for silica sand 


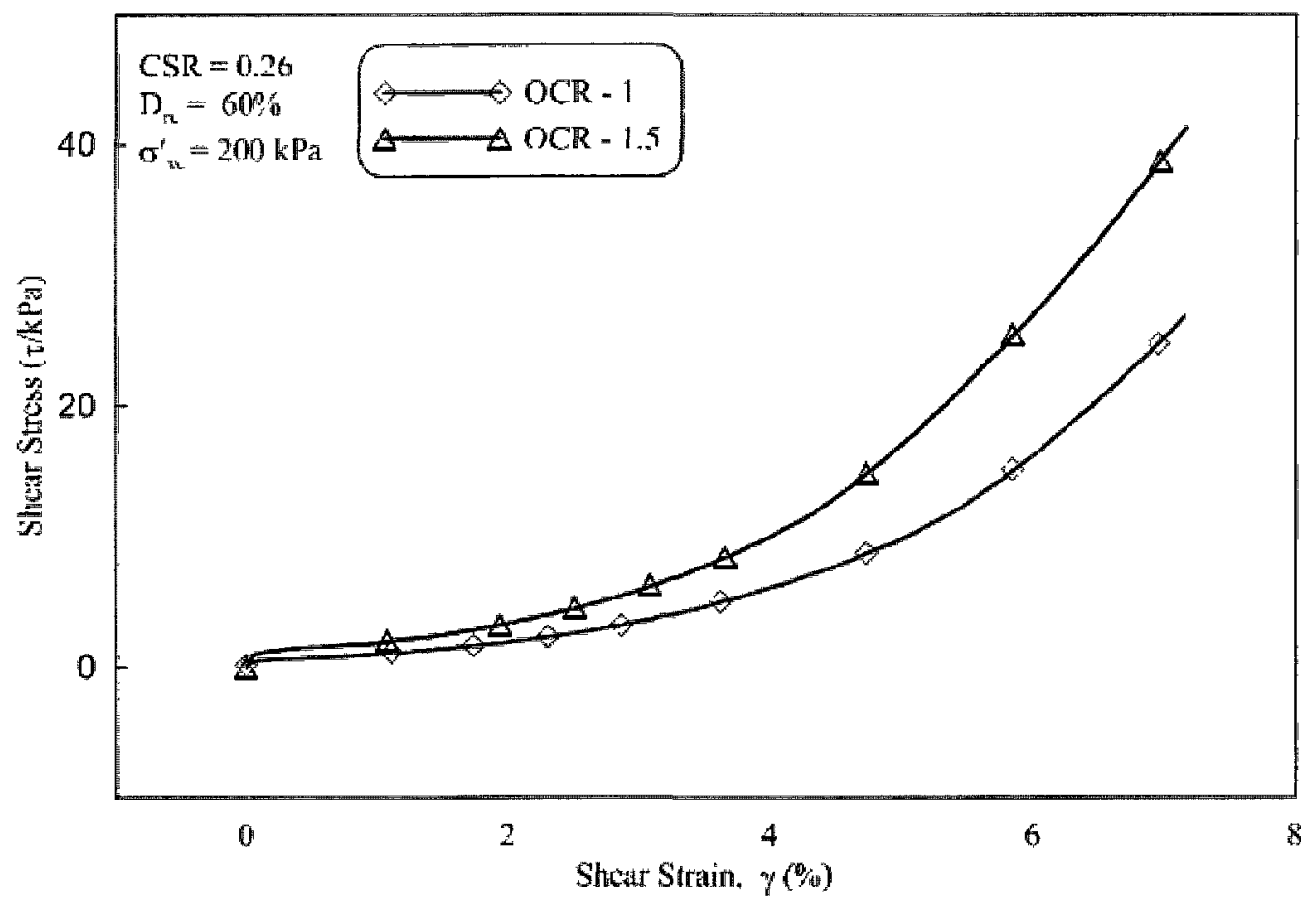

Fig. 6.31: $\quad$ Effect of OCR on post liquefaction for silica sand

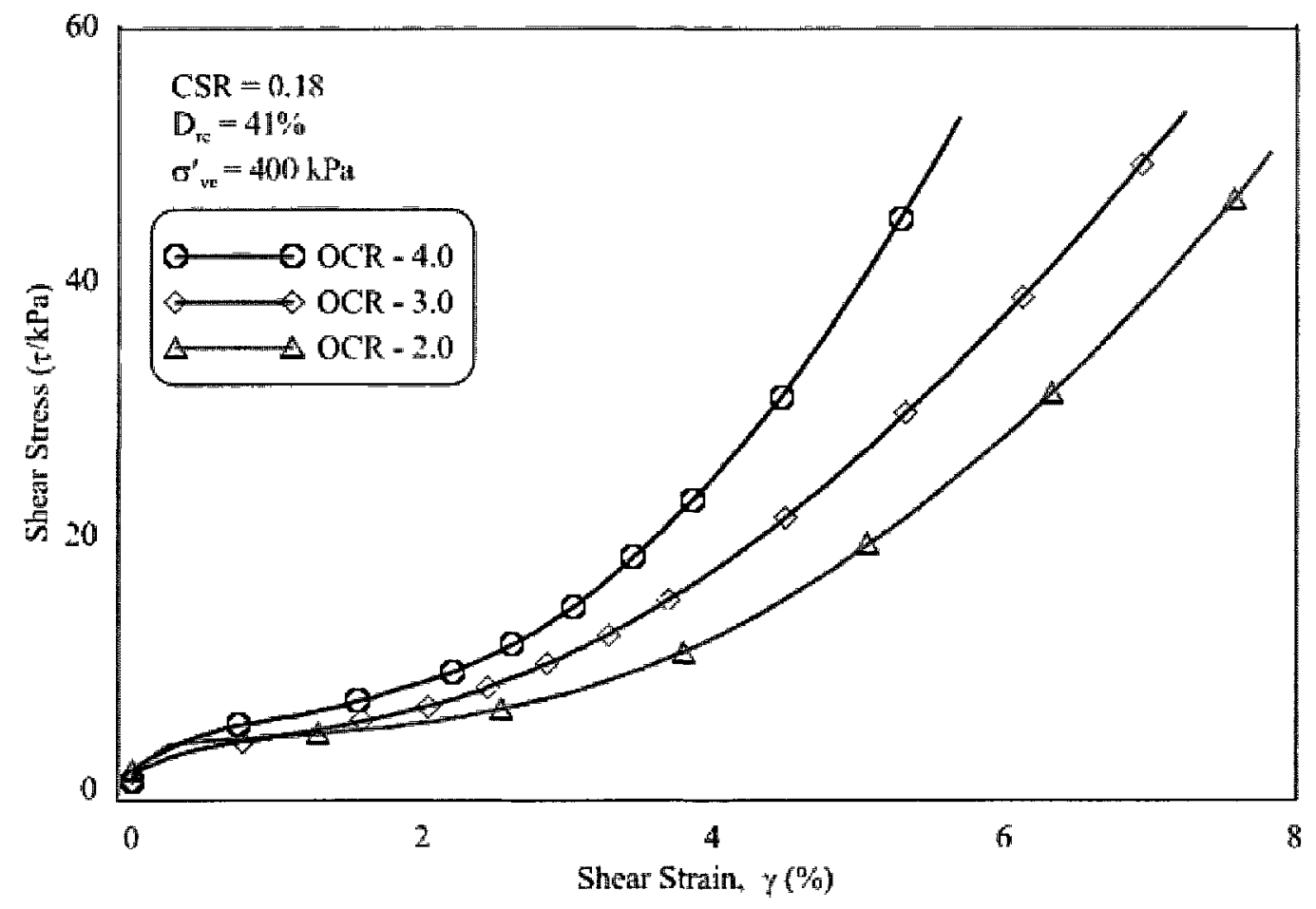

Fig. 6.32: $\quad$ Effect of OCR on post liquefaction for Fraser sand 


\section{SUMMARY AND CONCLUSIONS}

Liquefaction of soils, both due to seismic and/or monotonic loading, is a major concern in geotechnical practice. Cyclic resistance of sands depends on several initial state parameters, including confining, static shear stresses and the level of overconsolidation. Cyclic shearing due to earthquake loading leads to principal stress rotation in-situ. A comprehensive experimental study was undertaken to provide additional insights into the effects of principal stress rotation on liquefaction susceptibility, and to establish a systematic methodology to estimate the cyclic resistance of overconsolidated sand at different initial stress states.

\subsection{HOLLOW CYLINDER TORSIONAL SHEAR TESTS}

Cyclic torsional shear tests were conducted using the hollow cylinder device to assess the influence of the rotation of principal stress on liquefaction potential. Both smooth and jump rotations were imposed on the loosest deposited sand, subjected to a given level of cyclic stress ratio. The largest inclination of the direction of principal stresses coincided with the peak cyclic shear stress during loading. Test results clearly indicate that liquefaction resistance is dependent on the magnitude of stress rotation, and the lowest resistance was measured when the principal stresses were inclined at $45^{\circ}$ (jump rotation tests with fixed directions) or rotated between about $45^{\circ}$ to $60^{\circ}$ (smooth rotation tests with continuous rotation) to vertical. This observation was somewhat unexpected given the current perceptions in the literature that suggest that weakest 
responses would be obtained when major principal stress is inclined at $90^{\circ}$ to vertical along the bedding planes.

These results indicate that the orientation of the plane of maximum shear stress, and not the direction of the normal major principal stress, along the horizontal bedding planes leads to the weakest response. Obviously the direction of major principal stress is important, and its alignment along the bedding planes leads to softer response, but its influence appears secondary, and the orientation of the plane of maximum shear stresses along the bedding plane play a more prominent role. This is quite logical given the importance of shear in soil mechanics. $\alpha_{\sigma}=45^{\circ}$ implies perfect alignment of the maximum shear stress plane along, and a $45^{\circ}$ inclination of $\sigma_{1}$ to the weak horizontal plane. $\alpha_{\sigma}=60^{\circ}$ causes some strengthening on account of the $15^{\circ}$ deviation of the maximum shear stress plane from horizontal direction, and weakening since $\sigma_{1}$ is more closely aligned with the bedding planes.

\subsection{SIMPLE SHEAR TESTS}

The undrained monotonic, cyclic, and post cyclic simple shear tests were conducted over a wide range of effective vertical stress, relative density, and overconsolidation ratio (OCR). All simple shear tests were conducted on air pluviated specimens, and the findings are expected to be applicable to natural soils deposited under gravity. Fraser Delta sand, which is composed of subangular particles, and Silica sand which is predominantly sub-rounded were tested to assess possible influence of particle shape on $K_{\sigma}$ and $K_{\alpha}$ factors. The main research focus was on the behaviour of Fraser River sand, which underlies a seismically active and heavily populated region of Canada, and results from the tests on silica sand were used to draw comparisons. The main focus of the research simple shear was to better understand the effects of overconsolidation, 
and that using cyclic simple shear tests was to assess the effects of overconsolidation on $K_{\sigma}$ and $K_{\alpha}$ factors. A summary of the test program is noted below, and conclusions are drawn on the basis of the test results presented in this thesis.

\subsubsection{Monotonic simple shear tests}

Undrained behaviour of sand was assessed at confining stress levels ranging between 100 to $1200 \mathrm{kPa}$ at select density states. Tests were conducted on both normally consolidated and overconsolidated sands. Effect of OCR on shear modulus, and modulus degradation were assessed by running tests at OCR values ranging from one (NC) to 16 . These results indicate:

- Fraser River sand does not exhibit significant strain softening even in the loosest deposited state attainable by pluviation. The response is highly dilative at higher density states. Silica on the other hand sand strain softens over a range of initial states. The contractive tendency, and thus liquefaction potential of the sand increases with increasing effective stress level at a given density. The normalized behaviour of the loosest deposited sand does not vary much with increasing stress level on account of the increase in relative density due to stress densification. (e.g.:- medium denser $\&$ denser state) at a fixed effective vertical stress level.

- Overconsolidation significantly increases the dilative tendencies of the sand at a given density and stress level. The influence of overconsolidation can be noted at fairly small levels of OCR

- Initial Shear modulus of sand increases with increasing confining stress level and overconsolidation ratio. Commonly used exponential relationships (with exponent, $\mathrm{n}=$ $0.5)$ underestimates the shear modulus. These tests results suggest an exponent, $\mathrm{n}=0.7$ might be more appropriate for Fraser River sand. Modulus reduction curves are a 
function of OCR, and these test results indicate values proposed in the literature for other sands are consistent with that obtained for Fraser River sand.

- The effective stress ratio at phase transformation, and ultimate failure state are essentially constant in a sand, and do not depend on relative density, stress level or OCR. However, it varies between the two sands, which indicate they depend either on mineralogy and/or particle shape.

\subsubsection{Cyclic Behaviour}

Undrained cyclic loading tests were performed on both Fraser River and Silica sands to assess liquefaction potential, and its dependency on relative density, confining stress level, static shear stress level and overconsolidation ratio. Hundreds of cyclic simple shear tests were conducted at different initial states, and cyclic stress ratio (CSR). Cyclic tests with no initial static shear were conducted at 100,200 , and $400 \mathrm{kPa}$ confining stress level, and OCR levels of 1 , 1.5, and 2.0. A limited number of tests were conducted at $\mathrm{OCR}=3 \& 4$. All cyclic tests with initial static shear ( $\alpha=0.1,0.2 \& 0.3$ ) were conducted on specimens consolidated to $100 \mathrm{kPa}$. Following conclusions are drawn from the cyclic test data.

- Relative density is a good indicator of cyclic resistance CRR at a given confining stress and OCR level. The number of cycles to liquefaction increases with increasing relative density at a given load level (CSR).

- Overconsolidation significantly increases the number of cyclic to liquefaction. At a given stress level and relative density state, the number of cycles increases exponentially with increasing OCR. The rate of increase is considerably higher at smaller load (CSR) levels. Even small levels of OCR can dramatically change the number of load cycles a sand can withstand at a given CSR. 
- The influence of confining stress level on cyclic resistance is not overly significant in the tested consolidation stress levels of $100-400 \mathrm{kPa}$. The correction factor $\mathrm{K}_{\sigma}$ systematically decreases with increasing confining stress, relative density, and overconsolidation ratio. However, measured $K_{\sigma}$ values varied between 0.90 and 1 in both sands. The differences in $K_{\sigma}$ measured in Fraser river sand and silica sand at a given stress, density state were fairly minor. This suggests that particle shape does not influence $K_{\sigma}$ by much.

- $K_{\sigma}$ values systematically decrease with increasing OCR, but the magnitude of the changes are fairly small, and $K_{\sigma}$ values can be considered to be not dependent on OCR in design practice

- The dependence of the cyclic resistance ratio, CRR on overconsolidation is quite significant, but not at a comparable rate at which the number of cycles increase at a given CSR. A relative new factor termed $K_{O C R}$ defined as the ratio of CRR of the overconsolidated sand to that of normally consolidated sand, following the work of Ishihara et al (1978), can be used to account for the effects of overconsolidation when assessing site specific liquefaction potential. $K_{O C R}$ values are not affected by the confining stress level, and are essentially linearly related to OCR.

- Overconsolidation profoundly influences the correction factor $\mathrm{K}_{\alpha}$. Dramatic reductions in $K_{\alpha}$ are noted at $\mathrm{OCR}=1.5$, but the changes with further increase in OCR values are minor. $K_{\alpha}$ values reach as low as 25\% in Fraser River sand, and about $15 \%$ in Silica sand at a fairly high $\alpha=0.3$.

The dramatic differences in $K_{\alpha}$ of normally consolidated and overconsolidated Fraser River sand is a serious concern, as it might lead to potentially unsafe designs in 
overconsolidated soils (even after considering the increase in CRR due to the $K_{O C R}$ factor). $K_{\alpha}$ values in normally consolidated Silica sand are quite low, and thus the differences in $K_{\alpha}$ between normally consolidated and over consolidated Silica sand is not as significant.

\subsubsection{Post-Liquefaction Behaviour}

Post-liquefaction undrained behaviour of sands was assessed following liquefaction due to cyclic loading. The dependence of the post-liquefaction stress strain relationship on density, and OCR were evaluated, and yield the following conclusions.

- Deformation during post-liquefaction shearing occurs on account of dilation, and associated negative pore water pressure generation. The three zones of deformation identified by Vaid \& Thomas (1995) can be consistently identified in all post liquefaction tests. No tendency to reach a steady state was noted during post liquefaction loading, and shear strength increased with increasing strain level.

- Initial shear modulus following liquefaction is essentially zero, and very large strains may have to mobilize to support static shear stresses.

- Shear modulus increases with deformation, and at a faster rate in denser sands at a given stress level and OCR.

- The rate of dilation, and increase in shear modulus is also dependent on OCR. Heavily overconsolidated sand regain strength at a much faster rate. 


\section{REFERENCES}

Adalier, K. \& Elgamal, A., (2005), Liquefaction of over-consolidated sand: a centrifuge investigation, Journal of Earthquake Engineering, Imperial College Press, 9(1): 127-150,.

Arthur, J.R.F., Chua, K.S., and Dunstan, T., (1977), "Induced Anisotropy in a Sand", Geotechnique, 27(1): 13-30.

Arthur, J.R.F., Chua, K.S., Dunstan, T., and Del Camino, J.R., (1980), "Principal Stress Rotation: A Missing Parameter", Journal of the Geotechnical Engineering Division, ASCE, 106(4):419-433.

Arthur, J.R.F., and Menzies, B.K., (1972), "Inherent Anisotropy in Sand", Geotechnique, 22 (1):115-128.

ASTM. (2001a). Standard Test Methods for Maximum Index Density and Unit Weight of Soils Using a Vibratory Table (D-4253-00). Annual Book of ASTM Standards, American Society for Testing and Materials, Philadelphia, PA. 04.08.

ASTM. (2001b). Standard Test Methods for Minimum Index Density and Unit Weight of Soils and Calculation of Relative Density (D-4254-00). Annual Book of ASTM Standards, American Society for Testing and Materials, Philadelphia, PA. 04(8).

Bishop, A.W., (1966), "Strength of Soils as Engineering Materials", 6th Rankine Lecture, Geotechnique, 16(2):91-128.

Bishop, A.W., (1971), "Shear Strength Parameters for Undisturbed and Remolded Soil Specimens", Proceedings Roscoe Memorial Symposium on Stress-Strain Behaviour of Soils" Cambridge University, pp. 3-58.

Bishop, A.W., and Green, G.E., (1965), "The Influence of End Restraint on the Compression Strength of a Cohesionless Soil", Geotechnique, 15(3):243-266.

Bjerrum, L., and Landva, A., (1966), "Direct Simple-Shear Tests on a Norwegian Quick Clay", Geotechnique, 16(1):1-20.

Boulanger, R. W., Chan, C.K., Seed, H.B., and Seed, R.B., (1993), "A Low-Compliance BiDirectional Cyclic Simple Shear Apparatus", Geotechnical Testing Journal, 16(1):36-45. 
Broms, B.B., and Casbarian, A.O., (1965), "Effects of Rotation of the Principal Stress Axes and of the Intermediate Principal Stress on the Shear Strength", Proceeding, $6^{\text {th }}$ International Conference on Soil Mechanics and Foundation Engineering, 1:179-183.

Budhu, M., (1984), "Nonuniformities Imposed by Simple Shear Apparatus", Canadian Geotechnical Journal, 21(2):125-137.

Casagrande, A., (1975), "Liquefaction and Cyclic Deformation of Sands: a Critical Review", Proceedings Fifth Pan-American Conference on Soil Mechanics and Foundation Engineering, pp.79-133.

Castro, G., (1969), "Liquefaction of Sands", PhD Thesis, Harvard University, Cambridge, Massachusetts, 231p.

Castro, G., (1987), "On the Behaviour of Soils during the Earthquakes-Liquefaction", Proceedings of Soil Dynamics and Liquefaction, No. 42. Ed. A.S. Cakmak. Elsevier, pp. 169204.

Castro, G., and Poulos, S.J., (1977), "Factors Affecting Liquefaction and Cyclic Mobility", Journal of Geotechnical Engineering Division, ASCE, 103(6):501-516.

Castro, G., Poulos, S.J., France, J.W., and Enos, J.L., (1982), "Liquefaction Induced by cyclic Loading", Report submitted to the National Science Foundation, March 1982.

Chern, J.C., (1985), "Undrained Response of Sands with Emphasis on Liquefaction and Cyclic Mobility", PhD Thesis, University of British Columbia, Vancouver, Canada, 213p.

Dyvik, R., Berre, T., Lacasse, S., and Raadim, B., (1987), "Comparison of Truly Undrained and Constant Volume Direct Simple Shear Tests", Geotechnique, 37(1):3-10.

Field, W.G., (1963), "Towards the Statistical Definition of Granular Mass", in Proceedings $4^{\text {th }}$ American and New Zealand Conference on Soil Mechanics, 1:143-148.

Finn, W.D.L., Pickering, J., and Bransby, P.L., (1971), "Sand Liquefaction in Triaxial and Simple Shear Test", Journal of Soil Mechanics and Foundations Division, ASCE, 97(4):839851.

Finn, W. D. L., and Vaid, Y.P., (1977), "Liquefaction Potential from Drained Constant Volume Simple Shear Tests", Proceedings, $6^{\text {th }}$ World Conference on Earthquake Engineering, 1:21572162. 
Finn, W. D. L., Vaid, Y.P., and Bhatia, K.K., (1978), "Constant Volume Simple Shear Testing”, Proceedings, $2^{\text {nd }}$ International Conference on Microzonation for Safer Construction, 2:839851.

Franke, E., Kiekbusch, M., and Schuppener, B., (1979), “A New Direct Simple Shear Device”, Geotechnical Testing Journal, 2(4):190-199.

Gananathan, N., (2002). "Partially Drained Response of Sands", M.A.Sc. Thesis, The University of British Columbia, Vancouver, Canada.

Garrison, R. E, Luternuer, J. L, Grill, E.V, Macdonald, R. D. and Murray, J. w., (1969). "Early diagnetic cementation of recent sands, Fraser River Delta, British Columbia, 12:27-46

Green, G.E., (1971), "Strength and Deformation of Sand Measured in an Independent Stress Control Cell", Proceedings, Roscoe Memorial Symposium on Stress-Strain Behaviour of Soils, Cambridge University, pp. 285-323

Ha, D., (2003), "Effect of Initial Stress State on the Undrained Cyclic Behaviour of Sands", M.A.Sc. Thesis, Carleton University, Ottawa, Canada 157p.

Haynes, ME, and Olsen, RS (1998), "Influence of confining stress on liquefaction resistance, In Proc. Of the international Workshop on the Physics and Mechanics of Liquefaction,Eds. Lade, PV, and Yamamuro, JA, Baltimore, Maryland, USA. Sept 10-11.

Hatanaka, M., Sugimoto, M., and Suzuki, Y., (1985), "Liquefaction Resistance of Two Alluvial Volcanic Soils Sampled by In-situ Freezing", Soils and Foundations, 25(3):49-63.

Hight, D.W., Gens, A., and Symes, M.J., (1983), "The Development of a New Hollow Cylinder Apparatus for Investigating the Effects of Principal Stress Rotation in Soils", Geotechnique, 33(4):355-383.

Hight, D.W., Shibuya, S., and Symes, M.J., (1988), Discussion on "The Engineering Application of Direct and Simple Shear Testing", Geotechnique, 38(1):139-140.

Ishihara, K., Tatsuoka, F., and Yasuda, S., (1975), "Undrained Deformation and Liquefaction of Sands under Cyclic Stresses", Soils and Foundations, 15(1):29-44.

Ishihara, K., and Takatsu, H., (1978), "Yielding of Over consolidated Sand and Liquefaction Model under Cyclic Stresses", Soils and Foundations, 18(1):57-71.

Ishihara, K., and Takatsu, H., (1979), "Effects of Over consolidation and $\mathrm{K}_{\mathrm{o}}$ conditions on the Liquefaction Characteristics of Sand", Soils and Foundations, 19(4):59-68. 
Ishihara, K., and Yamazaki, F., (1980), "Cyclic Simple Shear Tests on Saturated Sand in MultiDirectional Loading", Soils and Foundations, 20(1):45-59.

Ishihara, K., (1993), "Liquefaction and Flow Failure during Earthquakes", Geotechnique, 43(3):351-415.

Iwasaki, T, Tatsuoka, F, Takagi, Y (1978), "Shear modulii of sands under cyclic torsional shear loading", Soils and Foundations, 18(1):39-56.

Kolbuszewski, J.J., (1948), "An Experimental Study of the Maximum and Minimum Porosities of Sands", Proceedings $2^{\text {nd }}$ International Conference on Soil Mechanics and Found Engineering, 1:158-165.

Kramer, S.L., and Seed, H.B., (1988), "Initiation of Soil Liquefaction under Static Loading Conditions", Journal of Geotechnical Engineering, ASCE, 114(4):412-430.

Kokusho, T, Yoshida, Y, and Esashi, Y (1982), "Dynamic properties of soft clay for wide strain range", Soils Found., 22(4):1-18.

Ladd, C.C., Foot, R., Ishihara, K., Schlosser, F., and Poulos, H.G., (1977), "Stress-Deformation and Strength Characteristics", State of the Art Report, $9^{\text {th }}$ International Conference on Soil Mechanics and Foundation Engineering, 2:421-494.

Ladd, P.V., and Lambe, T.W., (1963), "The Strength of Undisturbed Clay Determined from Undrained Tests", Proceedings, Symposium on Laboratory Shear Testing of Soils, ASTM, Philadelphia, PA, STP 361:342-371.

Lade, P.V., (1982), "Localization Effects in Triaxial Tests on Sand", Proceedings, IUTAM Symposium on Deformation and Failure of Granular Materials, P.A. Vermeer and H.J. Luger (eds), Balkema, Rotterdam, pp. 461-471.

Lade, P.V., (1992), "Static Instability and Liquefaction of Loose Fine Sandy Slopes", Journal of Geotechnical Engineering, ASCE, 118:51-71.

Lade, P.V., and Duncan, J.M., (1973), "Cubical Triaxial Tests on Cohesionless Soil”, Journal of the Soil Mechanics and Foundation Division, ASCE, 99(10):793-811.

Lade, P.V., and Wasif, U., (1988), "Effect of Height- to- Diameter ratio in Triaxial Specimens on the Cross Anisotropic Sand", Advanced Triaxial Testing of Soil and Rock, ASTM STP 977, R.T. Donaghe, R.C. Chaney, and M.L. Silver, Eds., American Society for Testing and Materials, Philadelphia, ASCE, pp706-714. 
Lee, K.L., and Seed, H.B., (1967), "Cyclic Stress Conditions Causing Liquefaction of Sand”, Journal of Geotechnical Engineering Division, ASCE, 93(5),47-70.

Logeswaran, P., (2005), "Behaviour of Sands under Simultaneous Changes of Volume and Pore Pressure", MASc Thesis, Carleton University, Ottawa, Canada, 177p.

Logeswaran, P., (2010), "Behaviour of Sands under Generalized Loading and Drainage Conditions", PhD Thesis, Carleton University, Ottawa, Canada, 273p.

Miura, K., Miura, S., and Toki, S., (1986), "Deformation Behaviour of Anisotropic Dense Sand under Principal Stress Axes Rotation", Soils and Foundations, 26(1):36-52.

Miura, S., and Toki, S., (1982), "A Sample Preparation Method and Its Effect on Static and Cyclic Deformation - Strength Properties of Sand", Soils and Foundations, 22(1):61-77.

Miura, S., and Toki, S., (1984), "Anisotropy in Mechanical Properties and Its Simulation of Sands from Natural Deposits", Soils and Foundations, 24(3):69-84.

Mohamad, R., and Dobry, R., (1986), "Undrained Monotonic and Cyclic Triaxial Strength of Sand", Journal of Geotechnical Engineering, ASCE, 112(10):941-958.

Mortensen, S.E., (1982), "Methods of Specimen Preparation for Sands and Their Effects on Soil Behaviour: A Literature Survey”, Internal Report, Norwegian Geotechnical Institute, Norway.

Mould, J.C., Sture, S., and Ko, H.Y., (1982), "Modeling of Elastic-Plastic Anisotropic Hardening and Rotating Principal Stress Directions in Sand", IUTAM Conference on Deformation and Failure of Granular Materials, Delft, pp. 431-439.

Mulilis, J.P., Seed, H.B., Chan, C.K., Mitchell, J.K., and Arulanandan, K., (1977), "Effects of Sample Preparation on Sand Liquefaction", Journal of the Geotechnical Engineering Division, ASCE, 103(2):91-108.

Nagase, H., Shimizu, K, Hiro-oka, A. Maeda, H \& Ishihara, H.,(2004), Effects of overconsolidation on liquefaction strength characteristics of sand samples under $\mathrm{k}_{0}$-stress conditions, In. Proc. of the $13^{\text {th }}$ World Conference on Earthquake Engineering, Vancouver, BC. Aug 4-8, 2004.

Nakata, Y., Hyodo, M., Murata. H., and Yasufuku, N., (1998), "Flow Deformation of Sands Subjected to Principal Stress Rotation", Soils and Foundations, 38(2):115-128.

Negussey, D., (1984), “An Experimental Study of the Small Strain Response of Sand”, Ph.D. Thesis, Department of Civil Engineering, University of British Columbia, Vancouver, Canada. 
Negussey, D., Wijewickreme, W.K.D., and Vaid, Y.P., (1988), "Constant Volume Friction Angle of Granular Materials", Canadian Geotechnical Journal, 25:50-55.

Oda, M., (1972b), "The Mechanism Fabric Changes during Compressional Deformation of Sand", Soils and Foundations, 12(2):1-18.

Oda, M.,(1981). "Anisotropic Strength of Cohesionless Sands", Journal of the Geotechnical Engineering. Division., ASCE, Vol. 107(9):1219-1231.

Oda, M., Koishikawa, I., and Higuchi, T., (1978), "Experimental Study of Anisotropic Shear Strength of Sand by Plane Strain Test", Soils and Foundations, 18(1):25-38.

Oda, M., Nasser, S.N., and Konishi, J. (1985). "Stress-Induced Anisotropy in Granular Masses", Soils and Foundations, 25(3):85-97.

Poulos, S.J., (1981), "The Steady State of Deformation” Journal of Geotechnical Engineering Division, ASCE, 107(5):553-562.

Poulos, S.J., Castro, G., and France, J.W., (1985), "Liquefaction Evaluation Procedure" Journal of Geotechnical Engineering, ASCE, 111(6):772-792.

Roscoe, K.H., (1953), "An Apparatus for Application of Simple Shear to Soil Samples", Proceedings, $3^{\text {rd }}$ International Conference on Soil Mechanics and Foundation Engineering, $1: 186-191$.

Roscoe, K.H., Schofield, A.N. and Worth, C.P., (1958), "On the Yielding of soil”' Geotechnique, $8(1): 27-53$.

Rowe, P.W., and Barden, L., (1964), "The Importance of Free Ends in the Triaxial Test", Journal of Soil Mechanics and Foundation Engineering Division", ASCE, 90(1):1-27.

Saada, A.S., (1981), Discussion on "Undrained Deformation Characteristics of Loose Sand under 3-D Stress Conditions", Soils and Foundations, 21(4):121.

Saada, A.S., and Puccini, P., (1985), Discussion on "The Development of a New Hollow Cylinder Apparatus for Investigating the Effects of Principal Stress Rotation in Soils", Geotechnique, 35(1):78-85.

Saada, A.S., and Townsend, F.C., (1981), "State of the Art: Laboratory Strength Testing of Soils", Symposium on Laboratory Shear Strength of Soil, ASTM STP 740:7-77.

Sayao, A.S.F., (1989), "Behaviour of Sand under General Stress Paths in the Hollow Cylinder Torsional Device”, PhD Thesis, University of British Columbia, Vancouver, Canada, 1996p. 
Sayao, A.S.F., and Vaid, Y.P., (1991), "A Critical Assessment of Stress Nonuniformities in Hollow Cylinder Test Specimens", Soil and Foundations, 31(1):60-72.

Seed, H.B., and Idriss I.M., (1970), "Soils moduli and damping factors for dynamic response analyses”, EERC, Rep. 70-10, University of California, Berkeley.

Seed, H.B., (1979), "Soil Liquefaction and Cyclic Mobility Evaluation for Level Ground during Earthquakes", Journal of Geotechnical Engineering Division, ASCE, 105(2):201-225.

Seed, H.B., Mori, K., and Chan, C.K., (1977), "Influence of Seismic History on Liquefaction of Sands", Journal of Geotechnical Engineering Division, 103(4):257-269.

Seed, H.B., Singh, S., Chan, C.K., and Vilela, T.F., (1982), "Consideration in Undisturbed Sampling of Sands", Journal of the Geotechnical Engineering Division, ASCE, 108(2):265283.

Shibuya, S., (1988), "A Servo System for Hollow Cylinder Torsional Testing of Soils", Geotechnical Testing Journal, ASTM, 11(2):109-118.

Shibuya, S., and Hight, D.W., (1987), “A Bounding Surface for Granular Materials”, Soils and Foundations, 27(4):123-136.

Sivakugan, N., Chameau, J.L., Holtz, R.D., and Altschaeffl, A.G., (1988), "Servo-Controlled Cubical Shear Device", Geotechnical Testing Journal, ASTM, 11(2):119-124.

Sivathayalan, S., (1994), "Static, Cyclic, and post liquefaction simple response of Sands”, Master Thesis, University of British Columbia, Vancouver, Canada, 154p.

Sivathayalan, S., (2000), "Fabric Initial State and Stress Path Effects on Liquefaction Susceptibility of Sands, $\mathrm{PhD}$ Thesis, University of British Columbia, Vancouver, Canada, $307 \mathrm{p}$.

Sivathayalan, S., and Logeswaran, P., (2007), "Behaviour of Sands under Generalized Drainage Boundary Conditions", Canadian Geotechnical Journal, 44(2):138-150.

Sivathayalan, S., and Logeswaran, P., (2008), "Experimental Assessment of the Response of Sands under Shear-Volume Coupled Deformation”, Canadian Geotechnical Journal, 45(9):1310-1323.

Sivathayalan, S., and Vaid, Y.P., (2002), "Influence of Generalized Initial State and Principal Stress Rotation on the Undrained Response of Sands”, Canadian Geotechnical Journal, 39:6376. 
Sladen, J.A., D'Hollander, R.D., and Krahn, J., (1985), "The Liquefaction of Sands- A Collapse Surface Approach", Canadian Geotechnical Journal, 22 (4):564-578.

Stedman, D., (1997), "Effects of Confining Pressure and Static Shear on Liquefaction Resistance of Fraser River Sand", MASc Thesis, University of British Columbia, Vancouver, Canada, 93p.

Stokoe, K, H, Darendeli, M. B, Andrus, R.D, and Brown, L.T (1990), "Dynamic soil properties: Laboratory, field and correlation studies." $2^{\text {nd }}$ Int. Conf. on Earthquake Geotechinical Engineering, (3):811-845.

Sture, S., and Desai, C.S., (1979), "Fluid Cushion Truly Triaxial or Multiaxial Testing Devices", Geotechnical Testing Journal, 2(1):20-33.

Sukumaran, B., Leonards, G.A., and Fox, P.J., (1996), Discussion on "Liquefaction and Post Liquefaction Behaviour of Sand", Journal of Geotechnical Engineering, 122(2):502-503.

Sutherland, H.B., and Mesdary, M.S., (1969), “The Influence of the Intermediate Principal Stress on the Strength of Sand", Proceedings. $7^{\text {th }}$ International Conference on Soil Mechanics and Foundation Engineering, 1:391-399.

Symes, M.J., Gens, A. and Hight, D.W. (1984), "Undrained Anisotropy and Principal Stress Rotation in Saturated Sand", Geotechnique, 34(1):11-27.

Symes, M.J., Gens, A., and Hight, D.W., (1988), "Drained Principal Stress Rotation in Saturated Sand", Geotechnique, 38(1):59-81.

Symes, M.J., Hight, D.W., and Gens, A., (1982), "Investigating Anisotropy and the Effects of Principal Stress Rotation and of the Intermediate Principal Stress Using a Hollow Cylinder Apparatus", IUTAM Conference on Deformation and Failure of Granular Materials, Delft, pp. 441-449.

Symes, M.J., Shibuya, S., Hight, D.W. and Gens, A. (1985), "Liquefaction with Cyclic Principal Stress Rotation", Proceedings. $11^{\text {th }}$ International Conference on Soil Mechanics and Foundation Engineering, San Francisco, 4:1919-1922.

Terzaghi, K. and Peck, R.B., (1948), "Soil Mechanics in Engineering Practice", $2^{\text {nd }}$ edition, John Wiley and sons, New York.

Terzaghi, K, Peck, R.B., and Mesri, G. (1996). "Soil Mechanics in Engineering Practice", $3^{\text {rd }}$ Edition, New York, John Wiley \& Sons Inc. p 504. 
Thomas, J., (1992), "Static, Cyclic and Post Liquefaction Behaviour of Fraser River Sand", M.A.Sc. Thesis, University of British Columbia, Vancouver, Canada, 117p.

Uthayakumar, M., (1995), "Liquefaction of Sands under Multi-axial Loading", PhD Thesis, University of British Columbia, Vancouver, Canada, 185p.

Uthayakumar, M., and Vaid, Y.P. (1998), "Static Liquefaction of Sands under Multiaxial Loading", Canadian Geotechnical Journal, 35(2):273-283.

Vaid, Y.P., and Campanella, R.G., (1974), "Time Dependent Behaviour of Undisturbed Clay", Journal of Geotechnical Engineering Division, ASCE, 103(7):693-709.

Vaid, Y.P., and Finn, W.D.L., (1978), "Static Shear and Liquefaction Potential", Journal of the Geotechnical Engineering Division, ASCE, 105(10):1233-1246.

Vaid, Y.P., and Chern, J.C., (1983), "Mechanism of Deformation during Undrained Loading of Saturated Sand", International Journal of Soil Dynamics and Earthquake Engineering, 2(3):171-177.

Vaid, Y.P., and Chern, J.C., (1985), "Cyclic and Monotonic Undrained Response of Sands", Proceedings Advances in the Art of Testing Soils under Cyclic Loading Conditions, Detroit, pp. 120-147.

Vaid, Y.P., Chung, E.K.F., and Kuerbis, R.H., (1989), "Preshearing and Undrained Response of sands", Soils and Foundations, 29(4):49-61.

Vaid, Y.P., Chung, E.K.F., and Kuerbis, R.H., (1990a), "Stress Path and Steady State", Canadian Geotechnical Journal, 27(1):1-7.

Vaid, Y.P., and Eliadorani, A., (1998), "Instability and Liquefaction of Granular Soils under Undrained and Partially Drained States" Canadian Geotechnical Journal, 35(6):1053-1062.

Vaid, Y.P., Sayao, A., Enhuang, H. and Negussey, D., (1990b), "Generalized Stress-PathDependent Soil Behaviour with a New Hollow Cylinder Torsional Apparatus", Canadian Geotechnical Journal, 27(5):601-616.

Vaid, Y.P., and Negussey, D., (1988), "Preparation of Reconstituted Sand Specimens", Symposium on Advanced Triaxial Testing of Soil and Rock, ASTM STP 977, pp. 405-417.

Vaid, Y.P., and Sivathayalan, S., (1996), "Static and Cyclic Liquefaction Potential of Fraser Delta Sand in Simple Shear and Triaxial Tests", Canadian Geotechnical Journal, 33(2):281289. 
Vaid, Y.P., Sivathayalan, S., and Stedman, D., (1999), "Influence of Specimen Reconstitution Method on Undrained Response of Sand", ASTM Geotechnical Testing Journal, 22(3):187195.

Vaid, Y.P., and Sivathayalan, S., (2000), "Fundamental Factors Affecting Liquefaction Susceptibility of Sands". Canadian Geotechnical Journal, 37:592-606.

Vaid, Y.P., Stedman, J.D., and Sivathayalan, S. (2001), "Confining Stress and Static Shear Effects in Cyclic Liquefaction", Canadian Geotechnical Journal, 38(3):580-591.

Vaid, Y.P., and Thomas, J., (1994), "Post Liquefaction Behaviour of Sand", Proceedings $13^{\text {th }}$ International Conference on Soil Mechanics and Foundation Engineering, New Delhi, India, pp. 1305-1310.

Vaid, Y.P., and Thomas, J., (1995), "Liquefaction and Post Liquefaction of Sand", Journal of Geotechnical Engineering", 121(2):163-173.

Vucetic, M, Lanzo, G, and Doroudian, M (1998), "Damping at small strains in cyclic simple shear test", Journal of Geotechnical and Geoenvironmental Engineering, 124(7), pp. 585-594.

Vucetic, M, and Dobry, R.,(1991), "Effect of soil plasticity on cyclic response", Journal of Geotechnical Engineering",ASCE, 117(1):89-107.

Wijewickreme, W.K.D. (1990). Ph.D. Thesis, "Behaviour of Sand under Simultaneous Increase in Stress Ratio and Principal Stress rotation", Department of Civil Engineering, University of British Columbia, Canada, 225p

Wijewickreme, W.K.D., and Vaid, Y.P., (1991), "Stress Nonuniformities in Hollow Cylinder Torsional Specimens", Geotechnical Testing Journal, 14(4):349-362.

Yamada, Y. and Ishihara, K., (1979), "Anisotropic Deformation Characteristics of Sand under Three Dimensional Stress Conditions", Soils and Foundations, 19(2):79-94.

Yoshimi, Y., Hatanaka, M., and Oh-Oka, H., (1977), "A Simple Method for Undisturbed Sampling by Freezing", International Conference on Soil Mechanics and Foundation Engineering, 9(1):23-28.

Yoshimi, Y., Hatanaka, M., and Oh-Oka, H., (1978), "Undisturbed Sampling of Saturated Sands by Freezing", Soil and Foundations, 18(3):59-73.

Yoshimi, Y., Tokimatsu, K., and Hosaka, Y., (1989), "Evaluation of Liquefaction Resistance of Clean Sands Based on High Quality Undisturbed Samples" Soils and Foundations, 29(1):93104. 
Yoshimine, M., Ishihara, K., and Vargas, W., (1998), "Effects of Principal Stress Direction and Intermediate Principal Stress on Undrained Shear Behaviour of Sand", Soils and Foundations, 38(3):179-188.

Youd, TL, Idriss, IM, Andrus, RD, Arango, I., Castro, G., Christian, JT, Dobry, R, Finn, WDL, Harder, LF, Hynes, ME, Ishihara, K, Koester, JP, Liao, SC, Marcuson, WF, Martin, GR, Mitchell, JK, Moriwaki, Y, Power, MS, Robertson, PK, Seed, RB \& Stokoe, KH, 2001, Liquefaction Resistance of Soils: Summary Report from the 1996 NCEER and 1998 NCEER/NSF Workshops on Evaluation of Liquefaction Resistance of Soils, Journal of Geotechnical and Geoenvironmental Engineering, 127(10): 817-833. 


\section{Appendix A}

(Fraser River Sand) 


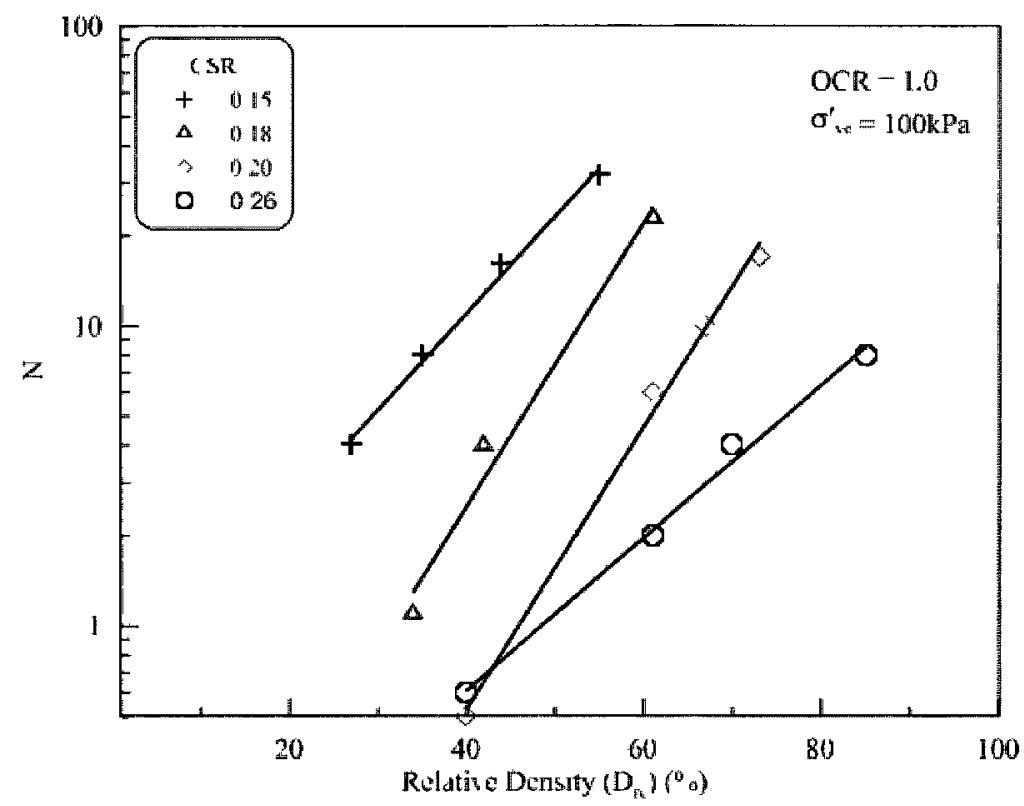

Fig. A1: Variation of number of cycles to liquefaction at $100 \mathrm{kPa}$ and $\mathrm{OCR}=1$

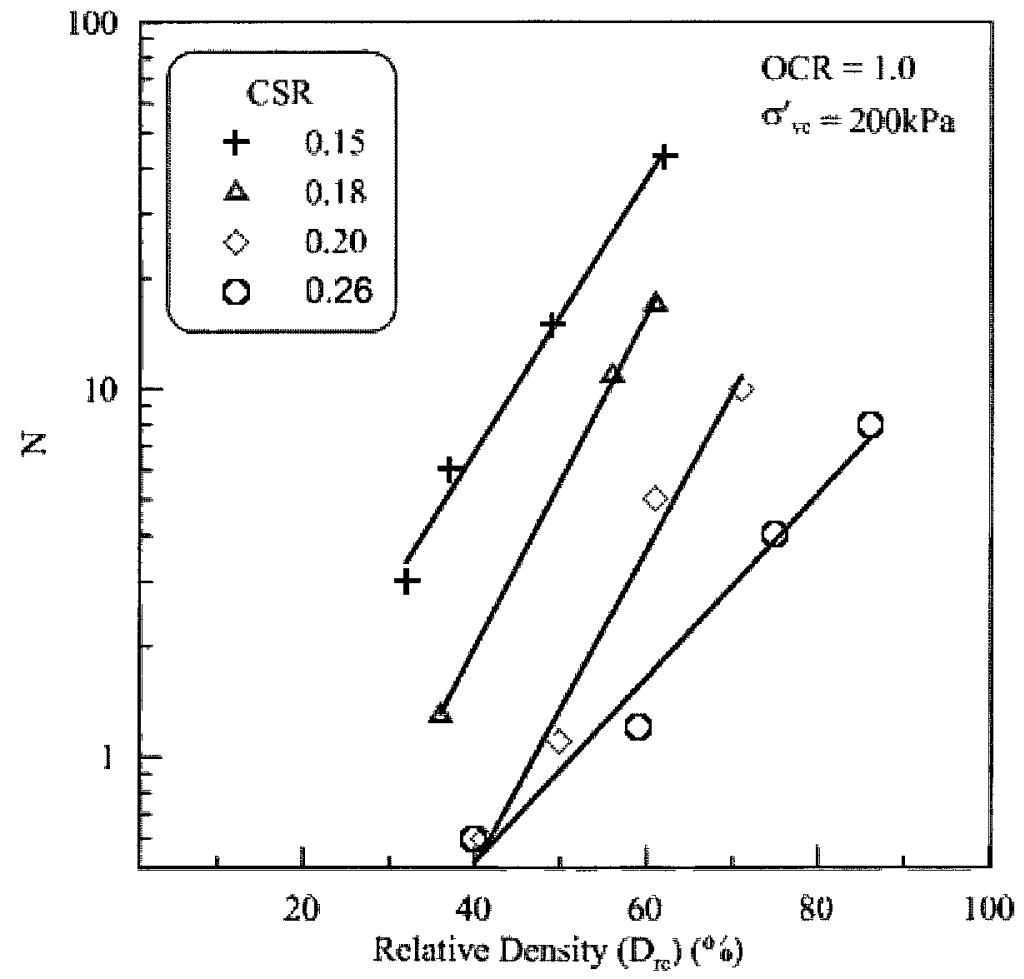

Fig. A2: Variation of number of cycles to liquefaction at $200 \mathrm{kPa}$ and $\mathrm{OCR}=1$ 


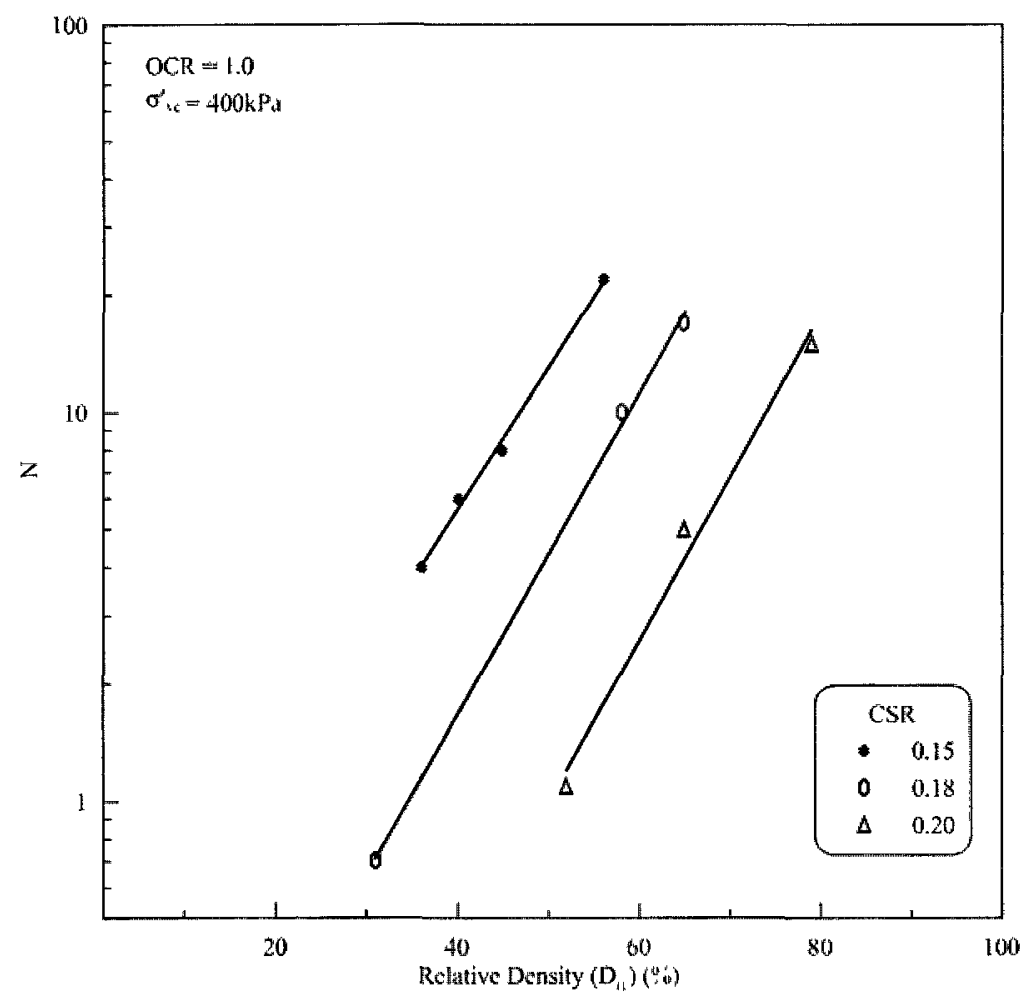

Fig. A3: $\quad$ Variation of number of cycles to liquefaction at $400 \mathrm{kPa}$ and $\mathrm{OCR}=1.0$

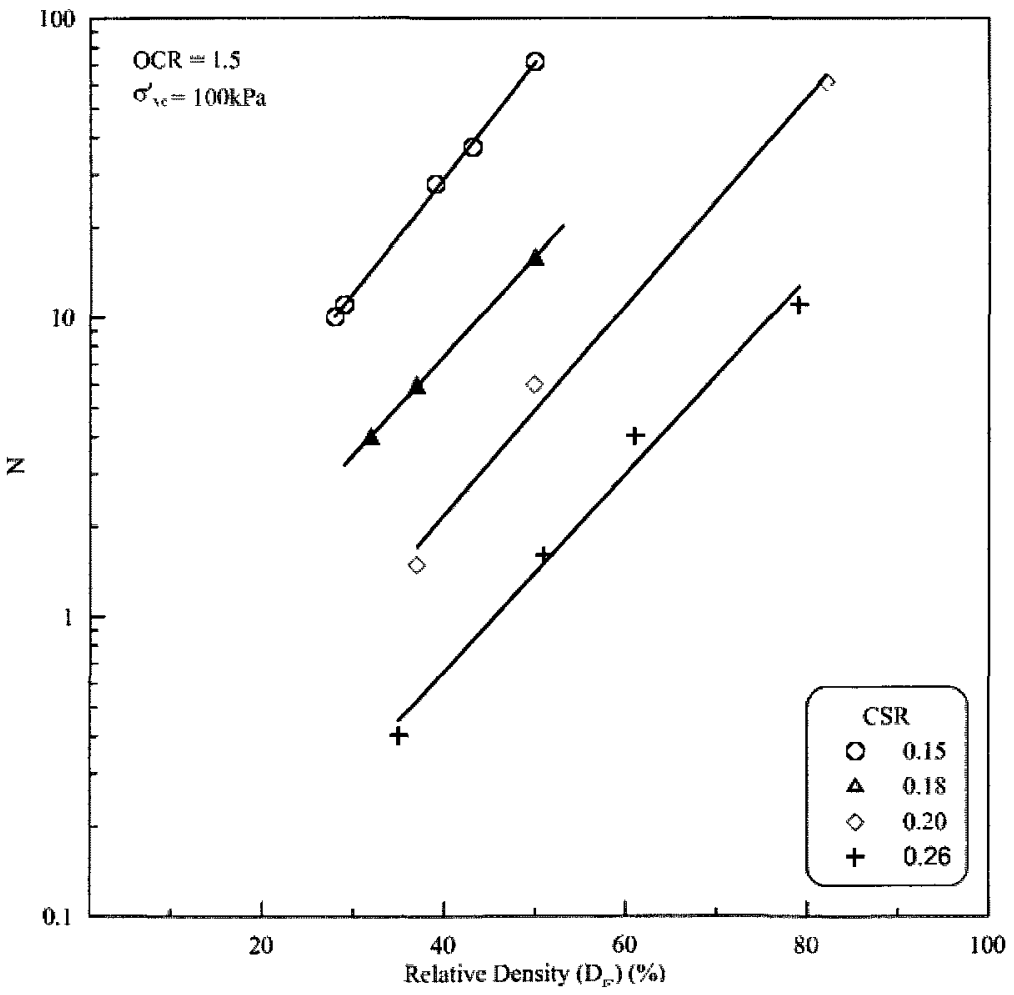

Fig. A4: Variation of number of cycles to liquefaction at $100 \mathrm{kPa}$ and $\mathrm{OCR}=1.5$ 


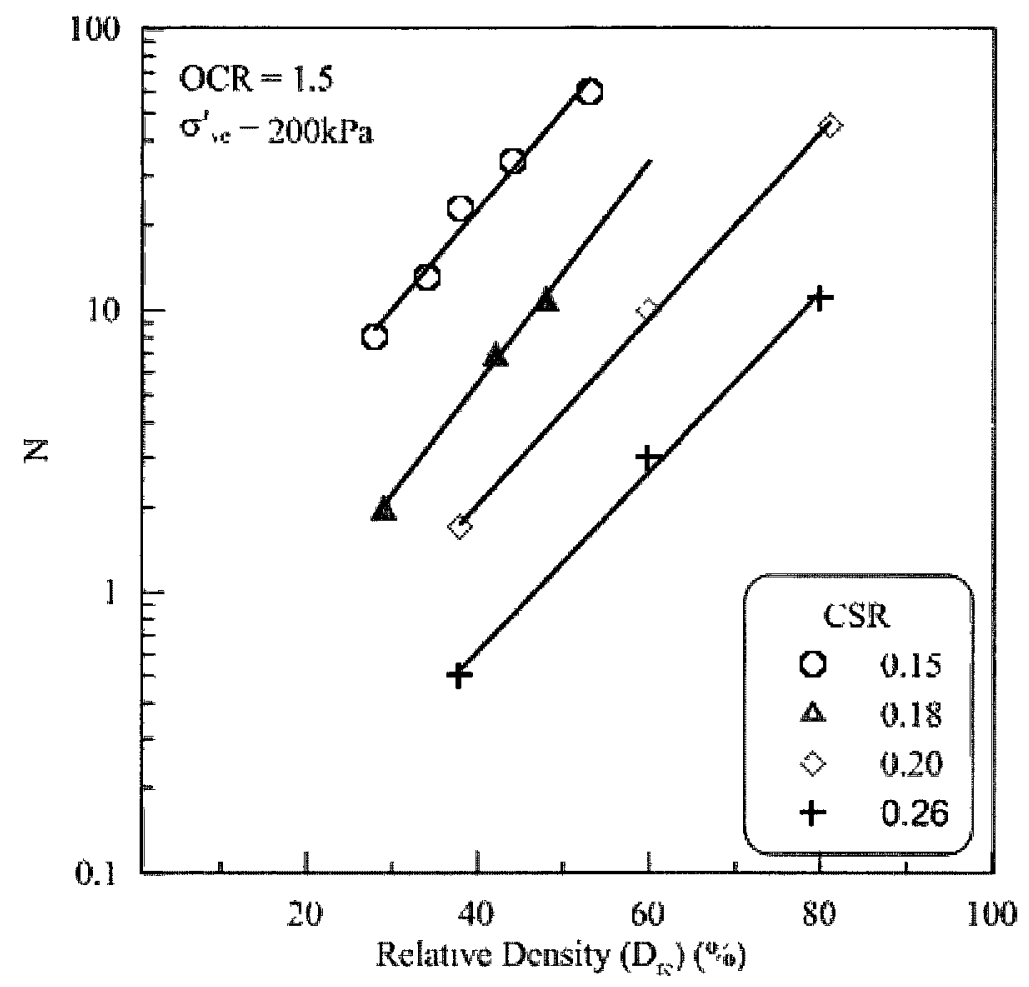

Fig. A5: Variation of number of cycles to liquefaction at $200 \mathrm{kPa}$ and $\mathrm{OCR}=1.5$

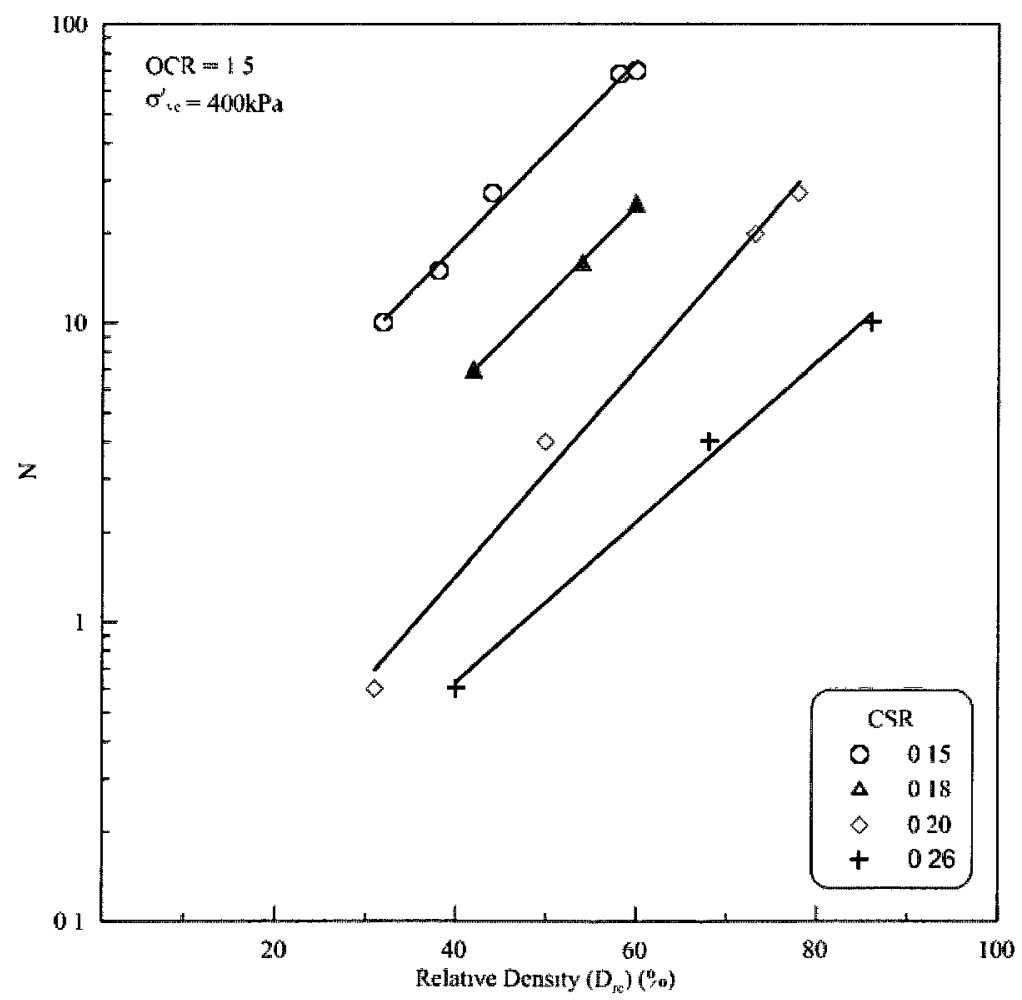

Fig. A6: Variation of number of cycles to liquefaction at $400 \mathrm{kPa}$ and $\mathrm{OCR}=1.5$ 


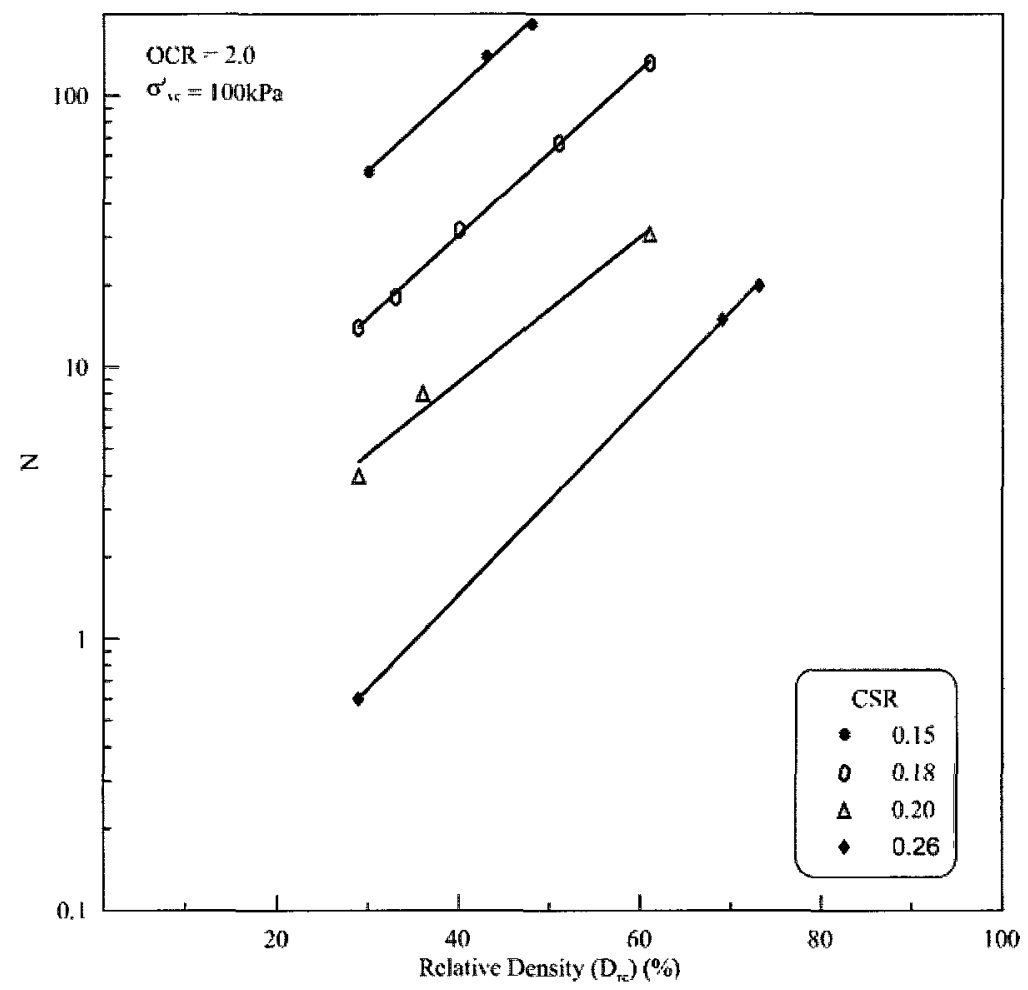

Fig. A7: Variation of number of cycles to liquefaction at $100 \mathrm{kPa}$ and $\mathrm{OCR}=2.0$

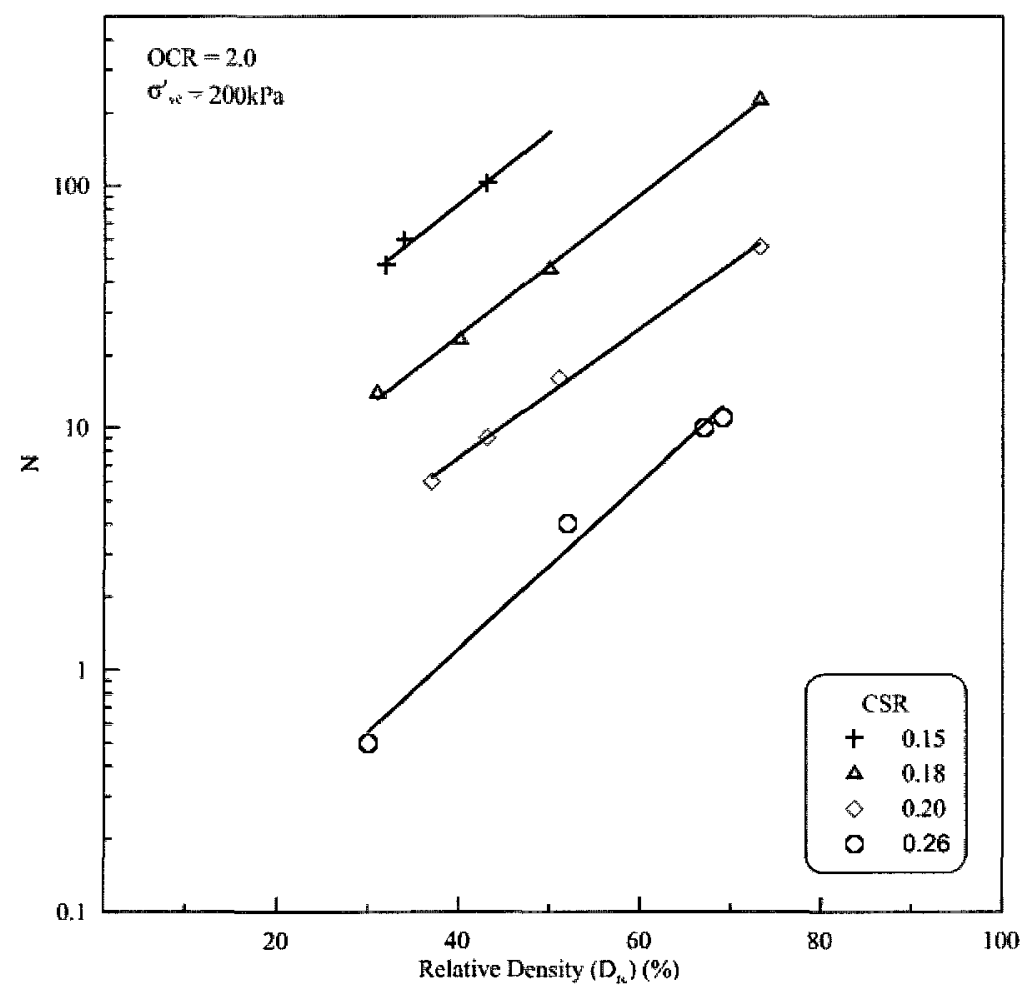

Fig. A8: Variation of number of cycles to liquefaction at $200 \mathrm{kPa}$ and $\mathrm{OCR}=2.0$ 


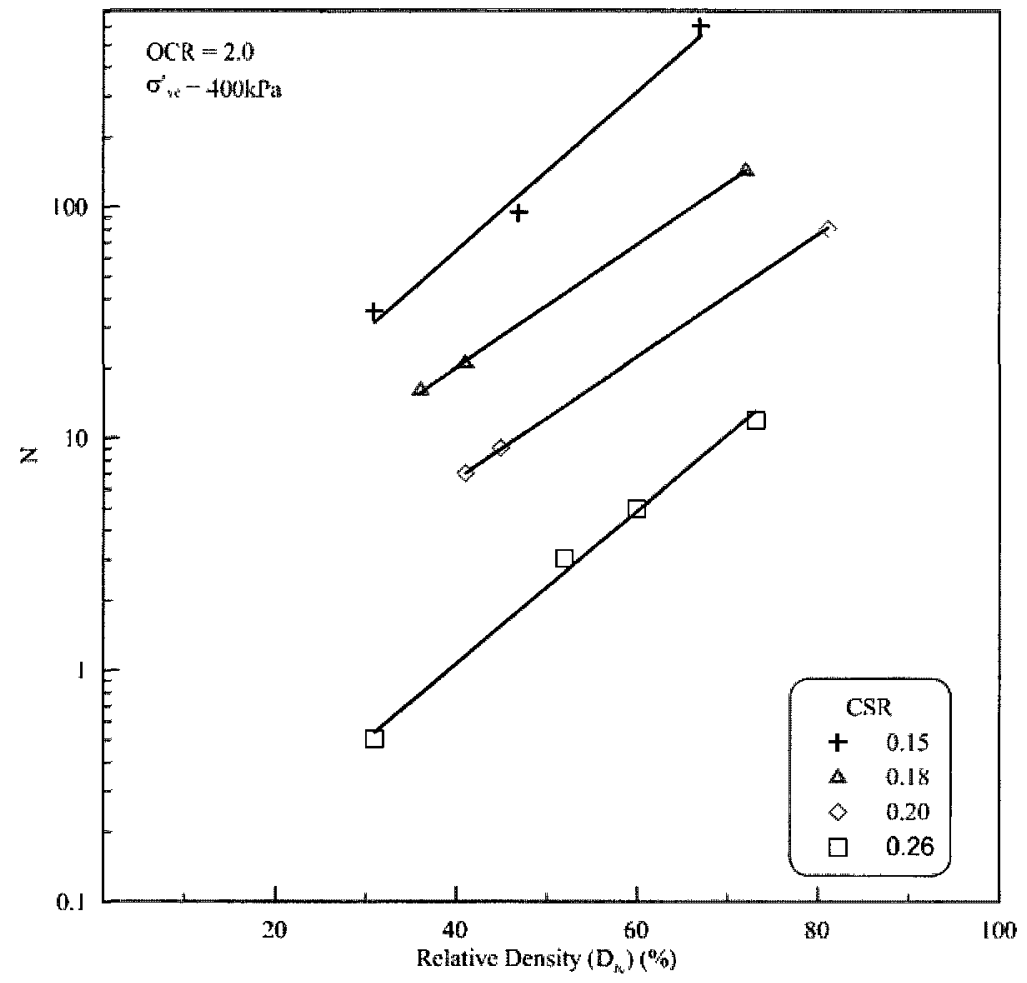

Fig. A9: Variation of number of cycles to liquefaction at $400 \mathrm{kPa}$ and $\mathrm{OCR}=2.0$

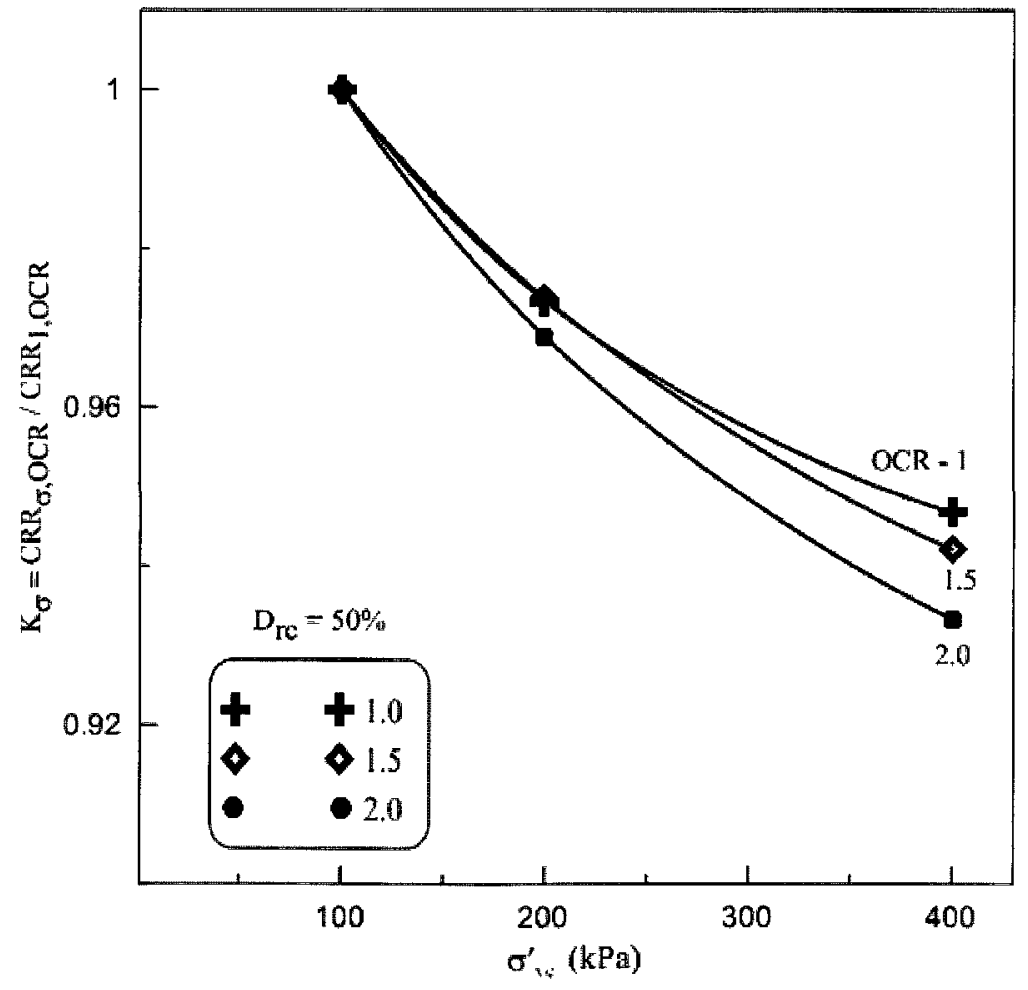

Fig. A10: The variation of $K_{\sigma}$ with confining stress level at $50 \%$ of FRS 


\section{Appendix B (Silica Sand)}




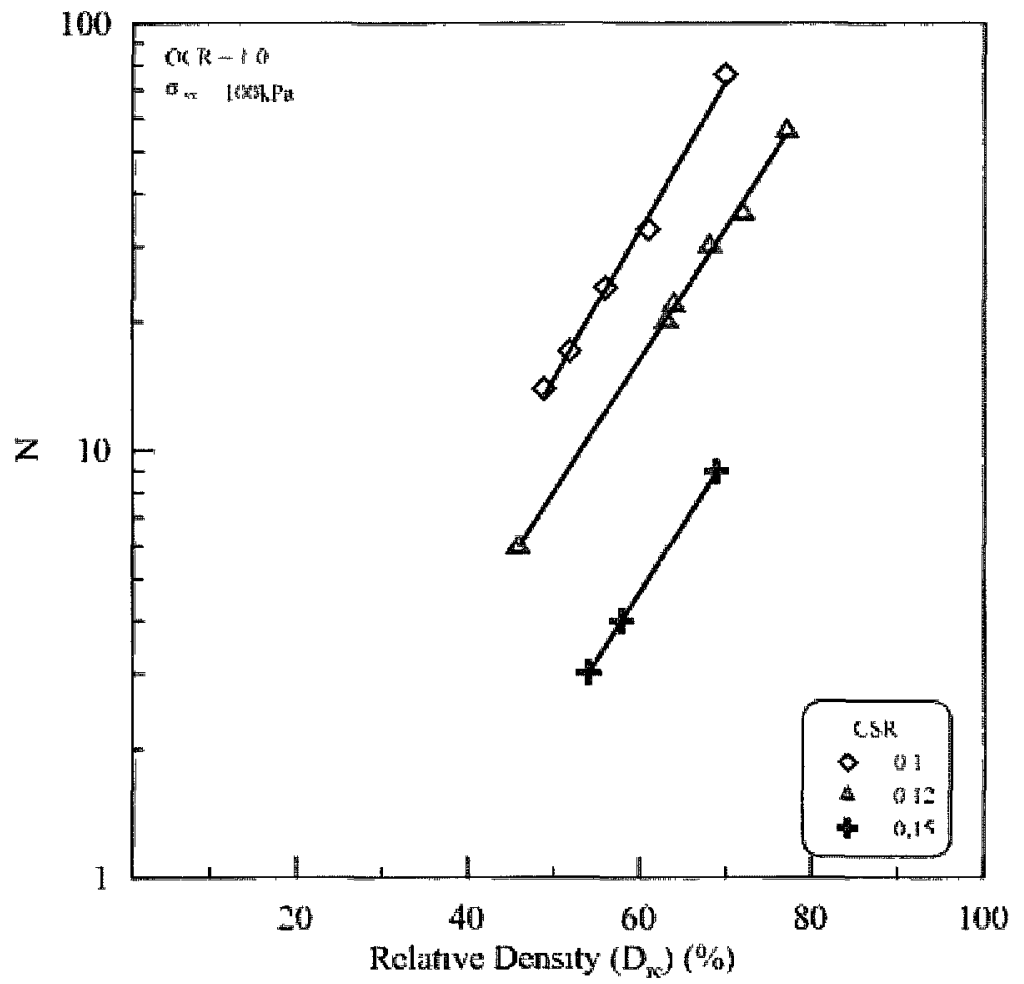

Fig. B1: Variation of number of cycles to liquefaction at $100 \mathrm{kPa}$ and $\mathrm{OCR}=1.0$

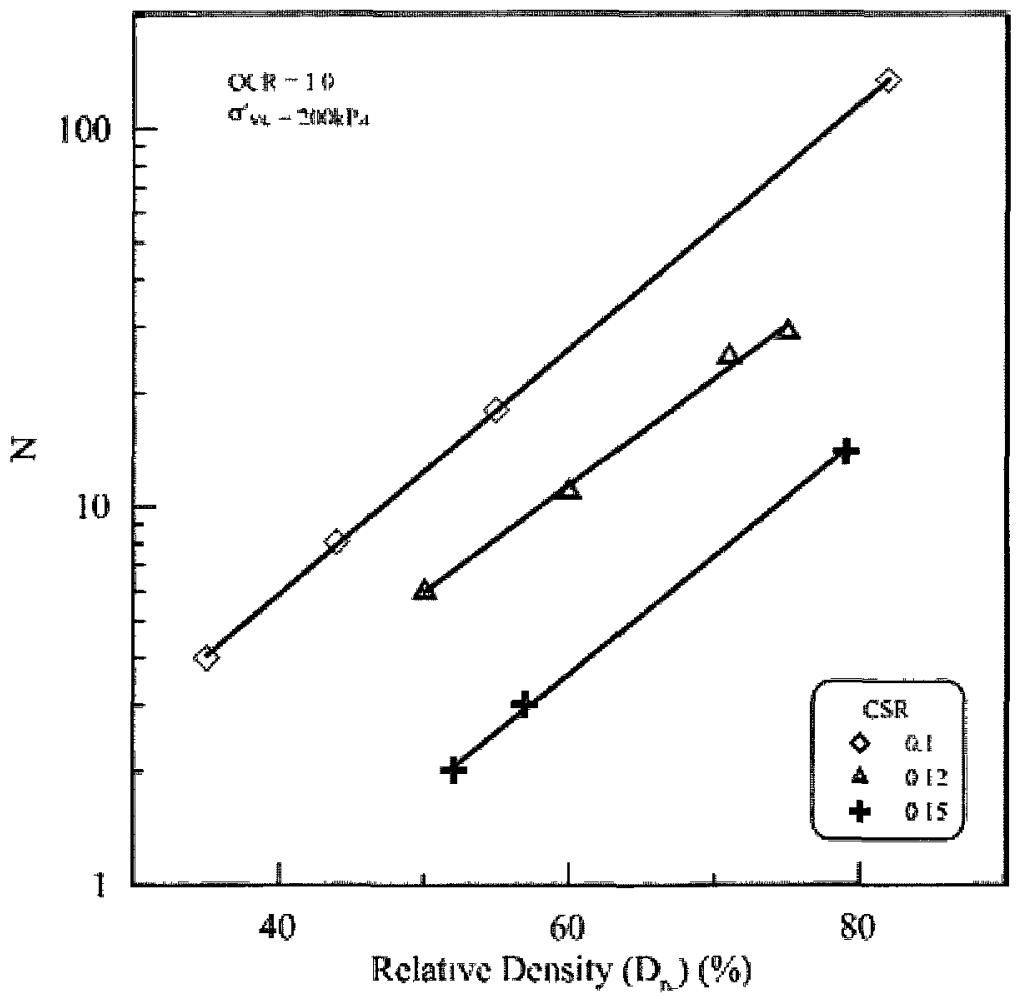

Fig. B2: $\quad$ Variation of number of cycles to liquefaction at $200 \mathrm{kPa}$ and $\mathrm{OCR}=1.0$ 


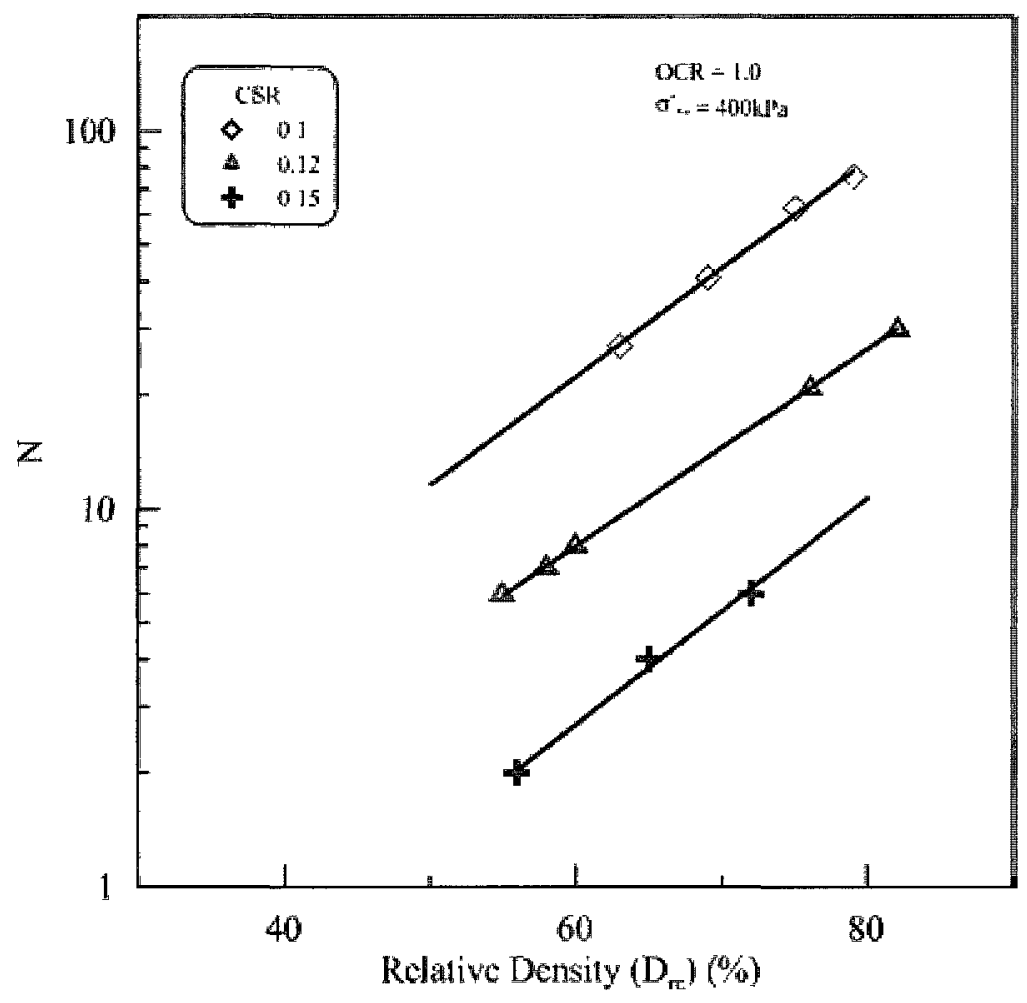

Fig. B3: Variation of number of cycles to liquefaction at $400 \mathrm{kPa}$ and $\mathrm{OCR}=1.0$

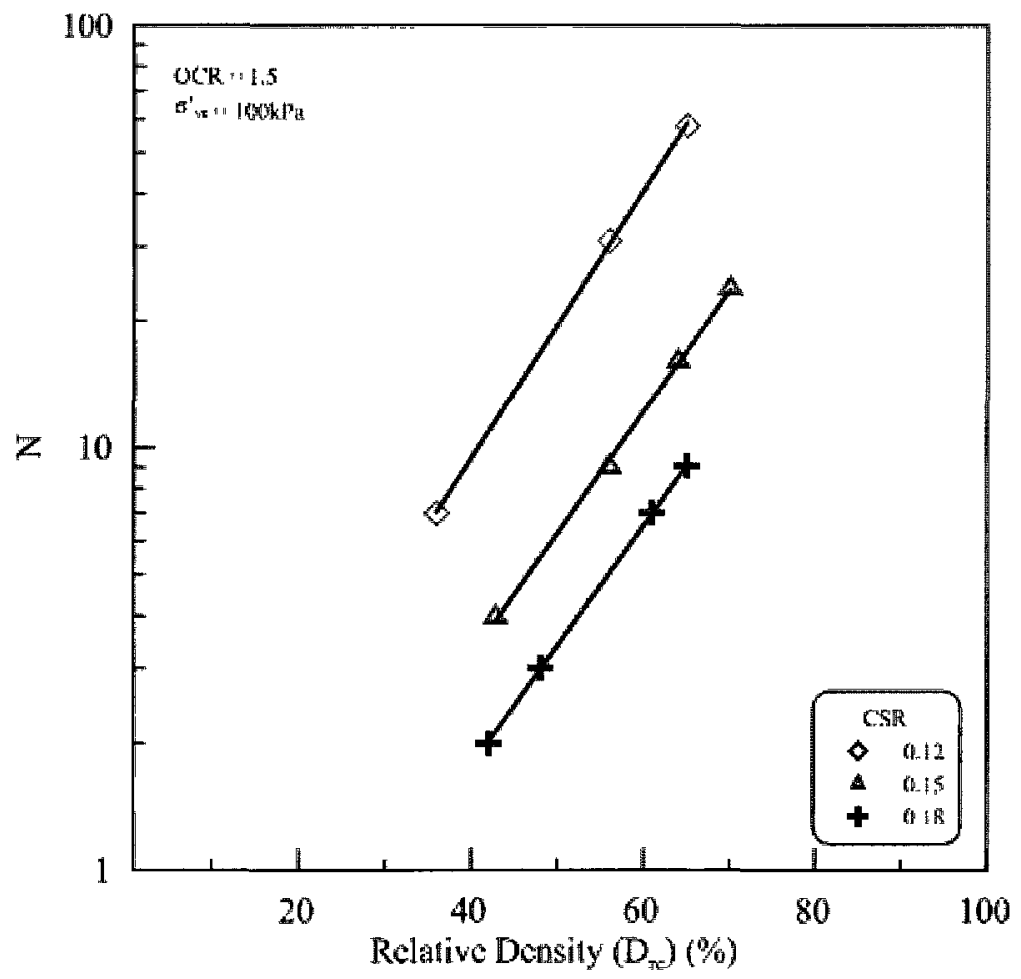

Fig. B4: Variation of number of cycles to liquefaction at $100 \mathrm{kPa}$ and $\mathrm{OCR}=1.5$ 


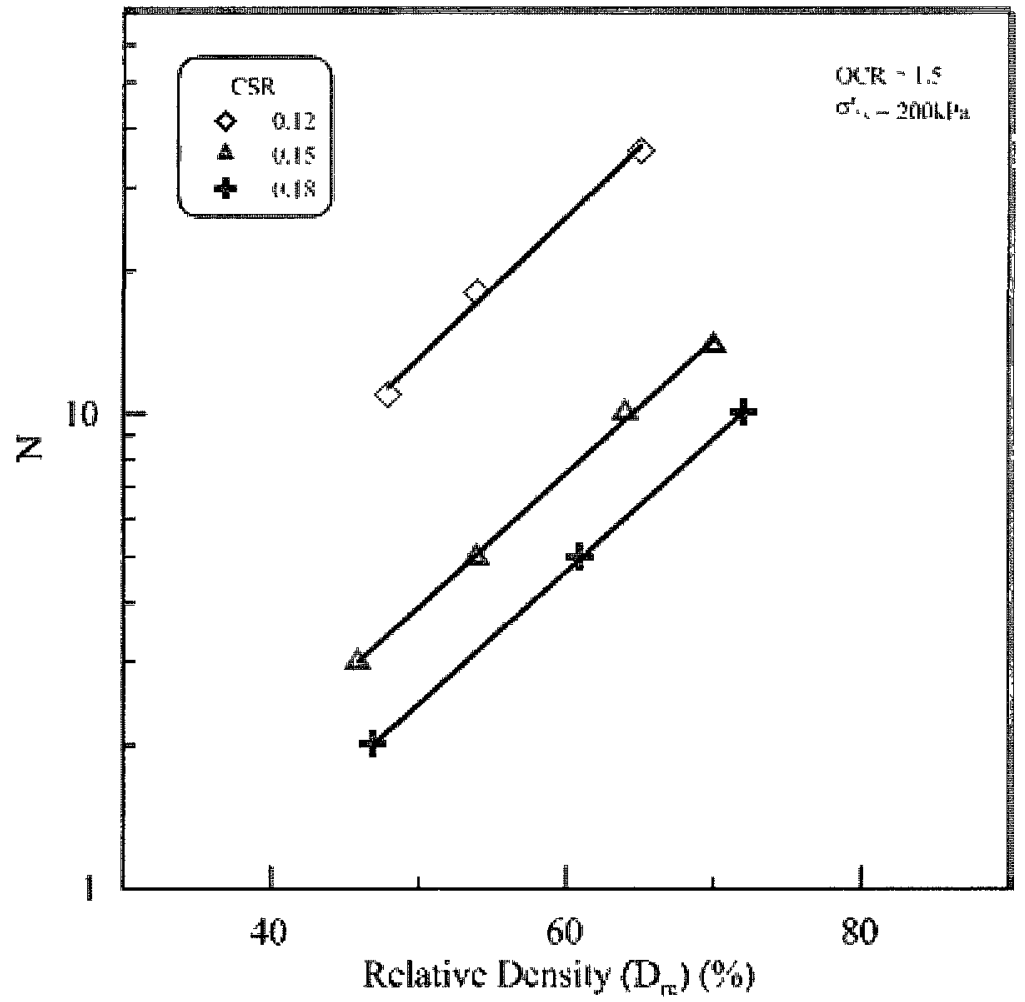

Fig. B5: Variation of number of cycles to liquefaction at $200 \mathrm{kPa}$ and $\mathrm{OCR}=1.5$

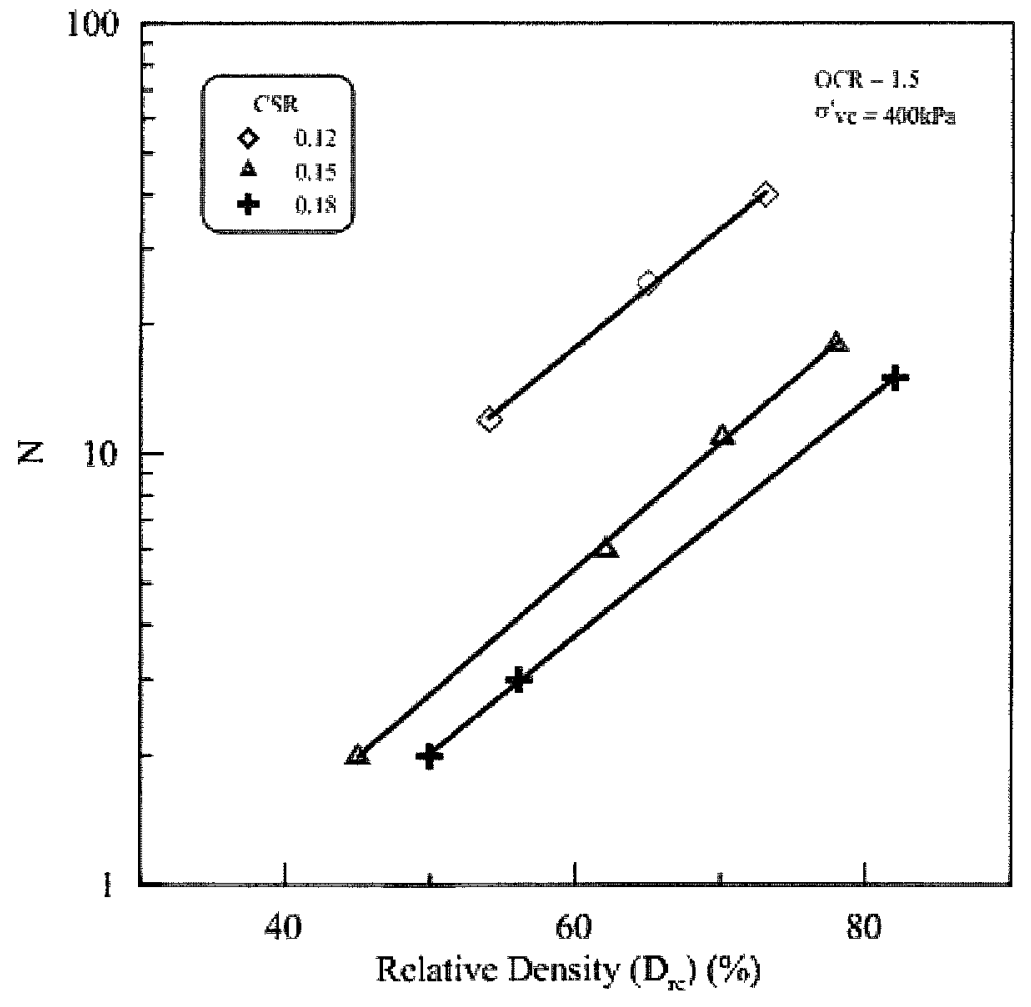

Fig. B6: Variation of number of cycles to liquefaction at $400 \mathrm{kPa}$ and $\mathrm{OCR}=1.5$ 


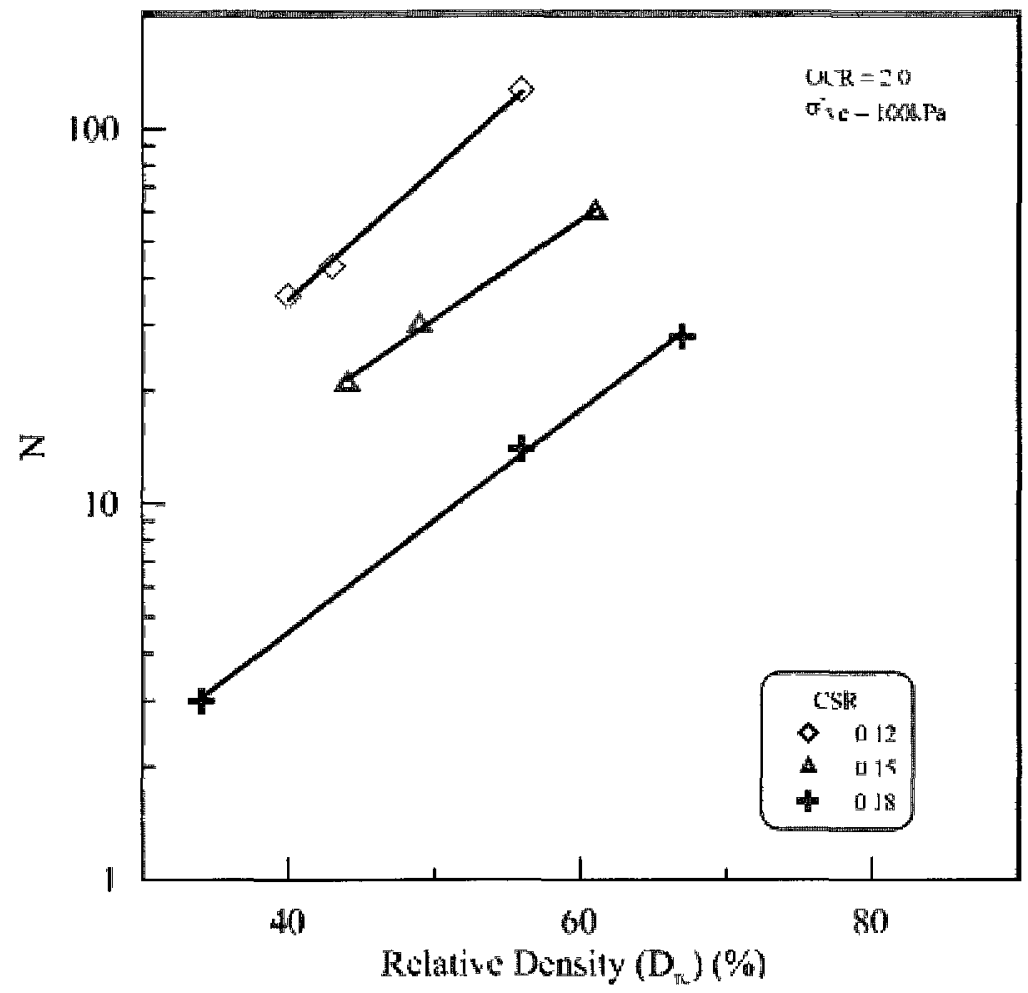

Fig. B7: Variation of number of cycles to liquefaction at $100 \mathrm{kPa}$ and $\mathrm{OCR}=2.0$

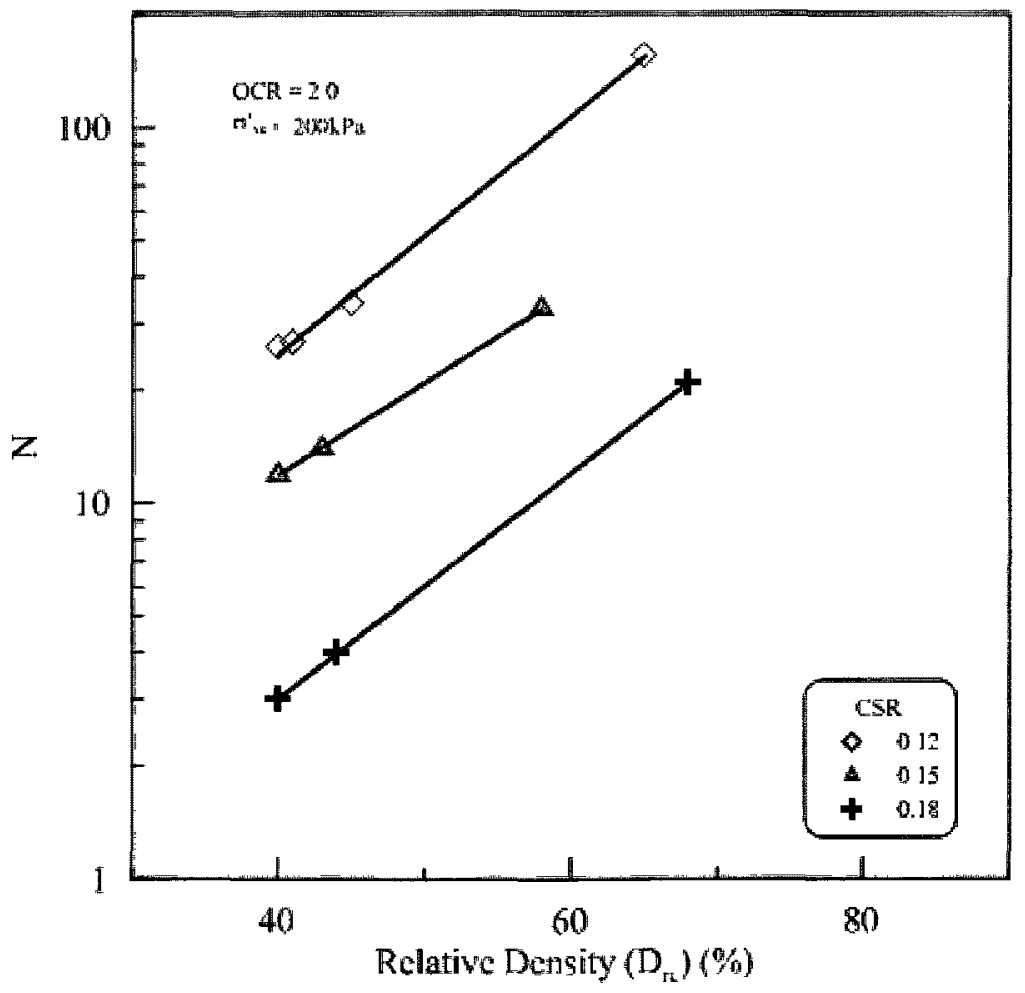

Fig. B8: Variation of number of cycles to liquefaction at $200 \mathrm{kPa}$ and $\mathrm{OCR}=2.0$ 


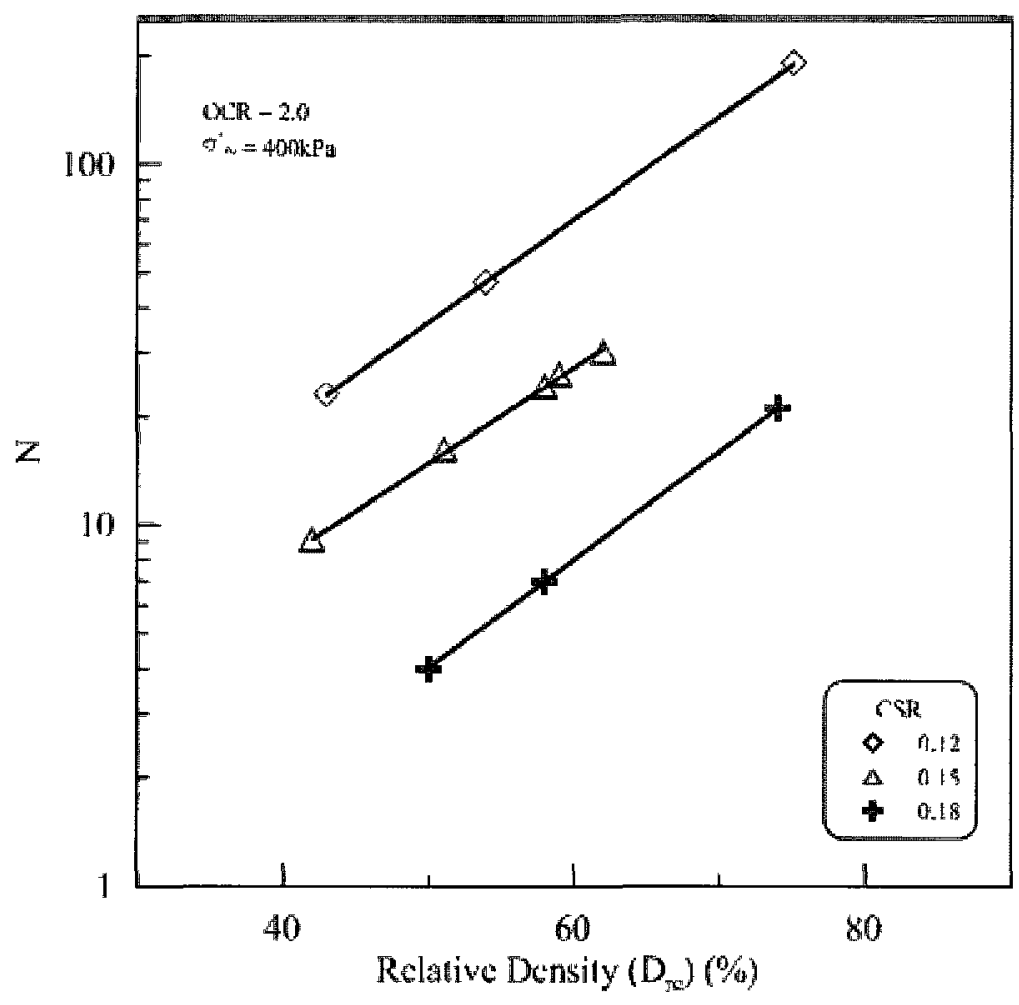

Fig. B9: Variation of number of cycles to liquefaction at $00 \mathrm{kPa}$ and $\mathrm{OCR}=2.0$

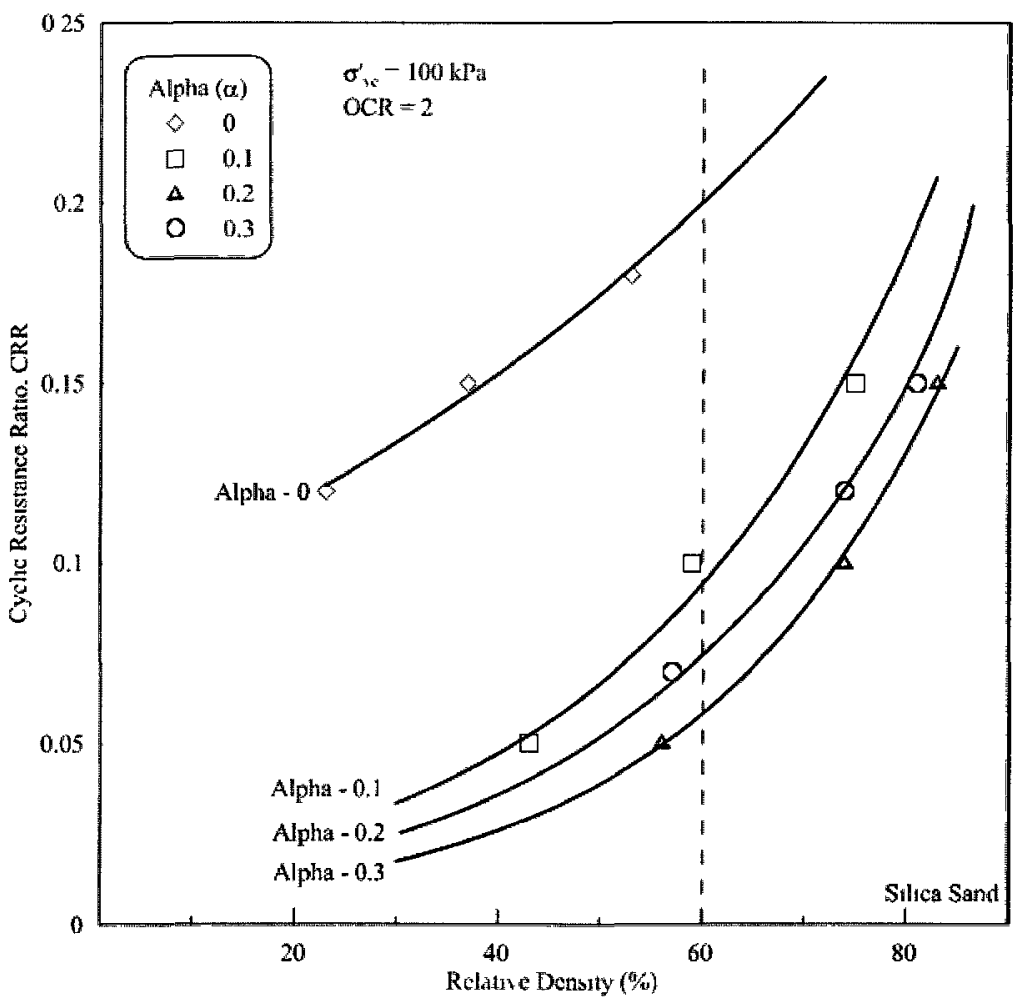

Fig. B10: $\quad$ Variation of CRR with relative density at $\mathrm{OCR}=2$ 


\section{Appendix C \\ (Test Program)}


Table C1.: $\quad$ Monotonic Simple shear tests on Fraser river sand

\begin{tabular}{|c|c|c|c|}
\hline Test No & $\sigma^{\prime}{ }{ }^{(\mathrm{kPa})}$ & OCR & $\operatorname{Dr}(\%)$ \\
\hline FRS-MO-1 & 100 & 1 & 31 \\
\hline FRS-MO-2 & 100 & 1 & 35 \\
\hline FRS-MO-3 & 100 & 2 & 32 \\
\hline FRS-MO-4 & 100 & 4 & 35 \\
\hline FRS-MO-5 & 100 & 8 & 38 \\
\hline FRS-MO-6 & 100 & 16 & 41 \\
\hline FRS-MO-7 & 200 & 1 & 32 \\
\hline FRS-MO-8 & 200 & 1 & 36 \\
\hline FRS-MO-9 & 200 & 2 & 34 \\
\hline FRS-MO-10 & 200 & 4 & 35 \\
\hline FRS-MO-11 & 200 & 8 & 37 \\
\hline FRS-MO-12 & 400 & 1 & 35 \\
\hline FRS-MO-13 & 400 & 1 & 38 \\
\hline FRS-MO-14 & 400 & 2 & 35 \\
\hline FRS-MO-15 & 400 & 4 & 36 \\
\hline FRS-MO-16 & 800 & 1 & 38 \\
\hline FRS-MO-17 & 800 & 2 & 40 \\
\hline FRS-MO-18 & 1200 & 1 & 41 \\
\hline
\end{tabular}


Table C.2: $\quad$ Cyclic Simple shear tests on Fraser river sand

\begin{tabular}{|c|c|c|c|c|c|c|}
\hline Test No & $\begin{array}{c}\sigma_{\mathrm{v}}^{\prime} \\
(\mathrm{kPa})\end{array}$ & CSR & OCR & $\operatorname{Dr}(\%)$ & $\mathrm{N}$ & $\begin{array}{c}\text { Alpha } \\
(\alpha)\end{array}$ \\
\hline FRS-Cy-1 & 100 & 0.15 & 1 & 27 & 4 & 0 \\
\hline FRS-Cy-2 & 100 & 0.15 & 1 & 35 & 8 & 0 \\
\hline FRS-Cy-3 & 100 & 0.15 & 1 & 44 & 16 & 0 \\
\hline FRS-Cy-4 & 100 & 0.15 & 1 & 55 & 32 & 0 \\
\hline FRS-Cy-5 & 200 & 0.15 & 1 & 32 & 3 & 0 \\
\hline FRS-Cy-6 & 200 & 0.15 & 1 & 37 & 6 & 0 \\
\hline FRS-Cy-7 & 200 & 0.15 & 1 & 49 & 15 & 0 \\
\hline FRS-Cy-8 & 200 & 0.15 & 1 & 62 & 43 & 0 \\
\hline FRS-Cy-9 & 400 & 0.15 & 1 & 36 & 4 & 0 \\
\hline FRS-Cy-10 & 400 & 0.15 & 1 & 40 & 6 & 0 \\
\hline FRS-Cy-11 & 400 & 0.15 & 1 & 45 & 8 & 0 \\
\hline FRS-Cy-12 & 400 & 0.15 & 1 & 56 & 22 & 0 \\
\hline FRS-Cy-13 & 100 & 0.15 & 1.5 & 29 & 11 & 0 \\
\hline FRS-Cy-14 & 100 & 0.15 & 1.5 & 50 & 72 & 0 \\
\hline FRS-Cy-15 & 100 & 0.15 & 1.5 & 43 & 37 & 0 \\
\hline FRS-Cy-16 & 100 & 0.15 & 1.5 & 39 & 28 & 0 \\
\hline FRS-Cy-17 & 100 & 0.15 & 1.5 & 28 & 10 & 0 \\
\hline FRS-Cy-18 & 200 & 0.15 & 1.5 & 34 & 13 & 0 \\
\hline FRS-Cy-19 & 200 & 0.15 & 1.5 & 53 & 60 & 0 \\
\hline FRS-Cy-20 & 200 & 0.15 & 1.5 & 38 & 23 & 0 \\
\hline FRS-Cy-21 & 200 & 0.15 & 1.5 & 44 & 34 & 0 \\
\hline FRS-Cy-22 & 200 & 0.15 & 1.5 & 28 & 8 & 0 \\
\hline FRS-Cy-23 & 400 & 0.15 & 1.5 & 44 & 27 & 0 \\
\hline FRS-Cy-24 & 400 & 0.15 & 1.5 & 58 & 68 & 0 \\
\hline FRS-Cy-25 & 400 & 0.15 & 1.5 & 32 & 10 & 0 \\
\hline FRS-Cy-26 & 400 & 0.15 & 1.5 & 60 & 70 & 0 \\
\hline FRS-Cy-27 & 400 & 0.15 & 1.5 & 38 & 15 & 0 \\
\hline FRS-Cy-28 & 800 & 0.15 & 1.5 & 41 & 17 & 0 \\
\hline FRS-Cy-29 & 800 & 0.15 & 1.5 & 44 & 20 & 0 \\
\hline FRS-Cy-30 & 100 & 0.15 & 2 & 30 & 52 & 0 \\
\hline FRS-Cy-31 & 100 & 0.15 & 2 & 43 & 140 & 0 \\
\hline FRS-Cy-32 & 100 & 0.15 & 2 & 48 & 182 & 0 \\
\hline FRS-Cy-33 & 200 & 0.15 & 2 & 32 & 47 & 0 \\
\hline FRS-Cy-34 & 200 & 0.15 & 2 & 34 & 59 & 0 \\
\hline FRS-Cy-35 & 200 & 0.15 & 2 & 43 & 103 & 0 \\
\hline FRS-Cy-36 & 400 & 0.15 & 2 & 31 & 35 & 0 \\
\hline
\end{tabular}




\begin{tabular}{|c|c|c|c|c|c|c|}
\hline Test No & $\begin{array}{c}\sigma^{\prime}{ }_{v} \\
(\mathrm{kPa})\end{array}$ & CSR & OCR & $\operatorname{Dr}(\%)$ & $\mathrm{N}$ & $\begin{array}{c}\text { Alpha } \\
(\alpha)\end{array}$ \\
\hline FRS-Cy-37 & 400 & 0.15 & 2 & 47 & 93 & 0 \\
\hline FRS-Cy-38 & 400 & 0.15 & 2 & 67 & 594 & 0 \\
\hline FRS-Cy-39 & 800 & 0.15 & 2 & 41 & 51 & 0 \\
\hline FRS-Cy-40 & 800 & 0.15 & 2 & 50 & 90 & 0 \\
\hline FRS-Cy-41 & 100 & 0.15 & 3 & 30 & 75 & 0 \\
\hline FRS-Cy-42 & 100 & 0.15 & 3 & 37 & 164 & 0 \\
\hline FRS-Cy-43 & 100 & 0.15 & 3 & 40 & 334 & 0 \\
\hline FRS-Cy-44 & 200 & 0.15 & 3 & 35 & 119 & 0 \\
\hline FRS-Cy-45 & 200 & 0.15 & 3 & 45 & 547 & 0 \\
\hline FRS-Cy-46 & 200 & 0.15 & 3 & 48 & 604 & 0 \\
\hline FRS-Cy-47 & 400 & 0.15 & 3 & 38 & 154 & 0 \\
\hline FRS-Cy-48 & 400 & 0.15 & 3 & 42 & 252 & 0 \\
\hline FRS-Cy-49 & 400 & 0.15 & 3 & 45 & 321 & 0 \\
\hline FRS-Cy-50 & 100 & 0.15 & 4 & 32 & 536 & 0 \\
\hline FRS-Cy-51 & 100 & 0.15 & 4 & 34 & 568 & 0 \\
\hline FRS-Cy-52 & 100 & 0.15 & 4 & 40 & 1071 & 0 \\
\hline FRS-Cy-53 & 200 & 0.15 & 4 & 29 & 205 & 0 \\
\hline FRS-Cy-54 & 200 & 0.15 & 4 & 42 & 985 & 0 \\
\hline FRS-Cy-55 & 400 & 0.15 & 4 & 42 & 798 & 0 \\
\hline FRS-Cy-56 & 100 & 0.18 & 1 & 34 & 2 & 0 \\
\hline FRS-Cy-57 & 100 & 0.18 & 1 & 42 & 4 & 0 \\
\hline FRS-Cy-58 & 100 & 0.18 & 1 & 61 & 23 & 0 \\
\hline FRS-Cy-59 & 200 & 0.18 & 1 & 36 & 2 & 0 \\
\hline FRS-Cy-60 & 200 & 0.18 & 1 & 56 & 11 & 0 \\
\hline FRS-Cy-61 & 200 & 0.18 & 1 & 61 & 17 & 0 \\
\hline FRS-Cy-62 & 400 & 0.18 & 1 & 31 & 1 & 0 \\
\hline FRS-Cy-63 & 400 & 0.18 & 1 & 58 & 10 & 0 \\
\hline FRS-Cy-64 & 400 & 0.18 & 1 & 65 & 17 & 0 \\
\hline FRS-Cy-65 & 800 & 0.18 & 1 & 33 & 1 & 0 \\
\hline FRS-Cy-66 & 800 & 0.18 & 1 & 57 & 7 & 0 \\
\hline FRS-Cy-67 & 800 & 0.18 & 1 & 74 & 29 & 0 \\
\hline FRS-Cy-68 & 100 & 0.18 & 1.5 & 41 & 15 & 0 \\
\hline FRS-Cy-69 & 100 & 0.18 & 1.5 & 51 & 28 & 0 \\
\hline FRS-Cy-70 & 100 & 0.18 & 1.5 & 70 & 92 & 0 \\
\hline FRS-Cy-71 & 100 & 0.18 & 1.5 & 61 & 53 & 0 \\
\hline FRS-Cy-72 & 200 & 0.18 & 1.5 & 38 & 10 & 0 \\
\hline
\end{tabular}




\begin{tabular}{|c|c|c|c|c|c|c|}
\hline Test No & $\sigma{ }^{\prime}(\mathrm{kPa})$ & CSR & OCR & $\operatorname{Dr}(\%)$ & $\mathrm{N}$ & $\begin{array}{c}\text { Alpha } \\
(\alpha)\end{array}$ \\
\hline FRS-Cy-73 & 200 & 0.18 & 1.5 & 44 & 15 & 0 \\
\hline FRS-Cy-74 & 200 & 0.18 & 1.5 & 54 & 27 & 0 \\
\hline FRS-Cy-75 & 200 & 0.18 & 1.5 & 67 & 56 & 0 \\
\hline FRS-Cy-76 & 400 & 0.18 & 1.5 & 41 & 11 & 0 \\
\hline FRS-Cy-77 & 400 & 0.18 & 1.5 & 50 & 18 & 0 \\
\hline FRS-Cy-78 & 400 & 0.18 & 1.5 & 56 & 25 & 0 \\
\hline FRS-Cy-79 & 400 & 0.18 & 1.5 & 71 & 57 & 0 \\
\hline FRS-Cy-80 & 800 & 0.18 & 1.5 & 40 & 9 & 0 \\
\hline FRS-Cy-81 & 800 & 0.18 & 1.5 & 49 & 14 & 0 \\
\hline FRS-Cy-82 & 800 & 0.18 & 1.5 & 66 & 32 & 0 \\
\hline FRS-Cy-83 & 800 & 0.18 & 1.5 & 74 & 49 & 0 \\
\hline FRS-Cy-84 & 100 & 0.18 & 2 & 29 & 14 & 0 \\
\hline FRS-Cy-85 & 100 & 0.18 & 2 & 33 & 18 & 0 \\
\hline FRS-Cy-86 & 100 & 0.18 & 2 & 40 & 32 & 0 \\
\hline FRS-Cy-87 & 100 & 0.18 & 2 & 51 & 67 & 0 \\
\hline FRS-Cy-88 & 100 & 0.18 & 2 & 61 & 132 & 0 \\
\hline FRS-Cy-89 & 200 & 0.18 & 2 & 31 & 14 & 0 \\
\hline FRS-Cy-90 & 200 & 0.18 & 2 & 40 & 23 & 0 \\
\hline FRS-Cy-91 & 200 & 0.18 & 2 & 50 & 45 & 0 \\
\hline FRS-Cy-92 & 200 & 0.18 & 2 & 73 & 228 & 0 \\
\hline FRS-Cy-93 & 400 & 0.18 & 2 & 36 & 16 & 0 \\
\hline FRS-Cy-94 & 400 & 0.18 & 2 & 41 & 21 & 0 \\
\hline FRS-Cy-95 & 400 & 0.18 & 2 & 72 & 144 & 0 \\
\hline FRS-Cy-96 & 800 & 0.18 & 2 & 41 & 19 & 0 \\
\hline FRS-Cy-97 & 800 & 0.18 & 2 & 49 & 28 & 0 \\
\hline FRS-Cy-98 & 800 & 0.18 & 2 & 66 & 74 & 0 \\
\hline FRS-Cy-99 & 100 & 0.18 & 3 & 35 & 75 & 0 \\
\hline FRS-Cy-100 & 100 & 0.18 & 3 & 45 & 128 & 0 \\
\hline FRS-Cy-101 & 200 & 0.18 & 3 & 32 & 47 & 0 \\
\hline FRS-Cy-102 & 200 & 0.18 & 3 & 41 & 81 & 0 \\
\hline FRS-Cy-103 & 400 & 0.18 & 3 & 41 & 67 & 0 \\
\hline FRS-Cy-104 & 100 & 0.18 & 3 & 26 & 80 & 0 \\
\hline FRS-Cy-105 & 100 & 0.18 & 3 & 29 & 177 & 0 \\
\hline FRS-Cy-106 & 100 & 0.18 & 3 & 45 & 413 & 0 \\
\hline FRS-Cy-107 & 200 & 0.18 & 3 & 29 & 89 & 0 \\
\hline FRS-Cy-108 & 200 & 0.18 & 3 & 33 & 203 & 0 \\
\hline
\end{tabular}




\begin{tabular}{|c|c|c|c|c|c|c|}
\hline Test No & $\sigma^{\prime}{ }_{v}(\mathrm{kPa})$ & $\mathrm{CSR}$ & $\mathrm{OCR}$ & $\mathrm{Dr}(\%)$ & $\mathrm{N}$ & $\begin{array}{c}\text { Alpha } \\
(\alpha)\end{array}$ \\
\hline FRS-Cy-109 & 200 & 0.18 & 3 & 61 & 1048 & 0 \\
\hline FRS-Cy-110 & 400 & 0.18 & 3 & 41 & 220 & 0 \\
\hline FRS-Cy-111 & 400 & 0.18 & 3 & 48 & 299 & 0 \\
\hline FRS-Cy-112 & 100 & 0.2 & 1 & 40 & 1 & 0 \\
\hline FRS-Cy-113 & 100 & 0.2 & 1 & 67 & 10 & 0 \\
\hline FRS-Cy-114 & 100 & 0.2 & 1 & 73 & 17 & 0 \\
\hline FRS-Cy-115 & 100 & 0.2 & 1 & 61 & 6 & 0 \\
\hline FRS-Cy-116 & 200 & 0.2 & 1 & 41 & 1 & 0 \\
\hline FRS-Cy-117 & 200 & 0.2 & 1 & 50 & 2 & 0 \\
\hline FRS-Cy-118 & 200 & 0.2 & 1 & 71 & 10 & 0 \\
\hline FRS-Cy-119 & 200 & 0.2 & 1 & 61 & 5 & 0 \\
\hline FRS-Cy-120 & 400 & 0.2 & 1 & 52 & 2 & 0 \\
\hline FRS-Cy-121 & 400 & 0.2 & 1 & 65 & 5 & 0 \\
\hline FRS-Cy-122 & 400 & 0.2 & 1 & 79 & 15 & 0 \\
\hline FRS-Cy-123 & 100 & 0.2 & 1.5 & 37 & 2 & 0 \\
\hline FRS-Cy-124 & 100 & 0.2 & 1.5 & 50 & 6 & 0 \\
\hline FRS-Cy-125 & 100 & 0.2 & 1.5 & 82 & 61 & 0 \\
\hline FRS-Cy-126 & 200 & 0.2 & 1.5 & 38 & 2 & 0 \\
\hline FRS-Cy-127 & 200 & 0.2 & 1.5 & 60 & 10 & 0 \\
\hline FRS-Cy-128 & 200 & 0.2 & 1.5 & 81 & 45 & 0 \\
\hline FRS-Cy-129 & 400 & 0.2 & 1.5 & 31 & 1 & 0 \\
\hline FRS-Cy-130 & 400 & 0.2 & 1.5 & 50 & 4 & 0 \\
\hline FRS-Cy-131 & 400 & 0.2 & 1.5 & 73 & 20 & 0 \\
\hline FRS-Cy-132 & 400 & 0.2 & 1.5 & 78 & 27 & 0 \\
\hline FRS-Cy-133 & 100 & 0.2 & 2 & 29 & 4 & 0 \\
\hline FRS-Cy-134 & 100 & 0.2 & 2 & 36 & 8 & 0 \\
\hline FRS-Cy-135 & 100 & 0.2 & 2 & 61 & 31 & 0 \\
\hline FRS-Cy-136 & 200 & 0.2 & 2 & 37 & 6 & 0 \\
\hline FRS-Cy-137 & 200 & 0.2 & 2 & 43 & 9 & 0 \\
\hline FRS-Cy-138 & 200 & 0.2 & 2 & 51 & 16 & 0 \\
\hline FRS-Cy-139 & 200 & 0.2 & 2 & 73 & 56 & 0 \\
\hline FRS-Cy-140 & 400 & 0.2 & 2 & 41 & 7 & 0 \\
\hline FRS-Cy-141 & 400 & 0.2 & 2 & 45 & 9 & 0 \\
\hline FRS-Cy-142 & 400 & 0.2 & 2 & 81 & 81 & 0 \\
\hline FRS-Cy-143 & 100 & 0.2 & 3 & 29 & 8 & 0 \\
\hline FRS-Cy-144 & 100 & 0.2 & 3 & 37 & 15 & 0 \\
\hline FRS-Cy-145 & 100 & 0.2 & 3 & 45 & 50 & 0 \\
\hline
\end{tabular}




\begin{tabular}{|c|c|c|c|c|c|c|}
\hline Test No & $\begin{array}{c}\sigma^{\prime}{ }_{v} \\
(\mathrm{kPa})\end{array}$ & CSR & OCR & Dr $(\%)$ & $\mathrm{N}$ & $\begin{array}{c}\text { Alpha } \\
(\boldsymbol{\alpha})\end{array}$ \\
\hline FRS-Cy-146 & 200 & 0.2 & 3 & 32 & 9 & 0 \\
\hline FRS-Cy-147 & 200 & 0.2 & 3 & 38 & 16 & 0 \\
\hline FRS-Cy-148 & 200 & 0.2 & 3 & 44 & 38 & 0 \\
\hline FRS-Cy-149 & 200 & 0.2 & 3 & 56 & 100 & 0 \\
\hline FRS-Cy-150 & 400 & 0.2 & 3 & 35 & 11 & 0 \\
\hline FRS-Cy-151 & 400 & 0.2 & 3 & 44 & 29 & 0 \\
\hline FRS-Cy-152 & 400 & 0.2 & 3 & 46 & 31 & 0 \\
\hline FRS-Cy-153 & 400 & 0.2 & 3 & 49 & 42 & 0 \\
\hline FRS-Cy-154 & 100 & 0.2 & 4 & 28 & 27 & 0 \\
\hline FRS-Cy-155 & 100 & 0.2 & 4 & 30 & 40 & 0 \\
\hline FRS-Cy-156 & 100 & 0.2 & 4 & 50 & 228 & 0 \\
\hline FRS-Cy-157 & 200 & 0.2 & 4 & 31 & 35 & 0 \\
\hline FRS-Cy-158 & 200 & 0.2 & 4 & 36 & 56 & 0 \\
\hline FRS-Cy-159 & 200 & 0.2 & 4 & 42 & 85 & 0 \\
\hline FRS-Cy-160 & 400 & 0.2 & 4 & 41 & 72 & 0 \\
\hline FRS-Cy-161 & 100 & 0.26 & 1 & 40 & 1 & 0 \\
\hline FRS-Cy-162 & 100 & 0.26 & 1 & 70 & 4 & 0 \\
\hline FRS-Cy-163 & 100 & 0.26 & 1 & 85 & 8 & 0 \\
\hline FRS-Cy-164 & 100 & 0.26 & 1 & 61 & 2 & 0 \\
\hline FRS-Cy-165 & 200 & 0.26 & 1 & 40 & 1 & 0 \\
\hline FRS-Cy-166 & 200 & 0.26 & 1 & 59 & 2 & 0 \\
\hline FRS-Cy-167 & 200 & 0.26 & 1 & 75 & 4 & 0 \\
\hline FRS-Cy-168 & 200 & 0.26 & 1 & 86 & 8 & 0 \\
\hline FRS-Cy-169 & 400 & 0.26 & 1 & 43 & 1 & 0 \\
\hline FRS-Cy-170 & 400 & 0.26 & 1 & 70 & 3 & 0 \\
\hline FRS-Cy-171 & 400 & 0.26 & 1 & 82 & 5 & 0 \\
\hline FRS-Cy-172 & 400 & 0.26 & 1 & 61 & 2 & 0 \\
\hline FRS-Cy-173 & 100 & 0.26 & 1.5 & 35 & 1 & 0 \\
\hline FRS-Cy-174 & 100 & 0.26 & 1.5 & 51 & 2 & 0 \\
\hline FRS-Cy-175 & 100 & 0.26 & 1.5 & 79 & 11 & 0 \\
\hline FRS-Cy-176 & 100 & 0.26 & 1.5 & 61 & 4 & 0 \\
\hline FRS-Cy-177 & 200 & 0.26 & 1.5 & 38 & 1 & 0 \\
\hline FRS-Cy-178 & 200 & 0.26 & 1.5 & 60 & 3 & 0 \\
\hline FRS-Cy-179 & 200 & 0.26 & 1.5 & 80 & 11 & 0 \\
\hline FRS-Cy-180 & 400 & 0.26 & 1.5 & 40 & 1 & 0 \\
\hline FRS-Cy-181 & 400 & 0.26 & 1.5 & 68 & 4 & 0 \\
\hline
\end{tabular}




\begin{tabular}{|c|c|c|c|c|c|c|}
\hline Test No & $\begin{array}{c}\sigma^{\prime}{ }_{v} \\
(\mathrm{kPa})\end{array}$ & CSR & OCR & $\operatorname{Dr}(\%)$ & $\mathrm{N}$ & $\begin{array}{c}\text { Alpha } \\
(\alpha)\end{array}$ \\
\hline FRS-Cy-182 & 400 & 0.26 & 1.5 & 86 & 10 & 0 \\
\hline FRS-Cy-183 & 100 & 0.26 & 2 & 29 & 1 & 0 \\
\hline FRS-Cy-184 & 100 & 0.26 & 2 & 69 & 15 & 0 \\
\hline FRS-Cy-185 & 100 & 0.26 & 2 & 73 & 20 & 0 \\
\hline FRS-Cy-186 & 200 & 0.26 & 2 & 30 & 1 & 0 \\
\hline FRS-Cy-187 & 200 & 0.26 & 2 & 52 & 4 & 0 \\
\hline FRS-Cy-188 & 200 & 0.26 & 2 & 67 & 10 & 0 \\
\hline FRS-Cy-189 & 200 & 0.26 & 2 & 69 & 11 & 0 \\
\hline FRS-Cy-190 & 400 & 0.26 & 2 & 31 & 1 & 0 \\
\hline FRS-Cy-191 & 400 & 0.26 & 2 & 52 & 3 & 0 \\
\hline FRS-Cy-192 & 400 & 0.26 & 2 & 60 & 5 & 0 \\
\hline FRS-Cy-193 & 400 & 0.26 & 2 & 73 & 12 & 0 \\
\hline FRS-Cy-194 & 100 & 0.26 & 4 & 28 & 11 & 0 \\
\hline FRS-Cy-195 & 100 & 0.26 & 4 & 36 & 22 & 0 \\
\hline FRS-Cy-196 & 100 & 0.26 & 4 & 41 & 30 & 0 \\
\hline FRS-Cy-197 & 200 & 0.26 & 4 & 41 & 24 & 0 \\
\hline FRS-Cy-198 & 200 & 0.26 & 4 & 48 & 41 & 0 \\
\hline FRS-Cy-199 & 400 & 0.26 & 4 & 39 & 18 & 0 \\
\hline FRS-Cy-200 & 400 & 0.26 & 4 & 55 & 62 & 0 \\
\hline FRS-Cy-201 & 400 & 0.26 & 4 & 60 & 88 & 0 \\
\hline FRS-Cy-202 & 100 & 0.15 & 1 & 28 & 1 & 0.2 \\
\hline FRS-Cy-203 & 100 & 0.15 & 1 & 41 & 8 & 0.2 \\
\hline FRS-Cy-204 & 100 & 0.15 & 1 & 68 & 398 & 0.2 \\
\hline FRS-Cy-205 & 100 & 0.25 & 1 & 28 & 1 & 0.2 \\
\hline FRS-Cy-206 & 100 & 0.25 & 1 & 37 & 2 & 0.2 \\
\hline FRS-Cy-207 & 100 & 0.25 & 1 & 58 & 8 & 0.2 \\
\hline FRS-Cy-208 & 100 & 0.305 & 1 & 32 & 1 & 0.2 \\
\hline FRS-Cy-209 & 100 & 0.305 & 1 & 45 & 2 & 0.2 \\
\hline FRS-Cy-210 & 100 & 0.305 & 1 & 77 & 11 & 0.2 \\
\hline FRS-Cy-211 & 100 & 0.08 & 2 & 41 & 1 & 0.2 \\
\hline FRS-Cy-212 & 100 & 0.08 & 2 & 48 & 4 & 0.2 \\
\hline FRS-Cy-213 & 100 & 0.08 & 2 & 61 & 47 & 0.2 \\
\hline FRS-Cy-214 & 100 & 0.1 & 2 & 54 & 1 & 0.2 \\
\hline FRS-Cy-215 & 100 & 0.1 & 2 & 63 & 4 & 0.2 \\
\hline FRS-Cy-216 & 100 & 0.1 & 2 & 72 & 17 & 0.2 \\
\hline FRS-Cy-217 & 100 & 0.2 & 2 & 43 & 6 & 0.2 \\
\hline FRS-Cy-218 & 100 & 0.2 & 2 & 49 & 38 & 0.2 \\
\hline
\end{tabular}




\begin{tabular}{|c|c|c|c|c|c|c|}
\hline Test No & $\begin{array}{c}\sigma_{\mathrm{v}}^{\prime} \\
(\mathrm{kPa})\end{array}$ & CSR & OCR & $\operatorname{Dr}(\%)$ & $\mathrm{N}$ & $\begin{array}{c}\text { Alpha } \\
(\alpha)\end{array}$ \\
\hline FRS-Cy-218 & 100 & 0.2 & 2 & 49 & 38 & 0.2 \\
\hline FRS-Cy-219 & 100 & 0.2 & 2 & 53 & 135 & 0.2 \\
\hline FRS-Cy-220 & 100 & 0.08 & 2 & 40 & 18 & 0.1 \\
\hline FRS-Cy-221 & 100 & 0.08 & 2 & 50 & 92 & 0.1 \\
\hline FRS-Cy-222 & 100 & 0.08 & 2 & 55 & 205 & 0.1 \\
\hline FRS-Cy-223 & 100 & 0.08 & 2 & 56 & 226 & 0.1 \\
\hline FRS-Cy-224 & 100 & 0.1 & 2 & 52 & 26 & 0.1 \\
\hline FRS-Cy-225 & 100 & 0.1 & 2 & 55 & 40 & 0.1 \\
\hline FRS-Cy-226 & 100 & 0.1 & 2 & 59 & 66 & 0.1 \\
\hline FRS-Cy-227 & 100 & 0.205 & 2 & 56 & 3 & 0.1 \\
\hline FRS-Cy-228 & 100 & 0.205 & 2 & 58 & 4 & 0.1 \\
\hline FRS-Cy-229 & 100 & 0.205 & 2 & 65 & 10 & 0.1 \\
\hline FRS-Cy-230 & 100 & 0.1 & 2 & 47 & 8 & 0.3 \\
\hline FRS-Cy-231 & 100 & 0.1 & 2 & 62 & 16 & 0.3 \\
\hline FRS-Cy-232 & 100 & 0.1 & 2 & 87 & 126 & 0.3 \\
\hline FRS-Cy-233 & 100 & 0.205 & 2 & 43 & 2 & 0.3 \\
\hline FRS-Cy-234 & 100 & 0.205 & 2 & 55 & 5 & 0.3 \\
\hline FRS-Cy-235 & 100 & 0.205 & 2 & 78 & 16 & 0.3 \\
\hline FRS-Cy-236 & 100 & 0.305 & 2 & 55 & 3 & 0.3 \\
\hline FRS-Cy-237 & 100 & 0.305 & 2 & 68 & 5 & 0.3 \\
\hline FRS-Cy-238 & 100 & 0.305 & 2 & 79 & 12 & 0.3 \\
\hline FRS-Cy-239 & 100 & 0.075 & 1.5 & 32 & 1 & 0.2 \\
\hline FRS-Cy-240 & 100 & 0.075 & 1.5 & 51 & 21 & 0.2 \\
\hline FRS-Cy-241 & 100 & 0.075 & 1.5 & 56 & 46 & 0.2 \\
\hline FRS-Cy-242 & 100 & 0.105 & 1.5 & 40 & 1 & 0.2 \\
\hline FRS-Cy-243 & 100 & 0.105 & 1.5 & 45 & 2 & 0.2 \\
\hline FRS-Cy-244 & 100 & 0.105 & 1.5 & 52 & 6 & 0.2 \\
\hline FRS-Cy-245 & 100 & 0.155 & 1.5 & 60 & 6 & 0.2 \\
\hline FRS-Cy-246 & 100 & 0.155 & 1.5 & 62 & 7 & 0.2 \\
\hline FRS-Cy-247 & 100 & 0.155 & 1.5 & 64 & 11 & 0.2 \\
\hline FRS-Cy-248 & 100 & 0.075 & 1.5 & 49 & 30 & 0.1 \\
\hline FRS-Cy-249 & 100 & 0.075 & 1.5 & 51 & 34 & 0.1 \\
\hline FRS-Cy-250 & 100 & 0.075 & 1.5 & 58 & 62 & 0.1 \\
\hline FRS-Cy-251 & 100 & 0.105 & 1.5 & 50 & 10 & 0.1 \\
\hline FRS-Cy-252 & 100 & 0.105 & 1.5 & 70 & 88 & 0.1 \\
\hline FRS-Cy-253 & 100 & 0.155 & 1.5 & 43 & 1 & 0.1 \\
\hline FRS-Cy-254 & 100 & 0.155 & 1.5 & 55 & 5 & 0.1 \\
\hline
\end{tabular}




\begin{tabular}{|c|c|c|c|c|c|c|}
\hline Test No & $\begin{array}{c}\sigma_{\mathrm{v}}^{\prime} \\
(\mathrm{kPa})\end{array}$ & CSR & OCR & $\operatorname{Dr}(\%)$ & $\mathrm{N}$ & $\begin{array}{c}\text { Alpha } \\
(\alpha)\end{array}$ \\
\hline FRS-Cy-255 & 100 & 0.155 & 1.5 & 62 & 13 & 0.1 \\
\hline FRS-Cy-256 & 100 & 0.075 & 1.5 & 35 & 1 & 0.3 \\
\hline FRS-Cy-257 & 100 & 0.075 & 1.5 & 54 & 16 & 0.3 \\
\hline FRS-Cy-258 & 100 & 0.075 & 1.5 & 63 & 75 & 0.3 \\
\hline FRS-Cy-259 & 100 & 0.105 & 1.5 & 41 & 1 & 0.3 \\
\hline FRS-Cy-260 & 100 & 0.105 & 1.5 & 68 & 32 & 0.3 \\
\hline FRS-Cy-261 & 100 & 0.105 & 1.5 & 69 & 35 & 0.3 \\
\hline FRS-Cy-262 & 100 & 0.125 & 1.5 & 47 & 1 & 0.3 \\
\hline FRS-Cy-263 & 100 & 0.125 & 1.5 & 61 & 7 & 0.3 \\
\hline FRS-Cy-264 & 100 & 0.125 & 1.5 & 83 & 175 & 0.3 \\
\hline FRS-Cy-265 & 100 & 0.18 & 1.5 & 32 & 4 & 0 \\
\hline FRS-Cy-266 & 100 & 0.18 & 1.5 & 37 & 6 & 0 \\
\hline FRS-Cy-267 & 100 & 0.18 & 1.5 & 50 & 16 & 0 \\
\hline FRS-Cy-268 & 200 & 0.18 & 1.5 & 29 & 2 & 0 \\
\hline FRS-Cy-269 & 200 & 0.18 & 1.5 & 42 & 7 & 0 \\
\hline FRS-Cy-270 & 200 & 0.18 & 1.5 & 48 & 11 & 0 \\
\hline FRS-Cy-271 & 400 & 0.18 & 1.5 & 29 & 2 & 0 \\
\hline FRS-Cy-272 & 400 & 0.18 & 1.5 & 42 & 7 & 0 \\
\hline FRS-Cy-273 & 400 & 0.18 & 1.5 & 48 & 11 & 0 \\
\hline
\end{tabular}


Table C.3: $\quad$ Cyclic Simple shear tests on Silica sand

\begin{tabular}{|c|c|c|c|c|c|c|}
\hline Test No & $\begin{array}{c}\sigma^{\prime}{ }_{\mathrm{v}} \\
(\mathrm{kPa})\end{array}$ & $\mathrm{CSR}$ & OCR & Dr $(\%)$ & $\mathrm{N}$ & $\begin{array}{c}\text { Alpha } \\
(\alpha)\end{array}$ \\
\hline SS-Cy-1 & 100 & 0.1 & 1 & 49 & 14 & 0 \\
\hline SS-Cy-2 & 100 & 0.1 & 1 & 52 & 17 & 0 \\
\hline SS-Cy-3 & 100 & 0.1 & 1 & 56 & 24 & 0 \\
\hline SS-Cy-4 & 100 & 0.1 & 1 & 61 & 33 & 0 \\
\hline SS-Cy-5 & 100 & 0.1 & 1 & 70 & 76 & 0 \\
\hline SS-Cy-6 & 200 & 0.1 & 1 & 35 & 4 & 0 \\
\hline SS-Cy-7 & 200 & 0.1 & 1 & 44 & 8 & 0 \\
\hline SS-Cy-8 & 200 & 0.1 & 1 & 55 & 18 & 0 \\
\hline SS-Cy-9 & 200 & 0.1 & 1 & 82 & 135 & 0 \\
\hline SS-Cy-10 & 400 & 0.1 & 1 & 63 & 27 & 0 \\
\hline SS-Cy-11 & 400 & 0.1 & 1 & 69 & 41 & 0 \\
\hline SS-Cy-12 & 400 & 0.1 & 1 & 75 & 63 & 0 \\
\hline SS-Cy-13 & 400 & 0.1 & 1 & 79 & 76 & 0 \\
\hline SS-Cy-14 & 100 & 0.12 & 1 & 46 & 6 & 0 \\
\hline SS-Cy-15 & 100 & 0.12 & 1 & 63 & 20 & 0 \\
\hline SS-Cy-16 & 100 & 0.12 & 1 & 64 & 22 & 0 \\
\hline SS-Cy-17 & 100 & 0.12 & 1 & 68 & 30 & 0 \\
\hline SS-Cy-18 & 100 & 0.12 & 1 & 72 & 36 & 0 \\
\hline SS-Cy-19 & 100 & 0.12 & 1 & 77 & 56 & 0 \\
\hline SS-Cy-20 & 200 & 0.12 & 1 & 50 & 6 & 0 \\
\hline SS-Cy-21 & 200 & 0.12 & 1 & 60 & 11 & 0 \\
\hline SS-Cy-22 & 200 & 0.12 & 1 & 71 & 25 & 0 \\
\hline SS-Cy-23 & 200 & 0.12 & 1 & 75 & 29 & 0 \\
\hline SS-Cy-24 & 400 & 0.12 & 1 & 55 & 6 & 0 \\
\hline SS-Cy-25 & 400 & 0.12 & 1 & 58 & 7 & 0 \\
\hline SS-Cy-26 & 400 & 0.12 & 1 & 60 & 8 & 0 \\
\hline SS-Cy-27 & 400 & 0.12 & 1 & 76 & 21 & 0 \\
\hline SS-Cy-28 & 400 & 0.12 & 1 & 82 & 30 & 0 \\
\hline SS-Cy-29 & 100 & 0.15 & 1 & 54 & 3 & 0 \\
\hline SS-Cy-30 & 100 & 0.15 & 1 & 58 & 4 & 0 \\
\hline SS-Cy-31 & 100 & 0.15 & 1 & 69 & 9 & 0 \\
\hline SS-Cy-32 & 200 & 0.15 & 1 & 52 & 2 & 0 \\
\hline SS-Cy-33 & 200 & 0.15 & 1 & 57 & 3 & 0 \\
\hline SS-Cy-34 & 200 & 0.15 & 1 & 79 & 14 & 0 \\
\hline SS-Cy-35 & 400 & 0.15 & 1 & 56 & 2 & 0 \\
\hline
\end{tabular}




\begin{tabular}{|c|c|c|c|c|c|c|}
\hline Test No & $\begin{array}{c}\sigma^{\prime}{ }_{v} \\
(\mathrm{kPa})\end{array}$ & CSR & OCR & Dr $(\%)$ & $\mathrm{N}$ & $\begin{array}{c}\text { Alpha } \\
(\alpha)\end{array}$ \\
\hline SS-Cy-36 & 400 & 0.15 & 1 & 65 & 4 & 0 \\
\hline SS-Cy-37 & 400 & 0.15 & 1 & 72 & 6 & 0 \\
\hline SS-Cy-38 & 100 & 0.12 & 1.5 & 36 & 7 & 0 \\
\hline SS-Cy-39 & 100 & 0.12 & 1.5 & 56 & 31 & 0 \\
\hline SS-Cy-40 & 100 & 0.12 & 1.5 & 65 & 58 & 0 \\
\hline SS-Cy-41 & 200 & 0.12 & 1.5 & 48 & 11 & 0 \\
\hline SS-Cy-42 & 200 & 0.12 & 1.5 & 54 & 18 & 0 \\
\hline SS-Cy-43 & 200 & 0.12 & 1.5 & 65 & 36 & 0 \\
\hline SS-Cy-44 & 400 & 0.12 & 1.5 & 54 & 12 & 0 \\
\hline SS-Cy-45 & 400 & 0.12 & 1.5 & 65 & 25 & 0 \\
\hline SS-Cy-46 & 400 & 0.12 & 1.5 & 73 & 40 & 0 \\
\hline SS-Cy-47 & 100 & 0.15 & 1.5 & 43 & 4 & 0 \\
\hline SS-Cy-48 & 100 & 0.15 & 1.5 & 56 & 9 & 0 \\
\hline SS-Cy-49 & 100 & 0.15 & 1.5 & 64 & 16 & 0 \\
\hline SS-Cy-50 & 100 & 0.15 & 1.5 & 70 & 24 & 0 \\
\hline SS-Cy-51 & 200 & 0.15 & 1.5 & 46 & 3 & 0 \\
\hline SS-Cy-52 & 200 & 0.15 & 1.5 & 54 & 5 & 0 \\
\hline SS-Cy-53 & 200 & 0.15 & 1.5 & 64 & 10 & 0 \\
\hline SS-Cy-54 & 200 & 0.15 & 1.5 & 70 & 14 & 0 \\
\hline SS-Cy-55 & 400 & 0.15 & 1.5 & 45 & 2 & 0 \\
\hline SS-Cy-56 & 400 & 0.15 & 1.5 & 62 & 6 & 0 \\
\hline SS-Cy-57 & 400 & 0.15 & 1.5 & 70 & 11 & 0 \\
\hline SS-Cy-58 & 400 & 0.15 & 1.5 & 78 & 18 & 0 \\
\hline SS-Cy-59 & 100 & 0.18 & 1.5 & 42 & 2 & 0 \\
\hline SS-Cy-60 & 100 & 0.18 & 1.5 & 48 & 3 & 0 \\
\hline SS-Cy-61 & 100 & 0.18 & 1.5 & 61 & 7 & 0 \\
\hline SS-Cy-62 & 100 & 0.18 & 1.5 & 65 & 9 & 0 \\
\hline SS-Cy-63 & 200 & 0.18 & 1.5 & 47 & 2 & 0 \\
\hline SS-Cy-64 & 200 & 0.18 & 1.5 & 61 & 5 & 0 \\
\hline SS-Cy-65 & 200 & 0.18 & 1.5 & 72 & 10 & 0 \\
\hline SS-Cy-66 & 400 & 0.18 & 1.5 & 50 & 2 & 0 \\
\hline SS-Cy-67 & 400 & 0.18 & 1.5 & 56 & 3 & 0 \\
\hline SS-Cy-68 & 400 & 0.18 & 1.5 & 82 & 15 & 0 \\
\hline SS-Cy-69 & 100 & 0.15 & 2 & 44 & 21 & 0 \\
\hline SS-Cy-70 & 100 & 0.15 & 2 & 49 & 30 & 0 \\
\hline SS-Cy-71 & 100 & 0.15 & 2 & 61 & 60 & 0 \\
\hline SS-Cy-72 & 200 & 0.15 & 2 & 40 & 12 & 0 \\
\hline SS-Cy-73 & 200 & 0.15 & 2 & 43 & 14 & 0 \\
\hline
\end{tabular}




\begin{tabular}{|c|c|c|c|c|c|c|}
\hline Test No & $\begin{array}{c}\sigma^{\prime}{ }_{\mathrm{v}} \\
(\mathrm{kPa})\end{array}$ & CSR & OCR & Dr $(\%)$ & $\mathrm{N}$ & $\begin{array}{c}\text { Alpha } \\
(\alpha)\end{array}$ \\
\hline SS-Cy-74 & 200 & 0.15 & 2 & 58 & 33 & 0 \\
\hline SS-Cy-75 & 400 & 0.15 & 2 & 42 & 9 & 0 \\
\hline SS-Cy-76 & 400 & 0.15 & 2 & 51 & 16 & 0 \\
\hline SS-Cy-77 & 400 & 0.15 & 2 & 58 & 24 & 0 \\
\hline SS-Cy-78 & 400 & 0.15 & 2 & 59 & 26 & 0 \\
\hline SS-Cy-79 & 400 & 0.15 & 2 & 62 & 30 & 0 \\
\hline SS-Cy-80 & 100 & 0.18 & 2 & 34 & 3 & 0 \\
\hline SS-Cy-81 & 100 & 0.18 & 2 & 56 & 14 & 0 \\
\hline SS-Cy-82 & 100 & 0.18 & 2 & 67 & 28 & 0 \\
\hline SS-Cy-83 & 200 & 0.18 & 2 & 40 & 3 & 0 \\
\hline SS-Cy-84 & 200 & 0.18 & 2 & 44 & 4 & 0 \\
\hline SS-Cy-85 & 200 & 0.18 & 2 & 68 & 21 & 0 \\
\hline SS-Cy-86 & 400 & 0.18 & 2 & 50 & 4 & 0 \\
\hline SS-Cy-87 & 400 & 0.18 & 2 & 58 & 7 & 0 \\
\hline SS-Cy-88 & 400 & 0.18 & 2 & 74 & 21 & 0 \\
\hline SS-Cy-89 & 100 & 0.12 & 2 & 40 & 36 & 0 \\
\hline SS-Cy-90 & 100 & 0.12 & 2 & 43 & 43 & 0 \\
\hline SS-Cy-91 & 100 & 0.12 & 2 & 56 & 126 & 0 \\
\hline SS-Cy-92 & 200 & 0.12 & 2 & 40 & 26 & 0 \\
\hline SS-Cy-93 & 200 & 0.12 & 2 & 41 & 27 & 0 \\
\hline SS-Cy-94 & 200 & 0.12 & 2 & 45 & 34 & 0 \\
\hline SS-Cy-95 & 200 & 0.12 & 2 & 65 & 157 & 0 \\
\hline SS-Cy-96 & 400 & 0.12 & 2 & 43 & 23 & 0 \\
\hline SS-Cy-97 & 400 & 0.12 & 2 & 54 & 47 & 0 \\
\hline SS-Cy-98 & 400 & 0.12 & 2 & 75 & 189 & 0 \\
\hline SS-Cy-99 & 100 & 0.08 & 1 & 29 & 1 & 0.2 \\
\hline SS-Cy-100 & 100 & 0.08 & 1 & 61 & 10 & 0.2 \\
\hline SS-Cy-101 & 100 & 0.08 & 1 & 92 & 302 & 0.2 \\
\hline SS-Cy-102 & 100 & 0.1 & 1 & 30 & 1 & 0.2 \\
\hline SS-Cy-103 & 100 & 0.1 & 1 & 53 & 5 & 0.2 \\
\hline SS-Cy-104 & 100 & 0.1 & 1 & 91 & 74 & 0.2 \\
\hline SS-Cy-105 & 100 & 0.12 & 1 & 32 & 1 & 0.2 \\
\hline SS-Cy-106 & 100 & 0.12 & 1 & 60 & 7 & 0.2 \\
\hline SS-Cy-107 & 100 & 0.12 & 1 & 82 & 30 & 0.2 \\
\hline SS-Cy-108 & 100 & 0.03 & 1 & 48 & 21 & 0.2 \\
\hline SS-Cy-109 & 100 & 0.03 & 1 & 77 & 185 & 0.2 \\
\hline
\end{tabular}




\begin{tabular}{|c|c|c|c|c|c|c|}
\hline Test No & $\begin{array}{c}\sigma^{\prime}{ }_{v} \\
(\mathrm{kPa})\end{array}$ & CSR & OCR & $\operatorname{Dr}(\%)$ & $\mathrm{N}$ & $\begin{array}{c}\text { Alpha } \\
(\alpha)\end{array}$ \\
\hline SS-Cy-110 & 100 & 0.03 & 1 & 87 & 336 & 0.2 \\
\hline SS-Cy-111 & 100 & 0.07 & 2 & 29 & 1 & 0.2 \\
\hline SS-Cy-112 & 100 & 0.07 & 2 & 63 & 24 & 0.2 \\
\hline SS-Cy-113 & 100 & 0.07 & 2 & 70 & 47 & 0.2 \\
\hline SS-Cy-114 & 100 & 0.07 & 2 & 90 & 253 & 0.2 \\
\hline SS-Cy-115 & 100 & 0.12 & 2 & 54 & 1 & 0.2 \\
\hline SS-Cy-116 & 100 & 0.12 & 2 & 70 & 7 & 0.2 \\
\hline SS-Cy-117 & 100 & 0.12 & 2 & 98 & 163 & 0.2 \\
\hline SS-Cy-118 & 100 & 0.15 & 2 & 63 & 1 & 0.2 \\
\hline SS-Cy-119 & 100 & 0.15 & 2 & 78 & 7 & 0.2 \\
\hline SS-Cy-120 & 100 & 0.15 & 2 & 85 & 16 & 0.2 \\
\hline SS-Cy-121 & 100 & 0.05 & 2 & 58 & 27 & 0.1 \\
\hline SS-Cy-122 & 100 & 0.05 & 2 & 68 & 95 & 0.1 \\
\hline SS-Cy-123 & 100 & 0.05 & 2 & 72 & 147 & 0.1 \\
\hline SS-Cy-124 & 100 & 0.1 & 2 & 62 & 15 & 0.1 \\
\hline SS-Cy-125 & 100 & 0.1 & 2 & 71 & 39 & 0.1 \\
\hline SS-Cy-126 & 100 & 0.1 & 2 & 76 & 73 & 0.1 \\
\hline SS-Cy-127 & 100 & 0.15 & 2 & 62 & 2 & 0.1 \\
\hline SS-Cy-128 & 100 & 0.15 & 2 & 71 & 6 & 0.1 \\
\hline SS-Cy-129 & 100 & 0.15 & 2 & 77 & 12 & 0.1 \\
\hline SS-Cy-130 & 100 & 0.05 & 2 & 65 & 21 & 0.3 \\
\hline SS-Cy-131 & 100 & 0.05 & 2 & 71 & 52 & 0.3 \\
\hline SS-Cy-132 & 100 & 0.05 & 2 & 77 & 114 & 0.3 \\
\hline SS-Cy-133 & 100 & 0.1 & 2 & 63 & 1 & 0.3 \\
\hline SS-Cy-134 & 100 & 0.1 & 2 & 80 & 42 & 0.3 \\
\hline SS-Cy-135 & 100 & 0.1 & 2 & 85 & 98 & 0.3 \\
\hline SS-Cy-136 & 100 & 0.15 & 2 & 78 & 3 & 0.3 \\
\hline SS-Cy-137 & 100 & 0.15 & 2 & 87 & 27 & 0.3 \\
\hline SS-Cy-138 & 100 & 0.15 & 2 & 90 & 42 & 0.3 \\
\hline
\end{tabular}

